\title{
Jurors' Perceptions of Testimony in Cases Involving Child-on- Child Sexual Abuse and Anatomical Forensic Interviewing Aids
}

\author{
Benjamin Thomas
}

Follow this and additional works at: https://researchrepository.wvu.edu/etd

\section{Recommended Citation}

Thomas, Benjamin, "Jurors' Perceptions of Testimony in Cases Involving Child-on-Child Sexual Abuse and Anatomical Forensic Interviewing Aids" (2016). Graduate Theses, Dissertations, and Problem Reports.

6794.

https://researchrepository.wvu.edu/etd/6794

This Thesis is protected by copyright and/or related rights. It has been brought to you by the The Research Repository @ WVU with permission from the rights-holder(s). You are free to use this Thesis in any way that is permitted by the copyright and related rights legislation that applies to your use. For other uses you must obtain permission from the rights-holder(s) directly, unless additional rights are indicated by a Creative Commons license in the record and/ or on the work itself. This Thesis has been accepted for inclusion in WVU Graduate Theses, Dissertations, and Problem Reports collection by an authorized administrator of The Research Repository @ WVU. For more information, please contact researchrepository@mail.wvu.edu. 


\title{
Market-based aid and economic reform
}

\author{
Neron R. Thomas
}

Dissertation submitted to the John D. Rockefeller IV School of Policy and Politics within the Eberly College of Arts and Sciences at West Virginia University in partial fulfillment of requirements for the degree of Doctor of Philosophy in Political Science.

Christina Fattore, Ph.D., Chair

David Hauser, Ph.D.

Philip Michelbach, Ph.D.

Karen Culcasi, Ph.D.

Robert Maxon, Ph.D.

\section{Department of Political Science}

\author{
Morgantown, West Virginia \\ 2018
}

Key words: Market-based aid, Non-market aid, Economic reform, Economic growth and development.

Copyright 2018 Neron Thomas 


\section{$\underline{\text { Abstract: }}$ \\ Market-based aid and economic reform}

Neron R. Thomas

This study examines the empirical links between market-based aid and economic reform in sub-Sahara Africa. My research question: Is market-based aid necessary for economic reform across sub-Sahara Africa? To answer that question, I applied both quantitative and qualitative approaches. Specifically, regression analyses were conducted to determine whether or not causality could be established between my dependent and independent variables. 22 subSaharan states were used. In addition, two case studies (Ghana and Senegal) were conducted to help explain some of the cultural nuances that may be missing from the statistical analysis. As a result of the Washington Consensus, International Financial Institutions (IFIs) and advanced economies have advocated for economic reforms - namely macro-level neoliberal structural adjustments - to help facilitate sustainable economic growth and development across emerging economies. This approach has been critiqued in the past since it uses a 'one-size-fits-all' approach and assumes that since similar reform efforts were successful in the west, then they should work in the sub-Sahara region absent of accounting for internal nuances such as cultural and traditional values, customs, structures and conditions. I argue that more market-based aid could be the best way forward, especially if economic reform efforts are tailored toward four key conduits that are essential for driving subsequent economic growth and development: government capacity, economic freedom, private sector investments, and domestic savings. I hypothesized the aforementioned are positively linked with market-based aid. 


\section{Dedication \& acknowledgements:}

I would like to dedicate this dissertation to my father, Rupert A. Thomas, for seeing some potential in me from an early age when I did not see it in myself; for making countless sacrifices working in some of the harshest places in the Middle East and Africa to invest in my potential when he could have invested in bettering himself, and for the patience he has consistently exercised in spite of me sabotaging his efforts on numerous occasions - whether it was failing to attend school, poor academic performance, and getting suspended and later expelled from high school for demonstrating frequent disciplinary issues. Though disappointed by many of my actions, and rightful so, he remained committed to saving me from myself. There are not enough fathers like him around. Many would have given up after few mistakes, but despite my endless mistakes he has always been there to give meaningful advice and guidance to get me back on track. If I am to ever become half the man and father he is, I would be beyond proud. Thank you for anchoring me over the years and opening my eyes to the notion that I can make it to and succeed in college. You are truly my inspiration!

\section{Acknowledgements:}

First and foremost, I would like to extend my sincere appreciation to my Dissertation Chair, Dr. Christina Fattore, for the continuous and meaningful support she has provided throughout my research endeavor. As expected, there were numerous obstacles, but her guidance and words of motivation never wavered even in light of my growing frustrations. It is my firm belief that without her guidance and support I would not have been able to navigate this process. Dr. Fattore, thank you! 
In addition, I believe my dissertation committee: Dr. Culcasi, Dr. Hauser, Dr. Michelbach, and Dr. Maxon are also deserving of being acknowledged for the pivotal roles they have played in my research. Their commitment and contributions through insightful and critical feedback and encouragement have been invaluable in helping me to prepare and complete my research.

This dissertation would not have been possible without the roles of other individuals who have contributed to my growth in various ways. Therefore, their contributions are worthy of being highlighted as well.

I would like to thank my mother, Claudette Johnson, for her continued support throughout my life. Being a single mother tasked with raising two rambunctious boys to their teens is never easy. I have witnessed her cry many times for the difficulties we contributed to. We were not cognizant of how our actions affected her due our tender ages and oftentimes perceived natural rebellious ways. Yet, she showed strength and commitment in raising us the best she could. That is why I was not surprised at her reaction when our father proposed sending us to boarding school in an unfamiliar continent and country. But, in retrospect, that was one of the best decisions she has made since it saved our lives from the harsh realities of living in Guyana. So, I just want to take this moment to truly say thank you! I know my brother and I generally have problems expressing our appreciation for all you have done for us, especially in light of all the challenges, but I hope you know you are sincerely appreciated.

Next, I would like to express my sincere gratitude to my step-mother, Jayne Thomas, for always showing interest in my wellbeing, academics, and growth. When we first met in 1996, I did not expect much, but she has surprised me in many ways over the years. She has always been 
there to provide remedies during times of difficulties; encouraged my father to continue supporting my brother and I when we indulged in juvenile foolishness or not taking life seriously enough; and provided motherly support when necessary. You have certainly been a 'value added’ to my life. Thank you!

In addition, I would like to thank my grandparents, Rupert Aubrey Thomas, Sr. and Irene Thomas, who were taken too soon for me to get sufficient time to know them well. Additionally, thanks to Ismay Cleaver Johnson and Llewellyn Prince Johnson for consistently providing wise counsel throughout my earlier years. I truly wish you could have all been here to witness me develop into the person I have become. Your contributions to my life have been invaluable, and I hope that you are resting peacefully knowing that your guidance and teachings will forever be cherished.

This list will not be complete without also extending my gratitude to Dr. Karen Kunz. I cannot count the number of times I felt defeated and unprepared for graduate school. However, whenever I went to her office to discuss my intentions to withdraw from school and return home, she always had a way of motivating me by sharing similar life experiences and helping me to put things into perspective. Even after I graduated from the MPA program, she continued to provide much needed mentorship and guidance as I tried to navigate not only school but life as well. Therefore, it is only fitting that I write this brief note of thanks! Dr. Kunz, thank you - not only for what you have done for me but also the tremendous things you do for other graduate students as well in making them feel appreciated. Your mentorship has been comforting and valued.

Thank you very much, everyone! You will not be forgotten.

Neron R. Thomas, 2018! 
Table of contents:

\section{Cover page: I}

\section{Abstract: II}

Dedication and acknowledgments: III - V

Chapter 1: Development in the post-colonial era in sub-Sahara Africa.
o 1.1 Background, 1 - 5
o 1-2 Trying to get SSA back on track, 5 - 8
o 1.3 Identification of problem, 8-9
o 1.4 Research question, 9 - 11
o 1.5 Objectives of study, $11-14$
o 1.6 Relevance of study, $14-17$
o 1.7 Limitations of study, 17 - 18
o 1.8 Organizations of research, $18-19$

Chapter 2: A theoretical review of the development strategies used in sub-Sahara Africa.
o 2.1 Introduction, 20 - 23
o 2.2 The Big Push, 23 - 27
o 2.3 African Socialism \& Import Substitution Industrialization, 27-34
o 2.4 The Washington Consensus, 34 - 41
o 2.5 Debt relief, 41 - 46
o 2.6 Aid for Trade, 46 - 54
o 2.7 Bringing back SAPs: Aid for economic reforms, 54 - 57

\section{Chapter 3: Theoretical framework}
o 3.1 Introduction, 58 - 59
o 3.2 Theory, 59 - 78
o $\quad 3.3$ Two gap theory, pages 78 - 78
o 3.4 Theory on donor information, 78 - 83
o 3.5 Theory on recipient knowledge, 83 - 86
o 3.6 Theoretical expectations, 86 - 91
o 3.7 Conclusion, 91 - 92

\section{Chapter 4: Research Design}

o 4.1 Introduction, 93 - 94

o 4.2 Quantitative analysis, 94 - 94

o 4.3 Indicators of market-based aid reform, $95-112$

o 4.4 Other indicators shaping development and reform efforts, 112 - 119

o $\quad 4.5$ Case analysis, $112-122$ 
o 4.6 Case selection, $122-126$

o 4.7 Data collection, $126-133$

o 4.8 Other factors influencing development and reform efforts, 133 - 134.

o 4.6 Conclusion, $134-135$.

\section{Chapter 5: Quantitative Analysis}

o $\quad 5.1$ Introduction, $136-137$

o $\quad 5.2$ Statistical findings, $137-143$

o $\quad 5.3$ Summary and conclusion, $143-149$

\section{Chapter 6: Senegal Case Analysis}

o $\quad 6.1$ Introduction, $146-149$

o 6.2 Post-colonial history of reform efforts by administrative heads, 149 - 160

o 6.3 The intersection between market-based aid, culture and government capacity, $160-176$

o 6.4 The relationship between market-based aid, culture and economic freedom, $176-186$

o 6.5 Examining the role of culture, market-based aid and private sector investment, $186-192$

o 6.6 Culture, market-based aid and domestic savings, 193 - 199

o 6.7 Other factor shaping reform efforts and development in Senegal, 199 - 2010

o 6.8 Conclusion, $210-210$

\section{Chapter 7: Ghana Case Analysis}

o 7.1 Introduction, $211-212$

o 7.2 Post-colonial history of reform efforts by administrative heads, 212 - 224

o 7.3 The intersection between market-based aid, culture and government capacity, $225-234$

o 7.4 The relationship between market-based aid, culture and economic freedom, $238-245$

o 7.5 Examining the role of culture, market-based aid and private sector investments, $245-251$

o 7.6 Culture, market-based aid and domestic savings, 251 - 257

o 7.7 Other factors shaping reform efforts and development in Ghana, 258 - 266

\section{Chapter 8: Conclusion}

o 8.1 Summary and of case findings, $268-272$

o 8.2 Critical development approach, $272-286$

o 8.3 Future directions, $286-286$

Appendix A, 287

Bibliography, 289 - 329 


\section{Figures and Tables:}

Table 3.1: Illustration of how aid types are categorized based on the conduits of economic reforms, 63 - 64 .

Figure 3.2: Illustration of causal theoretical links between market-based aid and conduits of economic reform, 72 .

Figure 4.1: Illustration of causal theoretical links between my dependent and independent variables, 93 - 93.

Table 4.2: Illustration of how market-based aid will be categorized, 96 - 97.

Table 4.3: Case selection using the Mill’s Methods of Agreement approach, 125 - 126.

Table 4.3: Illustration of how market-based aid is categorized, page 104.

Table 5.1: Descriptive statistics, 14

Table 5.2: Outputs for regression models, 146.

Table 6.1: Senegal at a glance, 146

Table 6.2: Allocation of aid types for government capacity building between 1985 and 2012, page 161 .

Table 6.3: Illustration of aid types for economic freedom between 1985 and 2012, page 176

Table 6.4: Illustration of aid types for private sector investments between 1985 and 2012, page 187.

Table 6.5: Illustration of aid types for gross domestic savings between 1985 and 2012, page 193

Table 7.1: Ghana at a glance, 211

Figure 7.2: Market- and non-market aid contributions for government capacity building between 1985 and 2012, page 227

Figure 7.3: Market- and non-market aid between 1985 and 2012, page 238

Figure 7.4: Market- and non-market aid contributions for private sector investments between 1985 and 2012, page 245

Figure 7.5: Market-and non-market aid contributions that affects domestic savings, 251 


\section{Chapter 1: Development in the post-colonial era in Sub-Sahara Africa.}

\subsection{Background:}

Sub-Sahara Africa (SSA) continues to puzzle many development specialists, policymakers and those in the social science research community alike for various reasons. Although being the largest recipients of foreign aid, with the exception of few ${ }^{1}$, SSA states share a similar fate in being amongst the poorest in the world in terms of per capita and GDP growth while other regions are making relatively faster strides due to commitment to pragmatic economic and political reforms. ${ }^{2}$ More concerning is that many SSA states are becoming more economically marginalized within the global economy due to failure to sufficiently reform their policies, institutions and practices to adapt to existing, emerging and anticipated economic forces as a means to best integrate into regional and global economies. ${ }^{3}$ This could be attributed to these states lacking sufficient capacity in terms of adequate technical knowledge, institutions, and economic infrastructures, etc., to integrate and compete (Mohan et al,2013; Hyden, 2006;

1 Botswana, South Africa, Mauritius, Ghana, Rwanda, Uganda and Kenya, etc., have shown a fair amount of economic progress in terms of per capita and GDP growth, according to IMF and World Bank reports, due in parts to economic and political reforms. In contrast, Zimbabwe, Angola, Congo, etc., continue to languish as nonreformers.

${ }^{2}$ The Asian Tigers received less foreign aid since the 1950s; yet they continue to make greater economic strides relative to SSA counterparts. For instance, South Korea has industrialized while Ghana has failed to reach similar heights in spite of being the recipient of greater sum of aid. Interestingly, South Korea does not possess a lot of natural resources; however, because of its free-market economy that emphasizes labor incentives, research, and technical education combined with an effective bureaucracy and state capacity, they have had more success. In contrast, Ghana has been affected by corruption, poor leadership, mismanagement of resources and revenues, and inefficient state enterprises due to a failure to modernize (Werlin,1991, 1994; Kim, 2015)

${ }^{3}$ This is reflected in the continent's decreasing share of the world's production and trade. Though it has large human capital its economic activities remains comparatively small. Plus, 34 states in the region are categorized as Heavily Indebted Poor Countries (IMF, 2007; Agboghoroma et al, 2009). 
Moyo, 2008; Glennie, 2008; Herbst, 2000; Hagan, 2002; Mayer and Milberg, 2013; Vijil and Wagner, 2010).

The aforementioned obstacles have contributed to Africans being worse off now than they were decades ago. Specifically, increasing population growth and failure to sufficiently put in place and enforce appropriate reforms has negatively affected economic growth and development while the rush to plunder state resources continue to be a common feature whereby the political and social elites, bureaucrats, and cronies alike siphon off and stash massive state revenues in foreign bank accounts, which they invest abroad rather than domestically. This is especially the case in states that have an abundance of natural resources, which has been a major source of exploitation. Similar actions are also true when states become aid recipients. Since national governments generally control its resources, which they use to finance state functions rather than rely on tax revenues, they are less inclined to be accountable to their citizens (Moyo, 2008; Glennie, 2008; Robinson, et, 2006; Leite \& Weidmann, 1999; Bulte, et al, 2005; Sala-iMartin and Subramanian, 2003).

Furthermore, SSA governments have knowingly and unknowingly entertained foreign direct investments (FDI) that have been sold as domestic revenue generators which often turned out to be blank checks, and in many cases contributed to financial vacuums in recipient states. Specifically, states are often forced to sell valuable resources at below market value while debt repayment fees remain disproportionately high, which contributes to financial disparities that negatively affects the revenue streams of these states. Moreover, their economic predicaments are furthered when recipients commit to the rhetoric of investors (and donors) while those same investors commit to themselves wherein the measurement of their success is based primarily on 
maximizing the capital they are able to extract from the deal over the life of the contract rather than establishing a platform where recipients could make adequate progress (rather than few social and political elites). For instance, in regards to resource mining, both illicit and licit extraction practices continue to cause great amounts of ecological and environmental damages across the region. In order to extract natural resources, companies deforest and mine numerous acres of valuable land. This is not only harmful to the environment but also to the people. Pollution and soil degradation often leads to losses in incomes for farmers, which is detrimental to these states since most still depend on primary commodities for revenues. Plus, chemicals used and produced during mining practices often contaminate the soil thus posing health risks. ${ }^{4}$ Yet many companies continue to cut corners to increase their profit margins (Kolver, 2013; African Progress Panel Report, 2014).

Similarly, foreign investors often gain a significant portion of profits from resource extractions. They succeed by purchasing mining rights at exceedingly low prices; evading taxes, and using anonymous ownership practices to increase profit margins at the expense of SSA states and citizens. Even when there are production sharing agreements in place, investors still stand to gain more relative to states. ${ }^{5}$ This is often due to poorly designed economic and trade agreements and regulations combined with poor management practices on behalf of and/or in collaboration with SSA states. Thus reforms that are designed for enhancing government capacity is expected to help mitigate this issue (Kolver, 2013; African Progress Panel Report, 2014).

\footnotetext{
${ }^{4}$ States with poor health care infrastructures are most affected.

${ }^{5}$ Many of these states are in desperate need of revenues; however, multinational corporations investing in the region are rational actors and therefore, they prioritize profits over morality.
} 
Furthermore, empirical findings suggest that resources are a source of conflicts in the region, especially in states that are economically poor and socially divided. Thus, resources, especially with high commodity value, such as diamonds, gold, petroleum, and cobalt, etc., are often used to finance rebellions not only against the state but also opposition social groups to gain access and/or control of resources. Such actions have (and in some states continue to) contributed to the stagnation of reform efforts. Those issues have also been amplified historically by regional economic and political instabilities due to political shocks, religious and ethnic tensions, poor governance, growing accounts deficits, chronic corruption levels, insufficient institutional development, expanding public sectors that has proven to be ineffective and inefficient as well as decreasing private sector investments, and overreliance on primary commodities due to failure to industrialize, among many other reasons. This has resulted in many SSA states having to sell themselves cheaply on the global market to attract foreign investors ${ }^{6}$ (Moyo, 2008; Africa Progress Panel report, 2014; Collier and Hoeffler 1998, 2000; Humphreys, 2005).

Additionally, governments have often exercised strong-armed tactics in their domestic economies wherein they exert too much control over commodities and service prices, production levels, exports, and imports, etc., through the use of state owned enterprises. ${ }^{7}$ This has also contributed to the lack of sufficient reforms and subsequent economic stagnation, regressions, and increasing dependence on external support. In turn, this has contributed to growing capital

\footnotetext{
${ }^{6}$ States have resorted to giving multinational corporations excessive tax breaks. Furthermore, valuable lands are sold significantly below market value. Those practices have contributed to underfunded public sectors and states losing much needed tax revenues.

${ }^{7}$ Some states still rely on marketing boards (or parastatal agencies), which are state owned enterprises (monopolies) tasked with purchasing domestic produce for sale on the foreign markets. However, one of the primary issues is that governments set produce prices low relative to regional and global market prices, which have contributed to cross border trading and loss of revenues.
} 
flight since investors are seeking incentives to invest, such as greater rates of returns and protection of property. Those cumulative factors and others have fueled a "viscous cycle" of indebtedness, fostering 'Africa's growth tragedy' (Easterly and Levine, 1997; Moyo, 2008; Herbst, 2000; Easterly, 2006; Easterly and Pfutze, 2008; Hyden, 2006; Ayittey, 2012; Paldam, 1998; Amin, 2013; Morrissey, 2001; Herzer and Grimm., 2011).

\subsection{Trying to get SSA on track:}

Since the end of colonialism, both African and Western leaders have employed various strategic measures, such as the 'Big Push', import substitution industrialization (ISI), Washington Consensus, debt relief, and Aid for Trade (AfT) to help catalyze economic reforms across the region. However, the aforementioned packages have had varying levels of success due to strict guidelines; donors not having an adequate understanding of the local realities of recipients; failures of donors to collaborate with recipients to design appropriate aid packages based on individual needs and expectations, which contributed to a majority of the policies that were imposed on recipients being inappropriate. That said, leaders have recently started to join forces to develop strategies aimed at designing and implementing reforms that are considered more appropriate in hopes that they would bring a renewal of hope for the region and Africans (Ayittey, 2002, 2012; Williamson, 2009; Vasquez, 1998).

One tactic that has been gaining considerable traction, especially in light of the most recent global economic meltdown in 2008, is advocating for more aid to be channeled toward economic reforms as a means to facilitate global economic integration. Ideally, this would include enhancing technical knowledge, institutions and capacity that fosters accountability, transparency, and the ability to develop and enforce appropriate policies. This should 
subsequently help safeguard state governments against entering into bilateral and multilateral agreements that do not bring sufficient benefits to SSA states while also deterring both local and foreign investors along with political officials from acquiring resources at unfair market prices. That said, elevating market-based aid has been touted as a vehicle for mitigating such occurrences, because it could help promote capacity building; legal and judicial development and reforms; trade policy development and regulations; enhancing infrastructures; and building productive capacity, etc., that works in concert to support fair market standards where the cost of transactions are determined by the willingness of buyers and sellers to participate in the market; there is protection of investors and their investments through legal and economic parameters, and the prosecution of violators that cheat the system to amass personal gains (at the expense of others). This contributes to economic liberalization by reducing trade barriers to help increase the size of the private sector; securing property rights; privatization of costly and inefficient public enterprises; deregulation of the market sector by relaxing government control and interference; and elimination of state monopolies, etc., in order to help fuel subsequent economic growth (Melo and Wagner, 2015; Stiglitz, 2004; Williamson, 2009; Berggren, 2003).

It is also important to assert that domestic reform means nothing if sufficient reforms are not made regionally and globally to facilitate market integration. Domestic reforms should come first whereby state governments make pragmatic and committed efforts to remove trade barriers that may negatively affect private sector development and trade, such as import and export licensing that are difficult to acquire, strict controls on imports and exports, and subsidies ${ }^{8}$;

\footnotetext{
${ }^{8}$ Subsidies generally distort the market and have dual impacts. For instance, while Western producers are able to sell their produce at home at or above market prices, they can also afford to dump excess at much lower prices in emerging markets. Flooding the markets with cheaper subsidized produce undercuts local farmers and putting many
} 
deregulations of market prices (consumer and producer); and privatization of inefficient state enterprises and monopolies and therefore opening the economy to trade and competition. Currently, one of the issues facing many states across the region is not necessarily the failure to reform, but rather selective implementation; meaning, when aid is received state governments have the power to decide if they should implement agreed upon reforms or certain elements of them. This has contributed to slow private sector development and international trade, limited economic freedom, and slow growth in domestic savings, etc. (World Bank, 1994; Buccola and McCandlish, 1999; Durevall and Mabugu, 2000; Nyoro, et al, 1999; Bates, 1981; and Glennie, 2008).

Some efforts to reform have also coincided with an increasing renewal or creation of regional economic and political reforms with the development of regional economic and trade agreements and communities. Many SSA states share common or similar colonial legacies and characteristics, especially regarding their administrative, economic and legal institutional frameworks. This has led to states forging stronger bonds regionally to facilitate greater trade. These trading blocs were developed to promote free or fair trade amongst member states for commodities and services, which could prove to be pivotal mechanisms for fostering sustainable regional development by supporting competition and export-oriented economies. This starts with mitigating many of the procedural barriers that are inhibiting free or fair trade; reviewing tariffs and non-tariff barriers, and reducing or abolishing import levies and export taxes. Those principles are accounted for in regional agreements, such as the West African Economic and Monetary Union (WAEMU), The Regional Integration Facilitation Forum (RIFF), The Southern

out of business. This is made worse when Western markets establish protective measures that support limiting the entry of imports from emerging markets. This is also the case for SSA state selling to each other. 
African Customs Union (SACU), and the Central Africa Economic and Monetary Community (CAEMC). Moreover, regional trade agreements have been established under the Southern African Development Community (SAADC), the Common Market for Eastern and Southern Africa (COMESA), the Economic Community of West African States (ECOWAS), and the East African Community (EAC).

Many states have also made efforts to align their domestic economic policies in accordance with international trade principles starting in the 1980s. More states have since followed suit in opening their economies by reducing highly restrictive tariffs and protective policies. This has led to varying levels of private sector growth and spurred development (Subramanian et al, 2000).

To summarize, many SSA states are currently not sufficiently integrated into regional and global economies. This is partly because their economies are not adequately open and they do not have sufficient capital to advance their economic reform agenda. Thus, I make the argument that more emphasis should be placed on increasing market-based aid as it is more beneficial in terms of driving economic reforms, which is expected to result in subsequent economic growth and development through integration (Clemens et al, 2004, 2012; Sachs and Warner, 1995; Vasquez, 1998; Burnside and Dollar, 2000; Ayittey, 2012; Heckelman and Knack, 2009; Stiglitz, 2002).

\subsection{Identification of problem:}

Central to this study is determining if market-based aid empirically works in terms of facilitating economic reform. Although the SSA region have received the largest sum of aid in 
the post-World War II era relative to other developing regions, only limited returns were gained while other regions with less funding have made more noticeable economic gains. This is puzzling and warrants a closer examination. This has formed the motivational basis for my research question. To answer my question, OLS regressions were using panel data was used to test my causal hypotheses. Additionally, I have conducted two case analyses - Ghana and Senegal, which are two West African states with many historical similarities but have made different reform efforts due to unique cultural norms and practices.

\subsection{Research question:}

This research contributes to the existing literature by posing the following question: Is market-based aid necessary for economic reforms? There is some literature that examines this relationship; meaning, we are privy to some analyses pertaining to the causal relationships between aid and reforms. However, what is seriously lacking is adequate empirical analyses aimed at determining the causal effects between particular aid types and economic reforms across the SSA region, or the role cultural and traditional nuances have on this relationship.

Some empirical findings suggest aid has either a limited or negative effect on economic reforms as it fuels consumption and corruption. In contrast, others found that states generally perform better economically (GDP growth) when aid is allocated toward economic reforms. Still others found that aid types matter in facilitating economic reforms. Specifically, certain aid types are more effective at promoting economic reforms relative to others since some aid types best lay the foundation and support this process (Clemens et al, 2004, 2012; Owens and Hoddinott, 1999; Mavrotas, 2002; Gomanee et al, 2002; Petersson, 2004; Vasquez, 1998; Easterly, 2007; Collier, 
1997; Przeworski and Vreeland, 2000; Sachs, 2005; Hansen and Tarp, 2001; Burnside and Dollar, 2000).

This research aligns with the latter two lines of thought, and is loosely motivated by studies conducted by Clemens et al (2004, 2012). They examined whether or not there are empirical linkages between aid types and economic growth and have coincidentally helped to steer the debate in a new and refreshing direction. After disaggregating aid into three types: early-impact (economic), long-impact (social), and humanitarian aid, they found that aid types have varying effects on economic growth when accounting for time. However, while the aforementioned studies presented us with sound reasons to consider how aid should be appropriated for economic growth and development, they failed to adequately examine the causal relationship between what I consider "market-based aid" and economic reforms. Also, they do not take into account the role culture plays in this process. Furthermore, the aforementioned study did not shed much light on the aid-economic growth interaction on the African continent, which is very culturally diverse. This study will attempt to build on the existing literature by examining whether or not an empirical link exists between market-based aid and economic reforms using regression analysis and two case studies to understand the effect cultural and traditional factors contribute to this process. In other words, does aid work harmoniously with cultural and traditional factors to shape economic reforms?

For the purpose of this study, I will divide aid distributions into two seemingly exclusive categories: market-based aid and non-market aid. Market-based aid will be conceptualized as all allotment (bilateral, multilateral, and private ${ }^{9}$ ) to SSA state governments that targets enhancing 
government capacity, economic freedom, private sector growth, and domestic savings. The opposite is true for non-market aid.

\subsection{Objectives of study:}

Foreign aid has generally been debated in different aspects due its complex nature. The states the sub-Sahara region comprises of are considered some of the poorest by many measures and at the same time the recipients of the largest sum of aid. Aid contributions have contributed to more destruction rather than stimulate economic reforms. Therefore, the primary objective is to gain a better understanding of this complex issue. Thus, by accounting for the theory guiding this study together with the research design, I will examine my research question.

One of the primary reasons behind SSA being selected as the chosen geographical area for this research is due to its high poverty level and aid dependency. The outcomes of this study is expected to challenge the rationalization of donors and policymakers in respect to how they choose to appropriate aid and for what purposes by helping them to make more informed and pragmatic decisions when deciding how they distribute aid and for what purposes. This will help mitigate the current travesty being witnessed across the region considering a large segment of the population still lives in poverty partly because of poor economic reforms and/or commitment to reforms. The aim of this dissertation is therefore to examine whether marketbased aid makes an empirical difference in supporting economic reforms.

The expectation is that findings will support the notion that market-based aid had positive effect on economic reforms in Ghana and Senegal, and SSA in general, in the post-independence

\footnotetext{
${ }^{9}$ The dataset used (Aiddata.org) only captures aid being transferred by bilateral, multilateral and private American foundations.
} 
era. Findings could help reinforce my argument that the time has come for policymakers to reorient their attention toward Structural Adjustment Programs (SAPs) again, which could prove to be pivotal mechanisms that could help facilitate much needed economic reforms across the region. However, the degree of reforms could only be solidified if efforts are made to account for internal realities and conditions of recipients. This includes accounting for differences in bureaucratic capacities and structures, technical knowledge, cultural and traditional nuances, population dynamics and ethnic diversity, etc. (Acemoglu et al, 2001; North, 1981; Jones, 2006; Landes, 1998; and Grief, 1994).

Additionally, the development literature has failed to sufficiently examine the effect that market-based aid may have on economic reforms, especially across the SSA region. This can be attributed to interest levels in the region waning considering the lack of overall progress. Or, perhaps the most important assumption why sufficient analyses of this kind have not been conducted is because databases of disaggregated aid disbursements are not common. Furthermore, some scholars argue that examining this nexus after disaggregating aid may obscure us from understanding the bigger picture; ${ }^{10}$ and that states seeking reforms generally do so in spite of and not necessarily because of aid. ${ }^{11}$ While those criticisms are dully noted, the debate is still raging on. Therefore, it is imperative that we continue to explore different ways to introduce new and pragmatic discussions to the development literature. This study argues that disaggregating aid will further our understanding of the interaction between aid and economic reforms at a more intricate level, which could help provide a solution to a prolonged issue and point policymakers in a direction that may help them design appropriate and effective aid

\footnotetext{
${ }^{10}$ Please see Rajan and Subramanian, 2005, 2009; and Kiiza, 2009.

${ }^{11}$ See Vasquez, 1998; and Bandow, 1995.
} 
policies that could trigger sustainable economic growth (Vasquez, 1998; Wedel, 1999; Easterly, 2002; Radelet, 2006; Clemens et al, 2004, 2012).

Furthermore, some of the most compelling studies in the development literature focus their efforts on measuring the effects aggregate aid has on economic growth. ${ }^{12}$ However, they all seem to have three critical flaws that could help explain why aid has often been viewed as ineffective across SSA (and across emerging economies, in general): (i) not all aid types affect economic reforms in the same ways; (ii) aid generally takes time to affect economic reforms; and (iii) domestic context must be accounted for when trying to understand the interaction between aid and reform efforts. In other words, funding for education, healthcare, trade policies and regulations, government capacity, banking and financial services, etc., may have swifter and more direct effect on economic reforms relative to aid appropriations for humanitarian efforts, disaster relief, and food aid, to name a few, which are likely to have limited or no direct effects on economic reform. ${ }^{13}$ This study is by no means devaluing the role of non-market aid. Rather, it is emphasizing that more should be done to increase market-based aid allotments, which could help recipients generate greater capital formation to finance their own humanitarian efforts, sanitation projects, etc., if necessary.

What does this study add to the existing literature? The aim is to add to the broader debate of the aid-growth nexus. This is done by taking an approach that differs from conventional analysis of this relationship. Rather than treating aid as a single variable, this study

\footnotetext{
${ }^{12}$ Boone (1996), Burnside and Dollar $(2000,2004)$ and others have examined the effects aggregate aid may have on economic growth without accounting for time dependence in their econometric models. While those studies add to the debate, their design flaws casts serious doubts on their explanatory powers.

${ }^{13}$ See Clemens et al, 2004, 2012; Owens and Hoddinott, 1999; and Mavrotas, 2002.
} 
disentangles aid and focus solely on the effect market-based and non-market aid has on economic reforms, and also examines the affects culture plays. This is vital because in examining the aid-reform relationship, studies have often overlooked this crucial relationship that could prove to have a significant, positive effect on economic reforms. Instead, a majority of the previous studies have bundled all aid types together. In other words, non-market aid which is generally associated with limited or no direct effect on economic reforms in the short-term or possibly some indirect effect on reforms in the long-term is aggregated with market-based aid, which generally has a faster and more direct effect on economic reforms. Therefore, it is not surprising that many of those studies have often failed to distinguish between the varying aid effects and the validity of results (Clemens et al, 2004, 2012; Owens and Hoddinott, 1999; Mavrotas, 2002; Rajan et al, 2005).

The literature has failed to dedicate sufficient efforts toward understanding the causal effects of market-based aid on economic reforms. There is a lot that can still be learned. More importantly, a better understanding of this relationship could put policymakers in positions to make informed policy prescriptions to advance the economies of SSA states while reducing their dependence on external support. I argue that not only does aid types matter but so does the amount of aid appropriated toward economic reforms. The expectation is that investing more market-based aid will have a positive effect on economic reforms.

\subsection{Relevance of study:}

This study addresses numerous areas of relevance in the development literature. Over the past 50 years, deliberate efforts have been made by donors and African leaders to develop SSA states - generally through aid allocations and policy prescriptions. The region is the largest 
recipient of aid, yet it remains the poorest and has thus far failed to graduate many states from aid dependency status whereby they no longer need substantial aid to attain targeted growth or to carry out civic functions. While some states have shown encouraging signs of reforming according to recent IMF and World Bank outlook reports, some scholars have branded aid to the region a 'colossal waste' due to many of these states showing signs of economic fatigue. ${ }^{14}$ Aiding reform efforts could provide a pivotal solution to this problem (Vasquez, 1998; Moyo, 2008; Tar, 2008; Bandow, 1995; Easterly, 2006; Ayittey, 2012).

Furthermore, a segment of the aid literature remains skeptical about the effect aid has had across SSA by indicating aid is committing more harm than good and therefore, it should be eliminated in favor of foreign direct investments (FDI) and other policy reforms. ${ }^{15}$ One of the premises of this study is to illustrate that cutting off aid entirely is irrational. Instead, policymakers and donors must be convinced that closer attention must be placed on increasing the volume of smart aid allotted to SSA - in this case aid for economic reforms. This route is expected to help break the cycle of underdevelopment and assist with putting recipients on the path of becoming less dependent on external aid and mitigating indebtedness. And although these states may not necessarily need foreign aid to appear stable as a means to attract foreign investments, it does enhance their chances by helping to facilitate economic stability and development, especially if inflows boost intellectual, legal, political, and equally important, economic reforms (Ayittey, 2012; Stiglitz, 1998; Rosegren and Jordan, 2000; Acemoglu et al, 2003).

\footnotetext{
${ }^{14}$ Stiglitz, 2004; Easterly et al, 2004, 2006; Moyo, 2009, and Collier, 1997 are some of the scholars arguing that aid has been wasted because it has perpetuated corruption, expanded the public sectors/expenditures, fostered poor governance, reduced institutional capacity, and delayed policy reforms, etc.

${ }^{15}$ Please see Boone, 1996; Moyo, 2009; Stiglitz, 2004; Jensen and Paldam, 2003; and Easterly, 2001.
} 
Similarly, many SSA states are currently experiencing financial struggles due to growing indebtedness to creditors and aid dependence. Even when donors pursue debt forgiveness strategies it does not seem to help recipients much or give sufficient reprieve, because the remaining debts are still substantial enough to command high levels of debt servicing fees. This study aims to illustrate that recipients will be better positioned to become less dependent on foreign aid in the long-term if they and donors agree to more market based aid as opposed to over-relying on non-market aid. This is crucial considering the recent (and past) global economic crises, which has led to massive declines in aid allocations that brought about donor aid fatigue as developed economies had to address their own domestic budgetary constraints as well as shift their policy priorities toward fighting the war on terror and regional security. This has undermined the volume of aid donors initially promised SSA and other developing regions. This meant aid dependent states were significantly affected during these economic crises. This gives reason why both bilateral and multilateral donors should provide more aid to domestic sectors where it will yield sustainable rates of return (Clemens et al, 2004, 2012; Radelet, 2006; U.N report, 2000).

This study comes at an opportune time considering there has been a 'Big Push' by the G8 states and International Financial Institutions (IFIs) to pledge more aid to SSA to meet its Millennium Declaration Goals (MDGs). This has, in addition to the recent global economic collapse, forced donors to re-examine how they distribute aid and for what purposes. Furthermore, donors are continuing to be advocates for aid to help emerging economies transition toward free markets. This also makes it an interesting topic to examine more closely. 
Also, the development literature is less comprehensive with respect to examining the effect aid types has on economic reforms. Previous studies have treated aid as a holistic variable; meaning, they examined how aid, in general, affects economic growth and development. In doing so, they fail to pinpoint what I consider to be an important link by not placing sufficient emphasis on the roles cultural and traditional attributes may also play in the market-based aideconomic reform nexus. This is not to devalue other intervening variables and aid types that may contribute to economic reforms. But, empirical findings indicate that aid helps to enhance other variables such as economic freedom, domestic savings, government capacity, and the size of the private sector, which spurs competition, productivity, stability, and institutional development, etc. Yet little analysis has been conducted to better understand the causal effects market-based aid has on economic reforms across the region while also addressing cultural attributes. This study adds to existing knowledge by disaggregating aid and analyzing the effects it has on economic reform. The expectation is that market-based aid will positively affect economic reforms.

\subsection{Limitations of study:}

There are theoretical, geographical, and data limitations to this study. This study is limited to 2 case analyses, which will be discussed in the research design section. Moreover, for the statistical analysis section, I was limited to 22 states. These states vary in terms of their economic reform efforts for various reasons, such as numerous catastrophes (man-made and natural), corruption, inadequate institutions, poor leadership, etc. Therefore, aid to these states have been vital for many reasons considering they find it difficult to practice self-sustenance. Moreover, the selected states vary in terms of their histories, cultures, and political constructs, 
etc. Therefore, there are many variables that may influence those states in similar and/or different ways when accounting for economic reform. And although the aim is to determine whether or not there is an empirical link between market-based aid and economic reforms, I believe I have chosen suitable variables to help answer my research question. Lastly, considering only two states are being analyzed to determine the role cultural and traditional values, customs and beliefs play the market-based aid-economic reform nexus, then findings will be difficult to generalize; however, OLS regressions will also be used to help address that issue, but the data used only spans 1985 to 2012.

\subsection{Organization of this research:}

The remainder of this dissertation will be organized as follows. Chapter two will review the theoretical development literature from a SSA context. After independence, donors and African leaders have employed various development reforms as vehicles for sustainable economic growth. This included using the Big Push, Import substitution industrialization (ISI), Structural Adjustment Programs (SAPs), debt relief, and Aid for trade, etc. I have elected to present the theoretical bases for the aforementioned strategies as well as discuss how they have evolved over time and why some may have had some success while others failed - or even harmed SSA's economic path for meaningful economic reforms and subsequent economic growth and development.

Chapter three presents the theoretical framework that guides this study as well as the theoretical expectations. Many SSA states continue to be marginalized in the global economy because they have failed to invest adequately in pragmatic economic reforms. This has resulted in citizens and governments not being able to capitalize on economic opportunities that could 
help maximize their domestic economic potentials. Failure to capitalize means less capital available for domestic investments. This contributes to continued sluggish economic growth and development. That said, I argue more efforts need to be made to increase market-based aid as it will have a positive effect on economic reforms relative to non-market based aid.

Chapter four will highlight the importance of market-based aid and economic reforms by presenting a layout of how I intend to test my causal hypotheses. Specifically, I will test the empirical links between my dependent and independent variables by laying out how I plan to operationalize my study to answer my research question.

Chapter five will present the Large-N aggregate analysis of selected SSA states followed by a discussion of findings. Similarly, chapters six and seven will focus on two cases analyses Senegal and Ghana, respectively, which were selected using Mill's method of agreement. The primary purpose behind the case analyses will be to determine how certain nuanced factors such as colonial legacies, cultural and traditional value systems, social structures, and the internal dynamics may have affected the economic reform efforts within states while accounting for the market-based aid received in the post-independence era.

Lastly, chapter eight will give a brief summary of the findings, implications and future studies to consider. Moreover, I aim to conclude by emphasizing the need for donors and African leaders alike to focus their attention on appropriating more market-based aid if SSA states are to improve their odds of securing sustainable economic growth and development. 


\section{Chapter 2: A theoretical review of the development strategies used in Sub-Sahara Africa.}

\subsection{Introduction}

The end of colonialism was widely celebrated as a joyous event and was expected to accelerate much needed changes across Sub-Sahara Africa (SSA). Many African leaders, though unprepared, were thrusted into public office with the monumental task of reconstructing the postcolonial African state. At that juncture, many economies were left decimated while some were on the brink of or in economic and political ruins, institutionally weak and socially disintegrated in parts. Moreover, many of these states lacked sufficient human and financial capital as a result of high mortality rates; capital and intellectual flight became the norm, high urbanization rates threatened social chaos as increasing volumes of rural dwellers went in search of higher paying jobs and betterment, debts to internal and external creditors rose rapidly as central governments borrowed frequently and in large quantities to foster reform through investments in large scale policies and projects while widespread poverty and unemployment contributed to political instability (Rono, 2002; Herbst, 2000; Hyden, 2006; Meredith, 2005; Heidhues and Obare, 2011; Easterly, 2006).

Those and other issues have lingered because former colonial powers failed to put in place appropriate measures to address the dominant issues that existed at the time or anticipated before withdrawing their political control from the region. Therefore, newly elected African leaders were tasked with organizing to design strategic and systematic reform agendas aimed at facilitating growth and development. This included creating appropriate institutions, pouncing at opportunities to transform their failing economies, supporting the development of entrepreneurial 
classes, addressing political instabilities, and raising sufficient capital to invest in domestic economies to attract external investors, among many other immediate needs. One of the primary objectives of these states was to maneuver toward industrialization and free markets. But, in order to progress they needed to not only address the aforementioned issues but also design and enforce pragmatic domestic reforms (Akintunde, 2011; Ayittey, 1994; Moyo, 2009; Easterly, 2006; Meredith, 2005; Bates, 1981; Acemoglu et al, 2011; Herbst, 2000).

Like many emerging economies across the globe, SSA states sought swift development remedies, because Africans rightfully were demanding higher incomes and better standards of living. The overarching sentiment at that juncture was 'Africa must run while others walk.' The evidence of history and economic doctrines indicate that in order to achieve such ends, states must shift their economies from primary commodities based to industrial based within a free market system. With the support of Western donors, especially through the provision of foreign aid and technical assistance, African leaders pursued various reform efforts to help facilitate economic growth and development. This often meant states adopted policies that diverted scarce resources from traditional economic sectors (agriculture, fishing, arts and crafts, etc.) to modern sectors such as industry and manufacturing that are geared toward feeding the needs of western markets while placing little emphasis on domestic needs (Bates, 1981; Hyden, 2006; Heidhues and Obare, 2011; Milward, 2000).

Between the 1950s and 1970s, reform strategies were more state-centric - namely the Big Push and import substitution industrialization (ISI). Those strategies were deemed necessary to help fuel the industrialization process, because of the growing political and cultural divisions; minimal to non-existent entrepreneurial class; small and often weak private sectors; and limited 
capital availability. Therefore, states were tasked with playing more integral roles in advancing economic growth by implementing broad policy frameworks to promote strong government control over domestic economies; and developing large-scale public enterprises, market protections, and heavily subsidizing local business ventures, etc. (Acemoglu et al, 2011; Bates, 1981; Hans, 1950; Prebisch, 1950; Sarkar and Singer, 1991).

The economic crises during the 1970s and 80s helped to pave the way for a policy shift referred to as the Washington Consensus. Through actors including the Bretton Woods institutions and the United States Agency for International Development (USAID), a set of economic reforms were brokered and advocated. Governments of emerging economies were issued directives to implement free market policies aimed at reducing government interferences in their domestic economies, fiscal and tax reforms, trade liberalization, privatization, etc., as conditions for aid (Berg Report, 1981; Williamson, 1999, 2004; Milward, 2000; Gloyd, 2004; Thomson, 2010).

That policy shift was short-lived, however, as by 1996 there was another policy shift referred to as the Post-Washington Consensus. This shift emphasized the need for both donors and recipients to invest in infrastructural changes and capacity development through Aid for Trade and Debt Relief-type agreements with central governments. Those instruments were deemed essential if emerging economies are to develop by enhancing economic efficiency and global economic integration which, in turn, would propel long-term economic growth and development (Stiglitz, 1999, 2004, 2008; Birdsall and Fukuyama, 2011).

The aforementioned strategies operate on different theoretical footing but draws on the sentiment that certain protocols must be followed if states, in general, are to ever experience 
sustainable economic growth and development. Central to all of those policy suggestions are two core components: the need for (i) policy reform, and (ii) capital to help pave the way for industrialization. However, the reality is that those development strategies have had varying levels of success across SSA. While some have had some positive effects, others were dismal and have had lasting effects on the economic landscape across the region. That said, the proceeding narrative discusses the theoretical basis of five dominant development strategies used from the dawn of independence until present to help SSA states pursue industrialization.

\subsection{The Big Push}

As many SSA states began gaining independence in the 1950s, they needed strategies that would help facilitate the state building process with the objective being to industrialize as quickly as possible. One of the earliest development strategies employed was the classic 'Big Push' model. Central to this approach is the notion that state governments must play a more important role in addressing a state’s failure to industrialize by endorsing policy frameworks that enhances the coordination of large-scale domestic investments in productive activities and the transfer of modern technologies in order to help them break the cycle of underdevelopment. This was expected to allow them to 'take-off' economically. Put simply, in order for states to reach their optimal levels of coordination and productivity, there must be a Big Push - massive publicled investments - which would help augment the financial gap and allow emerging economies to scale and generate self-sustaining growth (Rosenstein-Rodan, 1943; Rostow, 1960; Nurske, 1953; Hirshman, 1957; Murphy et al, 1989).

This strategy essentially theorizes that investments are generally the byproduct of savings, and the quantity of accumulated national savings is determined by per capita incomes. 
However, since many SSA states at that time were low income and accordingly, low saving, they became victims to the vicious cycle of poverty. That is, these emerging economies are trapped at low-income status and will remain so because they have low capital accumulation, investments, and productivity, among other intervening variables, unless they are able to implement appropriate reforms that accounts for domestic realities or contexts. Moreover, African realities were also exacerbated by the fact that domestic industries were severely uncoordinated. Therefore, it was argued that sufficient investments must be financed by external entities, which would help to dissolve this cycle and connect emerging economies to a cycle of long-term productivity and economic growth.

Central to the Big Push model is the need to invest not only in financing large-scale, state-led enterprises but also the need for technical assistance as conduits for economic 'takeoffs' and subsequent sustainable growth. Equally important, state governments were needed to implement broad or far-reaching policy frameworks that permitted them to coordinate and manage state-led investments as well as the private sectors by ensuring that investments are complementary in that they are interconnected and fulfilled necessary purposes. In other words, it was essential that projects were linked into network-like systems at the national level whereby they operated simultaneously as if in an ecosystem wherein each project is dependent on each other for the system as a whole to become highly productive. The private sectors did not have the capacity to organize such large tasks nor were they trusted by the state considering they are rational actors and therefore, what is in their best interests may not necessarily be in the state's best interest. Additionally, since state governments had more control over state development, there was less room for private actors to operate (Hyden, 2006; Meier and Stiglitz, 2001; Hoff and Stiglitz, 2000). 
Therefore, it was imperative for state governments to play central roles in coordinating and refereeing their domestic economies. This statist approach was endorsed as the best instrument to foster optimal economic performance. Conversely, the Big Push theory posits that economies are more likely to fail in the absence of coordinated, large-scale investments which will result in inferior economic outputs whereby scarce resources are allocated and unfavorable conditions will only trigger underdevelopment. Thus it is important that state governments play an active role in trying to scale their domestic economies through large cash injections, which will foster economic growth by putting states on self-sustaining paths to industrialization (Rosenstein-Rodan, 1943; Rostow, 1960; Nurske, 1953; Hirshman, 1957; Murphy et al, 1989; Hoff and Stiglitiz, 2000; Meier and Stiglitz, 2001).

The classic Big Push strategy started losing its appeal in the early 1960s partly because of the crippling debt crisis and economic collapse across emerging economies. Some scholars postulated that centrally planned economies were the source of those economic shortcomings, because too much state control in their economies contributed to slowed economic reform and growth. Therefore, there were calls for a policy reforms to shift toward economic liberalization (Easterly, 2006; Meier, 2000; Hoff, 2000).

However, recently there has been somewhat of a resurgence of the Big Push theory, especially in light of the Millennium Development Goals (MDGs). At the fore of the Big Push reprisal is economist Jeffrey Sachs (2005), who has maintained the core of the classic Big Push argument but has made some modifications that accounts for present conditions. Sachs argue that emerging economies are too poor to save thus making it difficult for them to invest. Failure to invest makes it challenging to escape the "poverty trap," because they are not able to fill the 
"financing gap." Therefore, without a "big" capital infusion to "push" these emerging states out of their financing gaps, they are likely to remain in a cycle of poverty.

Where Sachs seems to break away from the classic Big Push theory is that he emphasizes the moral obligation that industrialized economies have to their emerging counterparts. Specifically, industrialized economies should be required to transfer more finances from the west to the rest - for free or as grants rather than soft loans. Additionally, all forms of external interventions such aid for healthcare provisions, education, humanitarianism, and assistance within the agricultural sectors, etc., should also be provided for free since emerging states are too poor to easily afford these necessities.

Where both theories overlap is their emphasis on coordination. However, unlike the classic theory which emphasizes the need for states to coordinate its domestic enterprises, Sachs takes it a step further by suggesting states also need to coordinate or collaborate with donors. This is primarily because both parties have some mutual interests in the types of policies implemented across the region rather than have donors dictate the types of policies that should be implemented for recipients to follow (Sachs, 2005).

The general failure of both the classic and more contemporary Big Push models led donors and development experts to contemplate alternative strategies that could help put the region back on track economically. After all, poverty rates were on the rise. Government borrowing and spending were becoming uncontrollable, pushing many states on the cusp of financial default while others had already defaulted. More concerning is that very few states achieved economic growth in the process. This prompted state leaders to institutionalize African 
Socialism and, concurrently, import substitution industrialization (ISI) as a policy mechanism to correct the problems that came to the fore as a result of the Big Push principles.

\subsection{African Socialism and import substitution industrialization (ISI).}

The empirical literature shows that a positive relationship exists between increases in per capita incomes, productivity, and the size of the industrial sector. Studies also find there is causality between the level of industrial productivity and economic growth. Theoretically, greater industrialization is expected to generate more wealth formation and accumulation. Increased anticipated economic gains from industrialization prompted many emerging economies to invest heavily in industrial development. However, because of their experiences with colonialism, many SSA leaders were skeptical about adopting neoliberal-oriented policies. They believed capitalism was evil and exploitative, and it is likely to enhance the appetite for wealth accumulation and concentrate said wealth in the hands of elites which, in turn, would widen the gap between the rich and poor. Therefore, governments felt the need to mitigate this issue by playing a central role in the economic planning and well-being of states by trying to secure equitable distribution of wealth. This came in the form of African socialism, which SSA states began implementing around the 1960s (Rostow, 1956; Richardson, 1990; Hill, 2011; Mendes et al, 2014; Linder, 1961; Knox et al, 2003; Peng, 2009; Todaro and Smith, 2009; Davis, 1994; Meyer, 2004; Ayittey, 2012; Nyerere, 1962).

African socialism started in the midst of the Cold War. Many states (including Kenya, Tanzania, and Uganda, to name a few) experienced some short-term growth after their central governments nationalized and controlled the productive, trade, and other major sectors of their economies. This was partly because the private sectors were still too weak and incapable of 
generating sufficient economic growth. Therefore, with some aid assistance from developed economies and multilateral agencies, SSA state leaders formulated comprehensive development strategies and invested in large-scale public infrastructures such as roads, ports, energy networks, telecommunication sectors, healthcare and educational institutions, etc. Additionally, governments committed to capacity building, enforcing policies to control market prices, and restricting trade and allocating credit and foreign exchange, etc. (Meredith, 2005; Owusu, 2003; Hyden, 2006; Heidhues and Obare, 2011).

It was out of Socialism and the statist concept that ISI was borne, and it could be argued that those aforementioned concepts operated simultaneously. Considering that at that juncture in time SSA states were still experiencing low levels of industrial development but high imports of basic goods, ISI was endorsed as a sound strategy to help the region catch up with their industrialized counterparts since that model had already proven successful in Western Europe and North America during the $19^{\text {th }}$ and early $20^{\text {th }}$ century. Thus, SSA states did not have to 'rediscover the wheel,' per se. Instead, they were expected to simply follow an already laid out plan for industrialization (Baker et al, 1986; Osogo, 1970).

Pivotal to the ISI concept was the need to produce substitute goods locally that a large part of state budgets were generally spent on importing. This included pharmaceuticals, agricultural equipment and machinery, and consumer goods, etc. The expectation was that in order to catalyze economic growth and development, SSA states must employ policies that endorses a shift away from being predominantly primary commodities export based. Producing consumer products meant greater export revenues, which could then be reinvested into domestic economies. This mechanism was viewed as an instrument that would facilitate the 
industrialization process, enhance the exchange of technologies, and create new jobs as well as markets and wealth for these states. In other words, it was supposed to jump-start the domestic economies of SSA states and reduce their dependency on external support. Thus many SSA states began developing domestic banking systems, transport infrastructures, telecommunication networks, power grids, and large manufacturing plants, etc. (Ogujiuba et al, 2011; OECD, 1986; Ayittey, 2012).

Theoretically, this policy shift made a lot of sense. SSA states were failing to develop because they lacked sufficient industrial depth and had become too dependent on manufactured imports such as consumer products, machinery, technology, and fertilizers, etc. Thus, it was imperative that they invested in industrializing their economies as a conduit for economic diversity, higher growth rates, securing their economies from being vulnerable to external shocks and, more importantly, protecting domestic industries from international competition and/or exploitation. This involved states imposing various restrictions on imports to both conserve foreign exchange and protect local economic interests.

States such as Nigeria, Kenya, Tanzania, Ghana, Zambia and Madagascar were amongst the first wave to implement large-scale ISI programs to protect competing local industries through strict protective tariffs, exchange rate controls, import quotas, vast government subsidies to local industries, and special preferential licensing for capital goods imports to allow infant domestic industries to mature. These were deliberate efforts to replace consumer imports by promoting both the emergence and expansion of domestic industries such as textiles, household appliances, consumer products, etc. In Ghana and Kenya, for instance, governments implemented stringent restrictions on foreign trade by placing high tariffs on imports to protect 
competing local industries. In some other states, measures were also put in place but more in an effort to conserve foreign exchange than to promote industrial protectionism. Coincidentally, this meant many policies that were implemented by state governments sheltered local enterprises from foreign competition, resulting in inhibited growth and development. Many inefficient companies survived in the markets because of strong support and subsidies from state governments. However, this practice came at substantial costs, which were later relayed to citizens (Acemoglu et al, 2011; Bates, 1981; Rono, 2002; Prebisch, 1950; Hans, 1950; Sarkar, 2005; Sarkar and Singer, 1991).

There are many determinants that favored this state-driven approach. During that time period, numerous SSA states were still experiencing political unrests due to broad cultural and ideological differences. In addition, states had weak political and economic institutions in place as well as poor governance, which fueled those issues. Equally important, most states had very small private sectors, or a small to non-existent entrepreneurial class. Political and economic stability as well as strong private sectors that are driven by an entrepreneurial class and sound leadership are essential catalysts for industrialization. Therefore, the expectation was that strong central governments would swiftly address those issues and help facilitate the industrialization process (Bates, 1981; Hyden, 2006; Nzau, 2010; Ukuku, 2008).

In order to launch and sustain ISI projects, states needed several primary components in place. This includes capital/investments, surplus, infrastructural support, technological advancements, and access to global markets. Those components are very inter-connected and crucial in regards to adding much needed value to land and labor for these states in their quest to build and sustain economic growth (Sandbrook, 1999; Ladipo, 1999). 
SSA states did not have the immediate capital needed to finance ISI projects themselves or many of the aforementioned components. Therefore, they had to rely on external support. They began borrowing large volumes of bilateral and multilateral loans. This led to some early but short-lived success stories in states such as Kenya, Ivory Coast, Cameroon, and Zimbabwe, primarily because of large domestic and regional markets. But the overall track record of ISI has been dismal at best. This was because those projects contributed to massive debt accumulations; the agricultural sectors declining tremendously as governments focused most of their attention on developing industries and less on supporting farmers; only limited capital being mobilized from citizens for investments; there only being small pockets of skilled workers available to operate these industrial plants; and the general failure of state governments to properly integrate local farmers into the mainstream economy, etc. (Hyden, 1970, 2006; Harold et al, 1996; Bates, 1981; Herbst, 2000; Ogujiba et al, 2011).

Additionally, there was a lack of sufficient technological advancement, excessive political interferences by both domestic and international actors, poor policy development and implementation, limited access to global markets, and inappropriate project selections. In many states, governments appropriated scarce resources disproportionately to big projects that were very capital-intensive and did not yield sufficient returns to keep operational costs manageable. Even more distressing, many projects did not take advantage of the resources of SSA states. The persistence of these constraints simply encouraged inefficiencies in the industrial sectors. This coupled with poor coordination and the development of unviable and high costing industrial plants - many of which did not have sufficiently skilled workers further escalated operational 
costs and set SSA on a path to economic destruction (Hyden, 1970, 2006; Nzau, 2010; Ogujiuba et al, 2011; Ayittey, 2012; ECA, 2013; Storm, 2010).

As previously noted, SSA states were able to secure bilateral and multilateral loans to help address their financial constraints, but the sad reality is that large loan acquisitions simply resulted in states accumulating larger and more unmanageable debts. This did not help to advance the industrialization process considering states were tasked with spending large portions of their incomes toward servicing debt fees. This came to be known as the 'African debt crisis,' because many of these states were already considered highly indebted and could not feasibly move toward industrialization if they are spending significant amounts of their relatively small incomes to service the large debts they had incurred over time. This certainly contributed to the failure of the region to industrialize, because it placed an insurmountable amount of fiscal burden on state budgets. Debt servicing led to less hard currency being available for these states for purchasing goods, machinery, technology, spare parts to sustain their industrial sectors, and general investments. Moreover, failure to secure adequate infrastructures (energy, transportation, storage units, etc.) also played a role in impeding the process since it led to higher production and transaction costs. Oftentimes, factories were built without much consideration for proximity to ports and appropriate markets, availability of energy sources, qualified human capital (Fellis, 1996; Brown, 2001; Sessay and Ankrinade, 1998; Jaylor and Williams, 2004; Ukuku, 2008; Ayittey, 2012; Bates, 1981).

Some of those issues were a result of political strategizing - both internal and external. At that juncture in time, states were still going through the early state building process. Therefore, since many were divided along cultural and political lines, projects were often used by leaders as 
political bait to secure and maintain strategic political support in order to get them into office and keep them there. This opened the doors to widespread nepotism, corruption, mismanagement and favoritism along particular cultural and political lines. Adding to the inefficiencies of these projects is the fact that there was a lack of qualified individuals with adequate managerial skills to help maintain efficiency and those that were qualified were often passed over in favor of relatives and cronies (Ayittey, 2012; Martin Meredith, 2005).

Another ill-advised strategy that contributed to the failure to industrialize the region rests on the fact that SSA states were pressured into devaluing their currencies in order to gain access to more funding. This only resulted in states having to cut back on how much they spent on imports since their currencies became less competitive on the global market. Moreover, it led to the erosion of the industrial sectors. These errors increased the levels of dependency of SSA states, which greatly affected their plight to reform and develop. Furthermore, by devaluing state currencies, states were expected to become more competitive on the international markets. Instead, this strategy only succeeded in further reducing the utilization of factories across the region as a result of diminishing purchasing power of states as well as the demand for these products in regional and global markets (OECD, 1986; Hyden, 1970; Mendes, 2013).

A combination of the aforementioned elements contributed to the derailment of the region's plans to industrialize. ISI was intended to play a critical role in the region's attempt to achieve industrialized status, foster swift economic growth, and reduce state dependence. However, it became an unmitigated disaster that only led to an expansion of the public sector which did not have the capacity to take on the added responsibilities of overseeing the operation of large projects and initiatives. The failure or lack of leadership only made matters worse, 
because it essentially opened the doors to large black-markets for both domestic and foreign goods and, more concerning, it helped to reduce the incentive to produce locally and diversify the domestic economy. This has had profound effects on the size of these economies ever since. SSA leaders again found themselves at the crossroads where they had to acknowledge previous development strategies had failed, and it was time to explore other avenues.

\subsection{The Washington Consensus}

Amidst the economic chaos during the 1970s and 1980s such as the debt and oil crises, many policy experts argued that state-centric policies (Big Push, ISI, and African Socialism) were at fault due to excessive government interferences in their domestic economies. Economic growth was paralyzed, poverty rates rose, macroeconomic instability became the norm, and the debt crisis was getting worse. In order to reverse those trends, which were furthered by sharply declining primary commodities prices and increasing interest rates, the IMF together with the WB and the United States Agency for International Development (USAID) instituted the Washington Consensus, which was substantiated by findings in the Berg Report (1981).

The Washington Consensus and the Berg Report promoted the notion that economic failures across SSA can be attributed to poor governance and policy choices. They found that scarce state resources were being grossly mismanaged; exchange rates policies were faulty, and there were excessive government interference in domestic economies. Furthermore, governments protected inefficient industries; implemented irrational subsidization protocols; taxed the low income rural producers high rents in addition to escalating corruption levels became major hindrances to regional progress. The report suggested that states should refrain from excessively interfering in their economies and implement free-market practices by drastically reducing trade 
barriers and controls on exchange rates. Additionally, states must introduce more legal and regulatory structures, privatize inefficient public enterprises (downsize the public sector), etc., in pursuit of free market practices (Berg Report, 1981; Williamson, 1999, 2000).

The Washington Consensus was very much a neo-liberal policy response to previous policy failings and took aim at macroeconomic restructuring. Its secondary role was to concurrently correct previous policy failings by providing systematic policy frameworks to restore political and economic order through stabilizing and restoring efficiency in all sectors of the emerging economies. This approach was designed and promoted as the guiding principles of free market ideologies.

The central idea behind the Western Consensus was to essentially move states away from state-centric development approaches, which instituted a plethora of state controls that were argued to be the source of market inefficiency, escalated borrowing, and the debt crisis that was spiraling out of control. The free market strategy was prescribed as an instrument to fuel economic growth as a result of reforms. This included macroeconomic stabilization through fiscal and monetary reforms, privatization of inefficient public sector enterprises, trade liberalization, securing property rights, establishing a broader definition of the role of markets in relations to governments through deregulation reforms, and requiring emerging economies to implement these market-oriented reforms as conditions for aid. This later became known as 'structural adjustment loans' and 'structural adjustment policy' (SAP).' SAPs were viewed as a vehicle for economic reform and growth, because they were expected to improve economic efficiency and productivity. That, in turn, was expected to facilitate both capital formation and savings which could be used for re-investments to further expand the depth of domestic 
economies (Gloyd, 2004; Summers and Pritchet, 2001; Rono, 2002; Mohan et al, 2000; Williamson, 1999, 2004; Logan, 2015; Thomson, 2010; Milward, 2000; Edlyne, 2004; Geo-Jaja and Mangum, 2010).

Those measures were also viewed as essential for organizing economic activities in order to foster competition, economic efficiency, and choice in order to help accelerate growth. Moreover, the objective was to get these states to integrate into the global economic system, which was expected to promote economic sustainability. In turn, this would allow states to service their outstanding debts and reduce their overreliance on external support (Williamson, 1999, 2004 a \& b; Harvey, 2005; Logan, 2005; Milner, 2005).

Two of the first regional SAPs were The Lagos Plan of Action (LPA) and the Regional Food Plan for Africa (AFPLAN). The primary aim of those programs was to develop the SSA region by building capacity. Through capacity building, states were expected to make progress as a result of being able to set their own pace and direction of development without excessive external interferences. However, both plans were found to be state-centric like ISI. The grassroots plans eventually proved unsuccessful mainly due to: (i) many states not having sufficient institutional capacity to implement development plans at that juncture; (ii) a drastic decline in Western financial support; and (iii) the rejection of socialist policies by the West.

By the 1990s, neoliberalism had come to the fore of development assistance, especially across SSA. Unlike previous development strategies that focused on using aid to develop infrastructures such as roads, ports, railways, schools, hospitals, etc., SAPs were more policybased lending that aimed to foster reforms. That is, aid was provided conditional upon recipient governments being obligated to make structural policy reforms. The central premise of those 
reforms were to fuel domestic productivity and foster economic diversity with the expectation of expanding the private sector; curbing the size of government and its spending practices by enhancing government capacity; employing policy parameters that advance economic freedoms (of suppliers and consumers); and working toward promoting domestic savings. In many regards, SAPs were supposed to remedy the dire economic conditions across SSA along with poor governance; questionable policy choices; high corruption rates; and weak institutional capacity (Thomson, 2010; Poyl, 2006; Heidhues and Obare, 2011; Noorbakhsh and Boorbakhsh, 2006; Stone, 2004; Moyo, 2009; Calderisi, 2006; Heidhues et al, 2011; Shliefer, 2009; Stiglitz, 2004; Rosengren and Jordan, 2000; Tisdell and Alauddin, 2002).

Central to structural lending is their concessional basis; meaning, in order to generate economic growth donors agreed to loan large sums of capital at extremely generous or below market interest rates. For instance, if a SSA state government needs to borrow $\$ 10$ million to build a port they could borrow said amount from a private institution at approximately 10 percent interest rate over a 10 year period. The compound interest will be relatively high compared to borrowing the same amount from an IFI or Western state, which may charge approximately 2 percent interest rate for 20 years and an additional 5 year grace period. However, in return, recipients must implement economic reform directives in order to help the International Monetary Fund and World Bank to reach their development goals.

However, aid directives were often too stringent for SSA states to follow, resulting in many choosing to either ignore them in various capacities or put up political resistance upon receipt either covertly or overtly. Therefore, reforms were often delayed or recipients demonstrated a lack of commitment. In many instances, SSA states engaged donors in ritualistic 
dances whereby after being pressured to reform they would tease donors with intentions to cooperate but then they stepped back when aid had been received. This practice is often time consuming and expensive, especially if donors are forced to suspend aid in the process in an effort to encourage compliance. In contrast, in some cases whereby a state is of strategic geopolitical importance and is very persuasive, they are likely to receive strong aid support and softer conditionality terms in spite of their record of non-compliance (Boone, 1996; Collier, 1997; Ranis, 1996; Ayittey, 2012; World Bank, 2012; Vasquez, 1998; Svensson, 2000; Stiglitz, 2000; Mohan et al, 2000; Easterly, 2001; Heckelman and Knack, 2008; Remmer, 2004; Mohan et al, 2000).

Similar to conditionality, donors often use "tied aid" to achieve expected policy outcomes. For instance, recipients are often required to procure goods and services from donor states, specified states and/or firms to meet the conditions of the loan(s). This practice tends to result in donors overcharging recipients due to comparative disadvantage; meaning, recipients receive less value for each dollar spent when they could procure the same goods and services locally or regionally at cheaper rates. However, tying aid is generally used to support special interest groups in donor states, because it often helps to solidify political support at home. But this approach has proven to be more costly and less effective. This strategy was employed to mitigate high corruption levels in recipient states, but studies show this has had a negative effect on a states' ability to reform and develop. This is because in addition to recipients being forced to pay higher prices to acquire the same product and services from donors it also forces local businesses out of the market if the same products are provided for free or cheaper through the SAP agreements (Williamson, 2009; Montinola, 2007; Radelet, 2006; Ayittey, 2012). 
Equally important to SAPs are the understated ploys to democratize recipients. This rests on the notion that democratic structures help to facilitate development because they promote the rule of law, political stability, accountability due to transparency, and discourage corruption and political extremism. Thus, political liberalization becomes mutually supporting or a precondition for sound economic reforms to take place. This means SSA states must transition by creating more democratic institutions along with permitting more civil liberties in order to help accelerate policy reforms. This feeds into the assertion that good governance requires the use of appropriate institutions to create positive policy environments and enforce sound fiscal, monetary, and trade policies. In turn, this increases the incentives to invest (Akins et al, 2002; Rodrik, 2000; Rosengren and Jordan, 2000; Dollar and Svensson, 2000; Burnside and Dollar, 2000, 2004; Acemoglu, 2003; Bennedsen and Meisner, 2005).

However, the supremacy of SAPs was somewhat short-lived for various reasons. Although some SSA states such as Ghana, Tanzania and Mozambique experienced some economic success, the reality is that SAPs have been mainly unsuccessful since they failed to reduce poverty rates or stabilize domestic economies. This could be attributed to the fact that the amount of aid channeled toward SAPs varied significantly across states with more structural adjustment loans going toward states with stronger alliances with donors, or for geopolitical purposes while little or no attention was placed on incorporating the internal dynamics of individual states within the structural policies. Equally important, states that experienced greater levels of economic reforms were those that showed a genuine willingness to pursue economic reforms and committed to them. Conversely, although SAPs were intended to enhance state economies it proved detrimental to reform in some states. This is because donors became too fixated on their neo-liberal ideals to the point where they failed to carefully examine some of the 
more nuance (cultural, traditional, and historical) factors that contributes economic progress before crafting appropriate policy frameworks and expectations (Ayittey, 2012; Vasquez, 1998).

The aforementioned assertions are highlighted by the fact that SAPs were generally a one-size-fits-all approach without adequate collaboration with recipients; states were pressured into moving away from primary commodities exports to their own detriment; and states were also coerced into devaluing their currencies which made it significantly more expensive for them to purchase imported products, resulting in lower consumption. Also, SAPs were not designed collaboratively with SSA stakeholders. They were controlled and dominated by donors and small controlling elites in recipient states with vested interest. This contributed to their failures as the masses in recipient states found it difficult to embrace this new idea (Ayittey, 2012; Kieh, 2008; Vasquez, 1998; Alesina and Dollar, 1998; Tamang, 2009; Milner and Tingley, 2013; Stiglitz, 2000, 2004).

This led to problems with commitment in addition to high corruption levels, poor governance, and weak institutions. Those issues made it difficult to create sound policy environments to foster economic reforms. Moreover, many of the early SAPs were implemented with little or no attention to the varied contexts that exists across the SSA landscape (Collier, 1997; Easterly, 2001, 2007; Burnside and Dollar, 2000, 2004; Siglitz, 2000; Hyden, 2006; Moyo, 2009; Ayittey, 2012).

Despite the general failures of SAPs across SSA, I argue that the time is right to revisit this approach to advance the region's economic reform efforts. I firmly believe policymakers need to place emphasis on allocating more aid toward economic reforms as an avenue to facilitate economic growth. This, I believe, will be a smart use of aid. In contrast to general 
SAPs, the premise of my study will be to take a narrower examination of the aid-growth relationship. The initial goal of SAPs was for economic restructuring; however, it became broad in the sense that programs were created to address all social-related problems. This may have contributed to the general failure of SAPs also, because programs became too big, lost focus and were uncoordinated, resulting in them becoming too capital-intensive. Yet these programs persisted because they are viewed as moral obligations.

One of the goals is to help steer policymakers and donors away from viewing aid allocations as moral obligations. Instead, aid is a valuable resource and therefore must be invested wisely with more emphasis placed on rationality in order to increase the likelihood of achieving long-term economic success. Considering one of the primary studies that have motivated mine found that aid type matters, then I believe that it would be logical to invest in sectors that gives the largest rate of returns. That happens to be four conduits of economic reform: government capacity, economic freedom, private sector, and domestic savings. Combined, they are engines that essentially keep all other sectors of society functional if they operate efficiently. The expectation is that if recipients implement sound economic strategies, capital earned could be used to fund other sectors.

\subsection{Debt relief era}

There is a general consensus that high levels of debt could impede a states' ability to achieve or implement its economic reform agendas. Therefore, industrialized states and IFIs introduced a new policy initiative in 1996 in a bid to help mitigate the impeding effects that escalating debt burdens were having on emerging economies. This was especially for states considered as Highly Indebted Poor Countries (HIPCs). 
The theoretical presumption for this policy shift is simple. Excessive debts more often than not impaired economic reform efforts and subsequent growth by creating debt overhangs. This occurs when states are driven to accumulate huge debts as a result of continued borrowing in large amounts that eventually became unmanageable, thereby diminishing their ability to repay the debt and/or compound interest. During this process, scarce resources are "taxed away" by creditors since states are often put under increasing pressures to service their debts with capital that could otherwise be invested domestically.

Subsequently, this reduces the potential productivity and output levels of states, because it reduces the savings gap and raises uncertainty which is likely to discourage future creditors as well as domestic and foreign investors by escalating economic uncertainties (risk of defaulting, debt rescheduling, and arrears) as governments are tasked with implementing measures that would help them satisfy their debt obligations. This often involves raising taxes and interest rates on states loans, and reducing subsidies, etc. Thus, debt reliefs were posed as an efficient way of generating economic growth when states experience significant debt overhangs. Reductions in government debts were expected to give recipients more maneuverability to invest and boost domestic productivity, which is expected to trigger growth (O’Neill, 2002; Cax, 2005; Hepp, 2005; Lipumban, 2004; Easterly, 1999, 2002).

Generally, as debts soar, there is a tendency for governments to instruct their central banks to print more money, which could potentially lead to hyperinflation as is the case currently in Zimbabwe and Ghana in years past. Or, governments may elect to increase taxes on businesses and households to raise needed capital. However, those tactics often has direct effect on the size of the private sector and spending power of citizens. In other words, a spike in taxes 
creates a 'crowding out' effect in the private sectors as it takes away the incentive to invest, and if households are taxed more it also means they would have less hard currency to spend thus threatening the economic efficiency of the state.

Moreover, even amidst uncertainties, some investors may decide to take risks by investing. However, they are likely to remain very cautious by channeling money into projects that has swift returns or that would permit them to quickly liquidate their investments if conditions become too unfavorable rather than invest in long-term projects that are more likely to support sustainable growth. Such actions help to perpetuate the cycle of indebtedness that plunges these states into a 'poverty trap.' Debt reliefs were expected to relax this financial constraint by altering the composition of public spending by mitigating the debt stock owed and possibly the level of uncertainly, which may potentially attract new investors and seduce creditors into making more capital available to help generate economic growth (Krugman, 1988; Sachs, 1984, 1989; Clemens et al, 2003, 2005; Moyo, 2009; Arslanalp and Henry, 2006; Easterly, 1999, 2002; Pattillo et al ,2002, 2004; Fonchamayo, 2009; Iyoha, 1999; Johansson, 2008; Ben, 2010; Dobdinga, 2009; Cohen, 1993, 2000; OECD, 2003; Claessens et al, 1997, 1990).

SSA's desire to accelerate its economic growth and development has led to state governments borrowing large sums of bilateral and multilateral aid to finance ambitious and supposed viable projects. However, many of these states are held at ransom due to the strenuous budget constraints that debt servicing places on them, causing them to become more reliant on loans to not only conduct their basic government functions but also to service their debts. This forces governments to pursue debt cancellations, restructurings, or conversions. SSA states 
continue to take advantage of those forms of debt reliefs to help ease the burdens of budget deficits, resulting in their inability to save or invest in infrastructural development and human capital.

Debt cancellation is conceptualized as the reduction of debt obligations of debtors to creditors; debt restructuring involves renegotiating the existing terms of agreement and conditions that may result in rescheduling when debts must be repaid; lastly, debt conversion is a process wherein creditors and debtors negotiate the terms of agreement and agree to exchange the debts owed with something of potentially equal or similar economic value. Many SSA states continue to pursue those debt relief options because they have defaulted on their loans (IMF, 2003; Krugman, 1988; Moss, 2006; Johansson, 2007; Okoto, 2013).

There are several reasons that helps to explain the dire economic situation across SSA that has resulted in many states being subjected to debt relief. Historically, there have been an overreliance on external sources of financing to help generate domestic capital formation. The desire of these states to propel their economic growth has often pushed them to develop overly ambitious plans that are too capital-intensive and inefficient to sustain, especially when market access is limited. Consequently, there has been an increasing trend to import rather than produce domestically. The economic landscape becomes bleaker considering these states often employ poor fiscal discipline that has led to debt mismanagement whereby governments simply borrowed without much consideration for the long-term consequences. Such actions are often facilitated by the existence of weak economic institutions (Moyo, 2009; Hyden, 2006; Easterly, 1999, 2002). 
Additionally, there is the issue of escalating corruption whereby governments continue to expand public sectors as a means to shield them into office (civil services, security forces, nepotism) and siphoned large sums of money into their personal bank accounts. There is also the matter of political instability that needs to be accounted for. Those elements have contributed to the failure of states to attract sufficient investments. Even when they managed to secure big investments they are forced to sell themselves short by making concessions that are not mutually altruistic, resulting in these investments not generating sufficient tax revenues that goes back into the domestic economies (Jackson and Roseberg, 1982; Ajayi and Oke, 2012; Kapfer et al, 2007; Summers, 2000; Hyden, 2006; Marshall et al, 2002; Easterly, 2002; Fikru and Getachew, 2008; Arslanap and Henry, 2006).

Another factor that must be considered when discussing the current debt problems that continues to inhibit SSA's ability to reform rests on the unfavorable terms of agreement that they are essentially forced to sign off on considering that many states are in desperate need of capital. These loans are deemed concessionary, but the sad reality is that the interest rates are still high. Plus, there are penalty interests that are compounded into larger repayments over time. Moreover, even when creditors canceled significant portions of debts owed, the remaining debts and servicing fees still prove challenging for many states to manage. This has led them to delay their repayment and economic reform efforts (Easterly, 1999, 2002; Dikkstra and Hermes, 2001; Clemens et al, 2002; Patillo et al, 2002).

However, an argument could be made that governments are not consciously making an effort to delay paying off their debts because there is a disincentive to do so. Rather, they are just too heavily indebted to implement the necessary economic reforms that could help them generate 
economic growth. Thus, debt reliefs could incentivize economic reforms by reducing debt obligations, which will provide states with needed capital to invest in policy reforms that would foster economic growth and reduce dependency. Critics, on the other hand, assert that even if all debts are forgiven it will eventually accumulate again if recipients are not making sufficient efforts to increase their revenues faster than their expenditures. Moreover, others argue that debt reliefs often incentivize prolonged wasteful spending and poor economic policies (Easterly, 2001; Vasquez, 1998; Rono, 2002; Moyo, 2009; Johansson, 2007; Krugman, 1989; Bello, 2000; Jhingan, 2005).

That said, although the empirical literature agrees that large debt overhangs generally has a negative effect on economic reforms, they seem to disagree on the general mechanisms and the extent to which it may trigger economic regression. Some states - mainly middle income - were able to benefit from debt reliefs, while most of the HIPCs failed to take advantage. This is primarily because they did not have efficient economic institutions that are able to help fortify their investments. In contrast, the middle income states had those functional institutions as well as growing private sectors that attracted investors. Thus, numerous empirical findings have provided support as to why increasing debts may threaten economic reforms, especially across emerging economies (Clemens et al, 2003; Claessen et al, 1997; Patillo et al, 2002; Dijkstra and Hhermes, 2001, Easterly, 2001).

\subsection{Aid for Trade}

The existing literature on Aid for Trade (AfT) gives only a limited theoretical view in regards to the effect AfT may have on recipients (and donors) due to a lack of sectoral data of adequate quality over a sufficient timeframe. This initiative was launched in 2005 by the World 
Trade Organization (WTO) and is based on Goal 8 of the MDGs - Developing global partnerships for development by creating a new 'rules based, open, multilateral trading system, improved market-access including duty-free, quota-free market access for LDCs.'

A key component of the AfT policy framework is providing both bilateral and multilateral funding for capacity building by addressing institutional and policy constraints that are supposedly inhibiting emerging economies from maximizing their economic potentials. Investing in building capacity was expected to help connect emerging and developed economies as well as public and private sectors. This process involves developed economies directing AfT in various forms to emerging economies appropriated to state governments, NGOs, or private sectors to finance infrastructural development (building ports, railroads, roads, storage units, electricity grids, and communication networks, etc.), create productive capacity, training programs, implementing and regulating trade policies, etc. Addressing those domestic constraints were expected to reduce trade costs but increase exports and returns (Mayer and Milberg, 2013; Milberg and Winkler, 2013; Vijil and Wagner, 2010).

This policy shift became a crucial component to foreign aid distribution considering it was used with specific strategic intentions to entice recipients into enhancing supply capacity and teaching trade-related skills to help foster economic freedom. In some regards, this policy shift is in recognition of the unintended negative consequences previous aid policies have had in emerging economies, namely by partly reducing their competitiveness in the global economy. Moreover, it recognizes that further aid appropriations for trade liberalization will have insignificant effects if recipients have productive and supply capacity limitations, which inhibits their trade potential. To correct that, donors elected to focus more attention on improving trade 
development, facilitation, and other similar programs as conduits for competition, trade, and economic growth.

Thus, key to AfT is the understanding that poor infrastructural capacity not only makes it challenging for emerging economies to export and import goods and services, it also imposes high transaction costs on domestic enterprises thus making them less profitable. Smaller profits make it less likely for these enterprises to commit to investments, which will negatively affect the size of their economies. Therefore, trying to reduce transaction costs not only makes it easier for enterprises to conduct transactions, it also allows them to turn greater profit margins and facilitate more trades in the process (Vigil and Wagner, 2010; Krueger, 2008; Sachs, 2003; Acemoglu et al, 2001; Huhne et al,2013; Cali and Te Velde, 2011).

The aforementioned notions contributes to the theoretical explanation of why SSA states continue to lag economically. Theoretically, AfT suggests that SSA states are failing to develop because their economic policies are too inward oriented and they do not have adequate trade infrastructures as a result to help them capitalize on global market opportunities. Therefore, in order for these states to develop they need to commit to trade liberalization. This means opening their economies to foreign trades, investments, competition, and integrating into the global economy are absolutely fundamental for their long-term economic success. However, they cannot succeed if they do not have the necessary capacities to do so.

Moreover, in order for these emerging economies to maximize their trade potentials they must invest in domestic policy reforms that complements trade liberalization such as institutional, intellectual, and tax reforms, etc., which would help to augment the loss of tariff revenues. Additionally, efforts must be made to ensure macroeconomic stability, enhance 
healthcare to promote productivity, and more importantly, tackle corruption. Coupled with a trade liberalization framework and higher export earnings, these states are expected to be better positioned economically to invest in technologies and other services as well as improve their domestic saving constraints. This will allow them to expand their economies and, in turn, reduce their dependence on external aid (Sachs, 2003; Winters et al, 2004; Kneller et al, 2008; OECD, 2006, 2013).

The principal issue, however, is that many SSA states do not have the resources to initiate sufficient internal reforms and to develop capacities that are necessary to help them take advantage of the global free market system. AfT contributions aim to provide these states with technical and financial support that they could benefit from and allow them to cope with structural changes in the global economic arena. Additionally, this approach also focuses on 'mainstreaming' global trade in domestic economic development. This "involves the process and methods of identifying and integrating trade priority areas of action into the overall framework of country development plans and poverty reductions strategies” (OECD, 2006, 2013; WTO 2001; Stiglitiz and Charlton, 2006).

However, although AfT is pushed as a new instrument to facilitate growth, there is essentially nothing novel about it from a conceptual standpoint, per se, as it stems from Official Development Aid (ODA) at a fundamental level. As a result of regional and global economic imbalances in the past, this initiative was framed as an instrument that would more directly address this issue by targeting the development of productive and trade capacities of emerging states. The expectation was that it will mitigate transaction costs during trades not only by lowering trade barriers through free-market oriented policies but also building infrastructures to 
address high transportation, communication, and production costs; enhance the diversification of domestic markets and integration into new international markets, and the provision of technical support for the development and implementation of trade policies and regulations. This will, in turn, open up economies to new sources of capital and the exchange of knowledge, which will ignite sustainable economic growth (Sachs and Warner, 1995; Edwards, 1998; Greenway et al, 2002; Wacziarg and Welch, 2008).

That said, there is no questioning that in a globalized world, trade plays a central role when it comes to addressing sustainable economic growth. But, in order to achieve economic growth states must target and commit to economic reforms aimed at expanding trade, supply, and investments. However, the empirical literature has produced mixed findings that questions the AfT theory. On one hand, proponents found that AfT is an engine for reform and subsequent economic growth, while skeptics found the opposite to be true (Basnet et al, 2012; Stiglitz and Charlton, 2006; Rodrik and Rodriguez, 2000; Rodrik and Subramanian, 2008; Hynes and Plummer, 2013; Milberg and Winkler, 2013; Bearce et al, 2012; Cali and Te Velde, 2011; Fugazza, 2004; Helble et al, 2012; OECD and WTO, 2011; Huhne et al, 2013; Hallaert, 2012; Said, 2011; Novak-Lehmann et al, 2013; Munemo et al, 2007; Munemo, 2011; Pettersson and Johansson, 2013; De Melo and Wagner, 2015).

Proponents have sought to empirically quantify the effect of AfT on trade and economic growth using various models and datasets. And although considerable ambiguities exists regarding their individual arguments and use of statistical models, there is consensus that AfT has an overall positive effect on economic growth. In other words, studies show that aid directed toward trade facilitation increases the trade performance of recipient states (Helble et al, 2012; 
Cali and Te Velde 2011; Karingi and Leyaro, 2009; Hoekman and Shepard, 2013; SuwaEisenmann and Verdier, 2007; Cadot et al, 2013).

For instance, Suwa-Eisemann and Verdier (2007) stated "aid flows may affect trade flows, either because of the general effects they induce in the recipient country, or because aid is directly tied to trade, or because it reinforces bilateral economic and political links (or a combination of all three)." This idea is consistent with some of the findings of Helble et al (2012). They found that an estimated 1 percent increase in aid for trade facilitation could potentially create an increase in global trade of approximately U.S 415 million. Moreover, the effect of aid channeled to the "Trade policy and regulation" category tested strongly for robustness with significantly high impact on recipient exports. Plus, this category of aid exhibits the largest rate of return. Those findings were supported by Cali and Te Velde (2011) who suggests that trade facilitation increases trade performances amongst recipients by reducing trade costs. Furthermore, AfT has an overall positive and significant effect on imports. However, they concluded by illustrating this effect is entirely generated by aid specifically for economic infrastructures, while other AfT categories has no discernable effects on recipient exports.

Similarly, Karingi and Leyaro (2009) suggests that AfT, when controlling for other factors, is crucial for addressing trade capacity limitations and promoting trade across African states. The study found AfT lowers trade costs, enhances export diversification, and improves competitiveness among regional states. Similar sentiments are shared by Hoekman and Shepard (2013) who examined whether AfT is less effective in enhancing exports from smaller firms versus larger ones. They found all firms benefited from trade facilitation, because it permitted them to increase the volume of exports as a result of less time taken to export goods and at 
cheaper prices. Thus, smaller firms are able to gain from AfT the same way larger ones do considering the mechanism is the same for both.

In contrast, skeptics have used empirical findings to dispel those laid out by proponents. They acknowledge that AfT has seen a steady increase since its inception - even in light of the recent global economic downturn; yet Africa's share of the global trade continue to decline considerably because they are not able to take advantage of the preferential trade access made available to them. This leads them to question the theoretical basis of AfT, which stipulates that directing more aid for trade facilitation will automatically trigger an increase in trade; an increase in trade will propel economic growth; and trade-induced growth will improve the standard of living for citizens in recipient states. Studies show that investing in trade liberalization may be necessary for sustainable expansion of trade, but it is certainly not sufficient because there are other factors contributing to exports and imports, such as technical knowledge, health, having adequate labor forces, level of internal bureaucratic obstacles as well as the level of efficiency of the productive sectors competitiveness, etc. By the same token, a lack of access to credit makes it challenging for new enterprises to come to fruition or old ones to expand to take advantage of new market opportunities (Sachs, 2003; Stiglitz and Charlton, 2006; Stiglitz, 2003; Rodrik and Rodriguez, 2000; Clemens and Williamson, 2002; Agboghoroma et al 2009; IMF, 2007; Brun et al, 2005; Huchet-Burdon, 2009; Hoekman and Nicita, 2008; Portugal-Perez and Wilson, 2008; Fugazza, 2004).

Furthermore, there is the issue of who really benefits from this policy directive - donors or recipients? Studies show that many emerging states continue to be marginalized in the global market even though they have been granted more preferential trade opportunities. Many of these 
states happen to be in the SSA region. These states continue to struggle because of issues such as internal bureaucratic obstacles to trade; states being promised technical assistance to implement the agreement but it is not provided at the extent promised; and there is also the issue of insufficient financing and poor infrastructural capacities, etc. Moreover, the empirical literature suggests the effect of AfT varies considerably based on the type of intervention, income levels of recipients, and the sectors AfT is allocated to. Therefore, market access alone may prove insufficient for growth in SSA if those other factors are not adequately addressed (Hynes and Plummer, 2013; OECD, 2006, 2012; Brun et al, 2005; Huchet-Burdon, 2009; Stiglitz, 2003; Stiglitz and Charlton, 2006).

Similarly, some of the literature postulates that many of these states have failed to buy into the free trade system because the net benefits are not in their favor. By committing to trade liberalization they have to make sacrifices starting with eliminating trade tariffs, which constitutes a large source of revenue for them. Moreover, if they do not already have the trade and productive capacities in place, they are essentially forced to commit large upfront adjustment costs ranging from fiscal losses, preference erosion, institutional restructuring, and policy implementation and regulations, etc. This will require these states to move scarce resources from one sector to the next. More concerning is that it generally takes a long time before states are able to start reaping the benefits of the agreement if they chose to stay committed. Many of these states are not currently in position to absorb those adjustment costs, and some leaders prefer to invest resources elsewhere in the economy where it would lead to swifter returns, which is perhaps one of the reasons why many AfT continue to fail SSA (Stiglitz and Charlton, 2006; Hynes and Plummer, 2013; Laird, 2007). 
Additionally, SSA states are confronted with the fact that trade liberalization does not necessarily mean increase in trade revenues. Rather, its costs may outweigh its benefits since these states lose tariff revenues and domestic enterprises have to face increased competition from external enterprises. Eliminating trade barriers are expected to establish an altruistic relationship between economies; however, in SSA states this process has made access into the domestic markets easier and the relationship has become asymmetrical; meaning, donors continue to see an influx of their products into the markets of recipients, which floods out domestic competitors, bottleneck the economy via a 'Dutch Disease' type scenario. That is, opening the domestic markets to international competition may lead to an erosion of competitiveness as a result of real exchange appreciation - which effectively makes it more challenging for domestic products to be sold on the international markets due to the cost of acquisition relative to similar products produced in developed states, per se. In turn, this perpetuates dependency (Huhne et al, 2013; Morrissey, 2002; Munemo et al, 2007).

\subsection{Bringing back SAPs: Aid for economic reforms}

The Sub-Sahara region has navigated through various policy strategies in its bid to catch up with the developed world. One strategy that has had some success in other regions came in the form of SAPs, and they could prove effective across SSA as well if developed and implemented correctly. I argue that economic reforms are more likely if donors allocate scarce resources for that cause. SSA's chances for economic reforms are linked to continued support from external actors for restructuring the economies of these states, primarily through financial and technical aid to help them transition to more free market-like economies. 
Through sufficient aid to further develop domestic economies and institutions to better regulate transactions, buffer domestic economies from market imbalances, and foster competition these economies could be put on the path of economic growth. Therefore, this study asserts that market-based aid could be a long-term solution to SSA's longstanding lack of economic development. Addressing economic development through economic reforms will facilitate the exchange of ideas and innovation, which will enhance competition, market productivity, and growth as a result of integration into the regional and global economies. In turn, this will attract more capital investments that could be used to expand and diversify domestic economies, improve intellectual stock, healthcare provision, and secure property rights which are all imperative for economic growth to occur.

The causality between economic reforms and development remains an area of contention; specifically, whether market development precedes or follows economic growth. Some scholars argue that efficient markets facilitate development by igniting industrialization, mobilize domestic capital for commerce and spurring technological innovation by rewarding entrepreneurs with the most innovative ideas and products. In contrast, others assert "where enterprise leads, finance follows” (Robinson, 1952), because economic reforms create a demand for certain types of market arrangements, which responds to demands. Despite this, emerging economies require transfers of capital and technical assistance to maintain. However, to set them on the path to economic prosperity SAPs must be revisited. However, emphasis must be placed on developing individualized policies that accounts for the domestic realities of each state. Although SAPs have had minimal success across the SSA region in the past, they have proven to be highly successful in many emerging states such as Singapore, Taiwan, Hong Kong, South Korea, India, etc., and could be replicated across SSA with similar levels of success, but it is 
essential that efforts are made to localize these programs by factoring the roles cultural and traditional values, beliefs and practices play in the process (World Bank, 1993; Sachs and Warner, 1995; Rodrik, 1996; Rapley, 1996; Sachs, 2005; Adkins et al, 2002; Schumpeter, 1911; McKinnon, 1973; Shaw, 1973; Levine, 1997).

Central to the failures of SAPs across SSA in the past is that they were essentially forced upon states out of self-interests. Generally, when reforms are imposed they rarely have successful outcomes. Thus, it is imperative that reforms are people-driven; have a bottom-up component in that there is an element of participation and it is desired by those that the reforms will be impacting. Moreover, reforms must be developed by SSA states or with their support and implemented with their consent. Furthermore, reforms must be viewed as relevant to them and in their own best interests. These elements were lacking in early SAPs.

With the recent collaborative efforts between state governments and donors, marketbased aid could prove to be highly successful relative to the 'one size fits all approach' that has been traditionally employed. This is important considering each state has unique qualities as a result of their colonial heritages and cultural differences, which have affected their geographical, geopolitical, and social dynamics. Those differences have influenced their individual cultures, economies, politics, institutions and policies, territorial sizes, and resource wealth, etc. Unlike previous SAPS that have proven to be unpopular due to stringent conditions that were too harsh, rapid, and incorporated "economic models that did not fit the African social and political structures and conditions”(Rono, 2002), newer market reforms have some flexibility that allows for policy frameworks to be developed to account for some of the local realities of recipients. This is paramount because as SSA states are allowed to take or are given more ownership of 
market reforms it will have a positive effect on macroeconomic performance (Hezel, 2009; Harrison, 2006; Hyden, 2006; Milner and Tingley, 2013; Tamang, 2009).

With that in mind, development across SSA is ready for a revival. Many states within the region, especially those that will be examined, are now adequately stable and currently has sufficient institutional capacity and human capital to help usher in sustainable economic reforms. Furthermore, states are now in better positions to formulate and administer their own policies that accounts for domestic realities. In addition, they could collaborate and implement the numerous development initiatives placed upon them by donors without feeling overburdened. 


\section{Chapter 3: Theoretical Framework}

\section{1: Introduction}

The success of the Marshall Plan in some European states after World War II played a pivotal role in fostering optimism regarding the ability of foreign aid to help catalyze economic reforms and subsequent growth and development across emerging economies, if used effectively. This notion forms the foundation of numerous early economic reform models asserting that emerging economies are poor because they are not able to accumulate sufficient savings for subsequent investments. Therefore, foreign aid programs were by design expected to contribute toward bridging the savings gap and give recipients better odds of securing long-term economic growth and development by means of reforms. Thus in order to foster savings and economic growth, there must be pragmatic economic reforms that states are willing to commit to. This logic is supported by the development literature and numerous theoretical contributions. Some of those theories are relevant to this study in that they serve as pertinent components, and as such the following theories will be elaborated on: two-gap theory, and theories on donor and recipient information, which sets the parameters of my theory.

This chapter will serve three main goals. First, it provides the theory that guides this study. Second, it lays out a theoretical framework that will help explain the role of foreign aid across SSA between the end of colonialism and the present; discuss some central concepts and how they may have affected aid allocations, and establish a theoretical parameter that will help answer the research question posed in this study. Third, this section also outlines the theoretical expectations of this study. That said, particular attention will be placed on the interrelationships 
between market-based aid and how it affects four conduits of economic reforms: government capacity, economic freedom, private sector depth, and domestic savings.

\section{2: Theory}

I theorize that aid types matter in terms of facilitating economic reforms. The expanding development literature have provided valuable insights about the aid-reform nexus. However, there is a lack of sufficient analysis regarding how certain types of aid may have affected economic reforms across the region. Empirical findings show that many emerging economies perform better economically when they invest and commit to reforms. ${ }^{16}$ This includes providing policymakers with sufficient technical knowledge, training and resources to lead, design, and enforce macro-level policies (fiscal, economic, monetary, political, and judicial, etc.) that are appropriate for individual states. Thus, state leaders must have sufficient capacity to develop and enforce appropriate reforms that accounts for the specific realities of their own states rather than implementing a one-size-fits-all approach, which is generally designed by western policymakers without adequate understanding of the uniqueness of each state and how such uniqueness may affect reform development and its governance. That said, a proactive and competent government with adequate capacity to execute key functions should be able to promote and safeguard economic principles that would help it to maintain by safeguarding the economic freedoms of producers and consumers, which is expected to enhance private sector growth and domestic savings.

\footnotetext{
${ }^{16}$ Aid has been found to have a greater effect in states that are systematically conditioned with sound policy environments (fiscal, monetary, and trade, etc.). See Vasquez 1998; Burnside and Dollar, 2000; Sachs and Warner, 1995; Ayittey, 2012; Heckelman and Knack, 2009; Clemens et al, 2005, 2011; Owens and Hoddinott, 1999; Mavrotas, 2002.
} 
In order to accomplish such feat, adequate resources must be mobilized for developing and enforcing appropriate policies that targets enhancing: government capacity, economic freedom, private sector, and domestic savings. Those conduits have been at the forefront of economic reform since the infancy stages of the development discipline. This is not surprising since in practice those concepts are interconnected and play pivotal roles in contributing to reform. Ideally, one of the primary aims of the state is to become self-sufficient. In order to get there, they must achieve sufficient economic growth, which is closely associated with the government's capacity to function in an effective and efficient manner through its ability to formulate and implement appropriate policies. Enhanced government capacity is expected to facilitate greater economic freedom as a means to attract sufficient investments and domestic revenues. Greater economic freedom is expected to encourage private sector growth. Lastly, the growth of the private sector is expected to increase domestic savings if resources are invested wisely in order to maximize returns (Sachs and Warner, 1995; Burnside and Dollar, 2000; Clemens et al, 2005, 2011; De Haan and Sturm, 2000).

The aforementioned logic finds theoretical and statistical basis in the development literature and are often employed to justify arguments as to why emerging economies have generally had varying levels of economic successes and/or failures over the years. For instance, while aid contributions have paid relatively larger dividends in states such as Taiwan, Singapore, South Korea, India, and Ghana, etc., other states have been less fortunate. Many of the less fortunate states happen to be located in the SSA region. What is most concerning is that many of those states have failed to make sufficient economic progress relative to the amount of aid that has been appropriated (Ovaska, 2003; Heckelman and Knack, 2005; Adkins et al, 2002; Dawson, 
1998; Gwartney et al 1999, De Haan and Sturm, 2000; Ayittey, 2012; Mohan et al, 2000; Burnside and Dollar, 2000; Moyo, 2009).

This study suggests that SSA states have failed to make adequate economic reforms even in light of the previous and recent 'big push' by the Western aid institutions and governments. This is not for failure to allocate massive funding to the region. Rather, it is because of the aid type(s) appropriated to the region (which has contributed to a lack of economic reforms). Several empirical findings suggest that aid types have varying effects on economic reforms; meaning, some aid types have greater effects on economic reforms relative to others both in the short- and long-term. For instance, aid disbursements for humanitarian relief following disasters and emergencies are more likely to favor immediate consumption and/or satisfying humanitarian needs rather than fostering capacity building, economic reform, domestic savings, etc., which are paramount for reform and growth. Thus, studies find such aid types to have little or no direct effect on economic reforms. ${ }^{17}$ This makes sense, because economic reform is not a primary or secondary objective of said aid types. In contrast, aid allotted for enhancing trade policies and regulation, education, health, budget support, and government capacity, etc., has empirical grounding with facilitating economic reforms (Owens and Hoddinott, 1999; Alisina and Dollar, 2000; Clemens et al, 2005, 2011; Gomanee et al, 2002; Mavrotas, 2002; Vijil and Wagner, 2010; Winter et al, 2004; Cling, 2006; Brun et al, 2005).

This has led me to argue SSA states have struggled to achieve expected economic growth and development goals in part because donors (national governments and aid institutions) have historically failed to appropriate adequate aid specifically for economic reforms. Instead, they

\footnotetext{
${ }^{17}$ Please see Clemens et al, 2005, 2011; Owens and Hoddinott, 1999.
} 
have allotted money that foster mass consumption, and most of the decision-making hinges on what is considered moral obligation and not necessarily rational justifications. That said, an argument could be made that such strategies is in part to keep these states poor even though donors publically declare their aims to help foster reforms, which from an economic standpoint would disrupt the status quo. They want these states to remain dependent, while they (donors) remain in positions of economic superiority as a means to design and impose supposed solutions to address the problems of these states, which only adds to their problems rather than give them reprieve. Thus, it is a planned and systematic oppression to prevent these states from becoming independent, because with independence comes power, which creates some discomfort due to a change in the power dynamics of the global economic system.

For the purpose of this study, I defined market-based aid as allotments (bilateral, multilateral, and private ${ }^{18}$ ) to SSA state governments in post-independence era that targets enhancing government capacity, economic freedom, private sector growth, and domestic savings. The opposite is true for non-market aid. That said, figure 3.1 illustrates the rubric that was created to standardize what will be deemed market-based aid versus non-market aid according to this study. Central to the conceptualizations used is illustrating the aid types that would plausibly affect the four conduits of reform (Owens and Hoddinott, 1999; Mavrotas, 2002; Gomanee et al, 2002; Petersson, 2004; Clemens et al 2005; Vijil and Wagner, 2010; Winter et al, 2004; Cling, 2006; Brun et al, 2005).

\footnotetext{
${ }^{18}$ The dataset used (Aiddata.org) only captures aid transferred bilaterally, multilaterally, and from private American foundations.
} 
Table 3.1: Illustration of how aid types are categorized based on the conduits of economic reform.

\begin{tabular}{|c|c|c|c|c|}
\hline Aid sectors & $\begin{array}{l}\text { Government } \\
\text { Capacity }\end{array}$ & Economic Freedom & Private Sector & $\begin{array}{l}\text { Domestic } \\
\text { Saving }\end{array}$ \\
\hline \multicolumn{5}{|l|}{ Education } \\
\hline \multicolumn{5}{|l|}{ Health } \\
\hline \multicolumn{5}{|l|}{$\begin{array}{l}\text { Population Policies/programs } \\
\text { \& Reproductive health }\end{array}$} \\
\hline \multicolumn{5}{|l|}{ Water Supply \& Sanitation } \\
\hline \multicolumn{5}{|l|}{ Government \& Civil Society } \\
\hline \multicolumn{5}{|l|}{$\begin{array}{l}\text { Conflict Prevention, } \\
\text { Resolution, Peace \& Security }\end{array}$} \\
\hline \multicolumn{5}{|l|}{$\begin{array}{l}\text { Other Social Infrastructure \& } \\
\text { Services }\end{array}$} \\
\hline \multicolumn{5}{|l|}{ Transport \& Storage } \\
\hline \multicolumn{5}{|l|}{ Communications } \\
\hline \multicolumn{5}{|l|}{ Energy Generation \& Supply } \\
\hline \multicolumn{5}{|l|}{$\begin{array}{l}\text { Banking and Financial } \\
\text { Services }\end{array}$} \\
\hline \multicolumn{5}{|l|}{ Business \& Other Services } \\
\hline \multicolumn{5}{|l|}{ Agriculture (Production sector) } \\
\hline \multicolumn{5}{|l|}{ Forestry (Production sector) } \\
\hline \multicolumn{5}{|l|}{ Fishing (Production sector) } \\
\hline \multicolumn{5}{|l|}{ Industry } \\
\hline \multicolumn{5}{|l|}{ Mineral Resources \& Mining } \\
\hline \multicolumn{5}{|l|}{ Construction } \\
\hline \multicolumn{5}{|l|}{ Trade Policy \& Regulations } \\
\hline \multicolumn{5}{|l|}{ Tourism } \\
\hline \multicolumn{5}{|l|}{$\begin{array}{l}\text { General Environmental } \\
\text { Protection }\end{array}$} \\
\hline \multicolumn{5}{|l|}{ Women } \\
\hline \multicolumn{5}{|l|}{ Other } \\
\hline \multicolumn{5}{|l|}{ General Budget Support } \\
\hline \multicolumn{5}{|l|}{$\begin{array}{l}\text { Development Aid/Food } \\
\text { Security Assistance }\end{array}$} \\
\hline \multicolumn{5}{|l|}{ Other Commodity Assistance } \\
\hline \multicolumn{5}{|l|}{ Action Relating to Debt } \\
\hline \multicolumn{5}{|l|}{ Humanitarian Aid } \\
\hline \multicolumn{5}{|l|}{ Emergency Response } \\
\hline \multicolumn{5}{|l|}{ Reconstruction Relief } \\
\hline $\begin{array}{l}\text { Disaster prevention \& } \\
\text { Preparedness }\end{array}$ & & & & \\
\hline Administrative costs of donors & & & & \\
\hline
\end{tabular}




\begin{tabular}{|l|l|l|l|l|} 
Support to NGOs and GOs & & & \\
\hline Refugees in donor countries & & & & \\
\hline
\end{tabular}

\section{Government capacity:}

Government capacity is the capability of the state and its agents to exercise policymaking and regulatory control over its jurisdiction. This is achieved through adequate investments in technical training to enhance its bureaucratic/administrative, legal, economic/fiscal, institutional, and security infrastructures to design, implement and enforce its policy agenda. The below mentioned aid types are expected to have a positive effect on government capacity.

- $\quad$ Education plays a prominent role in driving government capacity. Enhancing government capacity requires committing to and investing in education to sufficiently equip citizens with adequate education and skills that would allow them to identify issues and trends; evaluate existing policies, and formulate pragmatic policy measures that promote effective governance and sustainability. Therefore, continuous updating of knowledge and skills is expected to enable governments and its agents to design appropriate and systematic policies that would drive economic efficiency and effectiveness.

- $\quad$ Health is central to driving government capacity, because the expectation is that a healthier population lives longer and could be more productive relative to states with less healthy populations. This logic applies to government capacity in that healthier policymakers should have higher job performance, which is pertinent for both policy development and enforcement.

- $\quad$ Government and Society is an essential vehicle for government capacity. Specifically, investing in judicial, economic and political reforms are critical for sustainable growth and development. Therefore, having the capacity to engage in and enforcing the aforementioned matters are expected to mitigate reform constraints. 
- $\quad$ Conflict prevention and resolution, peace and security are also very crucial elements needed to foster government capacity. Effective governance and supporting the protection of properties and rights of individuals mean supporting a climate that allows policy reforms to manifest. Thus, some emphasis on security and mediation is crucial as they help to promote domestic stability, which is pivotal for the development and enforcement of policy choices.

- $\quad$ Communication networks play an instrumental role in furthering government capacity. Communications capacity allows information and knowledge to be exchanged and gathered; issues and awareness raised that may affect attitudes, practice, and policy change; and focusing on efforts and issues considered a priority to foster decision-making, policy design, and operational planning.

- $\quad$ Trade Policy and Regulations is crucial because it provides technical assistance and training necessary to develop and implement trade policies. The exchange of technical knowledge that supports the development and implementation of trade policies and regulations is expected to help policymakers make appropriate adjustments to domestic trade apparatus as a means to open their economies.

- $\quad$ General Budget Support is paramount for promoting government capacity because it helps recipients to implement macroeconomic reforms due to budgetary shortfalls.

\section{Economic Freedom:}

The ability of state governments to ensure that labor, capital, and goods freely move and citizens participate in commerce while being provided sufficient protection from undue coercion and constraints of their liberties beyond the extent considered necessary to ensure and protect the 
interest of the liberty. Below are the four pillars of economic freedom, according to the Heritage Foundation Economic Freedom Index:

- $\quad$ Rule of law (property rights, freedom from corruption)

- $\quad$ Government size (fiscal freedom, government spending)

- $\quad$ Regulatory efficiency (business freedom, labor freedom, and monetary freedom)

- $\quad$ Market openness(trade freedom, investments, and financial freedom)

- $\quad$ Education forms the foundation of economic freedom, because it helps citizens to access crucial information and navigate government bureaucracies when trying to start domestic enterprises, securing vital documents, and funding. The expectation is that higher literacy will assist citizens in knowing their rights and will help drive efforts to participate through innovation and entrepreneurism. That said, education is expected to have a positive effect on economic freedom.

- $\quad$ Health is a key element of economic freedom, because it allows willing participants to actually participate in the marketplace. In other words, good health contributes to their freedom to participate.

- $\quad$ Government and Civil Society is expected to have a positive effect on economic freedom. The government is expected to have adequate infrastructure to regulate the rule of law, government size, efficiency, and market openness to help secure the interest of market participants.

- $\quad$ Conflict prevention, resolution, and peace and security should have a positive effect on economic freedom by safeguarding the rule of law and market openness while supporting regulatory efficiency and government size.

- $\quad$ Transport and Storage should positively contribute to economic freedom since it allows commercial freedom and participation in the marketplace. 
- $\quad$ Communication networks are critical for the enhancement of economic freedom, because it promotes the transfer of information, which is essential for investments. Specifically, access to information and data allows innovators and entrepreneurs to invest in projects that maximize their inputs.

- $\quad$ Energy generation and supply is vital for promoting economic freedom. The movement of labor, capital, and goods require sufficient investments in energy.

- $\quad$ Banking and Financial Services is pivotal for furthering economic freedom because they are formal institutions that are expected to protect and help promote the rights of investors and stakeholders. This is essential in promoting investor confidence. Also, these institutions promote market engagement by extending credit lines and savings, which could be used for investments in small and medium enterprises.

- $\quad$ Business and Other Services is expected to have a positive effect on economic freedom because they support business infrastructures development; support trade, legal, and regulatory reforms; public-private networking; and privatization.

- $\quad$ Industry should have a positive effect on economic freedom, because investments in industries are expected foster industrial policies and planning that supports industrialization through supporting infrastructures, Small and medium-sized enterprises, financial services, and co-operatives.

- $\quad$ Trade Policy and Regulations are essential to economic freedom and should have a positive effect on same. This is because investments in sound trade policies, planning, and trade institutions are expected to have a positive effect on trade facilitation. This includes either eliminating or mitigating import barriers; encouraging investments and trade with region and international enterprises, and safeguarding property and intellectual rights, etc. 
- $\quad$ General budget support is also essential, because it helps the government to formulate and implement policy reforms that helps to secure economic freedoms for citizens.

\section{Private sector size:}

Domestic credit allotted to the private sector though loans, trade credits, and accounts receivable to boost innovation, entrepreneurism, and investments.

- $\quad$ Government and Civil Society is expected to have a positive effect on private sector size through macro-economic, fiscal, and monetary planning and management.

- $\quad$ Banking and Financial Services plays a substantive role in expanding the size of the private sector by providing much needed credit lines to foster savings and in turn investments - and therefore supporting the creation of new markets or market expansion.

- $\quad$ General Budget Support is expected to have a positive effect on private sector size because it helps with program assistance; supporting macroeconomic planning and reforms; and the privatization process of inefficient public enterprises.

- $\quad$ Actions relating to Debt is expected to positively affect private sector size, because debt cancellation is associated with more resources being available for investments.

\section{Domestic savings:}

Disposable incomes not consumed. This is facilitated by investing in production capacity, mobilizing resources for investments, and investing in human capital to maximize investment potential.

- $\quad$ Education is expected to have a positive effect on domestic savings, because it contributes to enhancing productive capacity and quality labor force. The expectation is that 
highly skilled labor forces would positively improve production and the operation of domestic enterprises and, in turn, savings.

- $\quad$ Health: is expected to have a positive effect on domestic savings, because it promotes longer lives and therefore greater productive potential, which is crucial for one's savings potential.

- $\quad$ Government and Civil Society is expected to have a positive effect on domestic savings by developing and enforcing reforms that creates an environment conducive for growth. This includes supporting appropriate legal, economic, and political parameters that safeguards property and intellectual rights of citizens, investors, and financers alike.

- $\quad$ Conflict prevention, resolution, peace and security is essential for domestic savings because stability and protection promotes the development of domestic enterprises and secures the movement of goods and services to market, which contribute to savings.

- $\quad$ Transports and storage promotes domestic savings because it reduces costs for moving goods and services namely by helping market participants to more effectively and efficiently mobilize their goods and services for transport to bigger markets.

- Energy and supply is expected to have a positive effect on domestic savings. The growth of domestic industries and enterprises hinge on the ability of the government to secure sufficient supplies of energy to support continued production of goods and services thus helping to boost production and/or productivity.

- $\quad$ Banking and financial services provides credit lines that could be used for investments and innovation, and therefore is expected to have a positive effect on savings potential if investments are maximized. 
- $\quad$ Business and other services is expected to have a positive effect on domestic savings, because they support trade and business institutions, legal and regulatory reforms, public-private networking, and privatization. This is because it helps to generate business inclusiveness and competition.

- $\quad$ Production sector should have a positive effect on domestic savings, because the expectation is that an increase in the production sector will lead to greater revenues, especially if commodities values are greater on the market relative to production costs. This, in turn, should increase savings potential.

- $\quad$ Industry is expected to have a positive effect on domestic savings by way of investing in industrial policies, planning, and programs that caters to modernizing and/or rehabilitating domestic industrial infrastructures to enhance productivity and investments.

- $\quad$ Mineral resources and mining should have a positive effect on domestic savings, because investments in this sector is expected to lead to more effective and efficient mining of natural resources that lowers costs while maximizing revenues.

- $\quad$ Construction is pivotal for the growth and development of an economy, and therefore should have a positive effect on savings. The expectation is that this sector would provide employment and help expand the private sector.

- $\quad$ Tourism is expected to have a positive effect on domestic savings, because it supports job creation through the development of a tourism infrastructure, stimulating other economic investments and activities, and contributing to balance repayment to reduce debts, etc.

- $\quad$ Trade policy and regulation is expected to have a positive effect on domestic savings. This is because developing and enforcing regional and international trade agreements 
are expected facilitate free or fair trade, especially if this includes tariff reforms and the simplification and harmonization of international import and export procedures.

- $\quad$ Women are expected to have a positive effect on domestic savings, because it supports women's groups and networks through conferences and seminars, etc., which allows them to advocate for women's rights.

- $\quad$ General budget support is expected to positively affect domestic savings, because recipients could use support to help implement macroeconomic reforms that are expected to foster savings if it creates an environment conducive for economic growth.

- $\quad$ Actions relating to debt is expected to have a positive effect on domestic savings, because greater debt cancelations are expected to give recipients some capital for investments since they no longer have to pay debt-servicing fees.

I believe that in order to achieve economic growth, there needs to be sufficient economic reforms. A key avenue to achieve the latter would be to allot more market-based aid since it has a greater multiplier effect relative to non-market aid. For instance, the expectation is that investing adequate resources for the enhancement of economic freedom would encourage more entrepreneurs to willingly participate in market transactions and getting their goods and services to domestic, regional and global markets if governments have sufficient capacity to secure their rights and investments. This helps to create jobs; amplify production levels based on market demands, boost competition, innovation, and efficiency. A byproduct of this is revenues that governments and investors could reinvest in the domestic economy. Investments may include building and/or improving economic infrastructures to help reduce transaction and transportation costs, funding public schools to educate the populous or financing healthcare facilities to ensure that citizens have sufficient healthcare, etc. Over time, total revenues earned are expected to 
exceed the amount of aid allotted if productivity increases because of the labor force becoming healthier and more educated.

Figure 3.1: Illustration of the causal theoretical links between market-based aid and conduits of economic reform.

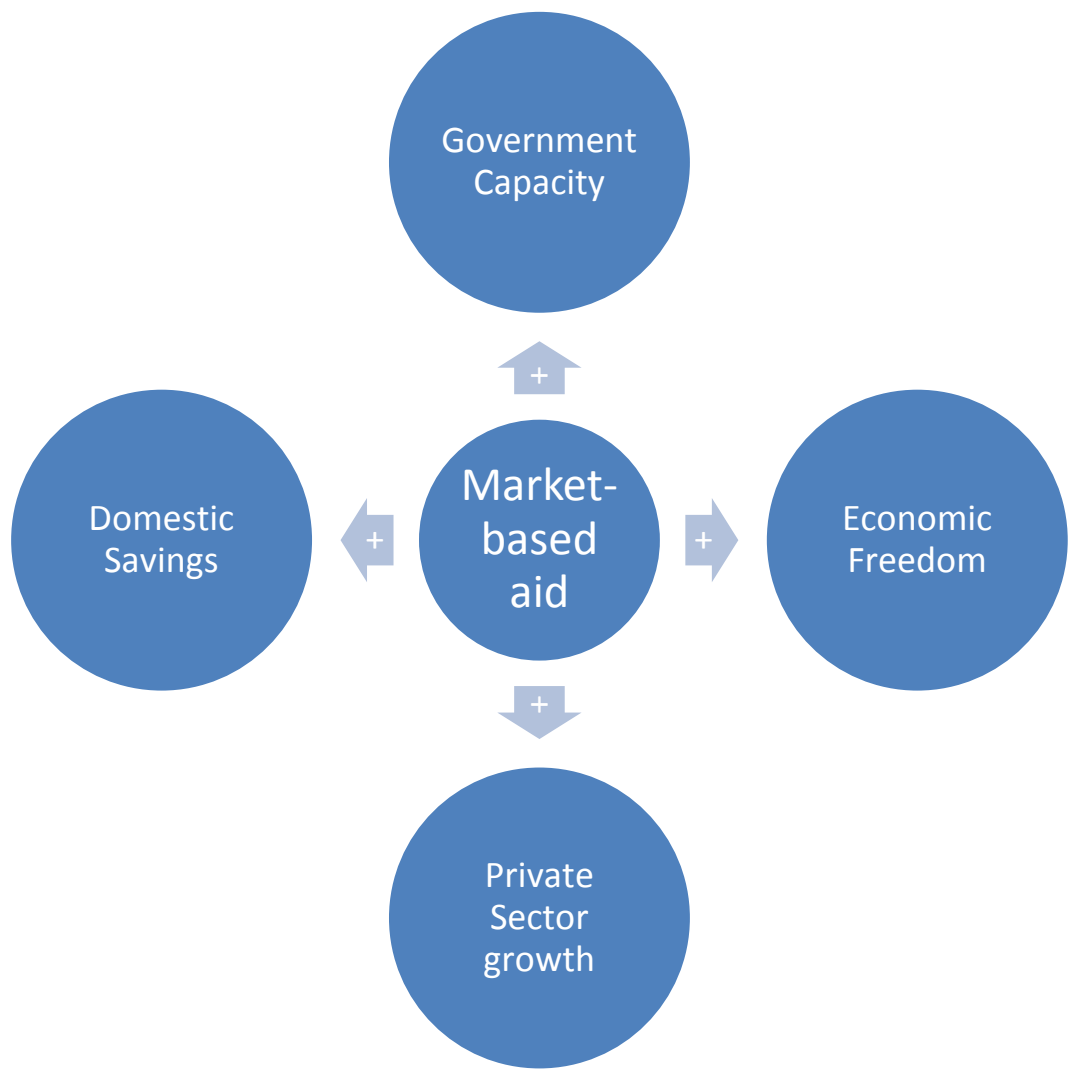

The illustration above depicts the theoretical links through which market-based aid is expected to have a positive effect on the conduits of economic reform. The starting point is based on one of the central assumptions of development economics in that emerging economies are poor because they have limited or no funds to invest in expanding their economies and thus aid disbursements are a vital remedy. The same notion holds true when it comes to economic reforms; meaning, without sufficient aid these states will not be able to design and implement appropriate reforms. Ideally, this process works best if states already have some element of 
government capacity, economic freedom, private sector, and domestic savings to build upon. Therefore, they are essentially enhancing existing elements as a means to facilitate greater market integration. Market-based aid is expected to support government capacity because it transfers technical training and knowledge to help recipients to design and enforce pragmatic economic policies. This should contribute to creating a domestic policy landscape that triggers confidence in financial actors (entrepreneurs, innovators, financers, etc.) in knowing that the government can protect their property rights and properties. In cases whereby properties are ceased by the government in 'imminent domain' type maneuvers citizens and investors alike will be fairly compensated. Such security measures are expected to mitigate skepticism amongst those actors regarding allocating their productive efforts and resources toward entrepreneurship and innovation. This, in turn, should expand the private sector, which facilitates efficiency and productivity through competition and investing in goods and services that maximize returns. This leads to higher savings. As capital accumulation grows, more capital is expected to become available for potential investments. This cyclical process is expected to increase economic growth (Burnshide and Dollar, 2000; Sachs, 2005; Gomanee et al, 2005).

That said, national governments and aid institutions must invest more resources toward enhancing government capacity, which plays a pertinent role in economic reforms and subsequent economic growth. More precisely, government capacity plays a central role in legitimizing and protecting the domestic economy from both internal and external forces by ensuring that at least minimal standards are implemented to regulate financial sectors; help mitigate corrupt activities; and help ensure that speculative borrowing for financing investments are minimized while providing adequate institutional safety nets to help domestic economic stabilization. This process is vital for facilitating sound economic and industrial policies, the rule 
of law, mobilizing capital and boosting investor confidence, and putting in place appropriate regulations that complements the domestic markets to help ensure they fulfil their potential. Equally important, sufficient resources should cater to transferring pragmatic technical knowledge and skills through adequate training so recipients can develop, enforce and regulate the macroeconomic and legal 'rules of the game' (Stiglitz, 2002; Thorbecke, 2000; Onis and Senses, 2007).

The importance of sound macroeconomic policies along with strong institutions to help stabilize exchange rates, foster political stability, and encourage technological acquisitions can help ensure policy credibility and reduce risks for investors. This is very important when trying to attract FDI. In addition, this affects government deregulations and selective interventions, which encourages a more outward oriented economy, in turn, promoting industrial advancement, human capital development, etc. (Stiglitz, 2002; Fine et al, 2003; Thorbecke, 2000).

Thus until investing in the development of the government's capacity is made a priority, it is unimaginable that economic reforms can be realized. Equally vital, national governments must demonstrate commitment to learn and enforce appropriate reforms that will help shape the structure of their domestic economic systems so that resources are distributed effectively and efficiency to appropriate ventures. This is paramount while accounting for the unique domestic realities or climate, needs and expectations of recipients in order to help facilitate open trade and global economic integration. Those factors should help in boosting productivity by governing economic regulations as well as securing the property rights of investors (Mankiw and Taylor, 2008; Blomstrom et al., 1996; De Mello 1997, 1999; La Porta et al 1997, 1998). 
Simultaneously, enhancing government capacity is expected to allow governments to put in place appropriate policy measures to relax their control over the domestic market systems while promoting the economic freedoms of citizens and investors. This is because appropriate measures are likely to prove cost effective since free-market principles are expected to allow the system to regulate itself while allowing the national government to focus on other pertinent matters. Those measures must emphasize mitigating the level of government interference in the market sectors; enforcing contracts, protecting property rights, and encouraging freedom of voluntary transactions, etc. Governments that fail to enforce contracts, usurp properties from citizens and investors without fair compensation, limit voluntary transactions, or violate any of the principles of economic freedom are likely to remain economically poor. This is because it creates an environment that disincentives entrepreneurship and innovation. Logically, this should negatively affect productivity considering potential investors are likely to become more skeptical of how their investments (labor and/or financial investments) translates to private gains (Gwartney et al., 1996; Dreher and Gehring, 2012; Boockman and Dreher, 2003; De Haan et al., 2006; Berggren, 2003; Carlsson and Lundstrum, 2002; De Haan and Sturm, 2000).

Aid could help facilitate private sector growth, too. With a government capable of developing and enforcing the right policy environments that provides sufficient safeguards for property and intellectual rights as well as initiating an environment that is conductive for potential investors and financers to make voluntary transactions, appropriating aid for private sector growth should become centerpieces in fostering domestic economic growth. This is because private sectors are the engines of the development process. Driven primarily by the need to enhance efficiency and widen profit margins, investors are expected to strategically invest in new markets and facilities while seeking innovative solutions to mitigate existing challenging in 
order to strengthen the foundation of economies. ${ }^{19}$ This helps to expand the domestic economy due to more industries and jobs being created, mobilization of capital, unlocking of innovative solutions to intractable development obstacles, higher exports and public revenues, production of affordable goods and services, and strategic partnerships being formed to help facilitate effective and efficient commerce, etc. As a whole, this is expected to maximize aid effectiveness because of the transformational and Keynesian multiplier effects that it should have on the economic development process, namely because of what efficient enterprises contribute to the economy (Stiglitz, 2000; Megginson and Netter, 2001; Rosengren and Jordan, 2000).

While aid institutions and developed economies have historically devoted a lot of aid to SSA states, they have allocated relatively small amounts of aid and paid little attention toward the development of the private sectors. Instead, they support government upkeep through meeting government expenditures. ${ }^{20}$ In other words, this crucial sector has become very peripheral in terms of policy agendas, which has perpetuated their weaknesses and it does not help that many of these states do not have sufficient tools or policies in place to encourage private sector growth. In contrast, when aid institutions do make an effort to engage with the private sectors, they oftentimes do so without fully appraising the context in which they operate. The reality is that the private sector is different in Europe compared to those present throughout the SSA region, and the private sectors from one SSA state may be vastly different from that in another. Thus, there is a need for further engagement with the private sectors to understand the context in terms of cultural attributes, political structures, market demands, etc. Furthermore,

\footnotetext{
${ }^{19}$ None of the emerging economies that have managed to transform from low-income to middle and upper income status were able to accomplish that without sufficient attention on expanding their private sectors.

${ }^{20}$ A majority of the aid sent to the region is categorized under humanitarian aid and what Clemens et al $(2005,2011)$ and propping up the government (Vasquez, 1999).
} 
differences in output per worker often broadly characterize the private sectors of these emerging economies. Therefore, these sectors need some adjustments so that scarce resources are shifted from low to high productivity enterprises. This will require transferring inefficient public enterprises to the private sector, which helps to make decisions based on market forces (Ayittey, 2000; Devarajan et al., 2001; Rodrik, 1996; Brautigam, 2000).

A bigger private sector can lift economic growth by increasing the aggregate savings rates and investments, resulting in greater capital formation and accumulation. More precisely, increases in the quality and quantity of private sector services - if robust and efficient - will contribute to greater domestic savings because it will help mobilize resources and allocate them to the most productive enterprises. This strengthens competition and stimulates innovative activities that promotes efficiency. This is supported by the ability of an efficient private sector to ease the exchange of goods and services by providing diverse payment services; acquiring and processing information pertaining to enterprises and potential investments, thus appropriating capital to the most productive enterprises; and diversifying and increasing liquidity while mitigating risks, etc. Those functions affect investments and savings decisions, and henceforth finance economic reforms (Dowling and Hiemenz, 1983; Papanek, 1973; Stern, 1991; Lin, 1992; Liu and Guo, 2002; Jappelli and Pagano, 1994; Makin, 2006; Carroll et al., 2000).

That said, the development theories that follow vary in some regards in terms of their ideas and methods; however, they all share the same aid - to help foster the rate of economic reform across emerging economies. My primary assertion is that developed economies and aid institutions are contributing to SSA's failure to reform. While they have been promoting the idea that 'more aid is better,' they are missing an important element - not all aid types are the same 
and therefore, they do not have the same effect on economic reform. With that in mind, I argue that more smart aid will be more pragmatic; meaning, more market-based should be allocated for economic reforms. Moreover, this study will emphasize some cultural and traditional factors may affect the aid-reform relationship using two case analyses.

\section{3: Two-gap theory}

The empirical literature finds that the SSA region has failed to meet adequate reform expectations because it lacks sufficient resources. Therefore, there is a need for aid to help fill this void. This speaks directly to my central research question, which asks whether market-based aid is necessary for economic reform. The expectation is that market-based aid contributions could play an essential role in promoting economic reforms by helping to enhance government capacity, economic freedom, private sector growth, and domestic savings. A lack of funding to meet those needs is expected to constrain the ability of states to invest and integrate into the global marketplace. The expectation is that, if used correctly, market-based aid would help bridge this gap and contribute to the formulation and implementation of appropriate economic reforms (Chenery and Strout, 1966; McKinnon, 1964; Dollar and Easterly, 1999; Easterly, 2003; Hunt, 2003; Hewitt, 2000; Todaro, 2009).

To some extent, the two-gap model has some dubious theoretical bases and empirical failings. While it explains how the shortage of foreign aid exchange could limit reform efforts by constraining both trade activities and savings, it postulates but does not explain how those shortages come about in the first place, yet it strongly asserts that aid could have a multiplier effect on investments, reforms and subsequent economic growth. Furthermore, though this theory is simple and convenient in terms of specification and estimation, the issue seems to be 
oversimplified. However, the numerous economic models that followed have failed to supplant it. This is substantiated by the fact that the World Bank, IMF and many other aid institutions continue to employ the two-gap model during aid policy decision-making (Easterly, 2003; Shimeles et al, 2009).

Although the aforementioned theoretical failings, this study acknowledges that SSA states are in need of assistance to help meet existing policy needs; otherwise, the region is likely to continue lagging behind due to failure to accumulate sufficient savings and generate capital formation that is needed to develop and enforce appropriate reforms. Hence, the need for more market-based aid, which could play a paramount role in satisfying the void in order to help foster much needed economic reforms.

\section{4: Theory on donor information}

Whether market-based is sufficient for economic reforms has some contingency on donor information. The effectiveness of market-based aid allotments hinges on the ability of donorsboth bilateral and multilateral - to gain access to critical information from states aid is allotted to. This must include tapping into local knowledge. The expectation is that access to pertinent information (local knowledge) would allow donors to best determine: the type(s) of aid needed, appropriate projects to support, who needs it, where and how aid could be maximized, the quantity of aid required, how it should be managed to enhance its effectiveness, and what other donors are doing locally to mitigate overlapping, etc. Failing to address this information or knowledge gap has contributed to slow reform and implementation being incomplete. For instance, Easterly (2006) illustrates a relevant example that substantiates my argument. Having failed to gather sufficient information about the local dynamics of a mountain community in 
Lesotho, donors invested heavily in a policy that was supposed to promote the development of various programs to help modernize livestock management and agricultural productions as well as to enhance access to markets. However, producers residing in the area had already realized that cash crops were not competitive enough due to the areas' poor conditions. Furthermore, they were no longer interested in farming relative to the past as they were nomads who now work predominantly in South Africa with access to larger markets. Without sufficient information and knowledge pertaining to the dynamics of the region, donors financed those projects anyway, which did not foster sufficient economic improvements in the region and economic well-being of the people. Rather, they contributed to economic losses that helped to hold back the economy since the country had to take on that debt. The newly constructed roads, which were meant to help improve access to markets and generate economic growth and development, had the reverse effect in that more locals (including producers) left in droves while crops had to be brought in for those choosing to remain. Therefore, had sufficient knowledge and understanding of the domestic realities been acquired and employed, the outcome may have been different in terms of the policy choices the donors and state pursued.

Thus, information plays an essential role in putting donors in positions not only to assess what is needed but also to design measures that are most appropriate for recipients while accounting for the unique problems, local climates of individual recipients and for monitoring and evaluation purposes. This will also require effective coordination between aid donors and recipients so that information is transferred or shared, allowing for much needed evaluations and feedback. In addition, paramount to this debate is that in years past, donors have demonstrated varying levels of arrogance by developing policy solutions without committing adequate time toward properly assessing the issues intimately and incorporating the local realities of each 
country. Instead, they embrace and therefore promote the notion that SAPs is a proven concept. In other words, since it proved successful in Europe, then it will work in SSA states too. This has resulted in former Kenyan MP, Dr. David Karanja, stating that Western aid has not been effective because "Africa's development plans are drawn thousands of miles away in the corridors of the IMF and World Bank. What is sad is that the IMF and World Bank "experts" who draw these development plans are people completely out of touch with the local African reality.” Noted Political Economist, Dr. George Ayittey, later shared similar sentiments by indicating that aid donors often fail to adequately consult those in need to determine what they need and how best to develop appropriate plans. Thus, valuable information or inputs are often overlooked and therefore contributing to failure to employ pragmatic reforms. This leads to policy inconsistencies, which can be confusing, and oftentimes there is an overlapping array of objectives between aid institutions, which may not reflect the needs of Africans or fail to capture sufficient buy-in from them (Karanga in New African, 1992; Ayittey, 2012; Easterly, 2006).

Equally important, gaining access to pertinent information is generally negatively affected since aid institutions must follow extensive internal procedures and protocols. Aid is mobilized and managed by bilateral and multilateral institutions, which are guided by internal structures that are generally set within policy parameters of the states the aid institution(s) reside. For instance, whether it is a state or multilateral institution, such as the World Bank, IMF, U.N or USAID, etc., they all have internal bureaucracies that align with certain political interests. Even if those institutions are tasked with collaborating on strategic interests, they are still tasked with operating within the confines of their own bureaucracies to secure their own interests- often leading to a division or disconnect (Sobel and Leeson, 2007; Alisina and Dollar, 2000; Easterly, 
2006, 2007; United Nations Millennium Project, 2005; Commission for Africa, 2005; Alesina and Dollar, 2000).

The central role bureaucracies play in regulating aid institutions often inhibit their ability to access and share pertinent information, which has a direct effect on aid effectiveness. This is because the extensive procedures and protocols that governs those institutions often creates a divide between institutional knowledge and private or local knowledge. This divide negatively affects the goals and objectives that aid institutions are trying to achieve. Some of the divide originates from aid institutions lacking sufficient accountability. Bureaucracies often fail to recognize and utilize market forces to acquire pertinent information. For example, Easterly (2006) argues that there are planners (aid institutions) and searchers (private institutions), and since the primary goals and objectives of bilateral and multilateral aid institutions are not guided by profit margins, they are less inclined to let market forces dictate their operations. In contrast, since private sectors are guided by profit seeking they are required to be accountable to market forces or there will be consequences. Therefore, they are likely to place more emphasis on gathering sufficient and pertinent information before articulating plans of action. So, though both private and public institutions may share the same or similar objectives, the paths or methods of getting there often differs. Furthermore, recipients have limited or no leverage or means of disciplining aid institutions when or if they fail. However, recipients are left with the consequences made by aid institutions who essentially make decisions on their behalf. This furthers the accountability debate (Easterly, 2006).

Similarly, it is difficult to determine the level of economic reform that may have occurred within a specified timeframe. This is because the bureaucratic procedures and protocols often 
negatively affects how swiftly crucial feedback is relayed to aid institutions. An argument could be made that this is the case because aid institutions are not designed wherein there are incentives to prioritize information gathering. Instead, the bureaucracy dictates aid policies without placing sufficient emphasis on gathering local information

Central to gathering information is the need for aid institutions to coordinate. Many of the aid institutions in SSA have failed to coordinate key policy goals and objectives, which affects their chances of effectively obtaining same. The failure to coordinate only perpetuates the failure of these institutions to gather pertinent information, which continues to contribute to their failures across the region. The current top-down planning that many aid institutions employ often lacks sufficient coordination when developing aid policies, which makes it difficult to effectively tap into the local knowledge, which is absolutely critical to achieve success (Easterly, 2006, 2007; Tullock, 2005; UN Millenium Project, 2005).

\section{5: Theory on recipient's knowledge}

When trying to answer the question as to whether market-based aid is sufficient for economic reform it is equally important to emphasize the pertinent role information plays for recipients as well. The lack of sufficient recipient knowledge also contributes to failure to meet policy objectives laid out by donors. Even when recipients are operating with good intentions, they often lack a clear or thorough understanding of expectations due to lack of sufficient technical knowledge and information that details the mechanisms as to how they could get to expected outcomes. Moreover, an argument could be made that recipients face greater challenges to maximize aid contributions because of the difficulties they encounter trying to tap into the knowledge of aid institutions together with that of their own knowledge base (especially at local 
levels). The citizens in these states that has the knowledge and are in positions to know what is needed at the local levels are either not consulted, or they are not knowledgeable about the availability of aid, and how they may access it to help facilitate change (Ayittey, 2012; Easterly, 2006).

Additionally, recipient governments are generally forced to employ similar bureaucratic protocols of the donor institutions and states as a precondition to receive aid. This makes it difficult for recipients to analyze their needs and solicit feedback, because if the process does not account for how information is gathered locally, then it furthers the divide as well as aid failures. This issue is amplified when aid is allotted to poorly managed states, which may find it more difficult to gather pertinent information to incorporate into their decision-making and operational planning. Furthermore, many citizens generally have a sound knowledge of what needs to be done to enhance the effectiveness of aid; however, since they are not consulted it is often used to finance projects that may not be appropriate for some local communities. In contrast, when citizens try to provide feedback they are made to realize the extensive bureaucratic processes (red tapes) they must hurdle to relay crucial information to aid institutions, national governments, and policymakers. Moreover, following the aforementioned detailed steps does not guarantee that the information or feedback will be read or considered before decisions are made. This is likely to negatively affect aid effectiveness (Easterly, 2006; Mohan et al, 2000; Stiglitz, 2000; Hyden, 2006; Williamson, 2009).

Over the years, the information gap between donors and recipients appear to be on the decline. Leaders in both parties seem to have acknowledged that past development strategies failed to materialize due to failure to collaborate on designing pragmatic policies that accounts for inputs from both sides (donors and recipients) as well as those expected to be affected by aid 
programs. Thus, donors recognized that simply allocating more aid was not the best remedy for economic reforms. Instead, aid could only be an economic tool if invested correctly and with inputs from recipients. This is more so the case if recipients demonstrate both willingness and commitment to improve their domestic economic situations, which begins with citizens and governments supporting policy reforms they enact. This process could be facilitated by investing more market-based aid to help transfer technical knowledge and information to keep aid recipients informed, which could help build consensus and buy-in.

When taken as a whole, the aforementioned theories contribute in helping to answer research question posed. Combining some of the core elements emphasized in those theories, I am not surprised aid has thus far been a failure across SSA. Therefore, the theoretical framework presented in this study aims to help explain not only why aid has failed to achieve its intended goals and objectives but also why it may continue to do so if aid disbursement practices are not changed to account for the fact that aid types matter and cultural factors must also be considered. Therefore, in addition to addressing the role of culture in this process, more must be done to increase aid types that has a greater effect on economic reform rather than emphasizing aid types geared toward consumption or has little or no effect on economic reform if the aim is to seek sustainable economic growth and development.

This study proposes an approach that I expect to find has empirical basis. Specifically, donors should orient funding efforts toward avenues that could plausibly affect economic reforms. Therefore, instead of channeling more aid toward projects that are inefficient and financially burdensome (to aid institutions and national governments), there should be empirical bases for allotting more market-based aid as a mechanism for promoting economic reform that 
involves furthering four economic conduits: government capacity, economic freedom, private sector, and domestic savings. Those factors play pertinent roles in the economic growth process and development. Central to this logic is that investing in enhancing government capacity will put state government in better positions to formulate and implement policies that are more appropriate for their individual economies while taking into considering the unique cultural and traditional contexts and dynamics. This would encourage private actors to adapt to the changing landscapes of recipient states because of protections provided by the state and the incentive structures, resulting in them tapping into local knowledge and prioritizing feedback mechanisms as means to maximize their efforts and investment practices. This would then create both private and public revenues that drives domestic savings, which would fuel further investments. This viewpoint forms the basis of my theoretical expectations.

\section{6: Theoretical expectations}

This research focuses on the effects market-based aid has on economic reforms on select SSA. I theorize there should be a positive empirical link between market-based aid and economic reforms to suggest that donors should favor market-based aid relative to non-market aid if the objective is to encourage long-term economic growth and development. Central to my theory is that not all aid types have the same effects on economic reforms. Thus, investing in policy reforms catering to government capacity, economic freedom, private sector growth, and domestic savings are expected to contribute to greater economic reform relative to disbursements for humanitarian efforts. Therefore, if there is empirical basis to support my theory I would suggest that it would be more pragmatic to increase investments in avenues that are most productive to the economy. This forms the foundation of my causal hypotheses that follows. 


\section{Causal hypotheses:}

\section{$\mathrm{H}_{1}$ : Market-based aid will have a positive effect on government capacity.}

Government capacity is one of the most pivotal factors for achieving economic reforms. This has to be in place already or further enhanced to be able to accommodate the complexity of policy packages being designed and implemented while taking into account the local realities of individual states. In other words, reform efforts must incorporate cultural, traditional and social factors of individual states. The expectation is that states that are best equipped in terms of technical knowledge to develop their own policies as well as have sufficient institutional capacity should be able to design and implement most appropriate reforms that extends across their jurisdictions. Currently, many SSA states continue to have weak government capacities, which has contributed to operational ineffectiveness and inefficiencies. This is primarily because there is a disconnect between technical knowledge, practice, domestic institutions, and culturally appropriate reforms which are needed to facilitate economic growth and development. That said, market-based aid could be an engine for developing government capacity, because through the exchange of technical knowledge and training recipients could learn how to design practical policy reforms to mitigate current, emerging and/or anticipated economic constraints (Burnside and Dollar, 2000; Acemoglu et al, 2001; Dollar and Kraay, 2003; Rodrick et al, 2002).

Therefore, market-based aid could play a crucial role in developing and implementing economic reforms. It would promote the transfer of core competencies, technologies, and information through valuable training, sharing of expertise, and funding to help recipients develop and implement appropriate reforms. Thus, funding education, health, security, 
communication, trade policy and regulations, and general budget support are crucial in building and maintaining government capacity that is capable of comprehending domestic contexts, issues, and trends followed by developing reforms based on the information available.

Securing those factors are expected to play an important role in helping to liberalize entrepreneurism and innovation. In absence of adequate government capacity - that is, services and protections enforced by the government as well as knowledge to address domestic issues there is little chance for economic growth because citizens are likely to be less active and involved in the domestic economy. For instance, without an informed government that is capable of designing and administering appropriate economic policies there is a likelihood of failure to obtain sufficient economic growth. This is because insufficient capacity and inability to provide protection of property is empirically linked to decreases in economic incentives, trade, entrepreneurism, and innovation, which are necessary for economic prosperity. Investors are less likely to invest while financers are also less likely to finance enterprises and entrepreneurs if there are not enough pay-off structures. Therefore, market-based aid could play a very transformational role due to its ability to empower recipients, entrepreneurs, and financiers alike so that they could perform functions effectively, efficiently, and sustainably in absence of continued external funding (Todaro, 2009; Burnside and Dollar, 2000; Bennedsen and Meisner, 2005).

\section{$\mathrm{H}_{2}$ : Market-based aid will have a positive effect on economic freedom.}

Market-based aid is expected to have a positive effect on economic freedom as a result of the conditionalities donors directly tie to disbursements that recipients must agree to and implement to ensure future aid allotments. This could be effective because it would compel 
recipients to adopt necessary economic reforms that endorse and guarantee principles of economic freedom. This includes supporting:

- $\quad$ Rule of law (property rights, freedom from corruption)

- $\quad$ Government size (fiscal freedom, government spending)

- $\quad$ Regulatory efficiency (business freedom, labor freedom, and monetary freedom)

- $\quad$ Market openness (trade, investment, and financial freedom)

However, the reality is that sometimes some recipients do not implement all the conditions that had been previously agreed upon, or sometimes implementations are incomplete. In such cases, donors may still influence the domestic policies of recipients because they are often moved to later implement policies previously neglected if they want access to future aid (Burnside and Dollar, 2000; Bearce and Tirone, 2010; Boockmann and Dreher, 2003).

Logically, recipients that are dependent on aid are reluctant to overturn changes after they have already been made. Thus allocating aid for economic freedom could achieve expected ends by requiring recipients to decentralize, develop stable institutions, and support policy environments that encourage investments. This is expected to promote economic growth because it fosters free market principles. The implication is that economic growth could be achieved when investors are able to enjoy the freedoms and protections of participating in free markets. The expectation is that market-based aid could foster greater economic freedoms to allow entrepreneurs and innovators to be rewarded for their ideas and resource investments, because entrepreneurs and enterprises alike are able to freely use their resources in ways that are expected to help them maximize their efforts and investments while the governments provide them with sufficient security. Indeed some states across East Asia have greatly benefited from such investments rather than rely on continuous injection of aid. This includes countries such as 
Japan, South Korea, Taiwan, Hong Kong, Singapore, Thailand, and China (Collier, 1997; Sen, 1999; Adkins, et al, 2002).

\section{$\mathrm{H}_{3}$ : Market-based aid will have a positive effect on private sector growth.}

Market-based aid is expected to play a central role in expanding the size of the private sector. The extent of the government's capacity to develop and enforce appropriate economic reforms should have a direct effect on its ability to expand its private sector; meaning, with more safeguards in place investors, financers, and innovators alike are likely to be more incentivized to participate in the market sectors since they are able to maximize their efforts and resources. Those activities could be supported by allotting market-aid to help improve the domestic conditions and expansion of the private sector by initiating and/or rehabilitating domestic enterprises. With emphasis on maximizing profits, private enterprises are likely to focus on enhancing efficiency whereby investors, innovators, and financers are likely to cater their attention on investing resources in markets that minimize risks while maximizing payoffs. This should contribute to the expansion of the economy because it is expected to advance competition and innovation; create jobs and capital, and help mobilize domestic resources. Together, those factors are expected to help generate private and national revenues, which may allow for further investments and growth of the private sector (Kimenyi, 2006; Oshikoya, 1994; Moshi and Kilindo; 1999).

\section{$\mathrm{H}_{4}$ : Market-based aid will have a positive effect on domestic savings.}

The literature finds there to be an empirical link between aid and private sector growth. This study aligns with those findings by suggesting that there is empirical association between 
market-based aid and private sector growth. Specifically, market-based aid is expected contribute to capital formation. This should increase the amount of disposable capital, which could then be re-invested in the domestic economy. This could be achieved because private enterprises place a lot of emphasis on information, which is consistent with profit seeking. This promotes innovation, competition, and rational thinking, which are vital for driving the economy. This fosters the effectiveness and efficiency of private enterprises in order to maximize profits while minimizing risks. The mobilization of domestic resources followed by the strategic investments in productive enterprises along with information accumulation fuels an increase in the quality and quantity of private enterprises. In turn, diverse goods and services are brought to markets; investors and financers are able to acquire and process information pertaining to enterprises and other potential investments, and said information puts investors and financers in position to evaluate and increase financing toward enterprises that are most productive and profitable. As a result, domestic savings are expected to increase (Basnet, 2013; Bhattarai, 2009; Burke and Ahmadi-Esfahani, 2006).

\section{7: Conclusion}

Should donors orient disbursements toward market-based aid? As argued above, this form of aid is expected to have greater effect on economic reforms relative to non-market aid. This is because the former generally goes toward various forms of capacity development while the latter generally goes toward consumption. However, it is also important to not discount the role cultural and traditional factors play in the process. The next section of this study will explain the methodology that will be used to answer the research question posed. 


\section{Chapter 4: Research Design}

\subsection{Introduction:}

The key premise of this chapter is to illustrate how I tested my casual hypotheses to determine if there are empirical links between market-based aid and multiple development indicators of economic reforms using two case studies (Senegal and Ghana) and large-N panel data regression models. The aforementioned case studies were selected using the Mill's Method of Agreement, and this analytical method allowed me to gain a good understanding of the interactions between market-based aid and four indicators commonly associated with economic reform: government capacity, economic freedom, private sector depth, and gross domestic savings. Below is a simple illustration of the causal hypotheses and expectations of this study. I argue there is a positive empirical link between market-based aid and my economic reforms. The theoretical bases were discussed in the previous chapter.

Figure 4.1: Illustration of causal links between my dependent and independent variables.

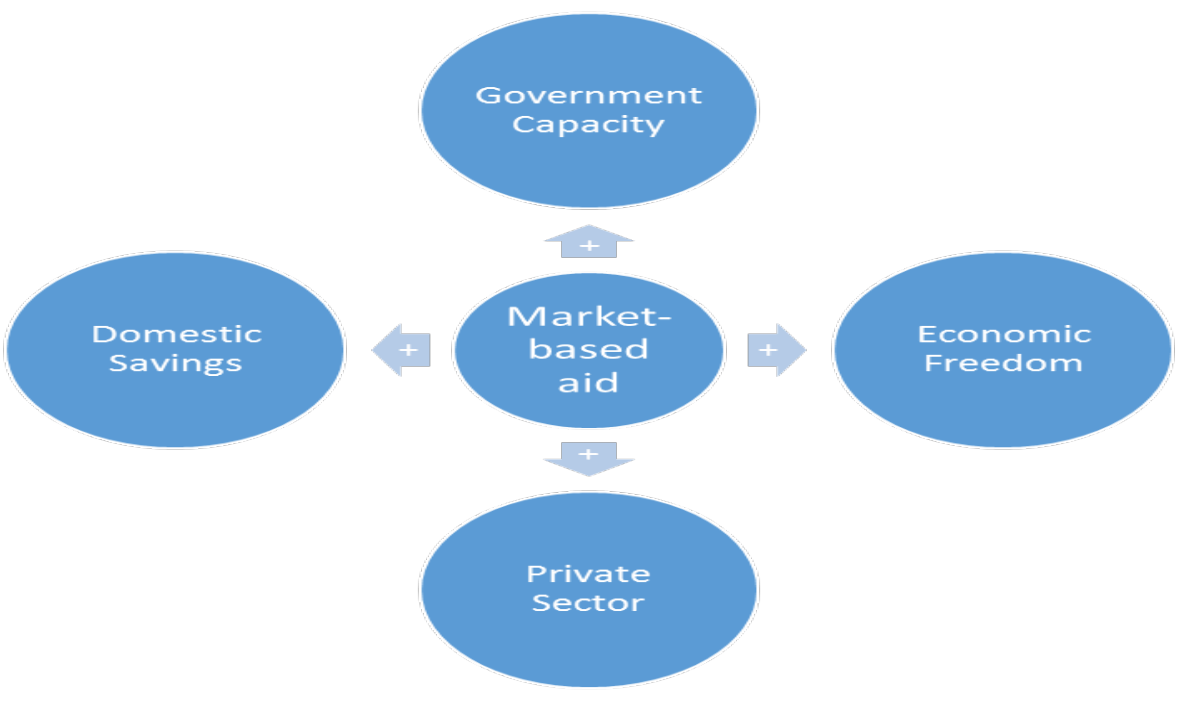




\subsection{Quantitative analysis}

To quantitatively analyze the empirical links between my dependent and independent variables, I used secondary data from four sources: (I) World Bank database; (II) www.AidData.org; (III) The Heritage Foundation Index of Economic Freedom; and (IV) the World Governance Indicators (WGI). Regressions were conducted using ordinary least regressions (OLS). The purpose for using this technique was grounded in three core justifications. First, OLS is a basic predication technique that allowed me to make maximum likelihood estimates of my causal hypotheses. Thus, it allowed me to estimate and make inferences about the causal effects between my dependent and independent variables. Second, this technique allowed me to make the most useful predictions while making it easier to analyze data relative to other regression techniques. Third, and similarly, this technique allows me to obtain sound results from a rather small dataset while producing outputs that are easier to interpret. The logic for utilizing statistical models was to either confirm or disconfirm findings in the case analyses. For the purposes of this study, my unit of analysis was aid amounts (U.S dollars in millions) allotted per country year to specific sectors or projects.

\section{Temporal domain:}

This section of the study aimed to test for empirical linkages between 1985 and 2012. The time span was determined primarily because of data availability. Current aid databases generally have not been disaggregating aid disbursements prior to 1985. This has limited many previous studies, forcing them to use shorter timeframes. This may have negatively affected their ability to make informed conclusions. Expanding the range allows me to develop more credible analysis and conclusions. 


\section{Spatial domain:}

Two requirements were considered when determining eligibility of states. They must have: (I) obtained independence and (II) have a recognized and continuous civilian government during the timeframe of interest. This is important because the literature shows that donors generally cut off or reduce aid in times when the democratic process is interrupted by military provocations. Thus, for aid to be more effective there needs to be sufficient political stability (Aisen and Veiga, 2006, 2010; Alesina et al, 1996; Jong-a-Pin, 2009).

\section{Indicators of Market-based Aid reform}

\section{Market-based aid:}

Market-based aid data was sourced from the www.Aiddata.org database, which documents yearly aid disbursements in disaggregated formats based on purpose/projects. Specifically, all aid that have been allotted for individual projects were classified based on purpose while accounting for the amount of aid allotted each year per project in millions of dollars (U.S). To help standardize this process, the yearly percentage changes will be used. I expect this variable to have a positive effect on economic reform.

The Aiddata database is heavily sourced from the OECD's Creditor Reporter System (CRS), which is a comprehensive database that validates aid transactions by OECD member states and multilateral aid institutions such as the IMF and World Bank. The data includes information such as the name of the donors, recipients, agencies implementing the projects, project descriptions, the amount and date of aid committed, etc. Additionally, the database 
coordinates with non-OECD states, such as Brazil, China, and South Africa ${ }^{21}$, etc., which helps to add validity and credibility considering it accumulates more aid data from a greater number of donors to give a more accurate reflection of the aid being disbursed to recipients. This allowed me to construct a variable that accounts for the sum of market-based aid according to the rubric that I have developed to standardize what is considered market-based aid versus non-market aid. That said, table 4.1 illustrates the rubric that was created to standardize what will be considered market-based aid versus non-market aid according to this study. Central to the conceptualizations is illustrating and justifying the aid types that would plausibly affect the four conduits of economic reform.

Table 4.1: Illustration of how market-based aid is categorized.

\begin{tabular}{|l|l|l|l|l|}
\hline Aid sectors & $\begin{array}{l}\text { Government } \\
\text { Capacity }\end{array}$ & $\begin{array}{l}\text { Economic } \\
\text { Freedom }\end{array}$ & $\begin{array}{l}\text { Private } \\
\text { Sector }\end{array}$ & $\begin{array}{l}\text { Domestic } \\
\text { Saving }\end{array}$ \\
\hline Education & & & & \\
\hline Health & & & & \\
\hline $\begin{array}{l}\text { Population Policies/programs \& } \\
\text { Reproductive health }\end{array}$ & & & & \\
\hline Water Supply \& Sanitation & & & & \\
\hline Government \& Civil Society & & & & \\
\hline $\begin{array}{l}\text { Conflict Prevention, Resolution, Peace \& } \\
\text { Security }\end{array}$ & & & & \\
\hline Other Social Infrastructure \& Services & & & & \\
\hline Transport \& Storage & & & & \\
\hline Communications & & & & \\
\hline Energy Generation \& Supply & & & & \\
\hline Banking and Financial Services & & & & \\
\hline Business \& Other Services & & & & \\
\hline Agriculture (Production sector) & & & & \\
\hline Forestry (Production sector) & & & \\
\hline Fishing (Production sector) & & & \\
\hline Industry & & & \\
\hline
\end{tabular}

${ }^{21}$ These states have played an increasing role in aid giving in the SSA region in recent years (Moyo, 2008; Glennie, 2008). 


\begin{tabular}{|l|l|l|l|l|} 
Mineral Resources \& Mining & & & \\
\hline Construction & & & & \\
\hline Trade Policy \& Regulations & & & & \\
\hline Tourism & & & & \\
\hline General Environmental Protection & & & & \\
\hline Women & & & & \\
\hline Other & & & & \\
\hline General Budget Support & & & \\
\hline $\begin{array}{l}\text { Development Aid/Food Security } \\
\text { Assistance }\end{array}$ & & & & \\
\hline Other Commodity Assistance & & & & \\
\hline Action Relating to Debt & & & & \\
\hline Humanitarian Aid & & & & \\
\hline Emergency Response & & & & \\
\hline Reconstruction Relief & & & & \\
\hline Disaster prevention \& Preparedness & & & & \\
\hline Administrative costs of donors & & & & \\
\hline Support to NGOs and GOs & & & & \\
\hline Refugees in donor countries & & & & \\
\hline
\end{tabular}

\section{Government capacity:}

This variable is defined as the capability of the state and its agents to exercise policymaking and regulatory control over its jurisdiction. This is achieved through investments in technical training to enhance its bureaucratic/administrative, legal, economic/fiscal, institutional, and security infrastructures. Gross Domestic Product (GDP) was used as a proxy for government capacity. This proxy is a yardstick measure that captures not only the political but also social, economic and cultural dimensions of a state's welfare and ability to address same. This is key because good governments are expected to promote an environment that has both effective and efficient policies and institutions that accounts for domestic contexts. Central to sound governance is the need for efficiency, transparency, and participation. Efficiency pertains to a government's ability to use its governing apparatus (policymakers and institutions) 
to develop and regulate sound and consistent policies that are fair to its citizens ${ }^{22}$ while also accounting for their needs. Additionally, transparency pertains to the government's ability to make available, or grant access to, all pertinent information to the general public with clarity regarding its activities. This is essential because a lack of transparency is likely to foster corruption and, in turn, reduce efficiency and accountability. Lastly, a government's capacity is also furthered by its ability to encourage participation wherein citizens are allowed to provide inputs and/or contribute to key decision-making that they are governed by. That said, this variable will be measured using the yearly percentage change of the cumulative dollar value in millions (U.S) of GDP of each state. I expect this variable to have a positive effect.

Based on table 4.1, aid allotment toward the below mentioned sectors will be considered for promoting government capacity.

- $\quad$ Education is expected to positively affect government capacity. Enhancing government capacity requires the population to be sufficiently educated and skilled to identify issues and trends, evaluate existing policies, and formulate pragmatic policies to govern effectively and sustainably. Therefore, continuous updating of knowledge and skills should enable government and its agents to develop strategic and systematic policies.

- $\quad$ Health plays a central role in enhancing government capacity, because a healthier population is expected to live longer and more productive lives, which is pertinent in policy development and enforcement.

- $\quad$ Government and Society is expected to positively affect government capacity. Investing in judicial, economic, and political reforms are critical for growth and development.

\footnotetext{
${ }^{22}$ This means establishing a system that distributes income and services in a fair and efficient manner.
} 
Therefore, having the capacity to engage in and enforce the aforementioned matters are expected to mitigate reform constraints.

- $\quad$ Conflict prevention and resolution, peace and security is expected to positively affect government capacity. This is because effective governance and supporting the protection property and intellectual rights as well as providing a climate that that allows policy reforms to manifest. Thus, some emphasis on security and mediation is crucial as they help to promote domestic stability.

- $\quad$ Communication networks play an instrumental role in furthering government capacity. Communications capacity allows information and knowledge to be exchanged and gathered; issues and awareness raised that may affect attitudes, practice, and policy change; and focusing on efforts and issues considered a priority to foster decision-making, policy design, and operational planning.

- $\quad$ Trade Policy and Regulations is crucial because it provides technical assistance and training necessary to develop and implement trade policies. The exchange of technical knowledge that supports the development and implementation of trade policies and regulations is expected to help policymakers make appropriate adjustments to domestic trade apparatus as a means to open their economies.

- $\quad$ General Budget Support is paramount for promoting government capacity because it helps recipients to implement macroeconomic reforms due to budgetary shortfalls.

\section{Economic Freedom:}

Economic freedom relates to one's ability to voluntarily enter into contracts within the framework of a stable and predictable legal system that has the capacity to enforce contracts and 
protect all persons and private properties while limiting the degree of government interventions, regulations, and taxes. This helps to create a market economy that fosters voluntary exchanges and competition. The failure of governments to secure economic freedom is expected to constrain the activities of current and potential investors/entrepreneurs while making persons and private properties vulnerable. This is likely to contribute to lower productivity and subsequent economic decline. The absence of economic freedom generally corresponds with a lack of economic growth and the existence of poverty and hardship, which is prominent across the SSA region (Berggren, 2003; Gwartney et al, 2002).

Economic freedom is associated with the ability of state governments to ensure that labor, capital, and goods freely move and citizens participate in commerce while being protected from undue coercion and constraints of their liberties beyond the extent considered necessary to ensure and protect the interest of liberty. Below are the four pillars of economic freedom, according to the Heritage Foundation Index:

- $\quad$ Rule of law (property rights, freedom from corruption)

- $\quad$ Government size (fiscal freedom, government spending)

- $\quad$ Regulatory efficiency (business freedom, labor freedom, and monetary freedom)

- $\quad$ Market openness(trade freedom, investments, and financial freedom)

The Heritage Foundation's Index of Economic Freedom (EF) was relied upon to measure economic freedom. This index measures EF using four broad categories outlined above that is then consolidated into one composite score ranging from 0 to 100 with a greater value corresponding to a higher economic freedom. I expect this variable to have a positive effect.

I. Rule of law (property rights, freedom from corruption) 
The property rights component measures the ability of individuals to legally acquire private properties and protection by state government. Thus, it measures the degree of a state's legal laws to protect property rights and its government's capacity to enforce those laws. This requires assessing the likelihood of private properties being expropriated as well as analyzing the independence of the judiciary, the degree of corruption within the judiciary, and the freedom that individuals and businesses play in enforcing contracts.

The index uses a 0-100 scale. States that provide greater legal protection of private properties are given higher scores. In contrast, the greater the uncertainty of a government to expropriate private properties, the lower the state's score; and states that provide intermediate protection in those categories are allocated intermediate scores.

Freedom from corruption implies that mitigating corrupt activities fosters economic freedom by contributing to economic security and certainties during voluntary contracts. The score is drawn heavily from the Transparency International's Corruption Perceptions Index (CPI), which measures corruption levels of states. The CPI uses a 10-point scale wherein 10 indicates limited government corruption while 0 refers to extensive corruption. However, to standardize the score, the Heritage Foundation converts the raw CPI data to a 0-100 scale by multiplying scores by 10. For instance, if a CPI score is listed as 5, then its freedom of corruption score will be 50 .

\section{Government size (fiscal freedom, government spending);}

Fiscal freedom measures the taxes imposed by the government. This includes top marginal taxes on (i) individuals, (ii) corporate incomes, and (iii) total tax burdens as a 
percentage of GDP. That said, fiscal freedom is divided into three equally weighed components, which are measured on a 0-100 scale whereby 0 indicates limited fiscal freedom while 100 indicates otherwise. This variable is calculated using a 'quadratic cost' function that reflects revenue returns that are directly correlated with tax rates.

Government spending (federal, state, and local) - consumption and transfers- pertains to the government's total expenditures as a percentage of its GDP. This variable promotes the notion that too much government spending, especially spending beyond their means, leads to budget deficits and debts. That said, a 0-100 scale is used that indicates the level of government spending with zero being used as benchmarks. The measure uses a quadratic function to determine the extent to which spending practices will affect economic freedom; meaning, larger government spending relative to GDP is expected to have a negative effect on their score while the opposite is true for those that spending smaller amounts.

III. Regulatory efficiency (business freedom, labor freedom, monetary freedom);

Business freedom constitutes the efficiency in which governments are able to regulate domestic businesses. This includes coding for the difficulties regarding starting, operating and closing ventures. More precisely, the score is based on 10 equally weighed factors from the World Bank's Doing Business data, which pertains to the extent of the procedures, time, cost and minimum capital (\% of income per capita) needed to start a business; the procedures, time and cost (\% of income per capita) required to obtain a business license; and the time, cost (\% of estate) and recovery rate (\$) for closing a venture. This is done on a 0-100 scale, with 0 indicating limited business freedom. 
The labor freedom score is a measure that accounts for the legal and regulatory frameworks of the state's labor market. This pertains to a state's minimum wage policies, rights against layoffs, severance requirements, hiring procedures as well as policies regarding work hours. Data gathered from the World Bank’s Doing Business study, the above mentioned factors were assigned a score on a 0 to 100 scale using a quadratic function.

Monetary freedom is a measure of price stability. This involves assessing inflations and price controls and their effects on market activity. Ideally, price stability with minimal macroeconomic intervention provide a good free market environment. The monetary freedom score is based on: (i) the weighted average inflation rate for the most recent 3 years; and (ii) price controls, which are plugged into a quadratic function to generate a monetary freedom score.

IV. Market openness (trade freedom, investment freedom, financial freedom).

Trade freedom measures the level of tariff and non-tariff burdens that exists in a county, in turn, affecting the volume of import and exports of goods and services. The trade freedom score is calculated using two factors: (i) the trade-weighted average tariff rate, and (ii) non-tariff barriers, which are applied to a quadratic function to determine a score with higher tariffs indicating greater trade restrictions while the opposite is true for lower tariffs.

Investment freedom measures the level of constraints on the disbursements of capital for investments by individual investor and enterprises alike. Thus, the expectation is that states that are economically free will permit investors to mobilize their capital and invest it where they consider it to be most productive. This may include moving capital from one project to another, 
domestically or internationally without restriction. Each state's is given an investment freedom score from 0 to 100, with those having limited or no restrictions having a higher score.

The reality is that each state has their own regulations pertaining to domestic and foreign investments. More precisely, some states have harsher restrictions on access to foreign exchange while others impose payment restrictions, transfers, and transactions. Additionally, some states limit which domestic industries foreign industries can invest in. Moreover, domestic labor laws, corruption, bureaucratic red tapes, and political and security conditions, etc., are also factors that contributes to the level of freedom that financial actors have in participating in the markets.

To measure investment freedom, the index evaluates various restrictions: national treatment of foreign investment, foreign investment code, restrictions on land ownership, sectoral investment restrictions, expropriation of investments without fair compensation, foreign exchange controls, and capital controls.

Financial freedom measures the efficiency of the banking system as well as its independence from unnecessary government interventions and controls. The expectation is that state ownership by financial institutions generally negatively affects competition and the availability of services. That said, in ideal cases governments minimally intervenes in the affairs of the market, market forces regulates market terms and credit, and the government does not own financial enterprises. This index score financial freedom by evaluating five broad areas: The extent of government regulation of financial services; the degree of state intervention in banks and other financial firms through direct and indirect ownership; the extent of financial and capital market development; Government influence on the allocation of credit, and Openness to foreign competition. These areas are evaluated on a 0 to 100 scale, with 100 reflecting easy and 
effective access to financing opportunities (for both individuals and enterprises) due to limited government interventions and restrictions. Yearly percentage change will be used to measure economic freedom. I expect this variable to have a positive effect on economic reform.

Based on table 4.1, aid toward the below mentioned sectors will be considered for promoting economic freedom.

- $\quad$ Education forms the foundation of economic freedom, because it helps citizens to access crucial information and navigate government bureaucracies when trying to start domestic enterprises, secure vital documents, and funding. The expectation is that higher literacy will assist citizens in knowing their rights and will help drive efforts to participate through innovation and entrepreneurism. That said, education is expected to have a positive effect on economic freedom.

- $\quad$ Health fosters productivity, and a healthy labor force is expected to reduce government spending relative to an unhealthy population.

- $\quad$ Government and Civil Society is expected to have a positive effect on economic freedom. The government is expected to have adequate infrastructure to regulate the rule of law, government size, efficiency, and market openness.

- $\quad$ Conflict prevention, resolution, and peace and security should have a positive effect on economic freedom by safeguarding the rule of law and market openness while supporting regulatory efficiency and government size.

- $\quad$ Transport and Storage should positively contribute to economic freedom since it allows commercial freedom and participation in the marketplace.

- $\quad$ Communication is critical for the enhancement of economic freedom, because it promotes the transfer of information, which is essential for investments. Specifically, access to 
information and data allows innovators and entrepreneurs to invest in projects that maximize their inputs.

- $\quad$ Energy Generation and supply is vital for promoting economic freedom. The movement of labor, capital, and goods require sufficient investments in energy.

- $\quad$ Banking and Financial Services is pivotal for furthering economic freedom because they are formal institutions that are expected to protect and help promote the rights of investors and stakeholders. This is essential in promoting investor confidence. Also, these institutions promote market engagement by extending credit lines and savings, which could be used for investments in small and medium enterprises.

- $\quad$ Business and Other Services is expected to have a positive effect on economic freedom, because they support business infrastructures development; support trade, legal, and regulatory reforms; public-private networking; and privatization.

- $\quad$ Industry should have a positive effect on economic freedom, because investments in industries are expected foster industrial policies and planning that supports industrialization through supporting infrastructures, Small and medium-sized enterprises, financial services, and co-operatives.

- $\quad$ Trade Policy and Regulations are essential to economic freedom and should have a positive effect on same. This is because investments in sound trade policies, planning, and trade institutions are expected to have a positive effect on trade facilitation. This includes either eliminating or mitigating import barriers; encouraging investments and trade with region and international enterprises, and safeguarding property and intellectual rights, etc. 
- $\quad$ General budget support is also essential, because it helps the government to formulate and implement policy reforms that helps to secure the economic freedoms of its citizens.

\section{Private sector investment:}

This indicator measures the percentage of GDP that has been allotted (in millions of U.S dollars) to the private sector on a yearly basis by state governments to help boost private sector growth and development. This includes loans, non-equity securities, and trade credits, etc., to help boost innovation, entrepreneurism and investments. Yearly percentage change will be used to standardize this variable. I expect there to be a positive effect, because the private sector plays a central role in driving economic growth because it is a source of job creations, innovation, and investments that contributes to raising domestic incomes and revenues. Moreover, market forces can help monitor market agents and exert corporate controls by mitigating the principal-agent problem that leads to inefficient investment practices and limited economic growth. That said, excessive government debt accumulation generally creates a credit squeeze, which may have a direct effect on the amount of domestic private sector credit that is available. However, by increasing the volume of credit disbursements to the private sector rather than inefficient enterprises are expected to help increase economic growth. For this measure, I will be relying on the World Bank database (Fry, 1998; Levine et al, 2000).

Based on table 4.1, the aid toward the below mentioned sectors will be considered for boosting private sector growth and development. 
- $\quad$ Government and Civil Society are expected to have a positive effect on private sector size through macro-economic, fiscal, and monetary planning and management.

- $\quad$ Banking and Financial Services plays a substantive role in expanding the size of the private sector by providing much needed credit lines to foster savings and in turn investments - and therefore supporting the creation of new markets or market expansion.

- $\quad$ General Budget Support is expected to have a positive effect on private sector size because it helps with program assistance; supporting macroeconomic planning and reforms; and the privatization process of inefficient public enterprises.

- $\quad$ Actions relating to Debt is expected to positively affect private sector size, because debt cancellation is associated with more resources being available for investments.

\section{Domestic savings:}

Domestic savings is defined as income or resources acquired by an economy annually and is not readily consumed through the purchasing of goods and services or appropriated toward development projects. In other words, it is disposable income that have been accrued and has been postponed of current consumption but could help facilitate growth and development through investing in enhancing production capacity, mobilizing further resources for investments, and improving human capital to maximize investment potential. Thus, this capital can be used to help generate returns to the economy at a future time. The expectation is that an increase in the propensity to save and invest could contribute to economic reform and growth if invested wisely. This could help to generate higher per capita, which is also pivotal for capital accumulation which can be used for future investments when the appropriate opportunities arise 
(Dowling and Hiemenz, 1983; Papanek, 1973; Stern, 1991; Lin, 1992; Liu and Guo, 2002; Jappelli and Pagano, 1994; Makin, 2006; Carroll et al., 2000).

This variable was measured using the percentage of savings per year relative to GDP based on the World Bank's database. I expect this variable to have a positive effect, because sustained low or negative savings relative to GDP is likely to translate into slow or negative economic growth. In contrast, optimal domestic savings has the propensity to boost economic growth, because it could be used for financing much needed investments while mitigating a state’s dependence on foreign aid.

The reality is that state governments that have been able to accumulate domestic savings have a choice between consuming today versus tomorrow as it is generally a way to foster further wealth accumulation over time while also raising the standard of living in the process. However, savings accumulation does not constitute investments. Moreover, one of the central issues is whether this choice is made in such a way that would maximize resources and create incentives that emphasize current consumption that triggers optimal savings rates. This capital is vital for enhancing not only a state's future capital formation potential and capital availability but also securing its long-term economic growth. This involves appropriating sufficient capital toward investing in developing the private sector, banking and business institutions, economic infrastructures, education, and health, etc. Additionally, there is also the fact that not all emerging economies are able to save, which may have had detrimental economic effects on their economic prosperity.

Based on table 4.1, aid toward the below mentioned sectors should help facilitate domestic savings. 
- $\quad$ Education is expected to have a positive effect on domestic savings, because it contributes to enhancing productive capacity and quality labor force. The expectation is that a highly skilled labor force would positively improve production and the operation of domestic enterprises and, in turn, savings.

- $\quad$ Health: is expected to have a positive effect on domestic savings, because it promotes longer life and therefore greater productive potential, which is crucial for one's savings potential.

- $\quad$ Government and Civil Society is expected to have a positive effect on domestic savings by developing and enforcing reforms that creates an environment conducive for growth. This includes supporting appropriate legal, economic, and political parameters that safeguards property and intellectual rights of citizens, investors, and financers alike.

- $\quad$ Conflict prevention, resolution, peace and security is essential for domestic savings because stability and protection promotes the development of domestic enterprises and secures the movement of goods and services to market, which contribute to savings.

- $\quad$ Transports and storage promotes domestic savings because it reduces costs for moving goods and services, and also helps citizens to more easily take their goods and services to bigger markets.

- $\quad$ Energy and supply is expected to have a positive effect on domestic savings. The growth of domestic industry and enterprises hinges of the ability of the government to secure sufficient supplies of energy to support continued production of goods and services thus helping to boost production levels. 
- $\quad$ Banking and financial services provides credit lines that could be used for investments and innovation, and therefore is expected to have a positive effect on savings potential if investments are maximized.

- $\quad$ Business and other services is expected to have a positive effect on domestic savings, because they support trade and business institutions, legal and regulatory reforms, public-private networking, and privatization. This is because it helps to generate business inclusiveness and competition.

- $\quad$ Production sector should have a positive effect on domestic savings, because the expectation is that an increase in the production sector will lead to greater revenues, especially if commodity values are greater on the market relative to production costs. This, in turn, should increase savings potential.

- Industry is expected to have a positive effect on domestic savings by way of investing in industrial policies, planning, and programs that caters to modernizing and/or rehabilitating domestic industrial infrastructures to enhance productivity and investments.

- $\quad$ Mineral resources and mining should have a positive effect on domestic savings, because investments in this sector is expected to lead to more effective and efficient mining of natural resources that lowers costs while maximizing revenues.

- $\quad$ Construction is pivotal for the growth and development of an economy, and therefore should have a positive effect on savings. The expectation is that this sector would provide employment and help expand the private sector.

- $\quad$ Tourism is expected to have a positive effect on domestic savings, because it supports job creation through the development of a tourism infrastructure, stimulating other economic investments and activities, and contributing to balance repayment to reduce debts, etc. 
- $\quad$ Trade policy and regulation is expected to have a positive effect on domestic savings. This is because developing and enforcing regional and international trade agreements are expected facilitate free or fair trade, especially if this includes tariff reforms and the simplification and harmonization of international import and export procedures.

- $\quad$ Women is expected to have a positive effect on domestic savings, because it supports women's groups and networks through conferences and seminars, etc., which allows them to advocate for women's rights.

- $\quad$ General budget support is expected to positively affect domestic savings, because recipients could use support to help implement macroeconomic reforms that are expected to foster savings if it creates an environment conducive for economic growth.

- $\quad$ Action relating to debt is expected to have a positive effect on domestic savings, because greater debt cancelations are expected to give recipients some capital for investments since they no longer have to pay debt-servicing fees.

\section{4: Other factors shaping development and reform efforts.}

There are several other factors that I believe plays an essential role in answering my research question. In choosing these factors, I focused on some of the key determinants of economic reforms emphasized in the development studies literature. Specifically, I drew from the literature that helped me to best add some explanatory powers. That said, the factors I employed are listed below:

\section{Non-market aid:}


This variable accounts for the annual percentage change of the aggregate aid that have been appropriated to SSA governments that do not directly facilitate economic reforms. This was measured in millions (U.S) per year for specific sector. For instance, non-market aid consisted of all aid appropriations that went towards such areas as water and sanitation, food aid, general environmental protection, humanitarian aid, and reconstruction relief, etc. This notion stems from a segment of the development literature that found certain aid types - many that aligns with my non-market aid conceptualization - has very little, zero, or negative effects on economic reforms. This is because those aid forms generally supports consumption and/or meeting social and/or humanitarian needs rather than building much needed productive capacity, enhancing economic infrastructures, and developing trade policies and regulations. For instance, aid for disasters and emergency relief has been found to have little or no effect on economic reforms, because this aid form is disbursed with the primary objective not being to foster economic liberalization and integration. That said, www.aiddata.org was sourced for this data, which disaggregate annual aid commitments to states in U.S dollar amounts - adjusted for 2013 (Owens and Hoddinott, 1999; Clemens et al, 2005, 2011; Gomanee et al, 2002; Mavrotas, 2002).

\section{Corruption:}

This variable measures the annual percentage change in "the perception of the extent to which public power is exercised for private gain, including both petty and grand forms of corruption, as well as "capture" of the state by elites and private interests" (WGI). The existence of corruption generally has a negative effect on economic reform, because it constitutes a failure of the government to enforce appropriate policies that would force all members of the country including citizens and firms - to obey the rules by holding them accountable. Moreover, it often 
leads to the mismanagement of funds and resources which could be contributed to policy development and enforcement. The expectation is that states with higher corruption levels are likely to promote bribes and rent seeking, patronage, nepotism, close ties between politics and businesses, etc. This hinders economic reform because aid is likely to be used in inefficient ways. Therefore, failing to mitigate corruption is expected to be economically burdensome as resources are siphoned off without taxation with the possibility of not being reinvested back into the domestic economy. Moreover, corruption may have an undesirable effect on economic reform since it often promotes greater yet inefficient government spending and consumption. This information was sourced from the World Governing Indicator, which ranges from 2.5(weak) to 2.5 (strong) perception of corruption (Moyo, 2008; Glennie, 2008; Kaufmann et al, 2006; Boone, 1996; Alesina and Weder, 2002; Tavares, 2003; Mauro, 1995).

\section{Political stability:}

This variable measures the annual percentage of the "perception of the likelihood of political instability and/or politically-motivated violence, including terrorism” (WGI). This indicator measures the perception the likelihood of the national government becoming destabilized or removed from office through unconstitutional or violent means such as gross domestic violence and/or terrorism. That said, this indicator captures the notion that the quality of the governance is likely to be compromised by the possibility of abrupt changes in the government, which often has a direct effect on the policy environment as it may inhibit the continuity of policies. Moreover, such changes may also undermine the ability of citizens to democratically self-determine. Equally important, SSA states have historically experienced varying levels of political instability. Given the uncertainly revolving around the effect of aid 
and economic reform, I consider it suitable to account for this variable when trying to understand the effectiveness of market-based aid. Theoretically, it is important to include this variable because investors - both domestic and foreign - are likely to be attracted to more stable states and those with more lasting and democratic transitions and regimes. This is because it is likely to lower the risks associated with investing. As such, I expect to find this coefficient to be positive. That said, this information was sourced from the World Governing Indicator, which ranges from -2.5(weak) to 2.5 (strong) perception of political stability (Kaufmann et al, 2006; Alsan et al, 2006; ICRG, 2005).

\section{Voice and Accountability:}

This measure accounts for the extent to which citizens of a particular state is able to participate in democratically electing their own governments in addition to having freedom of expression, freedom of association, and free media. The expectation is that there is a positive link between states that allow its citizens more freedom of expression and association and my variables as those citizens should be able to hold the government accountable. This, in turn, is expected to mitigate corruption while enhancing the chances for economic reform and prosperity. The annual percentage change will be used. This data was sourced from the World Governance Indicator Index.

\section{Government Effectiveness:}

This variable measures the "perceptions of the quality of public services, the quality of the civil service and the degree of its independence from political pressures, the quality of policy formulation and implementation, and the credibility of the government's commitment to such policies” (WGI). The expectation is that this variable will have a positive effect on my variable; 
meaning, governments that are deemed more effective are likely to utilize resources more wisely in an effort to enhance economic reform. The annual percentage change will be used for this variable. This variable will be sourced from the World Governance Indicators Index.

\section{Regulatory Quality:}

This indicator captures the "perceptions of the ability of the government to formulate and implement sound policies and regulations that permit and promote private sector development” World Governance Indicator). This indicator ranges from -2.5(weak) to 2.5 (strong) performances in the sector. Since this index began in 1996, I will be using the 1996 estimate to reflect the level of governance for the previous years (1985-1995) with the assumption that the level of governance is a gradual process and therefore, the expectation is that changes from weak governance to strong will not be abrupt. This data was sourced from the World Governance Indicator. The annual percentage change will be used. I expect this indicator to be positively related.

\section{Debt servicing fees:}

Many SSA states are currently tasked with paying large (and rising) debt service fees, which continues to contribute to their failure to reform. Since many of these states are already economically poor, the likelihood of moving toward industrialization is threatened if they are forced to pay large debt servicing fees relative to their small economies. Thus debt servicing fees places an unnecessary burden on these economies since it leads to there being less hard currency available for possible investment in goods, machinery, and technology, etc. The expectation is that this variable will have a negative effect on economic reform potential. This data was sourced 
from World Bank database, which measures debt servicing fees in U.S dollar amounts. The annual percentage change was used and is expected to be positive on economic reform.

\section{GDP per capita:}

This indicator measures the gross domestic product divided by the estimated midyear population. Data is reported in current U.S dollars, and sourced from the World Bank. The annual percentage change was used and is expected to have a positive effect on economic reform.

\section{Final consumption:}

This indicator measures the estimated sum private consumption and general government final consumption expenditure. Data is in current U.S dollars, and is sourced from the World Bank. The annual percentage change was used and is expected to have a negative effective on economic reform.

\section{Trade (\% of GDP):}

This indicator measures the total exports and imports of both goods and services as a share of the GDP. Data is sourced from the World Bank, and is expected to have a positive effect on economic reform.

\section{Inflation:}


This indicator measures the annual growth rate of the GDP relative to rate of price changes in the economy. Data was sourced from the World Bank and is expected to have a negative effect on economic reform.

\section{Trade index:}

This indicator is calculated "as the percentage ratio of the export unit value indexes to the import unit value indexes, measured relative to the base year 2000.”(World Bank data). The annual percentage change was used, and it is expected to have a positive effect on economic reform.

\section{Time lag of aid:}

A growing area within the development literature rests on the notion that many previous empirical studies have failed to make informative conclusions. This is because the statistical models used often do not account for the fact that different aid types have different effects on economic reforms across time. For instance, as previously suggested, not all aid disbursements are for facilitating market integration and liberalization. Furthermore, not all aid types will foster the development of trade policies and regulations; enhancing economic infrastructures, and boosting the productive sector. Therefore, when the expectation is that market-based aid will have a more immediate effect on economic reforms relative to non-market aid when accounting for time (Owens and Hoddinott, 1999; Mavrotas, 2002; Gomanee et al, 2002; Petersson, 2004; Clemens et al 2005).

The timing of when we should be testing the effect of aid disbursements on economic reforms have vastly been neglected in the development literature. Empirical studies have 
generally been in favor of using fixed observation periods, while emphasizing the effect that varying levels of time intervals may have on the process continues to be overlooked or contested (Temple, 1999; Islam, 1995, 2003; Clemens et al, 2005).

\section{Model specifications:}

\section{Conceptual causal hypotheses:}

$\mathrm{H}_{1}$ : Market-based aid will have a positive effect on government capacity.

Government Capacity $=\mathrm{f}\left(\mathrm{C}+\mathrm{B}_{1}\right.$ (Market aid) $+\mathrm{B}_{2}$ (Non-market aid) $+\mathrm{B}_{3}$ (Debt servicing fees) + $\mathrm{B}_{4}$ (Regulatory Quality) + $\mathrm{B}_{5}$ (Corruption) + B 6 (Government Effectiveness) + B 7 (Per Capita) + $\mathrm{B}_{8}$ (Trade as \% of GDP) + B 9 (Inflation) + lag + e)

$\mathrm{H}_{2}$ : Market-based aid will have a positive effect on economic freedom.

Economic Freedom $=\mathrm{f}\left(\mathrm{C}+\mathrm{B}_{1}\right.$ (Market aid) $+\mathrm{B}_{2}$ (Non-market aid) $+\mathrm{B}_{3}$ (Private sector investments) $+\mathrm{B}_{4}$ (Corruption) $+\mathrm{B}_{5}$ (Gross domestic savings) $+\mathrm{B}_{6}$ (Voice \& Accountability) + B 7 (Government Effectiveness) + B8 (GDP) + B9 (Political Stability) + B 10 (Trade Index) lag + e)

$\mathrm{H}_{3}$ : Market-based aid will have a positive effect on private sector size.

Private Sector Investments $=\mathrm{f}\left(\mathrm{C}+\mathrm{B}_{1}\right.$ (Market aid) $+\mathrm{B}_{2}$ (Non-market aid) $+\mathrm{B}_{3}$ (Regulatory Quality) $+\mathrm{B}_{4}$ (Voice \& Accountability) $+\mathrm{B}_{5}$ (Government Effectiveness) $+\mathrm{B}_{6}$ (Political Stability) $+\mathrm{B}_{7}$ (Gross capital formation) $+\mathrm{B}_{8}$ (Debt servicing fees) + $\mathrm{B}_{9}$ (GDP) + $\mathrm{B}_{10}$ (GDP per capita) $+\mathrm{B}_{11}$ (Gross domestic savings) + lag + e)

$\mathrm{H}_{4}$ : Market-based aid will have a positive effect on domestic savings.

Gross Domestic Savings $=\mathrm{f}\left(\mathrm{C}+\mathrm{B}_{1}\right.$ (Market aid) $+\mathrm{B}_{2}$ (Non-market aid) $+\mathrm{B}_{3}$ (Private sector investments) $+\mathrm{B}_{4}$ (GDP) $+\mathrm{B}_{5}$ (Debt serving fees) $+\mathrm{B}_{6}$ (Government Effectiveness) $+\mathrm{B}_{7}$ (Political stability) $+\mathrm{B}_{8}($ Voice \& Accountability $)+\mathrm{B}_{9}($ Final consumption $\left.)+\operatorname{lag}+\mathrm{e}\right)$

\subsection{Case analyses:}


Considering the aforementioned expectations, I used content analysis to help capture some of the nuance factors that are difficult to account for using statistical models. This included placing emphasis on some of the key historical, cultural and socio-economic events and factors that might have affected and therefore could help explain the relationship between market-based aid and economic reforms in Senegal and Ghana in the post-independence era. I firmly believe this technique is suitable for this particular study because it allows for replicable and valid inferences to be made from data analysis. In other words, it allows for the application of logic to interpret available information and data to produce necessary analysis that either supports or disconfirms my causal hypotheses using various forms of information and data. This included reviewing country reports, research journals, books, and interviewing country experts. Together, this helped me to identify and analyze contextual meanings of the data and information by highlighting key themes and concepts. I outlined the parameters of the qualitative framework used to execute this study below.

My approach to this research rests on analyzing the contexts that help to explain the relationships between market-based aid and economic reforms using two case analyses. There are several reasons for using case analyses in this research. The core reasoning rests on the fact that there are multiple realities through which SSA states (and the developing world, in general) could be interpreted. Like statistical analyses, case studies are powerful tools that could further our understanding of the aid-reform nexus, because they provide different yet unique perspectives through which I could either confirm or disconfirm my causal hypotheses. Specifically, case analyses play a pivotal role in this research since they help capture and reveal aspects of local realities or conditions that are difficult, if not impossible, to capture using 
statistical analysis. For instance, there are vast diversities - some of which are unique to individual states - due to the myriad of colonial heritage, geopolitics, cultures and social dynamics, etc., that statistical models cannot capture or explain. Therefore, case analyses become vital tools used to add context to local conditions (of individual states) wherein qualitative patterns and subtleties could be accounted for and emphasized. This is important because it recognizes that a one-size-fits-all approach for examining and explaining the aid-reform relationship will only add limited understanding to this complex relationship. Thus case analyses permitted me to explore and assess some of the key internal efforts that have been made toward economic reforms that may not be reflected in statistical modeling (Gerring, 2004; Seawright, 2008).

That said, case analyses allowed me to incorporate the geopolitical, historical, cultural, customs, traditions and local attitudes and practices that may have contributed to each case's reform processes, successes and failures. The aforementioned factors are difficult to quantify and therefore needs to be examined qualitatively. And even if those variables could be quantified, there is a possibility that a lot of nuances surrounding them could be lost in statistical modeling. Additionally, considering there is an absence of complete, accurate quantitative data in the postindependence era, case analyses helped to fill that void by extrapolating the needed understanding of each case being examined in a comparative way by asking the "how" and "why" types of questions that relates to my research question, in turn, expanding my explanatory power.

To summarize, case analyses adds to my research since it allowed me to get a more holistic view of the complex aid-reform nexus, rather than seeking to reduce matters to a set of 
positivistic variables, models and measurement procedures. Similarity, as a result of some gaps in data availability, case analyses enhances validity and reliability, yet mitigates bias.

\subsection{Case selection:}

For the purpose of this study, the Mill's Methods of Agreement was used to select appropriate cases. This methodology allowed me to select appropriate cases and answer my research question by means of establishing similarities and differences between cases in order to help explain the effect market-based aid has on economic reforms. Put more simply, to identify the causes of a given effect(s) it would be logical to first look for common factors that are present in each case in which the effect(s) are occurring (Skocpol and Somers, 1985).

Since the theoretical basis of this study asserts that there is an empirical link between market-based aid and economic reform, the Mill's Method of Agreement allowed me to examine this relationship. This was done by considering some of the other variables that may play pivotal roles in economic reforms but are difficult to quantify and contextualize, such as geopolitics, historical contexts, cultures, customs and traditions, etc. By using this method, I relied on common bases for comparison and analysis.

In thinking about some of the key attributes contributing to the understanding of my research question, I selected numerous variables identified in the development literature as well as using logic. I chose to focus on the West Africa region for two central reasons: (i) an argument could be made that this geographical location was at the forefront of the independence movement which led to several regional states first gaining their independence after aggressively pursuing the need for self-governance after many years of being held in political servitude; (ii) 
the region is very rich in cultural diversity and colonial legacies relative to other SSA regions which are often in colonial blocks. Those diversities have since led to some integration to create cultural complexities that are worth exploring to determine whether or not they might have affected the outcome of my research.

That said, I believe that trying to obtain a good understanding of my research question is predicated on selecting two states with similar starting points, because it gives a rough measuring stick by comparing the relative progress those states have made over the years. Ghana was the first state in the SSA region to gain independence in 1957 and Senegal was not far behind obtaining its own independence in 1959. Though there is a 2 years difference, I do not believe such a limited timeframe has given Ghana an advantage relative to Senegal considering there are various social and historical contexts that must be accounted for that has either contributed to its reform efforts or lack of.

Equally important to answering my research question is the need to understand how the colonial heritage and religious values may have contributed to its conditions and efforts to reform. Colonial legacies and religious affiliations play vital roles in culture. Therefore, the expectation is that cultural values learned and propagated over generations influence, and in some cases, dictate our purview, behavior, and rationale, etc., especially in the midst of changing social and political forces contributes to outcomes and expectations. In many ways, some of the aforementioned features could foster corruption, selfishness, thirst for power, divisive sentiments and other factors that may either clog or facilitate reform efforts. Thus in order to understand whether or not aid is effective there should be some examination of cultural traits that have been learned and passed down, such as honesty, willingness to be productive, openness to new ideas, 
social and/or religious doctrines prohibiting or facilitating certain practices, beliefs and behaviors, or social constructs that caters to molding expectations, etc., which may determine the type of reforms a state is more likely to pursue (Weber, 1930; Huntington, 1996; Inglehart and Baker, 2000).

Geographic disadvantage also plays a vital role in this process considering even though many states across the region may themselves being somewhat politically stable; have adequately educated and healthy populations, and large productive sectors, etc., which should put them on positions to establish and actively pursue agenda items, the reality is that many states are often located next to others that have periodically experienced civil turmoil. In such cases, it negatively affects the economic welfare and reform efforts of neighboring states, because in experiencing internal conflicts they are also eliminating themselves from being potential trade partners (cutting potential revenue streams that could finance reform efforts) or being able to contribute to innovation and ideas that could be employed to best utilize available resources. Instead, states that are somewhat stable have to revise their reform agendas to best safeguard their domestic efforts. Furthermore, states that are landlocked are often worse off, because they are geographically unlucky in terms of economic potential. For instance, Switzerland is possibly the only modern day state that defies the norm in that it is landlocked yet it continues to thrive economically relatively speaking, namely because it is surrounded by stable trade partners that contributes to its reform efforts and subsequent economic success. In contrast, when one looks across the SSA region, many states, in general, are involved in and/or surrounded by very unstable and conflict-ridden neighbors. This certainly affects their economies as well as the regional economy, because it has somewhat of a domino effect in terms of the types of policies they are limited to since such unstable environments obstructs governments, regional 
policymaking bodies and communities, and the private sectors from engaging in strategic reforms based on needs and expectations, nor does it allow for partnering of likeminded individuals, policymakers and entities - domestic, regional and foreign - to devise reforms that could sustainably drive growth and development (Collier and Gunning 1999; Sachs and Warner 1997).

The size of the economy is a rough measuring stick of a states' ability to invest in education and technical knowledge so that policymakers are equipped with adequate knowledge and skills to design, implement and enforce appropriate reforms to drive the economy. Similarly, unfair trade policies have also affected the ability of states to formulate and administer reform efforts. Specifically, the U.S, E.U and China have responsibly protected their domestic industries which African economies could compete with. This has had adverse effects on Africa's ability to trade. The inability to compete in a fair market system limits the ability of states to further invest in capacity building efforts, or developing their private sectors and enhancing economic freedom, and so forth. Thus, while Africa has made some progress over the years its limited access to fair trade continues to curtail its reform efforts. As a region, not only does more effort need to be placed on formulating appropriate economic reforms but also policymaker must show commitment as well (Collier and Gunning 1999; Sachs and Warner 1997).

Table 4.2: Case selection using the Mill’s Method of Agreement approach.

\begin{tabular}{|l|r|r|}
\hline & \multicolumn{2}{|l|}{} \\
\hline Independence & 1957 & Senegal \\
\hline Colonial heritage & British & French \\
\hline Religious majority & Christian & Islam \\
\hline Geography & West Africa & West Africa \\
\hline Size of economy/GDP (current) & 42.69 Billion & 14.77 Billion \\
\hline
\end{tabular}




\begin{tabular}{|c|c|c|}
\hline Private sector* & $\begin{array}{l}\text { Largely } \\
\text { informal }\end{array}$ & $\begin{array}{c}\text { Largely } \\
\text { informal }\end{array}$ \\
\hline Government capacity & Good & Good \\
\hline Economic freedom & Mostly unfree & Mostly unfree \\
\hline Domestic savings (\% of GDP) & $1.2-19.3 \%$ & $0.91-11.2 \%$ \\
\hline Geographic disadvantage & Yes & Yes \\
\hline Unfair trade policies & Yes & Yes \\
\hline Market-based aid (1985-2012) & $38,122,136,479.0$ & $22,555,555,520.0$ \\
\hline Non-market aid (1985-2012) & $4,774,371,535.0$ & 4,038,516,565.0 \\
\hline
\end{tabular}

* More than $50 \%$ of enterprises exist within the informal sector

\subsection{Data collection:}

Data was collected in two forms: (i) information gather from conducting interviews with country experts, and (ii) written documents, such as research journal and country assessments done by the World Banks and IMF, etc. The combination of the aforementioned data sources provided me with an opportunity to best analyze available data and, in turn, allowed me to make inferences. Below is the outline of how the two forms of data were gathered.

\subsection{2: Interviews with country experts}

10 country experts were interviewed using a semi-structured interview guide. Most of these interviews lasted between 30 and 60 minutes and were recorded using a digital recorder for subsequent transcription. In a couple instances, country experts requested interview questions to be forwarded to them by e-mail for completion at a time of convenience due to their rigorous schedules. This avenue provided a great opportunity for me to gain unique insights because it generated both information and validity for my causal hypotheses that may have been 
overlooked in the literature. Or, in some cases it allowed me to gather centralized information, per se, in that oftentimes in order to best answer certain research questions one must look at various sources. Expert interviews provided an element of efficiency in which my questions were answered. Furthermore, experts from various backgrounds are likely to approach the same questions differently and therefore, they contributed to the debate because they added different perspectives and also revealed possible areas of agreement and disagreement. This added to the legitimacy of my findings because experts were able to rely on their own experiences and research to substantiate their arguments (Holstein and Hubrium, 1995; Mayring, 2002; Abels and Behrens, 2005; Bogner et al., 2005; Meuser, 2001; Meuser and Nagel, 1991; Schnell, Hill and Esser, 1999).

Interviews were structured so that it gave participants an opportunity to elaborate on the relationships between market-based aid and my four indicators of economic reform: government capacity, economic freedom, private sector depth, and domestic savings. For instance, one of the questions asked was: How has Ghana’s/Senegal's unique history and cultural traditions together with market-based aid affected its domestic saving practices? In other words, considering the history and traditions of Ghana/Senegal, do you believe market-based aid allocations have had any effects on state saving practices? I firmly believe that this question is broad enough to allow experts to elaborate on some of the key factors that must be accounted for when addressing the aforementioned questions, yet it is narrow enough considering it sets parameters to guide the experts to contribute their knowledge and understanding to this research. Similarly, another question was: Economic freedom - defined as the ability of individuals to engage in free enterprises (free markets or trade) and the government securing one’s property rights, etc. - plays a crucial role in advancing economic reforms. Has Ghana's/Senegal's history and traditions been 
conductive for individualism in terms of fostering autonomy, risk-taking, and entrepreneurship? Furthermore, how has market-based aid allocations contributed to this process? Again, these are questions that caters to gathering sufficient information regarding the relationship between market-based aid and economic freedom. Please see appendix A for complete survey.

\subsection{3: County experts}

Experts are senior academics from various disciplines, such as Political Science, Economics, Political Economics, History, and Anthropology, etc., with several having served as consultants in the SSA region at various segments of their careers and/or conducted research there. Therefore, they were able to apply firsthand experiences to answering the questions asked. Moreover, the diverse disciplines from which they came adds credibility, because they were able to provide a more holistic discussion since they were able to analyze the core issues being discussed through different lenses or approaches that aligns with their particular disciplines. This opened the discussion for varying interpretations and analysis since the country experts offered differing viewpoints to the same issues. This contributed to a more expansive understanding of the key issues.

Country experts were selected based on whether they could contribute to my research by closely examining their research focus and backgrounds. This is important because it helps to ensure they could contribute their expert knowledge in helping to assess and clarify the issues at

hand, and provide expert opinions and suggest pragmatic solutions. Below is an overview of each expert to illustrate their individual qualifications to contribute to this study.

\section{Senegal country experts:}


Leonardo A. Villalon, Ph.D.

Dr. Villalon is currently the Dean of the International Center and Professor of Political Science and African Studies at the University of Florida. His research focuses on African politics, particularly the intersection of Islam, politics and democracy across Sahel countries (Senegal, Mali and Niger, to be specific). He has authored numerous books, including "Islamic Society and State Power in Senegal," “The African State at a Critical Juncture: Between Disintegration and Reconfiguration,” and “The Fate of Africa’s Democratic Experiments: Elites and Institutions,” along with many journal articles and book chapters.

Furthermore, he has taught in Senegal as a Fulbright senior scholar at the Université Cheikh Anta Diop in Dakar, Senegal, and at the Université Gaston Berger in St. Louis, Senegal. In addition, he served as the President of the West African Research Association; directed projects analyzing religion and education reforms in the Sahel region as a part of the Africa Power and Politics research consortium, and codirected the State Department funded “TransSaharan Elections Project”, which involved coordinating electoral-related matters in six countries: Senegal, Mauritania, Mali, Burkina Faso, Niger, and chad. Lastly, he was the Principal Investigator on a Minerva grant that studied political reforms, social change and prospects for stability in the aforementioned states.

Laura Lynn Cochrane, Ph.D.

Dr. Cochrane obtained her doctorate in Cultural Anthropology from the Washington University in St. Louis, and is currently an Associate Professor of Anthropology and Director of the Cultural and Global Studies Program at Central Michigan University. Her research in 
Senegal focuses on religious beliefs, and environmental and economic concerns. This includes examining the everyday practices of Sufism, and the effects of faith-based communal level economic development efforts.

Riall Nolan, Ph.D.

Dr. Nolan specializes in Social Anthropology with an emphasis on international development, issues of change, and cross-cultural adaptation. He has worked extensively in Africa within the development field, specifically in Senegal, Somalia, and Cote D'Ivoire. This included working on grassroots community projects with the Peace Corps, Project development and management with USAID, and policy analysis with the World Bank. Moreover, he has worked as a consultant for bilateral agencies and NGOs.

Martha Johnson, Ph.D.

Dr. Johnson’s areas of expertise includes Comparative Politics, Political Economy, and African politics. Her research caters to highlighting the West African contexts of the aforementioned fields with publications, such as "Donor Requirements and Pockets of Effectiveness in Senegal’s Bureaucracy” (2015), “Ethnic Politics and Women’s Empowerment in Africa: Ministerial Appointments to Executive Cabinets” (2014), "Lobbying for Trade Barriers: A Comparison of Poultry Producers' Success in Cameroon, Senegal, and Ghana” (2011). Moreover, she has served as a consultant for the Millennium Challenge Corporation and Research Associate for the United Nation’s Food and Agriculture Organization.

Babacar M'Baye, Ph.D. 
Dr. M’Baye’s work focuses on Pan-Africanism with an emphasis on how intellectuals in the black diaspora differs from those in Africa; and immigration, race, class, gender, and hybrid identities in culture and literature. He is the author of various books, including "The Trickster comes West: Pan-African Influences in Early Black Diasporan Narratives and "Black Cosmopolitanism and Anticolonialism: Pivotal Moments.

\section{Ghana country experts:}

Edmund Abaka, Ph.D.

Dr. Edmund Abaka is an Associate Professor and the Director of the Africana Studies Program at the University of Miami. His research focuses on West African history since 1800; conflict processes, human rights and international relations. That said, he has published a few books, including "House of Slaves”, "Kola is God’s Gift”, and “W.E.B Du Bois on Africa.”

Felix Kumah-Abiwu, Ph.D.

Dr. Kumah-Abiwu is an Assistant Professor of Pan-African Studies at the Kent State University. His research focuses on development, foreign policy, foreign aid, and social movements. Some of his work includes, "Oil wealth, resource curse and development: Any lessons for Ghana?”, “Democratic Institutions, Natural Resource Governance, and Ghana’s Oil Wealth”, and “Leadership Traits and Ghana’s Foreign Policy: The Case of Jerry Rawlings' Foreign Economic Policy of the 1980s”.

George Ayittey, Ph.D. 
Dr. Ayittey is a Ghanaian Political Economist that focuses on development, foreign aid, and political and economic reforms across Africa. Some of his published works, include “African unchanged: The Blueprint for Development”, “Africa in Chaos”, “The Blueprint for Ghana’s economic recovery”, and “Africa betrayed, defeating Dictator: Fighting Tyrants in Africa and around the world.”

Ray Kea, Ph.D.

Dr. Kea's research focuses on the history of West Africa and Ghana. He has published widely with two of his pivotal pieces being, "A cultural and social history of Ghana from the seventeenth to the nineteenth century: The Gold Coast in the age of transatlantic slave trade” and "Settlements, trade, and politics in the seventeenth century Gold Coast."

Joseph Kwadwo Tuffour, Ph.D.

Dr. Tuffour is currently the Vice-Dean and senior Lecturer in the Department of Banking and Finance at the University of Professional Studies, Ghana. His areas of expertise includes International Trade and Finance, African Development, Socio-Economics, Public Policy, and Public Sector Economics, etc. Prior to working in academia, Dr. Tuffour worked as a Research Officer for the Institute for Democratic Governance, the Ghana Cocoa Board, Ghana Chambers of Mines, and as an Associate Economist and Project Supervisor of Management and Economic Development Consultants Limited. He has also published various articles including, "Analysis of the effect of external debt on private investment crowding-out in Ghana," "Foreign aid, domestic revenue and economic growth in Ghana”, and "The effect of financial leverage on profitability of manufacturing companies listed on the Ghana stock exchange.” 
4.7.4: Gathering secondary data

The sampling frame for the case analyses will employ secondary data collection. Secondary data included reviewing annual country reports, along with political, economic, sociological and anthropological peer reviewed research journals, and books, etc. This data also helped to determine if there are empirical links between market-based aid and economic reforms.

\subsection{Other factors influencing development and reform efforts}

\section{Informal sector:}

The informal sector is defined as all unregistered and therefore unregulated jobs, enterprises and incomes within the domestic economy. These unincorporated revenue generators that contributes to produce and services could play a key role in reform efforts, because it is capital that the government finds difficult to tax even though they exist in the light and not in the shadows. Thus self-employed street vendors, home-based workers, etc., are considered enterprises; however, they are generally not taxed. I examined the status of the informal sector by reviewing annual country reports that documents rough estimates of enterprises that exist within the informal sector. These reports were developed by the IMF, World Bank, state governments, etc.

\section{Economic diversity:}

This pertains to diversity in economic structures and enterprises that contributes to the aggregate economic output. This includes enterprises in agriculture, forestry, and fishing; mining, construction, communication, finance and banking, education, etc., that helps to support 
economic resilience. In other words, states that are more economically diverse are likely to further their economic reform agendas relative to others that are less diverse. This information was gathered from reviewing country level reports developed by the government, World Bank, IMF, etc.

\section{Gender inclusiveness:}

This pertains to the gender disparity and freedoms that each gender has in contributing to the domestic economy and reform efforts based on the social constructs that were put in place in terms of legitimations as well as cultural norms and traditions that guide decision-making.

Generally, cultural belief systems either support or inhibit certain aspects of general equality and therefore, it affects appropriate reforms from being designed and implemented, because without insight and innovation from both genders, the agenda lacks sufficient input that captures the nuances of both genders. I relied on country reports that were developed by the government, IMF, World Bank, etc.

\subsection{Conclusion:}

I have outlined the method used to empirically test the relationships between marketbased aid and economic reforms in Ghana and Senegal as well as the OLS regression models. Over the years, there have been a lot of focus on the relationship between aid, in general, and economic reform; however, this could be somewhat misguided considering not all aid types affect economic growth and reform in the same way. Thus, I assert that in order for states to achieve sustainable economic reform donors must consider allotting more market-based aid, 
Neron Thomas

which is essential for these states if they are to establish and maintain sufficient economic growth and development. 


\section{Chapter 5: Quantitative Analysis}

\subsection{Introduction:}

Four Prais-Winsten (P-W) regression models were conducted to analyze the effects market-based aid had on my four dependent variables: Government capacity, Gross Domestic Savings, Private Sector investment, and Economic Freedom, respectively. The P-W technique was used because of its ability to control for serial autocorrelations in the error terms by employing a generalized least squares estimator method. This, in turn, transforms observations so they yield estimators that are considered more asymptotically efficient relative to OLS applied to the original data set. Moreover, this study used panel data between 1985 and 2012 that consists of relevant aid contributions to determine if empirical links exist. A fixed effect approach was applied, which was appropriate considering panel data was used. This remedy helped to control for the unobserved and observed heterogeneity within country differences. Each state has unique characteristics which could possibly influence or bias the explanatory and/or outcome variables. Therefore, there is a need to control for this. By removing the effect of time-invariant factors I am able to better determine the net effect that the explanatory variables have on the outcome variables, and mitigate the correlation between the unique features that may differentiate the various states.

Sample data was gathered from various sources, and 22 sub-Saharan states were accounted for. The main explanatory variable is market-based aid contributions, which was used to determine if yearly changes in contributions had any empirical links with the aforementioned dependent variables. To help make more informed conclusions, the literature was reviewed to determine logical control variables, which includes: non-market aid, political stability, 
corruption, government effectiveness, voice and accountability, total debt servicing fees, foreign direct investments, gross capital formation, and per capita, etc.

Central to this study is that while aid recipients may have failed to enhance growth and development due to failure to reform, which I assert could be attributed to the types of aid that have been disbursed. Thus, donors and policymakers should orient their attention toward aid types that are likely to have greater causal effects on reforms over time. Specifically, I articulate that market-based aid will have a positive effect on reforms: government capacity, economic freedom, private sector development, and domestic savings. That said, the proceeding section will be divided into four sections that discusses the separate statistical models and findings. Each section will be substantiated by a discussion that interprets the statistical findings and their implications on the effects market-based aid has on reform and potential long-term growth and development of recipients.

\subsection{Statistical Findings}

Table 5.2 below presents the statistical findings of model 1 , which corresponds to the empirical link between market-based aid and government capacity. The model shows that the coefficients are generally inconsistent with my hypothesis and literature. A very surprising finding was that only 0.003 percent of the change in government capacity could be predicted by the change in the numerous independent variables that were included in the model based on the R-squared value.

Holding all other variables constant, the results show that market-based aid is found to have a direct negative effect on government capacity with the coefficient value being -0.055 . 
This finding does not lend any support of my prediction that market-based aid will promote government capacity development. Rather, the results suggest that committing more marketbased aid toward government capacity building is likely to be misallocated and therefore will unlikely foster any positive effect on government capacity. However, though the coefficient was negative, the finding was not statistically significant. This does not necessarily mean that marketbased aid has a negative effect on government capacity, per se. Rather it could simply mean this relationship isn't statistically significant. However, this finding stands in contrast in with some of the findings in the development literature (Clemens et al, 2005, 2011).

As expected, the coefficient value for non-market aid is negatively related to government capacity, and not statistically significant. Specifically, the coefficient value is -.062 . This is consistent with the literature (Clemens et al, 2005, 2011). Again, this is not indicative of nonmarket having a negative effect on government capacity building, per se. It simply means that non-market aid is not statistically significant in regards to enhancing government capacity, which seems to contradict the literature which suggests that non-market aid should be negative but statistically significant (Clemens et al, 2005, 2011).

As predicted, debt servicing fees are negatively related to government capacity building. The expectation is that the money used to service state debts takes away valuable resources that could be used toward further enhancing government capacity building. However, surprisingly, this relationship is not statistically significant, which is inconsistent with the literature.

The additional independent variables: regulatory quality, voice and accountability, inflation and trade/GDP are all negatively related to government capacity, which is inconsistent with the literature. The expectation is that they would have had a positive effect on government 
capacity building. However, finding suggests that this relationship was negative and not statistically significant. In contrast, the coefficient values for corruption, government effectiveness, and per capita are positive, according to findings, but these relationships were not statistically significant. Lastly, the time lag variable did not appear to have any effect on government capacity.

Overall, the aforementioned findings were peculiar considering what the literature found. Specifically, findings were very inconsistent relative to the general consensus of the aid literature. This is likely due to the data used. In this study, secondary data was gathered from various sources and combined into one panel data set. In other studies, it was common for researchers to use primary data and/or blend primary and secondary data. Furthermore, differences in findings could be attributed to differences in techniques used to analyze the model. In other words, using different techniques and assumptions could contribute to different findings which could also cause heterogeneity-related issues. However, the reality is that when trying to create the perfect model it is difficult, or even impossible, to control for the variables that may affect the dependent variable. Therefore, the most that could be done is to try and mitigate the level of heterogeneity that exists in the model. This study was able to accomplish that. However, in summary, the model appears not to support my hypothesis that there is a positive correlation between market-based aid and government capacity.

According to model 2, which examines the empirical relationship between market-based aid and economic freedom, most of the coefficient values are inconsistent with my predictions and the literature. Moreover, the independent variable only predicts 0.026 percent change in economic freedom based on the R-squared value, which is very low. 
Based in findings, there were two variables that were positively related to economic freedom and statistically significant. First, trade index was positively correlated and statistically significant at the 10 percent interval. However, the coefficient value is extremely small (0.0003). This means that the greater the percentage of trade/GDP, the more likely it will affect economic freedom. This supports my prediction, because the more states are able to focus on trade the more revenue they should expect and therefore, the more likely they would have money to invest in enhancing their economic freedom.

Second, voice and accountability was positively related and statistically significant at the 5\% level. The coefficient value was 0.0015; meaning, when all other variables are kept constant one unit of market-based change will change the voice and accountability's effect on economic freedom by the aforementioned amount, which is very miniscule. This positive and statistically significant finding is consistent with my prediction, and is consistent with the literature that governments that are more accountable tend to be more effective in using its resources.

The coefficients for the other variables: non-market aid, private sector investment, change in GDP, change in FDI, and corruption are positively related to economic freedom but were not statistically significant. These findings were inconsistent with what I was expecting and the broader literature. In contrast, the gross savings variable was negatively related to economic freedom, but it is was not statistically significant. However, considering many states across Africa have limited savings or are indebted, this may help to explain the findings.

That said, though the findings do not support my hypothesis, it is still possible that market-based aid contributes to economic freedom. There could be various reasons why my findings may not have been consistent with the general consensus of the aid literature. First, the 
states that were used are different. Plus, the econometrics techniques that were used and the independent variables controlled for or the data likely contributed to the outputs. Also, starting in the 1990s, more and more aid has become more conditional for emerging economies to help them enhance their level of governance, which is pivotal for developing and enforcing appropriate policies that may result in citizens being more economically free. Therefore, as donors become more concerned and questions the quality of governance, both bilateral and multilateral aid, the expectation is that they would respond by reducing aid or encouraging recipients to improve their public expenditure management practices.

According to Model 3, which investigates whether empirical linkage exists between market-based aid and private sector investments, there were inconsistencies with my predictions. Specifically, the coefficient values and lack of statistical significance did not align with what I expected. However, the model does suggest that my independent variables predicts approximately 14 percent of the change in the private sector investment.

Based on findings, market-based was positively related to private sector investment; however, surprisingly, it is not statistically significant. In contrast, and as expected, non-market aid is negatively related with private sector investment with coefficient value being -0.08 ; meaning, that when all other variables are kept constant it would negatively affect private sector investments by the aforementioned amount for every unit change in market-based aid. This is statistically significant at the 1 percent interval.

Change in GDP was found to be positively related to private sector investment with the coefficient value being 1.63; meaning, for every unit change in market-based aid it is expected to 
positively change private sector investments by the aforementioned amount. This finding supports my prediction and also finds support in the aid literature.

The coefficients for market-based aid, regulatory quality, gross savings, trade/GDP, government effectiveness, voice and accountability, and per capita were found to be positively related to private sector investments; however, they were not statistically significant. In contrast, political stability was negatively related to private sector investment but was similarly not statistically significant.

Lastly, model 4 shows that some of the coefficient values are inconsistent with my prediction and literature. Moreover, only 3 percent of the change in gross domestic savings could be explained by market-based aid and the independent variables that were included.

First, the market-based coefficient value is positive but small. Specifically, the value is .316, which implies there is a positive correlation between market-based aid with gross domestic savings practices. However, the coefficient value suggests that the return may not be worth the investment considering that there is likely to be only a .316 unit of change on Gross Domestic Savings for each unit change in market-market based aid. Therefore, there is a disparity between the units.

In contrast, non-market based aid is negatively related (-0.034); however, it was not statistically significant. Similarly, variables such as change in GDP and political stability were also negatively related and not statistically significant. While it was expected that the GDP has a positive effect on savings, political stability was expected to have a negative effect. 
Other variables such as private sector investments, FDI, debt service, corruption, and government effectiveness all had a positive effect on savings practices; however, they were not statistically significant. In contrast, GDP consumption negatively related to savings and is statistically significant. The coefficient value is -.03. Therefore, the expectation is that if all other variables are constant one unit change in market-based aid will negatively affect savings by the aforementioned unit.

\subsection{Summary and conclusion:}

The primary purpose of this study was to test whether market-based aid could help explain variations in economic reforms across 22 sub-Saharan African states. The timeframe was from 1985 to 2012. Data was gathered from various sources, including the World Bank, The World Governance Indicators, the Index of Economic Freedom, and AidData.org. The data was then standardized to show the annual percentage change per variable.

This study yields one important finding. There are inconsistencies in terms of the relationships between the independent and dependent variables. Specifically, findings generally did not find support with my predictions or the development literature; however, that does not mean that the findings are less important or does not contribute to the existing literature. Though there were inconsistencies, it is still possible that there is causation, but they were not being highlighted in the statistical models used. Another assumption is that maybe the techniques used were inappropriate. Or further, maybe the states that were selected still lack sufficient capacity to use aid effectively and efficiently to improve their economic reform efforts. Therefore, much could be gleaned from the inconsistent findings, which could foster additional investigations. 
According to Werlin (2005), "no matter how much aid the developing countries get, without better governments, it is impossible to help the poor." While that notion may be true, I believe we may be missing a key component in understanding the empirical links between market-based aid and economic reform - and that is the role state specific nuances may contribute to this process, which may not be captured in statistical models. In other words, each state has unique issues and features, which may have made it challenging to try and investigate whether or not market-based aid may have affected economic reforms using an aggregate approach. Therefore, it is strongly recommended that the statistical links and findings are carefully examined, because the numerical variables alone cannot fully explain economic reforms. This has resulted in me conducting two case analyses to determine how internal cultural and traditional norms and customs could help to either confirm or disconfirm the statistical findings. This is because it is the belief of this study that cultural attributes definitely should be considered when trying to explain which factors affect economic reform efforts. I am aware that using sub-Saharan states makes it difficult, if not impossible, to generalize findings considering their uniqueness. Therefore, future studies that also incorporates states from other regions could help to shed light beyond these findings. 
Table 5.1: Descriptive statistics

\begin{tabular}{|l|r|r|r|r|r|}
\hline Variables & \multicolumn{1}{l|}{ Obs } & \multicolumn{1}{l|}{ Mean } & \multicolumn{1}{l|}{ Std Dev. } & \multicolumn{1}{l|}{ Min. } & \multicolumn{1}{l|}{ Max. } \\
\hline Market aid & 616 & 1.61 & 14.29 & -1.00 & 297.42 \\
\hline Non-market aid & 616 & 2.08 & 36.53 & -1.00 & 904.00 \\
\hline Debt servicing fees & 615 & 2.70 & 41.06 & -126.11 & 948.38 \\
\hline Regulatory Quality & 616 & -0.31 & 3.76 & -72.21 & 10.98 \\
\hline Voice \& Accountability & 616 & 0.37 & 2.76 & -3.31 & 51.36 \\
\hline Corruption & 616 & -0.32 & 5.01 & -90.71 & 6.27 \\
\hline Government Effectiveness & 616 & 0.05 & 2.36 & -13.52 & 51.62 \\
\hline GDP per capita & 616 & 0.07 & 0.43 & -0.97 & 9.27 \\
\hline Trade (\%GDP) & 588 & 83.78 & 54.39 & 23.72 & 531.74 \\
\hline Inflation & 601 & 32.38 & 255.83 & -31.56 & 5399.50 \\
\hline Economic Freedom & 616 & 0.00 & 0.08 & -0.40 & 1.20 \\
\hline Private Sector Investment & 615 & 0.16 & 1.05 & -1.00 & 20.10 \\
\hline Gross Domestic Saving & 616 & 0.41 & 25.31 & -223.60 & 571.00 \\
\hline FDI & 616 & 1.57 & 14.43 & -182.00 & 191.60 \\
\hline Trade Index & 616 & 109.91 & 37.85 & 21.40 & 315.60 \\
\hline Political stability & 616 & 0.01 & 4.43 & -2.36 & 108.00 \\
\hline Gross capital formation & 616 & 0.05 & 21.12 & -13.50 & 219.00 \\
\hline GDP & 616 & 5.3 & 70.58 & -113.67 & 1323.23 \\
\hline
\end{tabular}


Table 5.2: Outputs for regression models

\begin{tabular}{|c|c|c|c|c|}
\hline Variables & $\begin{array}{c}\text { Model 1: } \\
\text { Government } \\
\text { capacity }\end{array}$ & $\begin{array}{l}\text { Model 2: } \\
\text { Economic } \\
\text { Freedom }\end{array}$ & $\begin{array}{c}\text { Model 3: } \\
\text { Private sector }\end{array}$ & $\begin{array}{l}\text { Model 4: } \\
\text { Domestic } \\
\text { savings }\end{array}$ \\
\hline Market aid & $-.055(.206)$ & & $.000(.003)$ & $.316(.088)^{* * *}$ \\
\hline Non-market aid & $-.062(.995)$ & $-0.00(0.000)$ & $-.077(.028)^{* *}$ & $-.034(.029)$ \\
\hline Debt servicing fees & $-0001(.072)$ & & & $.027(113)$ \\
\hline Regulatory Quality & $-.014(.811)$ & & $.000(.012)$ & \\
\hline Voice \& Accountability & $-.111(1.073)$ & $.001(.000)$ & $.001(.016)$ & $.001(.054)$ \\
\hline $\begin{array}{l}\text { Corruption } \\
\text { Government }\end{array}$ & $.083(.588)$ & $-.000(.001)$ & $.001(.009)$ & $.001(.029)$ \\
\hline Effectiveness & $.407(3.044)$ & & $.000(.012)$ & $-.004(.065)$ \\
\hline GDP per capita & $2.815(7.011)$ & & $.044(.011)$ & \\
\hline Trade (\%GDP) & $-.069(.056)$ & & $.001(.002)$ & \\
\hline Inflation & $-.000(.0122)$ & & & \\
\hline $\begin{array}{l}\text { Economic Freedom } \\
\text { Private Sector }\end{array}$ & & & & \\
\hline Investment & & $0.001(.003)$ & & $.125(.154)$ \\
\hline Gross Domestic Saving & & $-5.08(.000)$ & $-.001(.017)$ & \\
\hline FDI & & $-.000(.000)$ & & $-.002(.033)$ \\
\hline Trade index & & $0.000(.000)^{* *}$ & & \\
\hline Political stability & & $.000(.001)^{*}$ & $-.0 .61(.066)$ & $-.023(.054)$ \\
\hline Gross capital formation & & & & $-.013(.018)$ \\
\hline GDP & & $.012(.126)$ & $1.63(.199)^{* * *}$ & $-.131(.682)$ \\
\hline Cons. & $11.266(5.56)^{*}$ & $-.251(.010) *$ & $.017(.109)$ & $.668(.382) *$ \\
\hline$* * * \mathrm{p}<0.001 * * \mathrm{p}<0.05 *$ & & & & \\
\hline R-Squared & 0.0031 & 0.0027 & 0.14 & 0.03 \\
\hline Durbin-Watson & 1.99 & 1.37 & 1.77 & 1.96 \\
\hline Observations & 585 & 594 & 522 & 537 \\
\hline
\end{tabular}




\section{Chapter 6: Senegal case analysis}

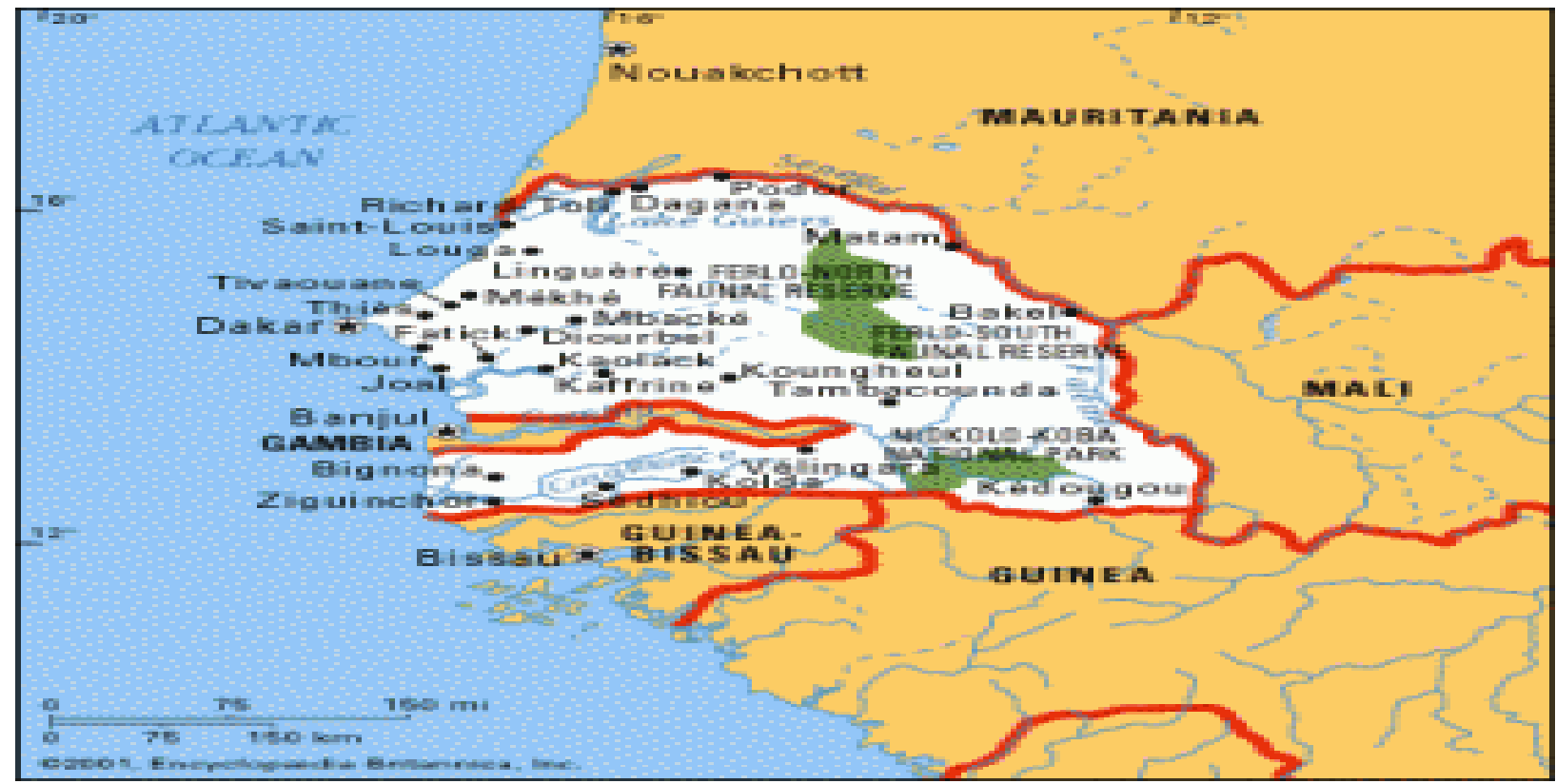

Map highlighting Senegal in the Africa sub-continent.

Table 6.1: Senegal at a glance

\begin{tabular}{ll}
\hline Unemployment & $25.6 \%$ (2013 estimate) \\
Life expectancy & 66.7 years (2015 estimate) \\
Population & 15.4 million (2016 estimate) \\
Literacy rate & $42.8 \%$ (2013 estimate) \\
Debt stock & $\$ 6.64$ billion (2016 estimate) \\
\hline Source: World Bank &
\end{tabular}

\section{1: Introduction}

Senegal, a former French colony located on the western coast of Africa, is considered one of the most stable economic and political states in the region relative to others. ${ }^{23}$ However, said

\footnotetext{
${ }^{23}$ Senegal has been a rare political success story with a historical legacy of stability and peace partly due to a strong and engaged civil society. Though there have been multiple military coup attempts, all presidents have been democratically elected. Similarly, the economy has generally experienced annual growth (World Bank, 2016; Arrief, 2013).
} 
stability has not translated into sufficient improved living conditions for Senegalese. ${ }^{24}$ With very limited natural resources, Senegal's key revenue generators include agriculture (peanuts, cereal, rice, corn, and millet), fishing, and phosphate. However, harsh weather patterns in the large and arid Sahel region in the north along with failure to successfully diversify the economy, ${ }^{25}$ declining primary commodities prices on the global market due to new global competitors, lack of sufficient capacity to capture taxes from a growing and dominant informal sector, and an increasing dependence on external aid for budget support, etc., has historically contributed to economic stagnation and crises. $^{26}$ This has historically spurred both frustration and disillusionment amongst citizens because it has contributed to consistently high unemployment rates while living conditions have declined, especially for those living in rural areas. ${ }^{27}$ This has conjured up many public displays of discontent against the state government through demonstrations and strikes, especially by the ambitious and educated urban youths around election seasons (Stiftung, 2009; Casey, 2011; UNDP, 2011; World Bank, 2007; IMF 2010, 2012).

Some of Senegal's contemporary development struggles could be traced back to precolonialism. The market infrastructure was designed and developed primarily to benefit France

\footnotetext{
${ }^{24}$ Human Development Index remains low, while the economy remains significantly vulnerable, leading to it being a frequent attendee of the Paris Club under the Multilateral Debt Relief Initiative of 2006. Yet, Senegal's public to external debt ratio continues to grow. For instance, in 2006 they were given a debt relief but by 2007 debt accounted for 25\% of GDP and by 2014 it rose to $49 \%$ (World Bank, 2016; IMF, 2014).

${ }^{25}$ Though the government has tried to diversify the economy it was unsuccessful due to failure to address droughts, climate, and shortage in rainfall as well as pre-colonial economic policies that continue to influence agricultural policies (specifically peanut) at the detriment of others.

${ }^{26}$ Over-reliance on global peanut markets (with France being the chief importer) has negatively affected Senegal's economy due to fluctuating prices and competition from new sources such as the U.S, China and Argentina, etc.

${ }^{27}$ Unemployment, particularly among urban youths and women, sometimes exceed $45 \%$ while income levels are unevenly distributed, especially between the middle and lower classes in the urban and rural areas.
} 
since it was streamlined to produce peanuts (mainly to meet the needs of the French market) ${ }^{28}$; there being a flawed state structure ${ }^{29}$; the economy being state controlled; and there being a high dependency on external aid for survival. Nearly 60 years later, French colonial legacies continue to exert great influence on Senegal's growth and development agenda. The monoculture system implemented under French colonial rule continues to leave the economy vulnerable while forcing the state and private sector to import necessities. For instance, the country has historically experienced food insecurities - namely due to climate and drought-related issues; however, instead of putting in place pragmatic measures to try and address those issues, the government continues to embrace colonial policies that caters to supporting the peanut economy rather than others, which has contributed to the state having to import over $70 \%$ of its food needs. To put things into further perspective, by independence (1960), peanut production accounted for more than 80\% of the state's exports (Diop and Diouf, 1990; Matsumoto, 2008; Arrief, 2013).

Furthermore, colonial policies left a patron-client state structure in place. Specifically, the French formalized a two pronged administrative system similar to the indirect rule system used in numerous colonies. First, the French administration organized Muslim religious/spiritual leaders - primarily "Marabouts” - who served as intermediaries or 'brokers' between the state and citizens. Thus, the state operated through 'Maraboutic' channels instead of official state channels. ${ }^{30}$ This was pivotal in organizing productive support in addition to the management and

\footnotetext{
${ }^{28}$ The French placed less emphasis on other agricultural sectors, including rice, which was a staple, resulting in Senegal having to import. This practice continues as France favors subsidizing the peanut economy relative to others.

${ }^{29}$ Aside from the monoculture economy is the way in which production and profits were distributed. The French mandated that peanut production begin at the local levels in Senegal but end up in French factories. Profits made were consolidated in the hands of French factory owners and small interest groups.
} 
distribution of state resources in an effective and efficient manner at the local level to catalyze and boost production. Second, a key element or value of the Maraboutic tradition is that disciples must submit to their Marabout leaders, especially regarding spiritual affairs. However, over the years this submission has extended into political and economic affairs as well (Beck, 2008; Diop, 1984; O’Brien, 1971; Wade, 1967).

This two pronged relationship between the Marabouts and the state helped both parties to secure their own interests. The state played a central role in regulating access to the global markets and trade profits that Marabouts benefited from, but it was the state - not the markets that fixed prices and controlled trade opportunities as well as determined who gained access to those opportunities. Thus, the state structure concentrated power and wealth in the hands of those with access to those opportunities. This system supported the state and also helped to create a powerful elite class in the post-colonial Senegal - primarily the Marabouts-who generated significant wealth through profits as a result of their role in organizing producers and substantially expanding the peanut sector. This is because under colonialism large land grants were given to Marabouts along with unclaimed lands that they took control of, financial subsidies, and agricultural leverage over the peanut sector contributed to them becoming key players in domestic economic and political affairs (Beck, 2008; Diop, 1984; O’Brien, 1971; Boone, 1990; Fatton, 1986; O’Brien, 1974; Baker, 1977).

\section{2: Post-colonial history of reform efforts by administrative heads.}

\footnotetext{
30 The Maraboutic system was essentially formalized under the French colonial administration as a form of new social order to help mitigate any potential social dysfunction (Gning, 2004).
} 
Each Senegalese administration that came to power have demonstrated different approaches regarding foreign aid, which may have affected government capacity, economic reforms, savings, and private sector investments. That said, the goal here is to provide a brief overview of how the various administrations have generally responded to aid; the development agendas they employed, and some of the ramifications of their policies. The reality is that the aforementioned issues have had some direct and indirect effects on Senegal's current condition.

The Leopold Senghor administration (1961-80)

After gaining independence in 1960, the new state inherited an administration that was rather strong in and around Dakar and some other key colonial cities. However, the administration remained relatively weak in rural areas which were predominantly governed by religious and communal leaders. The structure of the new state government did not vary much from the colonial structure. Rather, it emphasized the colonial apparatus and policies by continuing to operate through religious channels. This relationship played a crucial role in President Leopold Senghor's 20 years of leadership even though there were suggestions to separate the state from religion. ${ }^{31}$ However, adhering to such suggestions was risky for Senghor since he had leaned heavily on the support of Marabouts to win his presidency and was a Catholic in a predominantly Muslim country ${ }^{32}$ (Diop and Diouf, 1992; Diouf, 1992; Behramn, 1977; Villalon, 2011).

\footnotetext{
${ }^{31}$ Senghor's reign was the result of there not being a term limit (fixed at 7 years per term) in the initial Constitution, which instituted a single party parliamentary system; him being viewed as a post-colonial prophet, his close ties with France, and his ability to win the support of the Marabouts, while his opponents consistently tried to separate religion from state (Diouf, 1992; Behrman, 1977).

32 Though a catholic, Senghor won the support of the Marabouts and their followers.
} 
Senghor initially opposed foreign aid; however, Senegal was desperately in need of boosting its revenues by emphasizing exports to meet growing domestic needs. The French government offered financial subsidies toward securing their own interests in the peanut sector. This certainly did not help Senegal's broader economic objectives. Yet, Senghor opted to implement a political system similar to the French model, which he categorized under 'African Socialism' and promoted as a vehicle for fostering economic reforms. This was especially since the economy was accumulating huge deficits due in part to trade imbalances. Growing demands for consumer goods and services led to imports, which proved expensive, while exports were not sufficient to match rising import costs. Furthermore, the state contributed to trade imbalances since it often fixed prices and allotted subsidies that favored urban dwellers and negatively affected rural producers. This was supposed to generate a surplus for the state; however, it took away incentives for producers when the state reduced prices (Boye, 1993; Bates, 1981).

In addition, Senghor supported cultural exchanges; maintained close political and economic ties with France to help foster long-term economic and political reforms through collaborations; and channeled a large segment of the state's resources toward securing peanut production through co-operatives. However, this monoculture approach had disastrous effects on the economy as the peanut sector (and the agricultural sector as a whole) was vulnerable to both internal and external shocks such as droughts and declining commodity prices on the global market. Aside from French legacies, Senegal's failure to meet economic expectations could also be attributed to certain cultural underpinnings ${ }^{33}$ together with a lack of expertise or training in

\footnotetext{
${ }^{33}$ Marabouts have historically had a lot of currency in influencing the economy at the sub-national levels, especially in the productive sectors. Specifically, these leaders form extensive networks that continue to have significant control in the domestic economy. Also, traditionally, producers took excesses to Marabouts in exchange for blessings and charity to be distributed to those less fortunate.
} 
economic planning, which has affected its ability to successfully orient reform efforts toward diversifying the domestic economy. This contributed to there being a great disconnect between him, society, and a growing political opposition (Diop and Diouf, 1992; Gning, 2004; Ross, 2008).

External pressures starting in the 1970s to pursue political and economic reforms also contributed to reform mishaps. The Cold War and eventual failures of SAPs led many donors to promote the notion that democracy and good governance were key drivers of economic reforms. Democracy and good governance were viewed as prerequisites for greater economic integration into regional and global economies. However, the Cold War also altered the strategic significance of Senegal in regards to global geopolitics. ${ }^{34}$ This led to a loss of interest by the West (and other power blocs) in Senegal, which contributed to mounting internal pressures due to declining external support. This forced Senghor to actively pursue reforms to help mitigate growing discontent. One of the first reforms was amending the national Constitution to introduce a multiparty political system comprising of a: Liberal Democratic, Socialist Democratic, and Communist/Marxist party. The measure was to open the political system while mitigating the potential for fragmentations along ethnic, religious or regional lines. ${ }^{35}$ Additionally, he instituted reforms to foster peaceful transitions during election cycles, and neutralized the military by making them apolitical while they remained loyal to civilian leadership ${ }^{36}$ (Moore, 1993; Diallo and Lafreniere, 2014; Meredith, 2011; Hyden, 1999).

\footnotetext{
${ }^{34}$ Senegal joined the non-aligned movement in 1964 wherein they did not officially align with any of the major power blocs.

${ }^{35}$ Though diverse along ethnic, religious and regional lines, historically those factors have played insignificant roles in politics.
} 
However, while Senghor made efforts to reform the national political apparatus, little was done to reform economically. Senegal's early economic woes rested on Senghor's administration banning private buyers and insisting on using Marketing Boards to regulate primary commodity prices and helping to subsidize some producers. However, periods of droughts together with corruption escalated hostilities between local producers and the state. ${ }^{37}$ This problem was furthered by France's decision to stop subsidizing peanut production during the 1960s, which priced many locals out of the market while demands on the global markets also decreased. ${ }^{38}$ The government took a reactionary approach in 1967 by implementing a "chit system." This was a price regulation policy aimed at accumulating domestic surpluses that was supposed to be channeled toward development by reducing the price the state was willing to pay producers. ${ }^{39}$ However, this policy added more economic agony on producers because the state acquired produce on credit; meaning, producers were required to deliver their goods to regional Marketing Boards, but money was not exchanged on delivery but rather when goods were sold. This system contributed to the lowering of production as it decreased incentives for producers. Thus, poor economic reforms, which coincided with the oil and market collapses during the 1970s, helped to facilitate Senegal's first major economic collapse. This contributed to an increasing dependence on foreign aid as domestic outputs simultaneously declined, resulting in a

\footnotetext{
${ }^{36}$ The French also played a role in ensuring that the military remained apolitical because they supported Senghor and declared to the Senegalese army that they will intervene and restore Senghor to power if they ever disobeyed his authority. Moreover, they pressured the parliament to put their support behind Senghor even if they were loyal to other political leaders (Diouf, 1992).

${ }^{37}$ Marketing boards were consistently accused of manipulating prices for their own benefit and mismanaging funds that should have been directed back to producers.

${ }^{38}$ Cutting subsidies on staple items generally has drastic effects on the middle and lower classes - more so the women, because it reduced their purchasing power thus making daily hardships even more severe.

${ }^{39}$ There was a 15 percent deduction from market value under the chit system.
} 
swift escalation of state debts and servicing fees. This made producers vulnerable, because as the economy shrank so did personal income levels while personal debts increased. ${ }^{40}$ This hindered the ability of producers to repay loans - many of which were regulated by parastatal agencies (Golub and Mbaye, 2002; Martin, 2005; Kessler, 1980; Bates, 2005; Barker, 1977).

To buy political favor in the midst of mounting discontent, Senghor solicited foreign aid to help subsidize peanut prices; implemented a debt forgiveness program for producers, strengthened his support with the Marabouts, disbanded the chit system and then reverted to the previous system whereby producers were paid upon the delivery of peanuts and other produce. However, those efforts still failed to pivot the economy. This led to Senghor peacefully stepping down in 1981 and endorsing his prime minister, Abdou Diouf, as his successor ${ }^{41}$ (Barker, 1977; Bates, 2005).

The Abdou Diouf administration (1981-2000):

President Abdou Diouf signaled a visible shift in domestic policies since he was considered a technocrat with a vast administrative skill set. Though a protégé of President Senghor, he abandoned the in-ward oriented policies of his mentor who had employed social and economic reforms that closely regulated production, imports, exports and domestic market prices. A key reason for this shift came due to mounting internal and external pressures to construct a modern state built on a strong economy and industrial sector to complement the

\footnotetext{
${ }^{40}$ The market value of produce decreased which decreased production due to the incentive structures. Thus many producers shifted from one agricultural market to another to help mitigate their risks. Therefore, it was not uncommon for farmers to shift from peanuts productions, which was over-regulated by the state, to less regulated markets such as millets and cotton, etc.

${ }^{41}$ The Constitution stipulated that should the President fail to complete his term in office, then the Prime Minister may temporarily assume office until the next election.
} 
growing demands of the people by integrating the domestic economy into regional and global markets. ${ }^{42}$ Thus, he worked with Western donors to implement 'stabilization policies. ${ }^{43}$ Aid disbursements were contingent on neoliberal policies and institutional transformations. This included mobilizing technical support to help advance government capacity; transforming the market economy whereby entrepreneurs were given more liberties to establish small and medium-sized enterprises (SMEs); making efforts to support economic freedoms of market participants; and state governments removing itself from economic activities through decentralizing and privatizing inefficient state enterprises. However, monopolies still persisted in some politically strategic sectors - peanut and cotton, for instance, which stemmed from its cultural and historical development (Beck, 1999; Diouf, 1998).

A pivotal economic adjustment that Diouf helped to oversee was the devaluation of the CFA Franc in 1994, which is a single currency used by many Western and Central francophone countries. The purpose was to help make Senegal become more competitive regionally and on the global market. This strategy contributed to the economy growing between 3 percent and 4.3 percent between 1994 and 2000. However, from a holistic standpoint, efforts to make the domestic economy more competitive has failed to meet lofty expectations as low economic growth rates accompanied a collapse in industry and the agricultural sector due to domestic businesses being unable to compete with highly subsidized imports and key enterprises. Plus, the persistence of the separatist movement in the Casamance region has contributed to negative

\footnotetext{
${ }^{42}$ The internal political climate was changing because the economy was in dire shape. Thus, Diouf had little choice but to implement SAPs. Social activism, political opposition, tensions with Mauritania, Gambia and the secessionist movement in the Casamance region as well as opposition to the French and its legacy of centralized economic and political powers in the hands of a small elite contributed to the need for reforms.

${ }^{43}$ One of the first SAPs implemented was the devaluation of the CFA Franc by 50 percent to help make the economy more competitive within the global market.
} 
economic growth. This is because it is a lush and fertile area in the country that is often subjected to sporadic low-level instabilities, causing local producers and residents to flee (Powell, 2003; Gning, 2004; EU Commission, 2007; World Bank, 2010, 2016).

\section{Abdiulaye Wade's administration (2000-2012):}

In 2000, and under clouds of mounting discontent between the state, society, and political rivals, there was another political change. Abdoulaye Wade was elected to the presidency. In some regards, his policies reverted to socialism. He amended the Constitution to unravel some of the democratic progress made under the previous administrations to open the economy and democratize the political system; consolidated his presidential powers, abused his powers and institutions for private gains, used 'big man rule' to reshuffle his cabinet to help secure his hold on power while also employing family members in key political offices, and silenced his political opposition in the National Assembly as well as society using the state security forces and judicial branch. Also, while he initially moved to limit and reduce political terms from unlimited 7 year terms to two 5 year terms he later tried to renege toward the end of his second term. He was able to accomplish some of those feats because of key strategic amendments he instituted. This included granting military personnel the opportunity to vote; reforming the Supreme Court to provide him with political support; and legislating gender parity in government, etc. (Fall, 2011; Melly, 2012).

However, toward the end of his tenure his policy shifted, resulting in him placing some emphasis on the economy by rehabilitating the declining agriculture sector. Part of his initiative to rehabilitate the domestic economy came in the role he played in developing the New Partnership for Africa's Development (NEPAD), which centered on attracting FDI for advancing 
industry and private sector growth regionally. However, the plan was harshly criticized by some leaders for its potential to invite neocolonialism due to uneven economic arrangements and distribution of wealth. ${ }^{44}$ Moreover, rising unemployment rates, mismanagement of state resources, a growing informal sector that remained mainly untaxed, declining economic growth, and his move to revise the Constitution to extend his time in office beyond the stipulated term limit contributed to the loss of public and political support, which helped to seal his political fate at the ballot box (World Bank, 2016; Casey, 2011; UNDP, 2011).

\section{Macky Sall's administration (2012-present):}

2012 brought another shift whereby Macky Sall, a former premier in the Wade administration, was elected to office. One of the first things on the political agenda was creating a new Constitution. To accomplish that, he established the National Constitutional Reform Commission (NCRC). His goal was to get Senegal back on the democratic path by curbing presidential terms and committing to social and economic development reforms by making amendments aimed at reforming institutional frameworks that aligns with the country's ambition to become a modern state and maintain its position as a regional beacon of democracy. To achieve such ends, he promoted broad, participatory and inclusive policies oriented toward good governance, rule of law, decentralization, private sector growth, macroeconomic stability, poverty reduction, wealth formation, development of social services; and social protection and disaster risk management, among other areas.

\footnotetext{
${ }^{44}$ Some of the criticisms stem from the notion that this policy seems to replicate the Washington Consensus, especially in regards to it being executed in a top-down manner and in absence of civilian input or accounting for local contexts.
} 
Two other contributions is his reform of the judicial system to help curb corruption. He mandated all political officials submit documentation declaring their personal wealth before entering public office, especially if they are put in positions granting them access to state funds. Similarly, they are audited upon leaving office. Though some progress has been made, adequate economic reforms has not resulted in expected economic growth which appears to be static around the 2.5 percent despite an increase in aid disbursements, resulting in more debt accumulation (World Bank, 2016).

That said, the failure of Senegal to meet development expectations cannot be discussed without also acknowledging the role cultural factors has played. Many social and cultural values, beliefs, traditions and norms have contributed to the hindrance of reform efforts due to the stronghold some cultural beliefs and systems have on the way of life in Senegal. Though efforts have been made over the years it appears that certain cultural norms and values are too entrenched and being reinforced, not necessarily to hinder reform efforts, but rather to secure certain cultural and social constructs that have been in existence for generations. This has created somewhat of a wedge between political leaders tasked with moving the country forward and religious leaders (Marabouts) who have become very influential in terms of providing political and economic guidance as well as representation for the masses. Similarly, this is also further complicated by the fact that colonial legacies continue to exert itself since political leaders still seek advice and support from France and Marabouts before making key policy decisions. Moreover, some political leaders are also conflicted because of their religious affiliation and support for cultural preservation. Therefore, the success or failure of reform efforts could be determined by whether or not they are supported by Marabouts. And efforts to separate the state from religion has been problematic since it would require Marabouts relinquishing powers to the 
state, and in doing so they also cede collateral that comes with their positions, especially when it comes to pushing their own interests at the state level (Beck, 2008; Villalon, 2011; O'brien, 1971; Wade, 1967).

The next section of this narrative will provide the Senegal case analysis based on findings gathered from 5 country experts, country reports and peer reviewed research that helped to explain how Senegal's cultural attributes may have affected the effectiveness of market-based aid and economic reform efforts. The aim is to take into account how unique cultural traditions, beliefs, and social systems may have affected the effectiveness of market-based aid in regards to fostering government capacity, economic freedom, private sector investments, and domestic savings. Central to This discussion will emphasize the essential role the Mouride Brotherhood plays in the broader political bureaucracy since there is no separation between religion and state.

The Mouride Brotherhood is an institution in itself which has grown in strength during and after the colonial era with the support of the French. The spiritual authority associated with this institution has seeped into to the political arena, allowing them influence - and even dominate politics - when needed. Specifically, Senegal's quintessential brokers are the Marabouts who have managed to translate their religious authority into political influence over their devout disciples and also into political capital with political officials when needed through their ability to quickly mobilize large voting blocs along religious rather than ethnic lines.The state has historically been predominantly Muslim. Therefore, decisions made by the Mouride Brotherhood are easily promoted within the political arena, leading political leaders to frequently seek consultation with Marabouts before any major national policies are developed and implemented. The reasoning being that the support of Marabouts often times determine whether 
or not national policies succeeds at the local level. Moreover, since Marabouts have been able to accumulate personal wealth over the years, they do not necessarily need money from the government to execute tasks that serves their individual communities and interests. They could use their own funds. But in cases where the state needs them to help implement national policies and/or programs, it comes with funding that matriculates to the people. In both cases - whether funding comes from the state or from Marabouts - it generally helps to further secure the loyalty of the disciples of the Mouride Brotherhood. Thus, their roles are paramount to understanding the interaction between, and effectiveness of, aid allotments and my key variables since they are policymakers who could quite easily mobilize their disciples to either support or reject national policies if they do not align with their own interests (Beck, 2008; Robinson, 2000).

\section{3: The intersection between market-based aid, culture and government capacity.}

There were areas of agreement and disagreement between country experts and the literature regarding the effects market-based aid (henceforth "aid”) may have had on government capacity building when accounting for Senegal's unique cultural attributes. One expert who specializes in Islamic issues and politics in Senegal argued that aid has worked in some ways, but in some ways it has not when accounting for the cultural and historical contexts of Senegal. Similarly, another expert that focuses on how social constructs and culture affects development added that aid has worked, especially relative to other regional countries and without it the government would be less capable of designing and implementing its policies, because the amount of foreign exchange it receives through trade is still small relative to how much it brings in through aid. Therefore, without aid contributions the state is likely to fail in developing and implementing appropriate comprehensive, macro-level policies. In contrast, one expert, a social 
anthropologist by trade, who has worked in Senegal at the grassroots level and as a consultant for the Peace Corps, USAID, and World Bank was skeptical of the effect aid may have had in advancing government capacity. He argued that cultural belief systems have negatively affected this process and therefore, more aid is not necessarily a good idea. Instead, more efforts need to be made by donors to understand the culture and history of Senegal to best design reform efforts, because Senegalese do not view aid the same way in which donors expect. This discrepancy leads to wastage.

Figure 6.2: Allocation of aid types for government capacity building between 1985 and 2012.

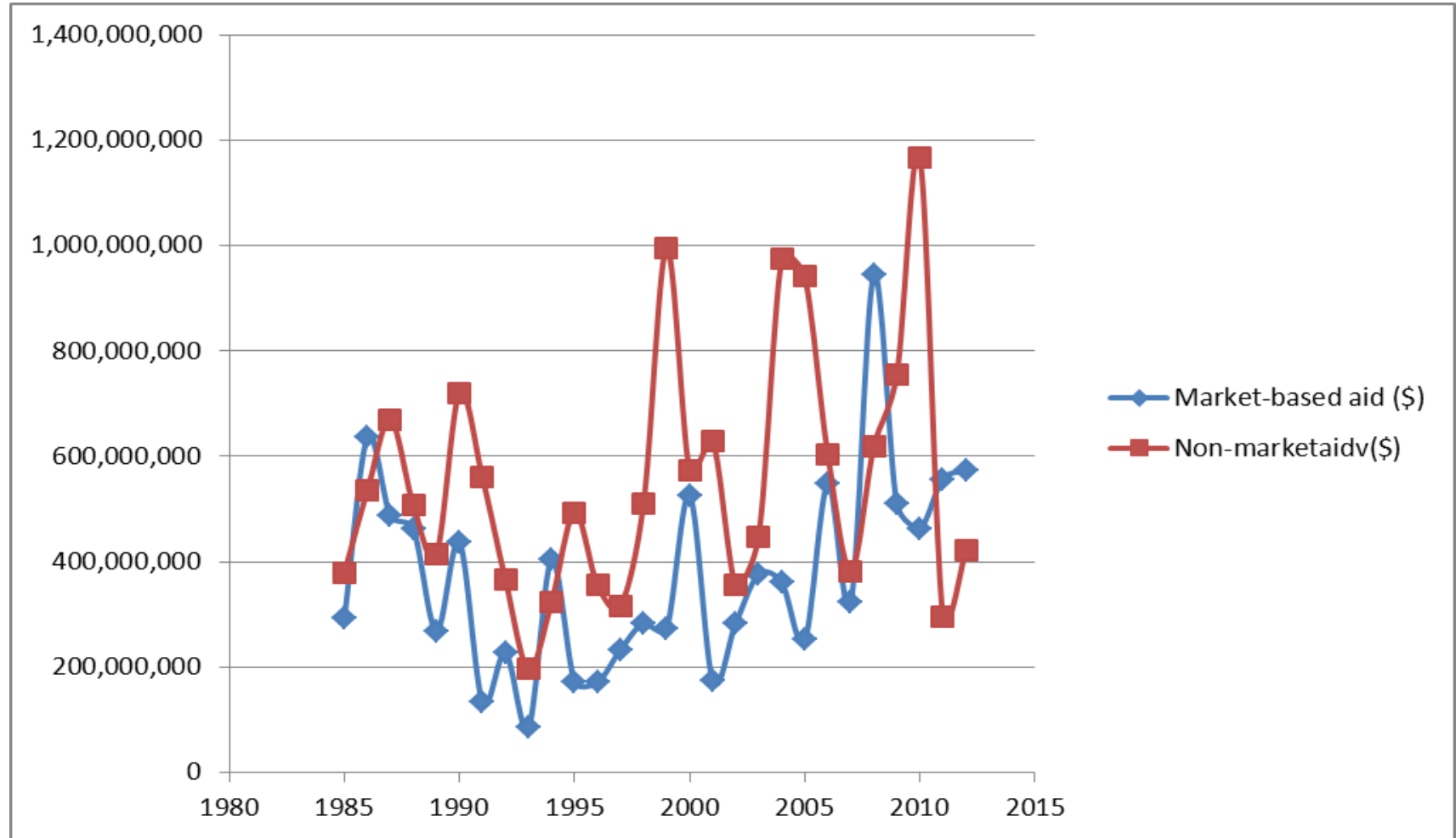

Source: Aiddata.org

Above is an illustration of the approximate market- and non-market based aid received by Senegal between 1985 and 2012. Donors have generally allotted more non-market aid to Senegal relative to market-based aid. For instance, in 1985, Senegal received approximately $\$ 400$ million 
for various sectors, including water and sanitation, transport, energy generation, tourism, agriculture, forestry and fishing, etc. In contrast, market-based aid toward government capacity development was approximately 291 million during the same year. This included aid toward education, healthcare, government capacity and civil society, general budget support, and trade policy and regulations, etc. In other contributing years, there were greater disparities between market-based aid and non-market aid with the greatest disparity being in 2010 .

That said, there is some agreement that aid has been effective in building Senegal's government capacity; however, such observations are only relative to other regional states. This is partly due to the notion that the capacity and infrastructures inherited from the French were better relative to other SSA states. This was due in part to Senegal's geographical positioning. Access to the Atlantic Ocean provided the French with strategic routes to Europe and its global markets, leading them to designate it as the capital of French West Africa. Thus, the French developed and supported institutions that comprised of trained and long-serving civil servants that helped the state to maintain and further capacity building efforts to better address their interests. This included investing in education and cultural exchanges with France, which allowed civil servants to incorporate new and traditional ideas when designing pragmatic policies. This led to one expert asserting that the government continues to make efforts to enhance its capacity so that it could employ appropriate policies that best caters to the needs and issues of Senegalese. This also involves working with citizens. Furthermore, what helped to make the system more effective and efficient is that the French practiced a somewhat indirect system of governance in Senegal whereby they incorporated and solidified an already existing social order (Mouride Brotherhood) while promoting assimilation, which encouraged the continued exchange of knowledge and cultures. A crucial part of this integrative strategy was 
geared toward minimizing the potential for social upheavals while optimizing efforts and resources to increase domestic productions for foreign trade (Bates, 2005; Meredith, 2011; Ross, 2008).

In order to accomplish that feat the French needed to gain favor from the Mouride Brotherhood, ${ }^{45}$ which has a stronghold on the predominantly large and devout Muslim population. For the French to enhance the effectiveness and efficiency of their domestic administration they needed to gain control of the religious leaders (Marabouts) who exerts not only spiritual but also political and economic influence over their disciplines. Therefore, a crucial part of this system was instituting a two pronged system of governance whereby Marabouts were employed as intermediaries between the state and communal systems that linked into the state economy through extensive networks. These expansive interconnected networks were geared toward cultivating greater peanut productions, which became the principal cash crop under the French administration. This relationship was mutually beneficial. The French provided Marabouts with materials (tools, fertilizers, land, educational materials, and government credits, etc.) who then exercised their religious influence over their disciples to organize them to boost production at the communal levels across the country thus increasing state revenues. Moreover, though gaining access to state controlled resources such as land and funding has contributed immensely to the growth of the Mouride Brotherhood and wealth of their leaders, the relationship between the state and the Mouride Brotherhood has historically been characterized by their inter-dependence due to the mutual benefits that emanates from frequent collaborations.

\footnotetext{
45 The Mouridic Islamic order is a large following of devout Muslims. Senegal currently is approximately 95\% Muslim.
} 
As suggested above, Marabouts have historically received financial incentives for their cooperation and collaboration. Part of the literature describes them as 'rational actors' because due to the incentive structure they were able to establish extensive production networks and controlled a growing market sector at the communal level (as a result of this control which they had over large segments of fertile land together with their authority over devout followers who are required to fully submit as part of their benediction to help ensure redemption). This also allowed them to quickly amass a lot of wealth over time. However, two country experts contradicted such notions by asserting that painting a picture of these individuals as wealth accumulators is made in absence of understanding the Senegalese culture, which is steeped in a tradition of giving. Prior to the French arriving, producers focused more on being self-sufficient. They produced enough to feed immediate families and for their next farm cycle. However, when excess is produced it was willingly given to Marabouts in exchange for personal blessings or for charity to others whose crops may have failed so they could feed their families. Moreover, it is also culturally appropriate for these leaders to use money acquired toward the upkeep and development of the community by supporting local needs. This includes helping to mitigate the effects of crop failures, droughts, provide microcredits, etc. Therefore, labeling them as wealth grabbers could be misguided ${ }^{46}$ (O’Brien, 1971; Wade, 1967; Barker, 1977; Diouf, 1992; Bates, 2005).

After independence, Leopold Senghor and other leaders that followed have maintained a system whereby they looked to France for support and guidance to address domestic matters.

\footnotetext{
${ }^{46}$ While Marabouts have accumulated wealth thus making them powerful figures- politically and economically, they have traditionally provided a lot of assistance to communities, especially to those less fortunate, in need or to provide services- schools, financial assistance during ceremonial events such as baptism and funerals; feeding the needy, etc.
} 
This has contributed to Senegal's failure to further enhance its capacity because they have generally tried to reinforce colonial strategies and the structure it helped to fortify whereby the state relied heavily on Marabouts (and regional Councils) to help enhance capacity and implement national policies at the local level. Therefore, the institutional framework for the market economy has not change much over the years. This could be attributed to Senegal's continued strong relationship with France in addition to the support politicians need from Marabouts to gain access to political office. ${ }^{47}$ This relationship continues to play a pivotal role in the maintenance of not only public administration but also developing good public administrators through educational exchanges. For instance, the country experts agreed that apart from promising to maintain the Mouride economic system, Senghor contributed immensely to the development and maintenance of a well-trained administration with the assistance of aid by investing in key legislations to develop primary, secondary, technical, and professional training institutions and universities that were geared toward training future leaders. ${ }^{48}$ The tradition of academics and technical training still exists today and continues to contribute to the development of qualified public administrators. Moreover, many Senegalese are also encouraged to pursue educational exchange to France and the West to further their education and professional training, which finds traditional grounding under colonialism. This has greatly contributed to Senegal's government being comprised of highly qualified and skilled public administrators.

The ability and professionalism of the Senegalese is evident in the capacity they exercised in spearheading the development and implementation of the New Partnership for

\footnotetext{
47 Mamadou Dia, the first premier under the Senghor administration tried to break free from this system by indicating that religious leaders should not be involved in politics. Rather they should focus on providing spiritual guidance.

${ }^{48}$ Senegal is credited with being the first state in francophone Africa to establish a university catering to the training of African leaders - Cheihk Anta Diop University, founded in 1957.
} 
Africa's Development initiative (NEPAD), which has now been implemented by all member states of the African Union (AU) as of 2001 as part of the region's economic growth strategy. This initiative is a broad policy framework geared toward accelerating economic co-operation and regional integration by targeting 8 key areas: political, economic and cooperate governance; agriculture; infrastructure; education; health; science and technology; market access and tourism, and environment. In parts, this likely contributed to some regional growth. According to a recent World Bank report, the composite SSA economy saw some economic growth between 2001 and 2015 with minimum growth (2.8\%) coming in 2008 during the global economic decline while it peaked in 2004 (11.5\%). ${ }^{49}$ In contrast, Senegal's economy declined in 2002 (0.6 \%) due to severe drought and heavy rains in parts of the country which decreased production in the peanut sector (and agricultural as a whole). However, the economy showed some resilience since it grew between 1.8\% and 6.6\% during 2003 and 2015. Per capita growth also increased between 2001 and 2015 from $\$ 482$ and $\$ 1094^{50}$ (World Bank, 2016).

Another economic strategy that brought some optimism in Senegal was the launching of the Western supported Plan Senegal Emergent (PSE) under the Macky Sall administration, according to one expert with insight on the initiative. The PSE strategy was articulated around three key pillars: (i) generating higher and sustainable economic growth and development by attracting FDI, enhancing export capacity and providing opportunities for the growth of SMEs, in turn, creating more jobs and deepening the private sector; (ii) catering to human development

\footnotetext{
${ }^{49}$ Prior to 2001, SSA's highest growth came in 1970 at $9.8 \%$ followed by economic declines in $1983(-1.45 \%)$ and 1992(-1.42).

${ }^{50}$ Compared to its neighbors, Senegal is still doing more favorably. For instance, according to World Bank reports, The Gambia per capita in \$442 in 2002441 in 2015; Guinea-Bissau’s per capita in 2002 stood at around \$303 and $\$ 573$ in 2015. The only aligning neighbor that had a greater per capita rate was Mauritania, which had a per capita of \$459 in 2002 and \$1,371 in 2015.
} 
and social protection; and (iii) emphasizing good governance, peace and security. Also central to the PSE framework is the promotion of fiscal consolidation, limiting public consumption, and increasing public savings as part of the long-term plan to help generate sufficient capital for higher public investments in areas such as human development, market infrastructures and economic reforms in order to attract more FDI. However, this policy is still in its infancy stages thus making it difficult to analyze. But, there is optimism that in the long-term this policy will prove beneficial to economic growth and development, because it aims to promote decentralization and strengthen the economy through private sector diversification. Since the implementation of this policy, there has been some growth in the non-traditional sectors such as information and communication, construction, and the assembly industry (household appliance, computers and vehicles), which has had some effects on the domestic market (PSE policy, World Bank report, 2014).

Though Senegal has experienced some growth in government capacity, the country experts indicated that failure to translate said capacity to economic growth and development does not rest primarily on aid allotments and the government's ability to design and institute pragmatic policies. Instead, sufficient emphasis has to be placed on role of cultural norms, beliefs and dynamics. Specifically, the Mouride Brotherhood has contributed to there being a wedge between the government, economy, and society. This is more evident when political leaders fall out of favor with the Marabouts. For instance, it generally difficult for policymakers to formulate, pass and enforce key policies without the support and guidance of the powerful Mouride Brotherhood who could easily mobilize their disciplines and push back against the state, resulting in wastage. Therefore, in such cases the extent of aid allocations and the government's capacity to carefully craft appropriate policies do not necessarily matter. One expert who 
conducts research on the effectiveness of Senegal's bureaucracy argued that while the Senegalese government has historically had sufficient capacity to design and implement its own policies, officials are often not able to fully exert their expertise in policies. Therefore, aid has not been good for enhancing capacity. First, aid contributions generally came with too many strings attached that inhibited the freedom policymakers has in contributing to the design and implementation of policies that addresses current issues. Instead, policymakers are generally instructed by donors on what to do and not do. Therefore, the ability of officials to act is often insulated though they may have pragmatic contributions or ideas. Moreover, in some cases officials with expert knowledge are not consulted adequately or their ideas are masked leading to policies that are implemented by the state has little or no relationship with the issues they are supposed to address.

Also, as previously mentioned, there is an element of religion and politics that helps to determine the level of policy and implementation effectiveness. According to one expert, one of the early leaders, Mamadou Dia, foresaw this problem after independence and tried to separate the state from religion, but the movement was unsuccessful because Islam had already become too imbedded in politics, policymaking, and implementation during the colonial era. In the postindependence era, politics and Islam continues to co-exist and is difficult to disengage from each other, because politicians are in fear of the political ramifications such a move would have considering the support they need from religious leaders and the influence those religious leaders wield within society. Furthermore, while aid is given to the state government to further enhance its capacity, they have to also channel some of that money and resources to the Marabouts (or the Rural Councils ${ }^{51}$ ) for their compliance at the communal level in term of endorsing national 
policies. This has traditionally been the way in which they operated. This is also essential considering that the people are more apt to look toward their religious leaders for their spiritual, economic and political guidance - and not politicians. However, since Senegalese are traditionally charitable they generally prefer to use any resources they may have gathered to benefit to community or others in times of need, because the expectation is that such behavior helps them to build or enhance social capital which could be converted to cash capital or service in the future. For instance, the experts agreed Marabouts generally use funds they may have acquired from the state for particular projects and redistribution around their communities. Considering the high poverty and unemployment rates, this may mean funding food and healthcare to those in need; build schools that would benefit the community; provide aid to disciples experiencing unfortunate life events such as deaths in the family, loss of their homes and livelihoods as a result of droughts, floods, fire, etc. Furthermore, microcredits are also allotted to those that may want to contribute to the economy by starting micro- and small business enterprises (Barker, 1977; Ross, 2008).

Additionally, one expert who specializes in faith based communal economic development suggested that an important factor that has also contributed to Senegal's current capacity standing rests on the positions of the different administrations and Marabouts toward foreign aid over the years. The four post-colonial administrations have had different policies toward foreign aid. Leopold Senghor's administration generally showed reluctance toward accepting foreign aid. This is partly because of his firm African Socialism ideology which emphasized self-sufficiency. Therefore, while he looked to France for guidance and training of public administrators he held

\footnotetext{
51 The Marabouts and Rural Councils are generally one and the same. The councils are comprised of democratically elected individuals, but because of the demographics they are likely of be made of devout Muslims that are influenced or led by Marabouts.
} 
strong reservations about the harmful effects of aid. Thus, there were more regulations implemented to control aid intake; otherwise, it would have gradually led overdependence on aid. However, due to external pressures and a failing economy due to the in-ward oriented growth strategies employed under the Senghor administration, the Diouf administration employed reforms that opened the economy. But while Senegal is still dependent on aid to conduct some key functions, there have been some efforts and progress made under the Wade and Sall Administrations to mitigate this by designing and implementing policies geared toward increasing productivity and attracting FDIs to help catalyze economic growth and development. This is reflected in the gradually decreasing percentages of aid received relative to GNI over the years, especially over the past decade or so. ${ }^{52}$

As previously indicated, the state relies on the Marabouts for guidance and help implementing its policies at the local level. The state facilitates this process through aid allotments. One expert indicated that generally Marabouts carefully analyze key policies delegated to them before deciding whether or not they should participate in the implementation process or endorse them for disciples to adhere to. When policies are opposed, aid funds accompanying the policies are likely to be declined too. This is usually when the aid has too many stringent conditions that they believe may hinder their communal standing or conflict with what they consider to be more pertinent goals and objectives for their communities; meaning, they put communal goals and objectives above the state's. So, as much as the community may need the aid, they are likely to reject it out of fear that it may have many short- and/or long-term

\footnotetext{
${ }^{52}$ According to World Bank data, in 1960 aid made up close to 32 percent of Senegal's GNI, which increased to 37 percent in 1961. However, since then as the economy grew the level of dependency decreased. Between 2000 and 2015, aid has made up between 15 percent and 23 percent of GNI.
} 
consequences to those in a particular community - and may use their own financial capital to fund communal projects that better align with their expectation.

That said, to maintain certain status quos the Mouride Brotherhood may initiate what Manranz (2011) calls 'leveling mechanisms' or ‘social leveling', according one of my experts. This is a way in which society controls the advancement of individuals, especially if it is at the detriment of the group. This practice is certainly not meant to target individuals or irrationally prohibit the development of communities. Rather, Marabouts use their influence to ensure that communities conform to certain traditional values and practices they believe may be threatened by certain national policies they consider to have adverse effects and may drive individuals to embrace more individualistic values. In doing so, they may void themselves of new and innovative ideas to mitigate potential social unrests amongst community members that may come about due to members deviating from long standing cultural values, which may generate relative comparativism. Therefore, 'leveling' against certain state initiatives mitigates potential harms before they have an opportunity to take root; however, this may negatively affect progress and the ability to further enhance capacity by virtue of the state being stripped of the opportunity to learn from advancing certain agendas. In contrast, Marabouts preserve cultural elements they value dutifully. This practice is important for Marabouts, because they want to manage their communities and be able to more directly handle local issues and concerns - whether it is in regards to infrastructures, energy, and resource allocation, etc. Thus, they play vital roles in controlling local conditions and levels of vitality since they have some level of autonomy. However, according to a country expert, one of the key weaknesses at the communal level is that when Marabouts do comply with state initiatives they often lack adequate skills for planning, implementing, following up on state initiatives and maintaining the policies and infrastructures 
to help fuel further capacity building. Another contributing factor is there is often a divide between the tasks delegated by the state and the aid given. In other words, there are disparities between the size and complexities of projects delegated to communal leaders to implement or oversee relative to the aid allotted. This may not affect the ability of the state to design policies but certainly its ability to enforce them.

Moreover, though the state government still technically has strategic control over the peanut economy, they have been losing grip due to external pressures to privatize and decentralize. As previously noted, the Senegalese economy has been highly dependent on the peanut economy through the massive taxes acquired from trade, which has historically provided revenues to help craft its policies, execute key functions, and further capacity building efforts. However, decentralization and privatization has had some adverse effects because it has contributed to the growth of the informal sector due to the state's continued efforts to disburse aid to local communities as well as craft economic policies aimed at furthering development. For instance, three pertinent policies that were viewed as engines for economic growth and development were the Western supported Return to Agriculture Project, The Accelerated Growth Strategy, and the National Strategy for Rural Transport, which were implemented to accelerate economic growth and development by enhancing agricultural production through training workshops and developing infrastructures to improve mobility and access in and around rural areas so producers could get produce to market. However, while the government has committed to developing and implementing pragmatic policy reforms such as the aforementioned, which accounts for the local contexts, country experts and the literature indicates that the government's policy range is often constrained by several key factors, including failure to address: (i) gender inclusiveness; (ii) lack of economic diversity; and (iii) the growing informal sector. However, an 
argument can be made that failure to reform does not appear to be such a critical issue. Rather, it is a failure to pragmatically execute policies due to lack of infrastructures, which stems from the colonial era wherein the state maintained a stronghold mainly in key urban areas. Though the state has made efforts to invest in capacity building measures across rural areas, they have experienced push backs from the Mouride Brotherhood which has more control across rural areas and aim to preserve certain cultural norms and values (World Bank report, 2014).

Additionally, external pressures have affected Senegal's capacity building efforts. According to two country experts, SAPs have been catastrophic, because in trying to solve some of the existing problems, they created many others. Stringent rules associated with SAPs forced many career civil servants to leave civil service for the private sector, which has had a negative effect on capacity building since valuable expertise is being lost. Moreover, officials are not able to fully contribute to policy reforms that address the issues at hand due to in part to the autonomy the Mouride Brotherhood has in brokering deals within the political institutions by converting their economic, political and social leverage into political leverage. Additionally, pressures to privatize, deregulate and liberalize have contributed to the growth of the informal sector and hindered capacity as the wedge between the government and market became greater. Yet, the government continues to channel aid toward reforms that also provide protections of entrepreneurs in exchange for votes. This aid for votes, per se, got out of hand and helped to facilitate the informal sector.

According to country experts, formal enterprises seem to be on the decline relative to informal enterprises because they are constantly being harassed by the government to pay higher taxes and compliance fees to compensate for declining tax revenues. Many formal enterprises 
generally exist in urban areas. However, many of those enterprises gradually became informal to try and evade burdensome taxes even though they may receive some government subsidies, credit, or training intended to help boost productivity. As the formal sector declines, it also reduces government revenues which may have been used to fund meaningful policies that supports the private sector since some or all aspects of the informal sector is not captured by the state. This has had implications on domestic capacity building since it undermines fiscal growth, and has led to tensions between the formal and informal sectors causing one sector to continue growing while the other decreases. Therefore, it is imperative that the state develops and commit to regulations that minimizes the informal sector; otherwise, it will continue to be a hindrance to capacity building efforts.

However, one expert did not express optimism in the state's ability to implement appropriate regulations to address the growing informal sector any time soon. He argued that while Senegal has made some progress in securing macroeconomic stability through reforms, there are often delays in implementing needed reforms, which has contributed to lower than expected annual growth rates. Part of the problem stems from there being a wedge between rhetoric and practice when it comes to policy administration. Similarly, another expert who worked as a development consultant in Senegal suggested that central to this problem is the political culture of the aid donors. They strategically choose who and what to support based on their own political interests. Thus, donors are not neutral actors. And though they have highly competent individuals tasked with analyzing domestic situations, many often speak with individuals like themselves - western educated bureaucrats in Senegal - that may have a biased understanding of the domestic realities or interests of the masses. Therefore, Senegalese 
bureaucrats often mirror what they think donors want or expect in order to maximize the amount of aid they receive.

The aforementioned along with cultural norms have contributed to the growing mismanagement of aid, which donors often deem as corruption. However, one expert asserted that this is a misconception due to the cultural norms of Senegal. Senegal is steeped in a culture of sharing whereby individuals are taught from a young age to share. This is viewed as a good vehicle for building and maintaining social capital. This same logic applies to aid, because Senegalese do not think the same way as others since they generally put more value on social capital relative to cash capital. This, according to one expert, is at the core of the misconception of there being a rise in corruption, because Senegalese do not see the practice of sharing as corrupt even though the aid may have been allocated to the state to serve particular purposes. Thus, while donors interpret this practice as a breakdown in the system, they fail to realize it is in actuality the system. However, when aid is misappropriated and used toward consumption rather than capacity building efforts, it has a negative effect on the ability of policymakers when it comes to designing and implementing appropriate policies. However, another expert disagrees by asserting that actual corruption does exist and continues to be an issue, especially at the state level. However, the extent of corruption often leads to some social leveling wherein Marabouts use their far reaching influence and associations to try and offset corruption or how aid is used, which also helps to maintain social order. This, in turn, affects how much aid is consumed appropriately at the state and communal levels for capacity building. In other words, Mauride Brotherhood operates as a checks and balance system, because it helps to keep the government accountable and being able to mobilize their disciplines to push back certain state policies that they do not favor. 
Some of the progress made to mitigate corruption is often reflected in The Transparency International index. For instance, Transparency International ranked Senegal at 61 out of 168 states in its 2015 corruption perception index, which is an improvement on the 112/182 in 2011. To put things into perspective the World Bank’s World Governance Indicators ranked Senegal as worse than average for lower or upper middle income SSA states. One of the strategies employed to mitigate corruption was The National Action Plan against Corruption, which is part of its Good Governance program. This plan centers on enabling non-state actors to help monitor and implement public policies and ensure transparency. However, this has led to some criticisms because corruption remains an issue (Arrief, 2013, National Action Plan).

\section{4: The relationship between market-based aid, culture and economic freedom.}

Figure 6.3: Illustration of aid types for economic freedom between 1985 and 2012.

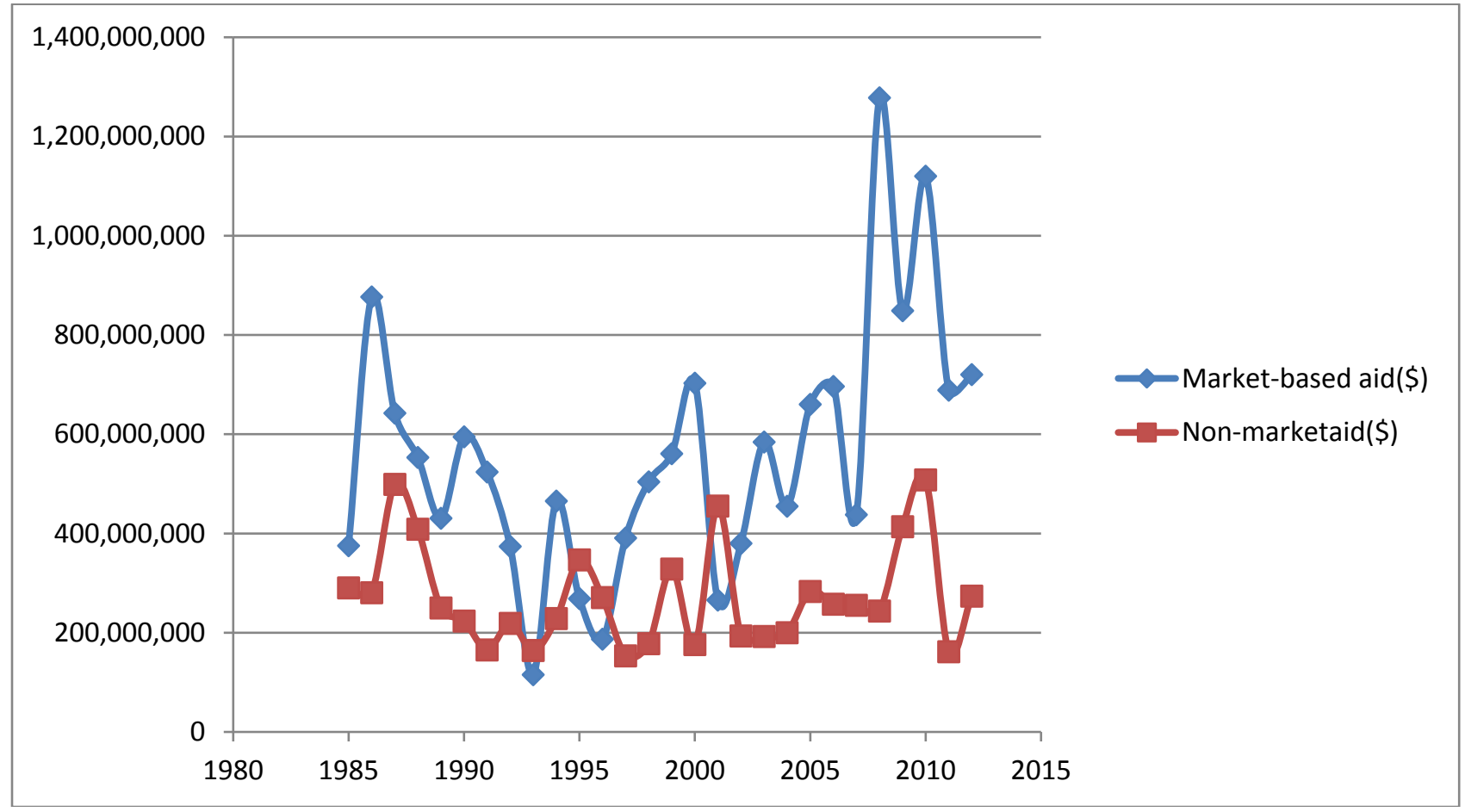

Source: Aiddata.org 
Above is a comparative illustration of aid types allotted to Senegal between 1985 and 2012. This illustration is very telling considering the disparity between market-based aid and non-market aid. Donors have allotted more market-based aid relative to non-market aid. There appears to be a trend in that when market-based aid increased or decreased there is an opposite reaction with non-market aid. Economic freedom is presently considered to be "mostly unfree", according to the Index of Economic Freedom. Thus, an argument could be made that further investments in sectors such as banking and financial services, business and other services, energy generation and supply, trade policy and regulation, government and civil society, etc., are necessary to develop and implement reforms that fosters economic freedoms. Though social capital seems to be crucial for conducting business in Senegal, advancing policies that legally protect the rights of consumers and producers are important since the strength of economic freedom by way of social capital are subjected to the strength of the bond one has with each other within the community. Generally, the parameters of those relationships are stronger at localized levels. Therefore, establishing a legal infrastructure that allows people to expand the parameters for which they are willing to conduct business if they are confident that a macro-level system would provide a similar security as social capital.

Dambisa Moyo (2009:58) argued "social capital, by which is meant the invisible glue of relationships that holds business, economy and political life together, is at the core of any country's development.” This sentiment resonates in Senegal in that social capital ${ }^{53}$ is a quite

\footnotetext{
${ }^{53}$ For the purpose of this study, social capital is defined as networks, associations and/or relations established and maintained to bond individuals together based on shared norms, values, and belief systems which, in turn, foster a stable and peaceful order.
} 
effective social policing mechanism that provides protections for those participating in the market and social contracts, according to all experts. This can be traced to deeply embedded cultural traditions, religious influences, historical experiences and the fact that Senegalese families are generally large. Strong sense of family and solidarity has expanded into daily life and society and continues to be enforced by social capital that helps to determine the roles, rules, and procedures that individuals must adhere to based on existing cultural norms, values, attitudes, beliefs and general dispositions. Considering the role such cultural attributes play in promoting solidarity and reciprocity that transcends generational lines, social capital is crucial for ensuring social contracts at the communal levels; however, this also seem to have some negative effect on economic growth and development as many use social capital to live on credit, which they may exchange for services if they cannot afford to repay personal debts.

That said, there are some agreements and disagreements amongst the country experts regarding whether or not aid has worked in harmony with existing cultural attributes to foster economic freedom in Senegal. One expert asserted that aid has played an important role in supporting access to microcredits and necessary protections for entrepreneurs to start small enterprises due to the legal frameworks that were established and maintained to support entrepreneurial activities. This was driven by SAPs during the 1980s and 90s. Another country expert supports the aforementioned notion by suggesting that a large quantity of aid has been channeled to Senegal under the guise of promoting economic freedom though they were already in the process of reforming due to the growing informal sector. This coincides with a general agreement amongst the country experts that the state has done a lot to deregulate, liberalize, and privatize its policies in light of SAPs while providing market participants with necessary protections to willingly participate in transactions. However, one expert argued that policies 
aimed at promoting economic freedom have had disastrous consequences in places like Senegal. This, according to another expert, is because economic freedom does not work the same way we all think since we cannot predict human behavior. In other words, there is too much going on to deductively reason.

The role cultural norms and beliefs play in the aid-economic freedom relationship must be addressed. For instance, the sharing mentality that exists in Senegal contributes to the growing informal sector wherein some aid is misappropriated. In 2010, the informal sector constituted approximately 90 percent of employment, 40 percent of national production, and 58 percent of the non-agricultural added-value. As expected, income levels within the informal sector are generally more volatile relative to the formal sector because the risks are higher and uninsured. Moreover, the growing informal sector continues to rob the country of much needed revenue; yet the political and religious relationships over the years seem to further this divide rather than address it (ANSD, 2013; IMF, 2014).

Enterprises existing within the formal sector are generally granted more protections through the legal system, while the state continues to provide access to micro-financing to help develop new enterprises. However, the country experts indicated that while aid has been disbursed toward privatization, deregulation, micro-financing and implementing legal structures to protect the rights of traders and costumers, the informal sector continues to be dominant and is largely dependent on social capital, which has culturally been accepted as the chief mechanism for contract enforcement between customers and traders. In contrast, many, especially in rural areas rely less on government for contract enforcements. The Senegalese culture emphasizes trust, social norms and networks when conducting business on a daily basis. Those factors, 
according to the experts, play a pivotal role during market transactions, because trust levels are high relative to other states and social networks play an important role in most economic transactions.

While many (mainly men) have been able to start micro- and small enterprises, such as boutiques, bakeries, auto repairs, construction and services, etc., which are open on a daily basis to feed demands, the economy has continually struggled to advance. This is, in part, because Senegalese have grown accustomed to living day-to-day because it is difficult to plan for the future or make sufficient money to either expand or fund new ventures as a result of the poor living conditions that have existed over the years for a large segment of the population. Moreover, another constraint is that access to electricity along with frequent power outages and poor infrastructures has made it difficult for traders to effectively maximize their economic freedom, according to two country experts. Yet, though life seems to be somewhat difficult for many, especially those in rural areas, they are nonetheless able to meet the needs of their families on a daily basis and generally embrace a very positive and optimistic outlook on life. This is because a key part of the Senegalese culture rests on solidarity - in good times and bad whereby emphasis is oriented toward family, community, and charity. This is a notion that the country experts emphasized whereby solidarity, which breeds trust and reciprocity, helps to establish and maintain social capital and could be exchanged for cash capital when needed. In other words, it is customary for the people to look out for each other to help ensure survival rather than trying to maximize personal gains. Thus, since they understand that life is difficult, they feel the need to exercise some aspects of both comradery and charity, which brings them closer together as a community. This practice transcends over the years whereby people earn trust based on their personal contributions to others and their communities as well as what their 
family legacies have accumulated. The greater the trust and solidarity amongst individuals the lesser the transaction costs of conducting business - and the greater the protections they are given. Greater levels of trust generally translate to willingness to conduct business with each other without questioning the motivations of individuals entering into the social contract. Moreover, customers and traders often purchase and trade with particular vendors based on the strength of their relationships and not necessarily on the quality of the goods and services vendors provide. The strength of this relationship also greatly influences the prices of the goods and services or one's bargaining powers, which has a direct effect on profit margins. In other words, one's social capital may help them determine the contracts they enter into or their ability to influence the rules guiding the contract.

There was a general agreement amongst country experts that elevated trust levels amongst Senegalese is due to their cultural beliefs in reciprocity, which has been very prevalent throughout Senegal's history. Individuals needing assistance of any sort - whether it be financial, materiel or some form of service, it is generally provided by someone within the immediate family or communal circles but then they become indebted to the person providing assistance. And it is this notion of indebtedness that helps to facilitate one's freedom to conduct business. When someone cannot repay his or her debt in a timely manner, that individual may negotiate another way to repay - oftentimes by providing a service or discreetly seeking help from family or other community members to assist in paying off their debts. Thus, social capital has been able to cultivate trust, reciprocity and solidarity amongst Senegalese, which has become central for conducting trade and initiating micro- and small enterprises. Crucially important is the fact that the strength of social capital also translates to the amount of interest borrowers may be tasked with repaying; however, oftentimes interests are not included. There are fewer 
opportunities for those with weak social ties; meaning, they generally lose resources quite easily since it prevents those individuals from entering into social groups or accessing the resources certain groups may have or provide to its members. Thus, one's economic freedom hinges more on their "radius of trust" rather than the state's ability to implement policies geared toward securing their rights in the marketplace, according to country experts.

That said, however, aid toward economic freedom in Senegal may have had both positive and negative effects. Social capital in Senegal emphasizes "interdependence rather than independence, according to one expert. It also means living in a community rather than living in social or spacial isolation, according to Manranz (2001). This reflects the daily mindsets of Senegalese in that solidarity forms the core of their identity, and repeat interactions and shared networks is at the root of social policing. On the other hand, those cultural norms tend to place little emphasis on maximizing personal gains, which could be reinvested. Since there is a strong sense of family, unity and charity, the expectation is that whenever someone wants something then someone within your family or community would have it or have access to it. Therefore, these groups are able to rely on each other through the social capital that they have developed over time. For instance, in many cases since the immediate families are big (in addition to community members), various members may own different things that each may need. Therefore, social capital enables them to share and help each other enforce contracts initially agreed upon through close ties (Manranz, 2011).

In many regards, due to the informal nature of the market sector, relationships are counted on to help each other succeed or exist, which Manranz (2001) suggests that in Senegal's culture "success in life is attained through personal relationships, through connections with 
people in positions of power and authority, and through spiritual means.” That said, there are many reasons why social capital is pertinent and not necessarily aid investments in promoting economic freedom. It helps to improve one's economic opportunities, foster access to the market, and mitigate instability and other social and economic issues. In contrast, if people fail to cultivate social capital the outcomes generally comes with consequences, such as less access to opportunities and resources.

\section{Social capital and economic freedom in Senegal}

Economic freedom in Senegal is fostered by the effects of social capital which, in turn, has had various effects on the domestic economy. At the individual level, one's social capital greatly influences their purchasing power, potential economic success and with whom and how they conduct business on a daily basis. Additionally, there are also social groups, which may form along gender, religious, or communal groups that rely heavily on each other as a means to secure and maintain their livelihoods. Moreover, customary laws which are generally enforced by religious leaders also play a pivotal role in the freedoms individual have in participating in the markets - whether it is in regards to property rights or protection of their investments.

If a community member is in need of something, they generally begin inquiry with family and friends. If they are not able to get the assistance they need, they may be directed to someone else based on their "radius of trust." Due to the social capital established and maintained from generation to generation, when one enters into a contract with others the close relationships of not only the two individuals involved in the transactions but also the other members that are connected to their inner circle helps to ensure contracts are secured. In times when one is not able to guarantee the terms of the contract, family members and friends will likely help pay the 
cost to fulfill the terms set in the contract. The costs paid are relayed to the person who was not able to maintain their end of the contract, resulting in that person becoming indebted to their family and/or friends instead (or whoever paid off the debt). This form of social structure allows individuals to more seamlessly participate in the market, because there is generally little or no tax paid to maintain contracts within their inner circles, ${ }^{54}$ according to one expert. In some regards there is a free-market or free trade practice since participants simply pay the value of the goods and services for which they owe. This relationship is mutual since many rely on social capital to help participate in the market and contribute to the economy rather than rely on the state. In turn, social capital helps to secure business opportunities and maintain social bonds within community members. That said, for market participants to work effectively it is imperative that they exercise trust. Being a part of common social groups help to ensure this trust and one's rights are fought for by the group. In cases where someone is new to the community, they are tasked with testing the level of trust they have from community members by asking favors - such as financial assistance or a service. If it is received, then it initiates trust and reciprocity, because it makes recipients feel indebted which begins a cycle.

That said, social networks and the depth of trust allow individuals to navigate the marketplace and also secure protection or insurance in the informal sectors. Transactions are frequent but they do not all involve monetary exchanges. Rather, goods and services are often taken on credit. But every transaction is said to make the relationships between the parties involved stronger. Many traders or owners of SMEs are able to maintain their existence because of these relationships, which generally provide network resources which, in turn, help them achieve their common goals. It is this cultural emphasis on trust and reciprocity that appears to

\footnotetext{
${ }^{54}$ In instances where there is interest, it is much lower than what one would pay to the formal banking institutions.
} 
limit economic growth, however. According to three country experts, this is partly because while close relationships foster one's ability to rely on others to assist them during times of needs, the cycle of borrowing often leaves many indebted to each other. The same logic applies when trying to establish businesses wherein one's social capital may provide the necessary links with others based on trust, which could allow one individual to extend credit, goods, service or recommendations of suppliers or buyers to another (Easterly, 2006; Fukuyama, 2001).

Though social capital play an important role in the domestic economy and economic freedom, it must be stated that not all citizens are economically free, per se. Customary and Islamic laws are still proving to be a barrier to women's participation in the domestic economy. The Senegalese Constitution was amended in 2001 to reaffirm the need for gender equality and prohibits all forms of gender discrimination. However, the legal framework has had problems penetrating customary and Islamic customs and practices which support the idea that a woman's place is in the home as wives, mothers and caregivers. This has been exerted historically in that it has proven difficult for women to inherit property directly, especially land, which forms a central part of the economy since a large portion of the economy is based on agriculture. The general failure of women owning land titles and other properties and resources limits their ability to fairly contribute in the market with equal protection as their male counterparts. This is furthered by the fact that though microcredits through formal institutions have been increasing in recent years, opportunities for women to secure it remain relatively low. This is because they generally do not have sufficient collateral and interest rates are rather high. For instance, it is not uncommon for banks to charge $15 \%$ or higher interest on short-term (6 months) small loans (\$50 - \$200), which is rather high for those in rural settings. According to one expert, high interest rates is causing more harm to one's economic freedom because ambitious entrepreneurs are 
limited if they cannot repay, and they are put out of business or they put themselves further into debt by taking further loans to repay loans. Therefore, entrepreneurs, especially women, are at a great disadvantage because they often find it difficult to obtain sufficient credit to finance SMEs, even if they have good social capital. Since they generally do not generate adequate income to repay debts, banks are often reluctant to provide them with loans. Some may resort to borrowing from families and friends, but it is generally minor relative to what formal banks could offer and it takes time to mobilize. This, in turn, has a direct effect on productivity and sustainable economic growth.

\section{5: Examining the role of culture, market-based aid and private sector investment.}

As expected, the country experts both agreed and disagreed that aid contributions helped to foster private sector growth. They suggested that it may have helped in terms of putting in place legal and policy infrastructures as well as provided capital to help encourage both foreign and domestic entrepreneurs and innovators to engage in the private sector. Together, this may have helped to initiate micro-level enterprises, which could be turned into small enterprises and then medium level enterprises and so forth, if managed properly. This could be seen in the recent rise in non-traditional sectors such as construction, telecommunication, technology, assembly and processing - many of which are led by local entrepreneurs. Additionally, Chinese entrepreneurs have steadily increased their presence, especially in Dakar, because they have recognized the potential for financial gains. Moreover, many Western companies and embassies are now located in Senegal, especially those formerly in Cameroon and Ivory Coast, and they have been working with the state and private sector to help open the economy to global markets while trying to secure the rights of the entrepreneurs and innovators. However, there still seems 
to be issues with corruption - both within the formal and informal sectors since entrepreneurs are often harassed to pay exorbitant taxes and compliance fees, or risk political repercussions. For instance, country experts indicated that the government still has a strong hand in the peanut market and is constantly being pressured by the West to privatize, parastatal agencies are tasked with granting entrepreneurs/private owners licenses to operate; however, the issuance of those licenses are given on preferential grounds and could be revoked if they fail to comply with advances made by the state and donors. Such practices have become customary. Yet, the private sector continues to add some depth due to increasing capital injections from the state. ${ }^{55}$

Figure 6.4: Illustration of aid types for private sector investment between 1985 and 2012.

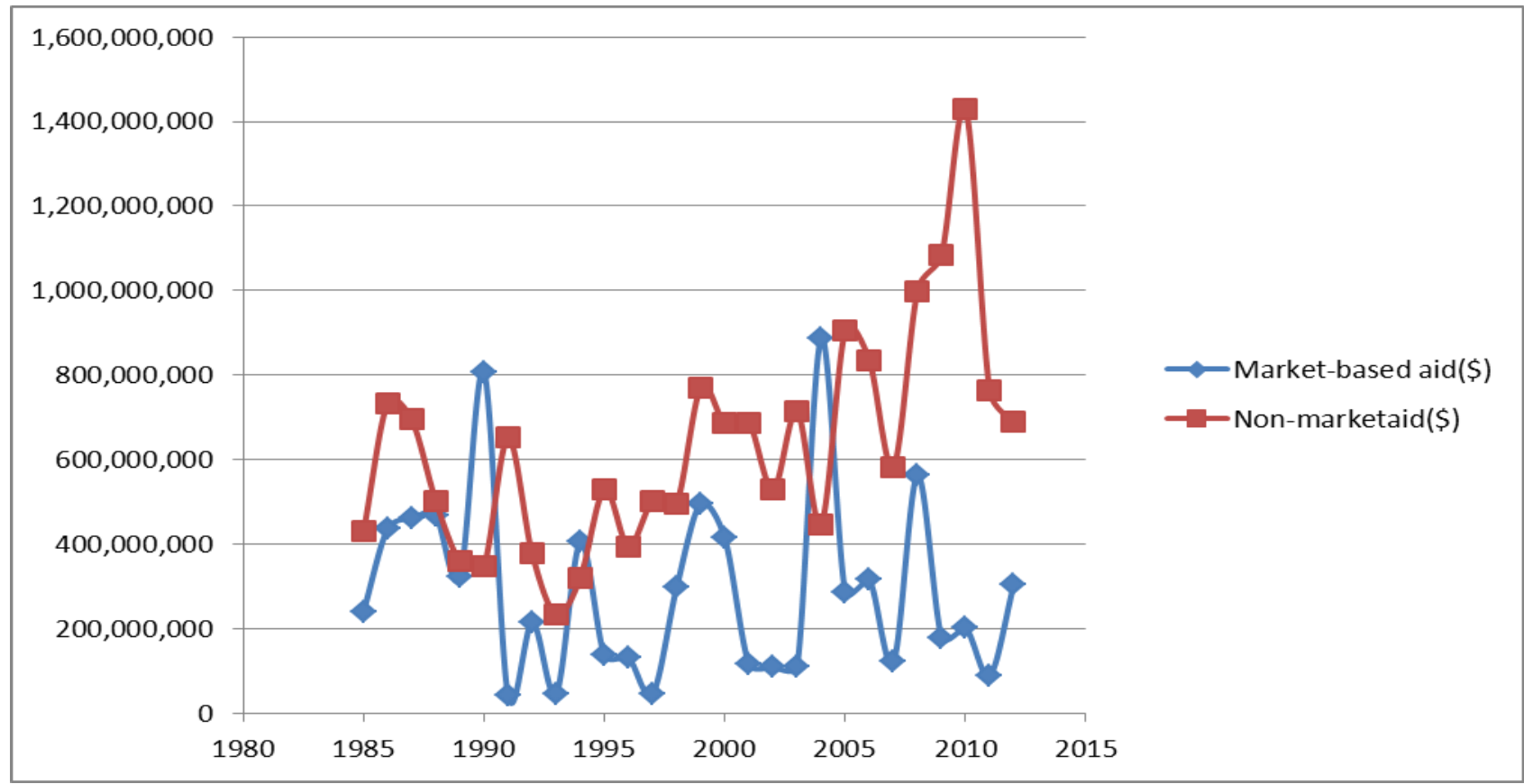

Source: Aiddata.org

55 According to World Bank estimates, in 1960 the state government allocated 15 percent of its GDP toward the private sector. The government allocated the great percentage of its GDP to the private section 21 years later - 37.5 percent. But this followed by a steady decline until 1995 (14.7 percent) followed by a steady increase. As of 2105, estimates show that the government invested 34 percent of its GDP toward the private sector. 
The aforementioned illustrates the allotments of aid types to Senegal between 1985 and 2012. Though stable, Senegal's economy consistently fails to meet growth expectations for various reasons, because of a growing informal sector and a lack of appropriate policies catering to economic diversity. Aid contributions for private sector - government and civil society, banking and financial services, and general budget support, which are crucial for developing and enforcing policies that furthers the private sector appears to be menial relative to the non-market aid. Specifically, in 1985 market-based aid was approximately \$240 million relative to approximately \$430 million in non-market aid. In contrast, by 2012, market-based aid was approximately \$300 million while non-market aid accounted for approximately \$700 million. An argument could be made that this aid disparity could help explain why Senegal's private sector has failed to meet expectations.

However, in order to better understand the relationship between aid and private sector growth some emphasis must also be placed on the cultural and historical contributions as well. Starting around the 1970s, Western aid agencies such as the WB, IMF and USAID, etc., began putting a lot of pressure on the state government to undergo massive economic reforms. The urgency was primarily fueled by the collapse of Senegal's economy and its vulnerability due to droughts, lack of economic diversity, the oil boom as well as state of the global economy at the time, which contributed to a decline in peanut prices. Those factors placed an enormous amount of pressure on the state government to turn to Western aid agencies for assistance. However, aid was appropriated with vast contingencies to reform, such as reducing public spending (reducing government size), implementing more appropriate monetary and fiscal policies, privatization of public operated enterprises, trade liberalization, and deregulation, etc., which were viewed as mechanisms for fueling export led economic growth and development. Specifically, aid agencies 
gave loans to help implement a free market system with the expectation that it would help Senegal to embark on a process of economic growth and development, requiring a shift from inward oriented growth to a free-market oriented model (Dembele, 2003; Owen, 2006; Perry, 2006).

Though there were some initial optimism regarding the shift to a free-market model, it became evident that free-market reforms were not contributing much toward the improvement of Senegal's growth expectations. This is partly because trade liberalization together with privatization contributed to the decline in the industrial and agricultural sectors. This shift undermined some of the progress made earlier through SMEs, which found it difficult to compete with massive imports that were subsidized by the government along with mismanagement. This helped to relegate the country into the Heavily Indebted Poor Countries (HIPC) initiative in 2000, which is operated by the WB and IMF, subjecting Senegal to not only debt relief but also more structural policy agreements. Yet, many obstacles to private sector growth continued to exist, such as bureaucratic burdens, corruption, poor labor laws, chronic energy shortages, poor transparency, the lack of judicial independence and dubious land title procedures (Arieff, 2013).

However, the state government in collaboration with domestic banking institutions and foreign aid agencies and NGOs has put a lot of efforts into deepening the private sector by commercializing microcredit to help entrepreneurs start SMEs. This is due in part with state economic policies such as the Plan Senegal Emergent (PSE), New Partnership for Africa's Development (NEPAD) and Projet Croissance Economique (PCE), which were all formulated with the central premise of helping to form a stronger economy built on economic diversity and 
elevating domestic productivity. However, those macro-level initiatives have had varying levels of success due to the time period in which they have been implemented; the markets they are targeting and microcredit regulations that have essentially isolated potential entrepreneurs, according to one country expert.

For instance, in 2010 USAID created the Projet Croissance Economique (PCE) in Senegal with a focus on hibiscus production. This was part of the plan to create economic diversity. The project identified this market as one with sound commercial potential as well as one that would help integrate more women into the economy since they have dominated this particular market over the years. However, growth over the years had declined due to the rising costs of seeds, land preparation, equipment, maintenance and transportation, which outweighed time and labor value. This PCE project supports interested entrepreneurs by providing access to microcredit, equipment and helping them to develop savings as a means to expand production. However, poor weather conditions together with low returns often makes this market less profitable for helping to expand or support other ventures. Therefore, it fails to contribute to significant economic growth.

Though programs supporting microcredit has increased over the years, two of my country experts emphasized that the risk is often too high, which isolates potential entrepreneurs. Specifically, formal institutions are charging high interest rates for small enterprises to survive. According to one country expert, entrepreneurs are limited because if they cannot repay their loans they are put out of business, or they put themselves in further debt by taking further loans to repay loans. A part of the problem is that while the government and private sector continue to try and make more credit accessible, it remains relatively unstructured; meaning, the time of 
maturation on loans along with the interest rates may vastly differ depending on the where and when you acquire the loans as well as the sector one chooses to invest in. Pivak (1999) labeled this practice "credit-baiting without infrastructure," which is very reflective of the Senegalese landscape, and those with small enterprises in the rural settings are most affected because they generally do not have sufficient options that generate high enough returns to repay their loans in a timely manner. In such cases, they are either priced out of the opportunity to become entrepreneurs who could contribute to the economy, or they could take a risk and potentially lose their businesses. Oddly, a large faction often take the risk and fall into a cycle of debt whereby they are borrowing from multiple sources to stay afloat with little chances of freeing themselves. This is furthered by their cultural values that encourages them to live for day by day rather than take credit to make macro-differences.

To help explain the failure of this cycle to generate private sector growth rather than personal debt, it is important to put some emphasis on the culture in terms of how Senegalese generally assign value to things, especially money. As previously discussed, many Senegalese put family and solidarity in high regards. Therefore, it is not uncommon for many to take small loans knowing they won’t be able to repay. Instead of mitigating losses in order to repay loans, many freely partake in the tradition of gift-giving (or assakas) whereby they give others a portion of their crops or goods through credit or charity, because family and solidarity generally trumps other avenues of their lives such as money or wealth accumulation. However, while participating in gift-giving/exchange continues to be an essential part of forming and maintaining social bonds it not something that allows individuals to easily break away from debt cycles, unless they possibly withdraw from some social groups that require gift giving or extending credit lines in times of need. However, without social relationships the expectation is that they may become 
vulnerable as access to resources is also taken away. Thus, credit has only contributed to the culture of dependency - at the national and individual levels, rather than fostered private sector growth. This is supported by three country experts who asserts that aid has not supported private sector growth because Senegalese has traditionally been entrepreneurial but within the informal sector. Moreover, aid has not worked because since aid agencies have gotten involved in Senegal many locals seems to have elected to work for these agencies rather than take opportunities to take loans, and interestingly they use earnings to further fuel their traditional practices that solidifies their social capital rather than focus on maximizing their personal wealth (Curry, 2003).

\section{6: Culture, market-based aid and domestic savings.}

Figure 6.5: Aid types and domestic savings between 1985 and 2012.

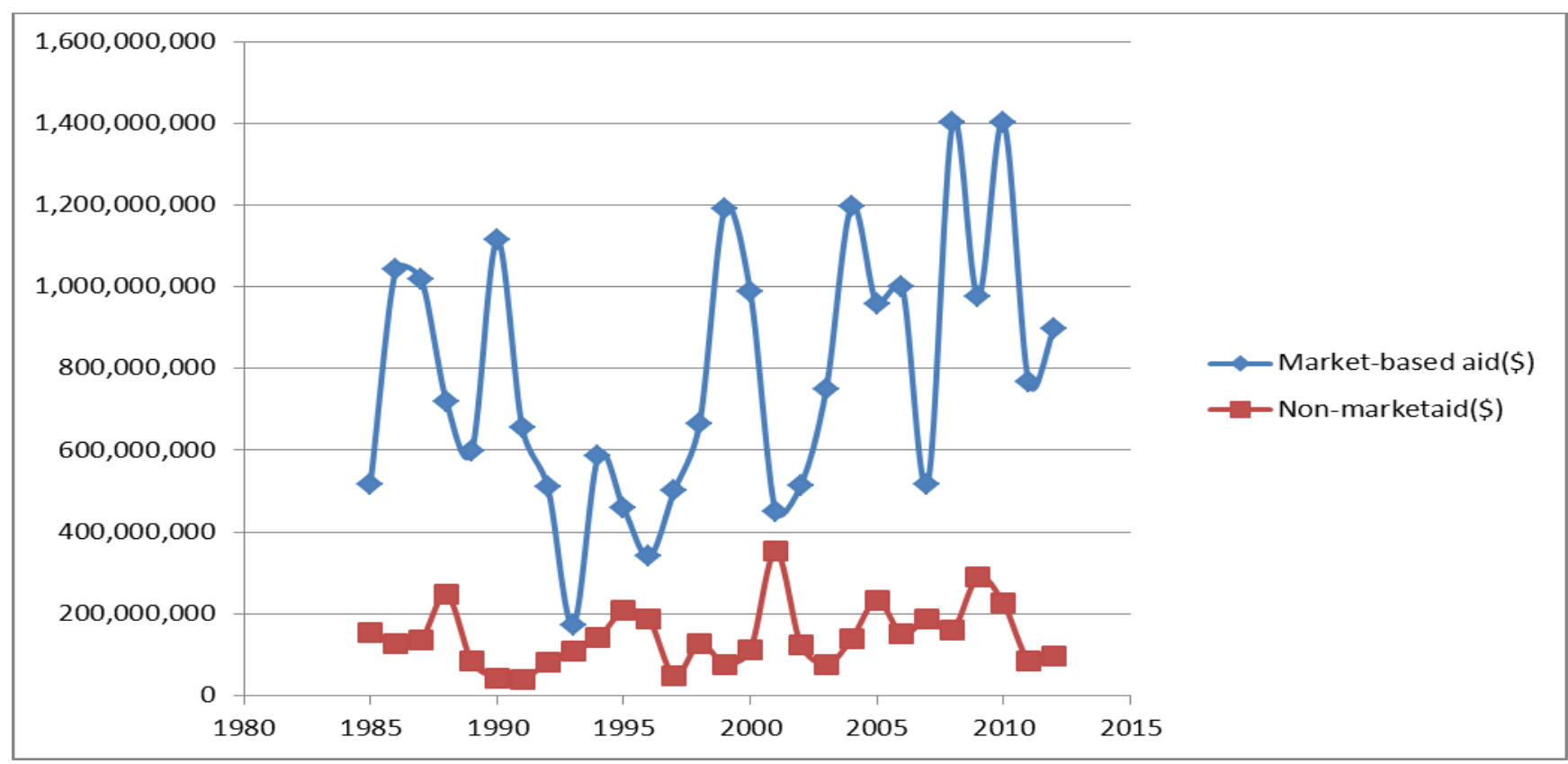

Source: Aiddata.org 
Above is an illustration of approximate aid types allotted to Senegal between 1985 and 2012. Market-based aid, which includes assistance for employing policies that emphasizes advancing education, healthcare, conflict prevention and resolution, transport and storage, communication networks, energy generations and supply, banking and financing services, and business and other services has generally been higher relative to non-market aid; yet gross domestic savings remain rather low. For instance, in 1985 Senegal received approximately $\$ 520$ million in market-based aid for aiding domestic savings. In comparisons, approximately $\$ 150$ million went toward non-market aid. However, according to the World Bank, Senegal secured approximately $\$ 171.6$ million. Moving forward to 2012, over $\$ 1.1$ billion was received for market-based aid relative to $\$ 95.7$ in non-market aid; however, gross domestic savings increased tremendously ( $\$ 1.17$ billion). Nonetheless, understanding some of the cultural factors of Senegal could contribute to understanding why there has not been further savings.

While the country experts generally did not know much about the role aid may have played in helping to generate domestic savings at the state level and how cultural attributes may have affected this relationship, they did contribute a firm understanding of this relationship at the individual and communal levels. However, an argument could be made that cultural dynamics that influences individuals and communities are also reflected at the state level since the country is considered an HIPC and is often soliciting debt forgiveness. Country experts emphasized that the Senegalese culture do not conceptualize savings the same way many others do - especially those in capitalist systems. This is because they generally do not base their self-worth on the accumulation of material wealth or riches but more on their ability to secure brotherhood through solidary. Furthermore, because there is such a large emphasis on gift-giving, resource surpluses food, money, clothing, etc. - are generally offered to friends, family and neighbors in needs. This 
system is pertinent, according to four of the country experts, because it helps individuals from being reduced to homelessness and begging. Moreover, due to the disconnect between state and society, many people are struggling to maintain; meaning, due to tough living conditions many are more concerned with their day-to-day living rather than focusing on amassing personal wealth. Therefore, most of the aid given generally goes toward consumption and not savings or investments, resulting in continued dependency.

\section{Tontines saving practices:}

One saving practice that has traditionally been used to help supplement incomes and generate savings is the "Tontine" system, which is a small-scale savings practice. In principle, social groups come together and pool agreed sums over an agreed timeframe. Group members then gets equal access to the pool based on an agreed upon order and the cumulated sum is disbursed. For instance, 12 friends or community members contribute one dollar each month to a Tontine and by the end of year they each get 12 dollars, which they may have found difficult to save on their own, because they may have been forced to put it toward consumption around the home. By paying into this system, they are saving since they get 12 dollars back, which could then be used toward hosting events (birthdays, weddings, etc.) or insurance in times of unforeseen events such as deaths, floods, fires, etc., according to country experts. Similarly, those in religious groups may pay dues that help to solidify social capital, which could be exchanged for cash capital in times of needs.

The aforementioned system is generally favored, especially within rural areas because those social groups are generally priced out of formal banking institutions due to large interest rates. Therefore, they rely on informal banking systems, or "Tontines", which provides a very 
crucial and financial network with little unpredictability. This is because people are faced with having to live on a day-to-day basis. According to country experts, many prefer this option of savings for various reasons. First, Tontines generally provide participants with easier access and friendlier terms relative to formal banking institutions. Second, it provides some level of independence, because participants may use the funds however they choose and without having to put up collateral. Third, pooling money helps participants to increase their purchasing power/social capital and, in turn, help mitigate the poverty. For instance, the Tontines could be used toward financing emergency needs, ceremonial events, or purposing household needs, etc. Fourth, Tontines generally help to foster solidarity, because it allows individuals to socialize and reaffirm social ties while also discussing some of the social problems that may exist. However, it remains to be seen how the effects of microcredits offered through Tontine systems helps to fuel savings at the macro levels. That said, one of the failures of the state and private sector has been its inability thus far to evolve the Tontine system into a more formal, large-scale banking system that may have been able to contribute to domestic savings.

\section{Aid, cultural constraints and savings:}

Currently, it appears that Tontine systems do not offer much in terms of generating sufficient savings because cultural traditions reminds them that family obligations trump everything else. Thus, participants in this savings scheme generally do not use their savings toward asset-building or income generating activities that may result in long-term economic gains to elevate them from poverty. Contrary to the mission of these saving practices, when participants are asked how they spent their savings, they are likely to indicate it is spent on meeting consumption or temporal obligations, according to two country experts. Specifically, 
many spend their savings toward domestic needs, their children, or ceremonial events (baptism, funerals, marriages, etc.). Therefore, trying to fuel entrepreneurial aspirations is often relegated on their priority list, especially among women who puts family first.

Moreover, it is a cultural norm for individuals invited to any ceremonial gathering come with some form of gift or contribution - mainly monetary, for the hosts. The amount given through gifts generally varies depending on the guests' cumulative resources. Many individuals participate in the Tontine system to save sufficient money to participate in these gatherings. Thus, if individuals participate in multiple events, it becomes a financial drain because they will find it challenging to accumulate wealth if they are tasked with sharing in addition to consuming. In some regards one could assert that savings are being wasted, but many Senegalese do not see it that way since they help to enhance their social capital which comes with added benefits. This is corroborated by the country experts who acknowledged that individuals generally use their money to attend social events whereby they save money for an entire year only to spend it on these events. Thus, while they can earn money through savings, they have not grasped the concept of managing it. However, that is a difficult argument to make considering these individuals live in a culture that does not emphasize savings the way others do. Rather, they live in a culture of gift-giving/exchange and development through saving that does not seem to be accounted for in their culture.

Ndeyedické system:

Another form of saving practice is the Ndeyedické system, which has traditionally been practiced on a larger scale amongst women. Participants select a person of choice - usually a best friend or person in need - to spend exorbitantly on through gifts and money that they might 
have saved. This fosters consumption and therefore has a negative effect on individual savings. This is a cultural practice embraced by many, and it helps to foster solidarity, but has little or no effect on actual personal savings. Moreover, both the Tontines and Ndeyedické systems are small-scale saving practices that have failed to contribute to sufficient personal wealth building, which could help explain Senegal's failure to experience economic growth and some of the prolonged issues that arose due to individuals choosing to focus on consumption rather than use savings toward investments and/or repaying existing debts. In cases where individuals elect to go into debt to feed their consumptive habits or needs, social capital generally allows designated friends and family members within their social groups to discreetly repay their debts, shifting the debt from one person to another and therefore, fostering a cycle of indebtedness.

That said, due to individual and communal spending behaviors there continues to be a large a wedge between the core mission of microcredits, savings and subsequent economic growth. Part of the issue stems from the cultural values that influence spending habits. Traditional constructs have led to Senegalese valuing money differently relative to others, especially those with capitalist mindsets. Therefore, it is generally uncommon for Senegalese to save money and invest in their futures to the degree one would expect, according to three country experts. Rather, and as previously mentioned, people prefer to invest more in establishing social capital and social prestige, which tends to carry more social value. This means having to be generous to others in the present. Thus, it is not uncommon to see a free exchange of food, money, services, etc., especially for those in need. Traditional values essentially dictate how much one is expected to give depends on their cumulative resources and wealth, which is then reciprocated when in times of need. Thus, some are willing to make sacrifices by giving away 
produce and money though it may leave them in debt, especially since daily life is generally based on frequent exchanges of gifts and reciprocating favors (Guerin, 2006).

While redistribution of wealth appears to solidify strong community bonds, networks, and also mitigating the level of uncertainty that generally comes with having to live from day-today, it only seems to elevate the long-term unpredictability of survival since many do not save or invest in their futures. The micro-level saving practices together with cultural values promote consumptive spending to meet immediate or short-term needs, thus fostering debt accumulation rather than sustainable economic stability. Therefore, these savings schemes seem to reaffirm economic instability at the individual and communal levels, which is also reflected at the state level.

More efforts need to be made to address the cultural constraints that may have been limiting the effectiveness microcredit has on saving practices. According to one country expert, more emphasis needs to be placed on developing institutions that encourage pragmatic savings that are appropriately planned and goal-driven. Equally important is the attitudes of Senegalese toward savings need to be molded if savings and later economic growth is to be realized. Thus, injecting more money into the system does not seem to be the answer to facilitating savings and subsequent economic growth. That is not to say aid will remain ineffective. Rather, for it to prove effective the mindsets of Senegalese need to change wherein they are made to place value on money similar to how they have traditionally valued social capital. Only then will they be able to save money and partake in managing their savings and contribute toward economic growth through meaningful investments. According to Geertz (1962), "Neither large-scale international capital transfers nor improvements in terms of trade can, in themselves, bring about 
domestic capital accumulation in the absence of effective efforts to raise the level of domestic saving.” This seems to put things in perspective somewhat, because it postulates that unless saving practices of Senegalese change, the chances for long-term economic growth through micro-level credits is unlikely.

\section{7: Other factors shaping reform efforts and development in Senegal.}

Predominantly Muslim (95\%) with approximately 16 million citizens and 10 major ethnic groups, Senegal is steeped in traditions that emphasizes religious beliefs, trust, social capital and networks that could help provide the missing link in explaining the lack of sufficient reforms and meeting economic growth expectations over the years even in light of increasing aid contributions and political stability. This includes corruption, debt issues; cultural beliefs of gender roles; cultural norms and laws governing access to credit, land, tools and other resources necessary to generate capital formation; investment practices; the role of religion and religious leaders; how Senegalese generally conceptualize savings and material wealth; and the size of the informal sector and its autonomous nature from the state economy, etc.

\section{Corruption:}

With every new administration came promises to employ better governance to address the perceived growing corruption issues. Presidential candidates generally ran on platforms promising to put in place pragmatic legislations that support transparency and good governance practices. Some of the more prominent legislations include the Ministry for Good Governance, The National Program for Good Governance, The National Anti-Corruption and Fraud Office, and the Commission Against Non-Transparency and Corruption. The expectation is that those 
measures would help report and investigate fraud, bribery, and embezzlement (WB, 2014; USAID, 2007).

Despite the aforementioned legislative changes the impact and incidences of corruption continue to be common. This is especially when dealing with government-related services, such as law enforcement, the judicial system, land titling, and how social elites and public officials use and/or mismanage state and foreign funds for contracting (particularly when it comes to funding large public works and solidifying social capital). Corruption continues to be considered an issue because the lines are blurred between local cultural habits and what is considered ethical misconduct in the west. Civil servants and individuals are generally unaware that their practices are perceived as corrupt. For instance, when it comes to aid allotments or gift giving, if a civil servant or individual refuse what is considered a gift it is considered impolite or rude rather than corrupt. Therefore, gift giving, even when it comes to disbursing aid that was given for different purposes could be redirected as it is part of the culture. The nature of giving is deeply embedded in the culture and therefore giving, even when it involves public officials, is not considered corrupt behavior. Thus, implemented regulations do not seem to deter perceived corrupt behavior since many Senegalese do not gather the same meaning these regulations aim to convey since cultural norms continue to outweigh foreign conceptions of ethical behavior. In other words, how corruption is conceptualized by the west is a foreign concept to many Senegalese. Therefore, according to two country experts, resources continue to be expended with minimal returns.

\section{Political stability:}

Senegal has historically been considered stable; however, there have been several instances whereby tensions of significance arose. This included some discontent during times of 
elections; rivalries between the major Islamic Sufi orders to which a majority of Senegalese belong; tensions regarding demands for further religious influence or values in the political arena; and continuing conflicts in the Casamace region. Although the aforementioned issues are pertinent on the domestic political agenda and often localized, they are generally not large enough to destabilize the country.

\section{Discontent leading up to elections}

Senegal has historically been viewed as politically stable; however, that image has been somewhat tarnished by bouts of low-level violence when segments of society considered election outcomes to be flawed. For instance, when the national election results were announced in 1988, putting President Diouf and the Parti Socialiste in office for another term along with a majority in the National Assembly there was an eruption of social discontent leading into the 1990s, particularly in some key urban areas that resulted in Senegal falling into a state of emergency. Thus Senegal being viewed a bastion of stability in the region was somewhat undermined. However, President Diouf made efforts to mitigate escalating issues with concessions to opposition political parties by implementing new reforms of electoral codes. However, that reform aided the ruling party in winning another election in 1993 to the dismay of the public, which again led to some discontent (Vallilon, 2011; Fall, 2011; Melly, 2012).

Additionally, in 2012, with President Wade in office and not wanting to relinquish power after exhausted his term limit (he also tried to amend the Constitution to extend term limits), political oppositions publically voiced their concerns of Wade becoming dictatorial. Political discontent spilled into the streets as his popularity plummeted, especially amongst those in urban 
settings. Demonstrations and protests became common and contributed to him ceding power to President Sall.

\section{Religious rivalries and fight for political influence}

Senegal has been overwhelmingly Muslim (95\%), with a majority of practitioners being affiliated with two Sufi Muslim orders. First, there is a Mouride Brotherhood which is a very structured and organized religious movement that ascended to power during the colonial era. Second, there is the Tijaniyya order which is also a widespread religious movement originating in northern Africa; however, leadership spreads across religious families throughout the region.

Since the colonial era, religious leaders have been called upon to mobilize support to promote their own preferences and/or that of their allies in government, namely the president, on key policy issues. The relationship between religious sects has generally been collaborative; however, recently there have been some tensions, especially in times when the president or key political officials show some bias toward a particular sect. For instance, when President Wade, a Mouride, won election he made a trip to the holy Mouridic city of Touba. This was quickly met with a sharp outcry from other religious sects as it was perceived as him showing favor to this particular sect and therefore, it had political implications when trying to gather support on national policies. This, in turn, affected the ability of policymakers to set their policy agenda considering they knew implementing it would be challenging without making concessions with the various religious movements and their leaders. This is because religious leaders continue to have more influence relative to politicians and therefore, the success or failure of a policy often hinges on the support of religious leaders. 


\section{The Casamace conflict}

The Casamace region extents along the southern portion of Senegal and is mainly cut off from the mainland region by the Gambia. This region has been a source of low-level but long standing conflicts for years. This has been mainly due to domination from the north and ethnic, cultural, economic and historical differences resulting from geographical separation.

In the 1980s, tensions rose and led to a somewhat small but disruptive separatist movement, The Movement of Democratic Forces of the Casamace. This movement comprised of the Diola ethnic group who are somewhat well integrated into society. This movement continued into the 1990s whereby there were sporadic attacks, namely against state and military properties. All presidents have included this issue on their platforms when running for office, but it has proven to be more complicated than expected. When the government chose to negotiate peace agreements it creates factions (of those denouncing certain elements of the agreement) thus continuing the conflict. The scope of the conflict continues to be unknown since it continues to evolve; moreover, it continues to draw much needed resources that could otherwise be used toward remedying needed reforms. The continuation of this conflict limits the economic potential of the country since this particular region is quite possibly the most fertile within the country and therefore any disruption causes losses in revenues.

Although this long, drawn out conflict does not appear to be a source of major concern or one that has potential to destabilize the country, it is nonetheless important that the government continue to address it in hopes of coming to appropriate accords to mitigate the conflict. Otherwise, this conflict may continue to be taxing on the government and people. 
Furthermore, from a pragmatic standpoint it would be wise to consider this issue a security risk that has some implications if left untouched.

\section{Debt issues:}

Senegal has experienced debt issues since gaining independence. Efforts have been made to address debt issues through debt restructuring and reliefs; however, that does not seem to have helped. According to World Bank and IMF reports, Senegal's debt issues continue to get worse. For instance, external debt as a share of GDP was $86 \%$ in the 60s. By 2001, this decreased to 69\% while accounting for 800 million debt relief from the Paris Club. Annual decreases were visible until 2006 when debt accounted for approximately 21 percent. However, there has since been some steady increases - 45\% in 2013 and 59\% in 2016. Most of this debt is a result of massive public borrowing to finance significant infrastructure development. The doubling of the public debt between 2006 and 2016 also led to an increase in debt servicing fees between 2 percent to 2.9 percent in the same timeframe. Debt servicing fees became an economic burden since it constrains the ability of the government to develop and implement appropriate policies (WB, 2017; IMF, 2017).

\section{Gender inclusiveness:}

One cannot analyze Senegal's current condition without placing sufficient emphasis on the role of women. Although the government has implemented policies such as Equality Now 1977, A National Strategy on Equity and Gender Equality, and The Convention on the Elimination of All forms of Discrimination Against Women (CEDAW), they are not properly and/or consistently enforced. For instance, property ownership rights continue to be problematic 
for women because it is culturally tabooed. Senegalese customary laws together with Islamic laws have traditionally prohibited women from owning properties. ${ }^{56}$ Instead, men are generally permitted to purchase and/or inherit properties. This is because society is structured around patriarchal norms and values. Therefore, men (mainly older men) are held in high regard, even if they may not be actively involved in politics, civil society or faith based associations. In cases wherein a woman becomes a widow she must marry the brother of her husband or re-marry in order to maintain properties, or the government could take ownership. Thus, while the state can formulate policies, cultural norms and beliefs continue to overpower those policies which may, in turn, affect the contribution of women (Guyeye, 2008; IFAD, 2004; Matsumoto, 2008).

While aid has been appropriated for designing and implementing policies geared toward integrating women into the production sector, they (women) do not have sufficient incentives to participate such as land ownership rights and equal pay. Particularly, though women comprise of approximately $70 \%$ of the work force in rural areas they make less than men since they have to pay high rents on lands they farm while land maintenance and tools are expensive. This limits their purchasing power and has a direct effect on their contribution to the economy. Additionally, a woman may plant 50 acres of land, but because they cannot legally own the land, the government could essentially come in at any time it pleases and seize it without fair or any compensation since they do not have the same legal protections or insurance policies as male counterparts. Moreover, men generally exert control over lands and other properties and therefore control women's access to same since men generally control spending within

\footnotetext{
${ }^{56}$ However, it must be noted that some progress have been made in recent years in that women have been able to purchase properties. Moreover, there have been some success in terms of getting women more involved in society, especially within the political arena and decision-making, with many now occupying various positions within the bureaucracy.
} 
households. Those factors create a sense of insecurity and foster low levels of sustainability for women who may be interested in pursuing business opportunities in the agricultural sector - and the economic sector, in general, through land ownership (Gueye, 2008; IFAD, 2004; Matsumoto, 2008; Ndiaye, 2009).

Over the years, however, the state, in collaboration with Western supporters, has formulated various reforms, such as The National Land Tenure Law of 1964 along with The Return to Agriculture and The Accelerated Growth Strategy in efforts to give women more protections and help integrate them into its growth and development plans. However, those legislations have failed to achieve expected results due to cultural norms that are difficult to cut through. In some regards, those legislations seem to have helped to solidify gender segregation in the state because women continue to bypass certain trainings that state programs offer in favor of those considered culturally acceptable for females. For instance, they often bypass training that pertains to governance and management, planning, and technical-related skills, because those areas are culturally considered masculine and therefore the patriarchs are supposed to acquire them. Instead, they partake in training sessions such as farming and domestic related tasks. Those trainings, however, do not provide women with sufficient empowering capabilities to acquire enabling knowledge that would put them in positions to be decision-makers or contribute in terms of developing and implementing policies.

Although sizeable aid has been allocated toward developing and implementing the aforementioned policies, cultural constraints continue to hinder the process whereby women are not able to contribute equally as men. This has inhibited their ability to maximize their potential by also playing a more fundamental role in the policies being advanced. Therefore, it is 
important that aid contributions for reforms continue to set criteria that encourage gender inclusiveness if Senegal is to further its development. Although women participate in society, there is little incentive, which in part excludes them and may be having a negative effect on reform efforts.

Economic diversity:

Part of Senegal's failure to reform is rooted in its history dating back to colonialism. The economy was streamlined based on peanut production. This practice continued in postindependence whereby the economy became too reliant on the domestic and global peanut markets. This has made the economy vulnerable to competitors and the government has not invested sufficient aid toward reforms to diversify. Moreover, they have failed to invest adequately in local processing to add value to produce that could be sold on the domestic, regional and international markets. However, they have recently taken some steps to help diversify the economy with the Plan Senegal Emergent (PSE). The principle aim is to help redistribute investments across the country for diversifying the economy as engines for sustainable economic growth and development (World Bank report, 2014; IFAD, 2004; IMF, 2010).

Emphasis on developing policies geared toward economic diversification is key for sustainable economic growth in Senegal, especially since it is essentially monoculture and vulnerable to weather and decline in global commodity prices. Historically, weather patterns have played a pivotal role in production and agricultural sustainability. Severe weather patterns have led to extensive rainfalls or droughts which has either killed off crops or reduced production levels. This generally poses a major problem for small producers, because they 
already fail to produce excess for trade. If economic growth is to be realized the government must appropriate sufficient aid toward policies that would foster diversification to help mitigate vulnerability due to weather and declining peanut price. $^{57}$ Moreover, lack of transport infrastructures has made it difficult for those living in rural areas to transport goods to market in a timely and cost-effective manner, which is reminiscent of the French administration which concentrated infrastructures around urban areas. This continues to be reinforced today. Lack of infrastructure limits not only range but also the amount of produce that producers can carry to market and their potential returns. In other words, it is difficult for producers to mobilize their produce on a larger scale. This also leads to wastage if producers are not able to get to market soon enough. .

\section{Informal sector:}

The government still relies on religious leaders to implement reforms at communal levels with state funds. However, this has contributed to the growth of the informal sector. While Marabouts maintain control over the populous, there has been some resistance over the years, notably because of declining commodity prices. To mitigate the fallout, Marabouts have advised devout disciples to prioritize families over other obligations; meaning, since many live from hand to mouth, they are encouraged to favor rational ideologies in terms of what is best for them and their communities. This has contributed to an increasing number of producers taking their produce across the border to neighboring states to secure higher prices. The cross-border trade is also connected to domestic wholesale-retail sales, which is also dominated by the informal sector. Due to the extensive networks developed under the colonial system, producers and

\footnotetext{
${ }^{57}$ Also, long-term development will require the government -both state and local - addressing the need for adequate storage and processing capacity to help boost the agricultural sector that finds markets across Europe and China.
} 
Marabouts have been able develop an extensive informal-formal network. Those networks play key roles in organizing the informal sector, which has become effective and powerful autonomous economies that the state is not able to tax. The informal sector has displaced a large part of the legal market economy and has otherwise undermined trade policies employed by the state to improve export and economic growth. Moreover, a growing number of producers have gradually moved toward other crops such as cotton, millet and maize because they are less regulated by the government, which has also contributed to the economy not achieving higher growth (Barker, 1977; Ross 2008).

\section{8: Conclusion:}

While aid is said to have contributed to Senegal's reform efforts and subsequent growth and development over the years, country experts and the literature suggests that it has not generated sufficient reforms considering the level of stability it has maintained and aid it has received. In other words, aid has not worked harmoniously with the cultural and traditional constructs of Senegal. However, to improve the government must orient its efforts toward four key avenues. First, more emphasis must be placed on prudent fiscal management and macroeconomic reforms, which requires more investments in government capacity building thus allowing them to formulate and implement appropriate policies. Moreover, the state must try its best to improve its public spending practices whereby they remain cognizant of the future and strategically target private sector investments and FDIs while trying to limit debt accumulations and reallocating scarce resources from low to high priority ones. Second, more focus has to be placed on increasing both domestic productivity and foreign exports, which would open the economy to FDIs. Successful and stable economies are driven by exports, which brings in 
needed FDIs which could be used toward further investments to grow the economy and make it more competitive in the global market. Third, they must continue to strengthen the climate of the private sector to help generate savings. This begins with more transparency and enforcing regulatory frameworks to help mitigate corruption, which remains high. This comes with many consequences, including the amount of FDI that is potentially lost. Moreover, by improving the business environment, more domestic entrepreneurs could contribute to the economy through SMEs. Finally, growth must be made more inclusive; meaning, the government must enforce pro-active reforms that targets human capital building, especially amongst women. 


\section{Chapter 7: Case study of Ghana}

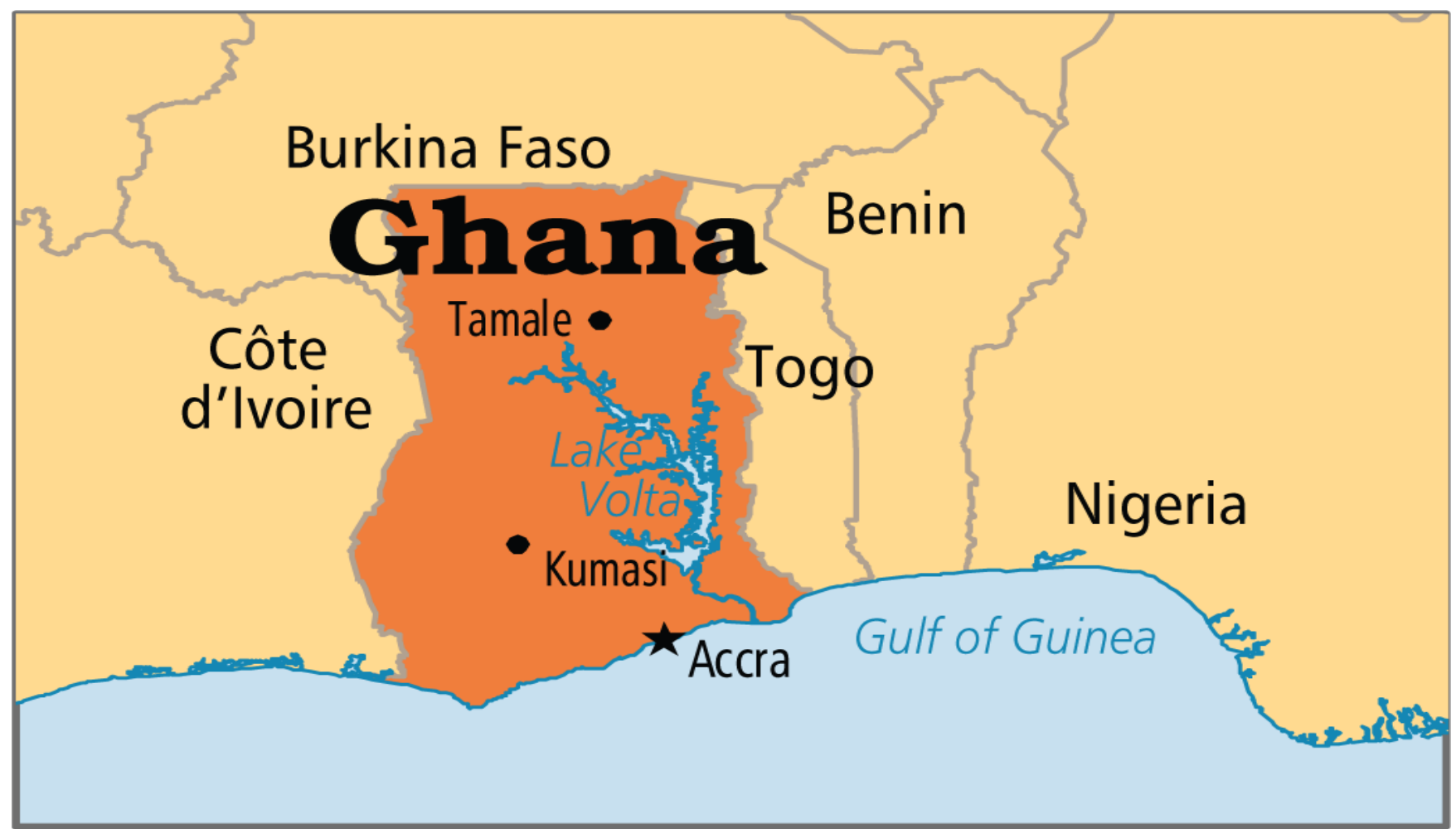

Map highlighting Ghana in the Africa sub-continent

Table 7.1: Ghana at a glance

GDP per capita

Unemployment

Life expectancy

Population

Literacy rate

Debt stock
$\$ 1,513$ (2016 estimate)

$5.8 \%$ (2017 estimate)

62.4 years (2015 estimate)

28.2 million (2016 estimate)

$71.5 \%$ (2010 estimate)

$\$ 9.1$ (2010 estimate)

Source: World Bank

\section{1: Introduction}

As the first SSA state to gain political independence in 1957, Ghana was viewed as the region's beacon for political and economic hope. This is partly because it inherited a relatively developed and stable economy due to it playing a central role in England's colonial rule within 
the region. This was also substantiated by its immense natural resource reservoir, which includes timber, gold and cocoa (of which Ghana was the leading global producer) as well as its key location as a port to global markets. Although sizeable investments made immediately after independence required some policy reforms that led to subsequent growth and development, Ghana soon encountered some economic struggles due to drastic changes in its political fortunes between 1966 and 1981, which coincided with low production, high levels of debts, balance of payment deficits, hyperinflation, unemployment and poverty, etc. However, the political arena began to stabilize around 1981. This appealed to Western aid agencies and FDIs whose aid contributions and investments helped to foster further reforms (Appiah, 2000; Kim, 2015; Anaman, 2006).

\section{2: Post-colonial history of reform efforts by administrative heads.}

\section{Dr. Kwame Nkrumah’s administration (1957-66):}

Under Dr. Kwame Nkrumah’s leadership (1957-66), the expectation was to put in place pragmatic reforms that would help further Ghana’s regional economic standing by aggressively emphasizing large-scale, state-controlled economic transformations and development projects to catalyze its industrialization agenda. ${ }^{58}$ Central to this policy endeavor was to swiftly move Ghana away from being aid dependent and toward self-reliance by establishing a sound domestic industrial base that could efficiently convert local commodities to finished products for both

\footnotetext{
${ }^{58}$ Upon being inaugurated, Nkrumah developed a "7 year plan." This involved tremendous state involvement in the domestic economy, which included the development of state enterprises in various strategic areas of the economy such as energy, utilities, cocoa, infrastructure and the mineral industries. Approximately 90 percent of the state budget catered to those enterprises (Osei, 1999).
} 
domestic consumption and exportation. ${ }^{59}$ Rapid industrialization became the central goal of the state since it was viewed as a key process for enhancing growth and development. ${ }^{60}$ This included placing emphasis on infrastructural development, such as the construction of the Akosombo dam which provided hydro-electric energy for Ghana and its surrounding neighbors; overseeing the construction of the first modern international port at Tema in 1961; the construction of a motor-way connecting Tema, Ghana’s leading industrial city with its capitol, Accra, as well as building numerous factories, refineries and the Volta River Bridge, etc., to help generate greater returns and mobility to enhance commerce. Those investments, however, took a massive toll on government expenditures which consistently exceeded the revenues it brought in. As a result, the government incurred significant debts to foreign creditors ${ }^{61}$ (Osei et al, 2013; Killick, 2010; Jedwab and Osei, 2012; Asem et al, 2013).

To help pay creditors and continue large-scale developments, Nkrumah employed a similar policy used under the British colonial era whereby he kept producer prices excessively low to generate greater state revenues. He used the state apparatus to impose his economic policy by coercively purchasing cocoa below market value from domestic producers then sold them on the global market at significantly higher prices (relative to purchasing price). The cost differential was supposed to help fund industrialization projects to stimulate growth and development. However, this policy was unsuccessful for numerous reasons and harmful to the

\footnotetext{
${ }^{59}$ As part of Nkrumah's African socialism ideology, he opposed Western aid support. That is not to say that he did not solicit aid, rather he initially limited how much aid he took since it was generally tied to capitalist ideals.

${ }^{60}$ Central to his strategy to move the economy forward while mitigating its vulnerability was reducing the economy's reliance on cocoa and mineral resources because he felt overreliance on few commodities could only foster economic vulnerability.

${ }^{61}$ According to World Bank data, by 1970 the state had already owed more than $1 / 2$ billion dollar, which increased to more than 1.5 billion by 1981 and continued to increase.
} 
economy. This policy negatively impacted the local producers since it significantly reduced the incentives of producers to increase production and contribute to the domestic economy; forced many to take their produce to neighboring markets where prices were relatively favorable; enhanced state revenue dependency on cocoa exports; and decreased Ghana's global competitiveness. This is because due to the high profit margins of cocoa on the global markets, it incentivized international competitors, which in turn significantly reduced market prices. ${ }^{62}$ Therefore, due to the state's overreliance on cocoa profits, whenever cocoa prices fell in the global market it had a direct effect on state revenues and domestic economic stability. Similarly, both gold and mineral resources experienced poor production levels due to state neglect of the mining infrastructures ${ }^{63}$ (Watkins, 2004; Huq, 1989; Hyden, 2006).

Though he solicited massive amounts of aid, Nkrumah was forced to abandon his grandiose industrialization plans due to shortage in capital, a shrinking domestic market, and mounting state debt, etc. Instead, he elected to orient the limited state resources toward modernizing the production sector and vigorously attempting to address its weak infrastructural capacity to help boost production and exports to increase foreign exchange and future investments. In effect, the expectation was that modernizing the production sector (primarily agriculture) was the best way to fuel industrialization. However, his African socialism ideals which partially meant the government imposed itself in the industrialization process and its domestic market, contributed to the bloating of state government expenditures while the private

\footnotetext{
${ }^{62}$ New market competitors included the Ivory Coast, Cameroon, Nigeria and Brazil, among others.

${ }^{63}$ The government historically favored investing more funds into the cocoa sector because it had a greater margin of return.
} 
sector and entrepreneurial class declined due to poor management and planning (Bates, 1981; Hyden, 2006; Meredith, 2005).

Staying close to his socialist beliefs, Nkrumah also employed import substitution industrialization (ISI) policies. This was a state-led economic and industrial development strategy that he had hoped would help trap foreign exchange and foster capital formation through strategic investments, resulting in economic growth. The rationale behind his decision to implement this strategy hinged on the notion that economic growth and development could only be realized through industrialization and that it was imperative that surplus from the domestic economy is allocated toward developing and strengthening the industrial sector. Moreover, at its core ISI is a protectionist policy that aimed to help safeguard the domestic industries against foreign competitors. This policy may have contributed to an increase in GDP based on the increased proportion that manufacturing and industries fed into the GDP. Specifically, the World Bank estimates that in 1965 the manufacturing sector contributed approximately 11.2 percent of the GDP which rose to 11.3 percent by 1966 and 13.3 in $1967 .{ }^{64}$

However, the aforementioned growth did not help satisfy economic growth expectations. Part of the problem stemmed from the fact that the state was not adequately equipped to coordinate large-scale industrial policy frameworks. Moreover, this statist approach proved costly because state enterprises were largely inefficient and became financial liabilities. This contributed to the state spiraling into fiscal debt while returns on investments were meager at best. Central to this failure is that many of the ambitious and grandiose projects never functioned

\footnotetext{
64 There was continual growth until 1977 before a steady decline, which coincided with the political instability that the country had been facing.
} 
at full capacity, never became operational, or were deeply affected by corruption. Capacity utilization was continually low for several reasons. This was partially due to lack of spare parts, low production of raw materials, and outdated technology, etc. (Hyden, 2006; Huq, 1989).

Additionally, continuous bank bailouts only served to minimize accountability and contributed to these enterprises ignoring performance indicators. Moreover, since nepotism was also common, many managers that led state enterprises were political appointees and/or cronies that assumed leadership through various degrees of political patronage. This also coincided with large financial rents or kickbacks paid to these individuals and political officials, thus redirecting large sums of scarce public resources into private accounts ${ }^{65}$. Lastly, a key part of the large-scale development policy was that the state often employed in excess to mitigate unemployment rates. Consequently, the economy experienced some instability. For instance, according to World Bank data, while there was some initial economic growth in 1961 (3.4\%), there was a sharp decline by $1966(-4.4 \%)$ in part due to the inward growth strategies and political instability. Similarly, GDP per capita depreciated from 0.2 percent to -6.4 percent within the same timeframe (World Bank, 2016; Huq, 1989; Osei, 1999).

Ghana’s economic issues did not rest solely on its poor industrial performance. To stay in power (and maintain a stronghold on his constituents), Nkrumah's cronies and political appointees were given full reigns over strategic state enterprises (cocoa, energy, and trade, etc.) even though they lacked or had little knowledge of how to lead those enterprises. Their incompetence also contributed to the state investing heavily in supporting the industrial sector while failing to employ competent managers, or investing in appropriate choices and decisions,

\footnotetext{
${ }^{65}$ Even government contracts became overly political and were over-estimated, which often led to money being channeled to private accounts.
} 
which were often made on political rather than economic bases. Those practices undercut the potential capital that could have been earned by these enterprises for reinvestments. This also undermined the productive capacities of those enterprises in that they were often unable to meet optimal capacity (Hyden, 2006; Tosh, 1980; Teal, 2002).

Moreover, shortages in government capital, having to pay off government officials, and the state interventionist tactics also played a key role and essentially limited the ability of the state to execute its reform agendas. In many aspects, the economic and political structures were viewed as instruments designed to maximize the wealth of the political leaders and their cronies. However, although there were external pressures to implement economic and political reforms, Nkrumah rejected the conditions that Western aid agencies were putting forward considering his socialist ideals. With the economy failing to improve, many Ghanaians became restless and demanded change - both politically and economically. However, Nkrumah retaliated by using the state apparatus to apply further political pressure not only to oppress his people but also to secure a one-party political system (Tosh, 1980; Teal, 2002; Austin, 2008; Jedwab, 2011; World Bank, 2016).

\section{Economic and political instability: 1966-1981}

Nkrumah was deposed as Ghana’s leader by a military coup d'état in 1966, which triggered economic fluctuation ${ }^{66}$. This coup d'état came about as a result of numerous accusations of massive economic mismanagement against President Nkrumah and his administration. Specifically, cocoa, which had been Ghana's prime foreign exchange, had experienced declining production levels and market value. This also had a direct effect on

\footnotetext{
${ }^{66} 1966$ marked the beginning of political instability whereby there were four successful military coup d'états.
} 
domestic commodities prices as well as the budget and balance of payment deficits, which created a situation wherein there were shortages in essential commodities that culminated into economic hardship for Ghanaians. The poor domestic economic climate and public mismanagement of funds made the path easier for this military coup. One of the other factors that also contributed was the growing friction between the socialist ideals endorsed by President Nkrumah and the liberal ideals embraced by the growing opposition led by The Ghanaian Armed Force/the National Liberation Council (NLC), which helped to solidify their legitimacy through popular support (Chazan, 1983; Huq, 1989; Bennett, 1975; Luckham, 1994; Hansen, 1991; Jedwab and Osei 2012).

Consequently, the primary objective of the military overthrow was to install an immediate solution to the dire economic problems that was inherited from the Nkrumah administration ${ }^{67}$. Central to the NLC's economic remedy was to reverse the economic and industrial strategies that had been implanted by the Nkrumah administration by endorsing liberal economic policies through collaborations with IFIs such as the IMF, WB and USAID as well as Western economies to formulate policies geared toward fiscal and monetary accountability and employing free-market principles. Moreover, they also had to minimize government expenditures, remove state subsidies, and reduce the stringency levels of import licenses and exchange controls that were in place. The expectation was that this approach would reverse the downward trend that the economy was experiencing at that juncture by favoring private capital. Three key policies that were implemented to help meet such ends were the Ghanaian Enterprises Decree of 1968, the Ghanaian Business Promotion Act, and the Small Business Loans Scheme

\footnotetext{
${ }^{67}$ The NLC was a transition government that struck an agreement with Western donors to install a democratically elected leader in return for aid. In October of 1969, Busia’s Progressive Party (PP) was sworn in.
} 
(SBLS). Those policies focused on encouraging Ghanaian entrepreneurs to getting involved in economic and industrial activities such as trade, commercial transport, banking, and manufacturing, etc. The state also provided funds for those that had plans to purchase or invest. However, this plan was not very successful as the conditions attached to the loans were too rigorous.

Additionally, economic policies were crafted to target unemployment, devalue the local currency to enhance market competition and address the balance of payment. However, the government failed to meet their objectives, and this contributed to the intensification of Ghana's economic woes. However, part of the problem was due to the oil shock, drought and global economic downturn starting in the 1970s. This contributed to the re-emergence of shortages of essential domestic commodities. This had a direct effect on the industrialization process and further unrests. For instance, in 1971 the Busia administration acknowledged the dire economic situation that Ghana was in and considering their pro-West orientation they proposed austerity measures as a means to help rescue the economy. This included reducing government spending, especially on non-essential government functions, revising its tax codes and trying to mitigate its default risks, trying to address budget deficits, and balance of payment issues ${ }^{68}$, etc. (Herbst, 1993; Chazan, 1983; Amissah, 1973; Bennett, 1975; Owusu, 1975).

Despite the economic measures undertaken by the Busia administration, there were still issues of significant budget deficits, balance of payment, reduction of military expenditure, and accumulation of debts, etc. Those issues proved to be too difficult to mitigate. One of the

\footnotetext{
${ }^{68}$ To a certain extent, though the government publically proclaimed their preference for economic liberalization and made efforts to cut public expenditures, it did not make sufficient cuts and instead thought it best to employ similar policies implemented under the Nkrumah administration that were state-led in nature.
} 
solutions that the government thought would help address those issues was further devaluing the currency by $44 \%$ percent. However, that policy was unsuccessful and subsequently led to Colonel Acheampong overthrowing the Busia government in 1972.

However, more inappropriate macroeconomic and institutional developments together with external shocks led to further economic decline while inflation and hardship rose. The Acheampong administration (or the National Redemption Council) swiftly took an anti-West approach and froze trade liberalization while orienting his policies toward the production sector $^{69}$. Central to this policy shift was the implementation of the Investment Policy Decree of 1975, which permitted the state to restrict the economic activities of foreign investors and capital. For instance, the decree allowed the state to forcefully acquire shares in foreign owned enterprises such as British Petroleum and Shell Limited, which were bought by the Ghana Commercial bank and the National Investment Bank. Additionally, they implemented stringent but arbitrarily applied import licenses which were deemed to go against public interests. Specifically, established private enterprises were denied import licenses if they were not supporters of the government or failed to give adequate kickbacks while less efficient enterprises that held political favor quite easily obtained licenses. Similar to previous administrations, economic mismanagement and mass corruption came to light. This may have contributed to the collapse of the economy and thus resulting in another military coup d'état in 1979 by JJ Rawling to remove the NRC government from power on the grounds of poor leadership (Meredith, 2005; Hyden, 2006).

\footnotetext{
${ }^{69}$ One of the main policies was the "Operation Feed Yourself”, which was geared toward boosting agricultural production and revenues. This policy was rather successful because it significantly reduced imports by 1975 while also increasing exports.
} 
However, the new administration did not prove to be capable of advancing sufficient economic reforms, and only led to greater hardships and social unrests - mainly targeted at the military rule. This led to the military regime putting in place measures to hand over the government to civilian rule. However, in contrast to previous military takeovers that consolidated their powers and modified the economy, the new government took strict aim at mitigating corruption and prosecuting past leaders who may have indulged in economic crimes. The expectation was that this approach would not only deter perpetrators but also help address the high levels of corruption that was apparent and may have been negatively affecting the economy. Therefore, the goal was to establish a government built on moral foundations. But after mounting domestic and external pressures, an election was scheduled to transition power to a democratically elected government. The 1979 election led to a victory by Dr. Hilla Limann and the People’s National Party (Shillington, 1992; Chazan, 1983; Huq, 1989).

Limann's administration inherited several economic problems considering the economy had been presided over by several military regimes that were not composed of economic experts. Plus, more emphasis was placed on political rather than economic stability. Therefore, the economy experienced some regression. In 1979 when Limann took office the GDP had fallen by an estimated -2.5 percent. Although the economy improved to 0.47 percent by 1980 , it declined by 1981 to -3.5 percent. Part of the reason stemmed from fallen production rates of its commodities. For instance, Cocoa fell from 1/3 share of the global market to only 1/8; gold fell by 47 percent; diamond by an estimated 67 percent; and manganese by 43 percent, etc. This placed the Limann administration in a bind in terms of trying to rehabilitate the economy. Therefore, they opted to dismantle the socialist ideologies it had endorsed and reached out to the West for assistance (World Bank, 2016; Watkins, 2004; Hutchful, 2002; Library of Congress). 
JJ Rawling resurfaced again in 1981 and ousted the Limann administration and committed to economic reforms by embracing neoliberal ideals in a bid to fuel economic growth by opening the domestic economy through his endorsement of free-market principles. This included focusing on capturing much needed foreign direct investments (FDI), deregulating the government, cutting public expenditures and fiscal mismanagement, and emphasizing the development of a competitive private sector. This included mitigating the 'public good' or 'community' approach that had existed under the socialist paradigm and placing more emphasis on the 'individual' to become more accountable for their own realities. However, this shift relied heavily on IFIs such as IMF, WB and USAID as well as developed economies for massive loans and grants which were used to help develop stabilizing policies. That said, though aid received was to foster numerous socio-political and economic projects, much emphasis was placed on market-based aid. This included channeling sizable aid toward developing key infrastructures (communication networks, roads, ports, etc.), budget support, energy, supporting industries and the production sector as well as formulating and implementing appropriate trade policies and regulations.

Between 1983 and 1991 was a period of stabilization reforms. One of the key reforms came in 1983 as the JJ Rawling's administration (the Provisional National Defense Council) agreed to implement the Western imposed Economic Recovery Programme. This was designed to help stabilize and liberalize the economy with emphasis placed on improving export industries by promoting efficiency and development through four key objectives. First, improving macroeconomic stability by addressing tax codes, reducing government spending, creating much needed economic incentives to help generate domestic production and devaluing the domestic 
currency (cedi). Second, the government aimed to undergo vast deregulations by relaxing its direct involvement in the production sector through the privatization of inefficient state-owned enterprises. Third, prioritizing the development and/or rehabilitation of key infrastructures, such as roads, ports, and railways, etc. Fourth, and equally important, the government aimed to also incentivize the private sector through much needed monetary reforms and reducing its private corporate taxes to encourage competition (Asem et al. 2013; Jedwab and Osei 2012; Kraev, 2004; Aryeetey and Tarp 2000).

The aforementioned reforms contributed to economic stabilization and modest economic success and in parts made Ghana appear to be a sound investment in the eyes of Western aid agencies. Ghana's appeal was further enhanced due to subsequent economic reforms between 1992 and 1996 whereby the state embarked on a series of economic and democratization reforms, which emphasized decentralization and the introduction of a multi-party system. This contributed to political stability and subsequent economic growth. For instance, the government implemented the National Institutional Renewal Program (NIRP) to help coordinate numerous public sector reforms that catered to fiscal balance and management, performance improvement, and increasing investment opportunities. Moreover, the government later made efforts to define its regulatory framework and emphasized the enforcement of contracts and property rights. The Liberal Investment Act (1994), The Free Zones Act (1995), The Statutory Corporations Act (1995) and the National Communications Act (1996) were initiated to help facilitate this process. Those policies contributed to greater foreign investments and subsequent economic growth. At that juncture in time, inflation levels declined from 122.9 percent in 1983 to 10.3 percent by 1985 and remained relatively stable since between 1985 and 2001 with the only anomaly being in 1995 when it increased to 59 percent. Additionally, the GDP grew between 3.3 percent (min.) 
and 8.65 percent (max.) between 1984 and 2001. However, this economic improvement was marginal and did not meet the growing expectations of the people. Specifically, while the economy improved and stabilized it did not bring immediate improvement to the standard of living. This led to social discontent and calls for further economic recovery (Appiah et al, 2000; Ninsin, 1998; Kraev, 2004; Asem et al, 2013; World Bank data, 2016).

The designing and implementation of economic policies were very much under the influence and guidance of western aid agencies who were consistently lobbying the state government with their policy choices, which came with financial support to make them more attractive while simultaneously convincing Ghana's state government to become more amendable to their policy suggestions. One of the key Western players that situated themselves in Ghana at the time was the Harvard Development Advisory Service (DAS), whose primary goal was development planning and project identification as a means for the state to gain access to funding and policy advice. Though policy advice covered all aspects of social and economic development, much emphasis was placed on the economy by way of catering to the productive sector, trade, infrastructural development, budget support, etc. The expectation was that these economic shifts would further change Ghana’s fortunes.

At the end of JJ Rawling's reign in 2001, the subsequent administrations continued to place a lot of emphasis on private sector development and free-market oriented policies. This contributed to generally positive economic growth ranging between 3.8 percent and an unprecedented 14 percent, thus making it one of the fastest growing economies in the region (Asem et al. 2013; Jedwab and Osei 2012; World Bank, 2016).

\section{3: The intersection between market-based aid, culture and government capacity.}


In trying to examine the effects between market-based aid disbursements and government capacity in Ghana, I tried to identify some of the more salient cultural traditions and values that may have had some implications on the aforementioned relationship. That said, it was imperative to keep in mind that British colonialism established a system of rule wherein they made efforts to incorporate the indigenous chiefdom and beliefs systems together with some its own cultural elements into a quasi-bureaucratic model wherein power was centralized at the state level, which became crucial in exerting its influence in the policymaking and administration process. The expectation was that such a model would help improve domestic production, governance and enforcement of policies at the local levels. ${ }^{70}$ To a certain extent, this model initially worked because local populations were viewed as "subjects" and not "citizens" that had individual rights. In other words, they were obligated to the state. Moreover, the chiefdom system lost political leverage over the years at the national level though they maintained influence at the communal levels. ${ }^{71}$ This often meant they had to mobilize along ethnic and clan lines, which makes it more challenging to influence the national agenda; however, they are often called upon by the state to help implement state policies at the local levels (Buame, 1996; Nugent, 1995).

The colonial government implemented a very top-down model in regards to its decisionmaking and also helped to solidify a small elite class that were indoctrinated into embracing

\footnotetext{
${ }^{70}$ After Ghana gained its independence, it emulated the colonial system/structure, which had created somewhat of a distance between the government and the people. Specifically, the relationship was a patron-client relationship between the state, chiefs and its citizens.

71 Traditional governments were strong (King and royal family). While a two-tier system in place, at the national levels the King has lost his value. 'Royal' and 'Paramount' Chiefs were called upon to shape policies and settle disputes; however, the constitution has since prevent them from being active in state governance, according to one of the country experts.
} 
principles of the colonial system through access to elite education. This pattern of administering continued even after colonialism ended because those that took control of the bureaucracy were trained under the British educational system. Therefore, having experienced similar socialization processes as their colonial rulers, they (the elites) saw themselves as the knowledgeable, powerful and authoritative figures and therefore, they expected their "subjects" to yield to their every command. This sort of belief system has continued in some regards after independence considering that bureaucrats and political leaders were also viewed as being anti-democracy and therefore moved to maintain a single party political system after gaining its independence. This system played a key role in the state being able to swiftly formulate and later implement its macroeconomic reform agenda (Kuklick, 1979; Chazan, 1983).

Ghana, in many regards, inherited relatively sound government capacity as a result of its positioning within the British Empire as well as the political structure that was installed and maintained in post-colonial Ghana, according to two country experts. This contributed to Ghana being labeled as a leading example of a strong and stable economy when it gained independence in 1957. However, some early economic progress was disrupted by an era of military power struggles due to poor economic performance that hinged not only on some of the economic reforms employed by the state but also widespread corruption and mismanagement of state resources. The 1980s brought an era of widespread economic and political reforms that were designed and implemented in collaboration with Western donors, which helped to bring about some stability and foreign investments and subsequent economic growth (Anaman, 2006; Killick, 2010; Osei et al, 2013; Jedwab and Osei, 2012). 
Figure 7.2: Market - and non- market aid contributions for government capacity between 1985 and 2012.

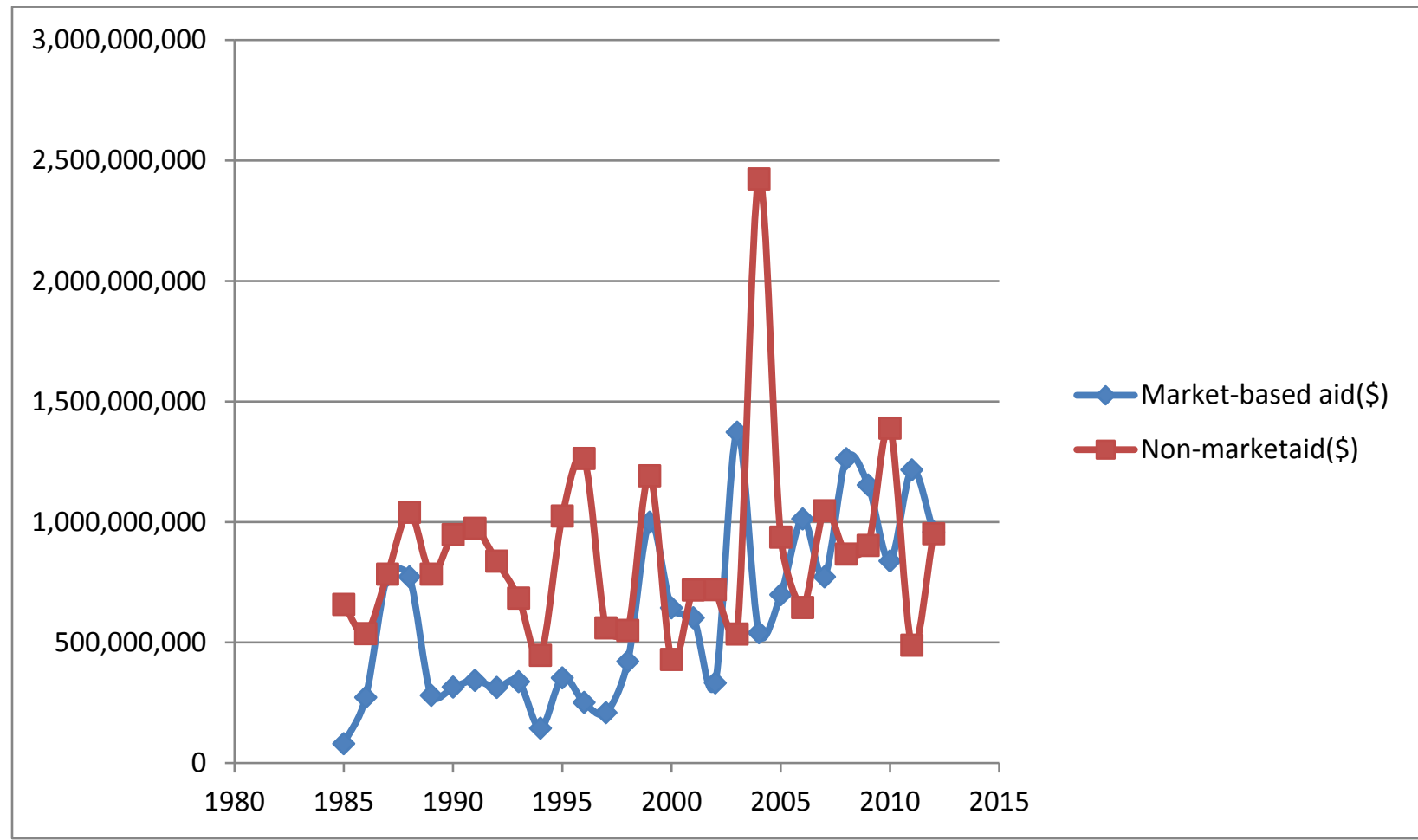

Source: Aiddata.org

Above is an illustration of market- and non-market based aid allocations for Ghana between 1985 and 2012. There has been some disparities between the aid allocations with nonmarket aid generally outpacing market-based aid. For instance, in 1985 market-based aid received was approximately $\$ 80.3$ million compared to approximately $\$ 660$ million in nonmarket aid. The point of greatest disparity came in 2005 when market-based aid accounted for approximately $\$ 540$ million, while non-market aid accounted for approximately $\$ 2.4$ billion. Such disparities could be a contributing factor to Ghana's failure to build its existing capacity.

An argument could be made that a central part of Ghana's ability to formulate and implement domestic reforms rests on the amount of aid it has been receiving over the years from 
aid agencies. Generally, the state has been receiving large amounts of aid - both bilateral and multilateral - to support government and civil society, its security apparatus, its communications infrastructure, business and financial services, trade policy development, education, and health, etc. However, as indicated above Ghana has generally received more in non-market aid to support broader humanitarian efforts, which may have affected its ability to further enhance its capacity to design and implement domestic policies.

My findings indicated that there may be some relationship between market-based aid, cultural factors, and economic reform efforts that targets government capacity. Country experts had mixed responses toward the role market-aid contributions may have had on government capacity building and subsequent economic growth while accounting for Ghana's cultural traditions and beliefs. According to two country experts, prominent economists, there isn't a positive link between market-based aid, culture and government capacity. More specifically, one of those experts argued that the link is too tenuous to be credible and the political culture of policymakers is far different from ordinary Ghanaians. However, he suggested that aid, in general, would be more effective at driving government capacity, but in order to accomplish such end a road map is urgently needed and it starts with intellectual freedom and a freedom of media [which helps] to keep policymakers on their toes. Moreover, he suggested that the institutional approach would be more helpful than the cultural approach in terms of trying to further the effectiveness of aid spending. Therefore, donors should invest more in institutions such as free media, independent judiciary, the civil service, the banking system, and security apparatus, etc., and if those institutions are more functional then it is reasonable that foreign aid may be wellmanaged. Those are certainly valid points, however, I found the aforementioned points of view dismissive of previous sentiments shared in his body of work wherein he is vocal about the need 
for donors to work with recipients to support traditional models and ideas when designing policies rather than dictate policies from Washington without taking into account local conditions. ${ }^{72}$ That said, another country expert that focuses on foreign aid and development asserted that market-based aid has helped in strengthening state institutions since donors have invested in institutions such as the electoral commission, parliament, media, judiciary and think tanks. Those institutions have worked in consort to enhance the capacity of the state to design, regulate and implement its domestic policies as well as helped to keep the government more accountable to the people. However, two country experts argued that the effectiveness of achieving the aforementioned hinges on where the aid is coming from and its configuration since aid from China is configured differently from aid from the West and therefore, the levels of success in driving capacity tend to vary accordingly. In other words, Western versus Chinese aid has had different effects on government capacity over the years for various reasons. Furthermore, the relationship being examined is also affected by the political structure and its engagement with the chiefdom system; the values of the people - specifically their reception of authority; and how resources are organized to satisfy social needs.

\section{Western versus Chinese market-based aid:}

According to a country expert that studies political history, it is difficult to discuss the effects of aid on Ghana's state capacity building efforts without shedding light on the divergent roles Western and Chinese aid may have played in this process. While Western aid has historically been considered the norm, the Chinese has steadily competed to increase their

\footnotetext{
${ }^{72}$ In Indigenous African Institutions (2006), he argues traditional institutions and practices still exists in Africa, such as Kings, Chiefs, and village markets. Since aid is generally top-down, and traditionally Africans operate on a bottom-up system, it creates a conflict and wastage. Thus, if west really wants to develop Africa it must learn about the culture and institutions and helping Africa to essentially return to its roots and building on their institutions.
} 
presence since the 1960s. This has certainly had some effect on the level of capacity development that the state may have experienced, because the conditions applied to aid disbursements and the processes entailed is different between the prior mentioned donors. Historically, the West has incorporated stiff conditions on aid disbursements. Moreover, they formulate and impose what they consider to be pragmatic policies that are in the best interests of the people of Ghana. However, said policies are generally constructed within the walls of aid agencies and often with little or no input from recipients. Thus, these policies are often foreign concepts imposed on the people. Furthermore, the evaluation processes are arbitrary, which makes it difficult for Ghana to meet the policy goals and objectives, or for them to become sufficiently competent in a short span of time. Even worse, there is often a lack of interest in complying with these policies considering a majority of Ghanaians fail to buy-in since the ideas employed by these policies are foreign to them since donors often fail to adapt the policies to local conditions. Yet, the expectation is that Ghana must become adequately knowledgeable in an appropriate timeframe so that it can, in turn, take full command of designing and administering its own policies after Western officials leave (Welle-Strand, 2010; Ramo, 2004; Burke et al, 2007).

In contrast, Chinese aid disbursements generally comes with little or no conditions. While the state is normally given more leverage to design and exert their own influence on policies, the Chinese tend to play a central role in the implementation of the agreed upon policies which may crowd out local participation ${ }^{73}$. In other words, the Chinese generally entertain very minimal local contributions in the implementation process, which poses a problem in that it also allows

\footnotetext{
73 Projects financed by the Chinese government or agencies generally offer few jobs to locals as contractors often bring their own workers to help them implement policies (Gong, 2007).
} 
for minimal exchange of technical knowledge thus causing more of dependence problem (Gong, 2007; Welle-Strand, 2010; Woods, 2008; Taylor, 2006).

\section{China's aid:}

China has been disbursing aid to Ghana since around the 1950s. Aid disbursements are guided by 4 key elements: (i) helping recipients build and maintain their capacity for selfdevelopment; (ii) imposing little political conditions or stipulations; (iii) trying to promote equality, mutual benefits and development; and (iv) remaining vigilant to reforms and innovation. Though debatable, those principles are purported to regulate China's aid relations in Ghana. At the core, those principles are very different from those practiced by the West. This is because China has consistently promoted the notion that aid should be disbursed to help recipients achieve self-development through capacity development, and that said aid should not be imposed with political or economic conditions nor should donors interfere with the internal affairs of recipients. Thus, there is much emphasis on peaceful coexistence, which is based on the need for mutual respect for both parties involved in the aid agreement so that individual sovereignty can be maintained. Therefore, the expectation is that respect for recipient's sovereignty will foster not only non-interventionism but also development. Such a platform is key for Ghana's capacity development, because since there are generally no impositions on aid disbursements, the state has more leverage to design policies that it feels aligns with its own development agenda. This non-intervention stance resonates well with Ghana's political philosophy of having state-centric authority together with its belief in having ownership over its domestic affairs (Gong, 2007; Woods, 2008; Taylor, 2006). 
Central to Chinese involvement in Ghana is their role in expanding the industrial base by channeling some technical support, grants, interest-free as well as concessional loans toward improving its productive sector, infrastructures (roads, communication, and ports), energy, and informational technology sectors to help enhance the economic landscape and, in turn, mitigate some of Ghana's development challenges. This is substantiated by Chinese-sponsored training sessions in areas such as trade, communication, energy, production, and economic planning, etc., according to one country expert. One of the major areas the Chinese has helped to address is the persistent energy problems. In the past, Ghana relied heavily on the Okosombo dam to generate electricity for Ghana and some of its neighbors. However, during times of poor rainfall it meant many individuals and businesses were affected. The Chinese came in and provided an estimated \$562 million in concessional aid (while the Ghanaian government supplied an additional \$60 million) along with technical support to build a new dam at Bui. The expectation was that this dam would be more efficient in terms of generating a greater energy capacity. This was important because the lack of energy supplies was slowing Ghana's development efforts since it was consistently causing local businesses to not only scale back but also shut down their operations. This has had a negative effect on the growth of the industrial sector. In turn, this has also limited economic activities. Had there been less energy problems the economy would have potentially grown further. For instance, a World Bank report estimated that if the energy issue had been mitigated the economy may have potentially experienced 7.5-8 percent growth. This is a sentiment shared by two country experts who argued that though the government implemented an electrification policy to help boost production, especially in rural areas, the lack of energy to help drive the electrification agenda contributed to some economic stagnation (World Bank, 2007). 


\section{Western aid:}

Western aid stood in contrast to Chinese aid since it comes with a lot of stringent political and economic conditions. Central to said conditions is the assumption that they will contribute to government capacity through technical exchanges. However, this has had some limiting effects on Ghana's ability to self-develop because it meant that the government had to become too reliant on aid while western donors dominated Ghana’s domestic policy agendas. This has often led to some friction between donors and the state government in that it has limited the ability of the government to make its own decisions and self-develop. Part of the issue rests on the fact that the conceptualization of development by western donors at times stood in opposition to what the Ghanaians consider development. Specifically, the West placed a lot of emphasis on political and economic reforms that mirrors what may have worked in the West in the form of SAPs and liberalization policies while paying little or no attention to the local realties of Ghana, such as socio-cultural dynamics. This has in turn affected the level of effectiveness of aid disbursements. Furthermore, while western donors allocate aid to the state they generally expect the state to collaborate with western agencies on the ground, but this relationship is often one that gives these agencies superiority over the state in terms of decision and policy-making. And though these agencies may provide some training and education to foster capacity it is often to westerners working in Ghana (not local) and therefore, in some regard the aid is very much like aid from China in that there is not much continuity considering that once those individual decide to leave they also take the knowledge and experience with them. This interrupts the capacity building process (Idun-Arkhurst, 2008; Yanbing and Ying, 2012).

\section{Market-based aid, the state, Chiefdoms, and local governance:}


Some of Ghana's economic success is tied to the amount of market-based aid that has been channeled toward government capacity, especially when accounting for some of the nuances of Ghana's cultural traditions and beliefs. This includes relying on the network of chiefdom systems that the British took advantage of wherein the state made use of chiefs to help govern and enforce policies at the local levels. Each administration after independence have acknowledged the importance of chiefdoms; however, they had varying attitudes toward fully involving chiefs in the government apparatus, according to one country expert. In essence, a lack of adequate participation of chiefs in the decentralization and development process initially contributed to poor economic reforms. Constitutional amendments did not make provisions for the participation of chiefs in local governance and socio-economic reform efforts. The rationale hinged on the notion that the state government perceived chiefdoms as a direct competitor or rival to its authority rather than acknowledge them as partners in the economic growth and development process. ${ }^{74}$ It was not until 1992 that constitutional amendments made reference to the relationship between chiefs and local governance as well as try to define their roles (IEA Ghana, 2010; Rathbone, 2000).

Chiefs continue to play a key role in fostering economic activities and implementing state policies at the local levels, because as a result of their positions they were able to facilitate inclusion, representation, consultation and participation. Therefore, by virtue of their positions they are able to come to collective decisions to better ensure they are looking out for the best

\footnotetext{
${ }^{74}$ To a certain extent, there were rivalry and competition because society and politics were divided along ethnic lines, which not only undermined the functions of institutions where there is a lack of understanding or trust between the chiefs and the government but also influence the amount of state resources are channeled toward the local governance.
} 
interest of their people. This is pivotal because the chiefdom system embraces a quasidemocratic model. Though chiefs are installed by lineage or social capital, they could nonetheless be voted out of office by those they preside over. However, in many regards, this system is a social institution that has helped to facilitate capacity development and subsequent economic growth in Ghana because it strongly encourages responsiveness, checks and balances, and collective bargaining. That said, this social institution plays a pivotal role in helping the state in its capacity development and policy enforcement, because through collaborations they are able to be responsive to the needs of the people before devising key economic policies. Moreover, the chiefs are provided with state resources to help ensure that specific duties are executed in a timely manner and key policies are maintained. In many ways, they are used as important hubs or guarantors to help ensure order, policy reforms and implementation with crucial government support, according to three country experts.

\section{Reception to authority:}

Partially as a result of colonialism, the Ghanaian people have been sensitized to yield to authority. Specifically, "subjects" were molded to show obedience to those in positions of power- government officials, wealthy individuals, chiefs, elders, etc. This value has transcended through the years and has become embedded in the Ghanaian tradition. Therefore, attitudes toward authoritative figures have essentially contributed to the process of governance in that obedience has become somewhat of a social mechanism that provides leaders with the ability to rule over their subordinates. Thus, it is viewed as uncustomary for subordinates to question or challenge the decisions made on their behalf by the leaders they elect into office - whether it is at the local or state levels. Those who openly challenge authority are considered disrespectful and 
are generally reprimanded based on their actions. This value contributes to the unification of the decision-making process whereby when issues arise at the local or community level, instead of them being openly voiced through protestation, it is customary for local chiefs to relay the collective decisions of the people to the top rather than risk undermining the state and/or its leaders. This cultural value has helped to mitigate protestation while elevating unity and success. In turn, this has contributed to policy development and implementation (Ayittey, 2012; Blocher, 2006; Crook, 2005).

\section{How resources are organized:}

To some extent how resources are organized at the communal levels has also had some influence at the state level. From a cultural standpoint, there has been a strong element of communalism wherein those in power are socially pressured to organize resources to meet collective needs. However, in order to accomplish this end, individuals are expected to satisfy what is deemed their moral and social duties and obligations by providing for their extended families who may not be in a situation to help themselves. This may include organizing resources and becoming representatives of others so that pragmatic decisions are made on their behalf. In such cases, the pressure is a two way process because subordinates have expectations for their leaders to organize resources and formulate policies that serves the best interests of the people while society also puts pressure on those in power to exercise due diligence to serve the best interests of their subordinates. This is important in fostering development because social expectations keep leaders in check by making them accountable.

Additionally, the social expectation that generally comes with one’s social position also shapes their administrative behavior Specifically, in situations wherein the bureaucratic structure 
is deeply implanted in the social system whereby individuals are pressured into becoming accountable not only to their nuclear families but also their extended families often has led leaders to become prone to exploiting state resources to satisfy personal, nuclear and extended family expectations. Who benefits often hinges upon ethnic and social group affiliations. Thus, the consequence of certain individuals being in positions of power is that aid allocations is often disbursed in disproportionate ways as social allegiances affects how aid is allocated to benefit friends, extended families and cronies, or to meet certain political rather than foster economic ends. It is not uncommon for policy considerations to favor some ethnic groups over others. Similarly, ethnicity has become one of the social links used by the state and leaders to solicit critical input from certain groups with the expectation that it will help drive capacity development. However, this has a consequence in that belonging to the wrong ethnic group has a tendency of limiting one's contribution to the capacity development process. Specifically, affiliations to the wrong social group(s) is likely to disqualify them from participating in enhancing government capacity when aid has been allocated and therefore rendering them excluded from contributing to the economic and industrial development process (Crook, 2005, IEA, 2010).

That said, according to one country expert, efforts are being enhanced through aid contributions to address the aforementioned issue. Specifically, The Ministry of Public Sector Reform has been working to facilitate good governance, civic engagement, and service provision by designing and implementing strategies that are responsive to the needs of the people, businesses, and private sector by building capacity and streamlining protocols to help ensure efficiency and effectiveness of service delivery. This is pivotal for helping to ensure 
accountability; however, conflicts pertaining to regulations have oftentimes contributed to ineffectiveness and inefficiency.

\section{4: The relationship between market-based aid, culture and economic freedom.}

Figure 7.3: Market- and non-market aid between 1985 and 2012.

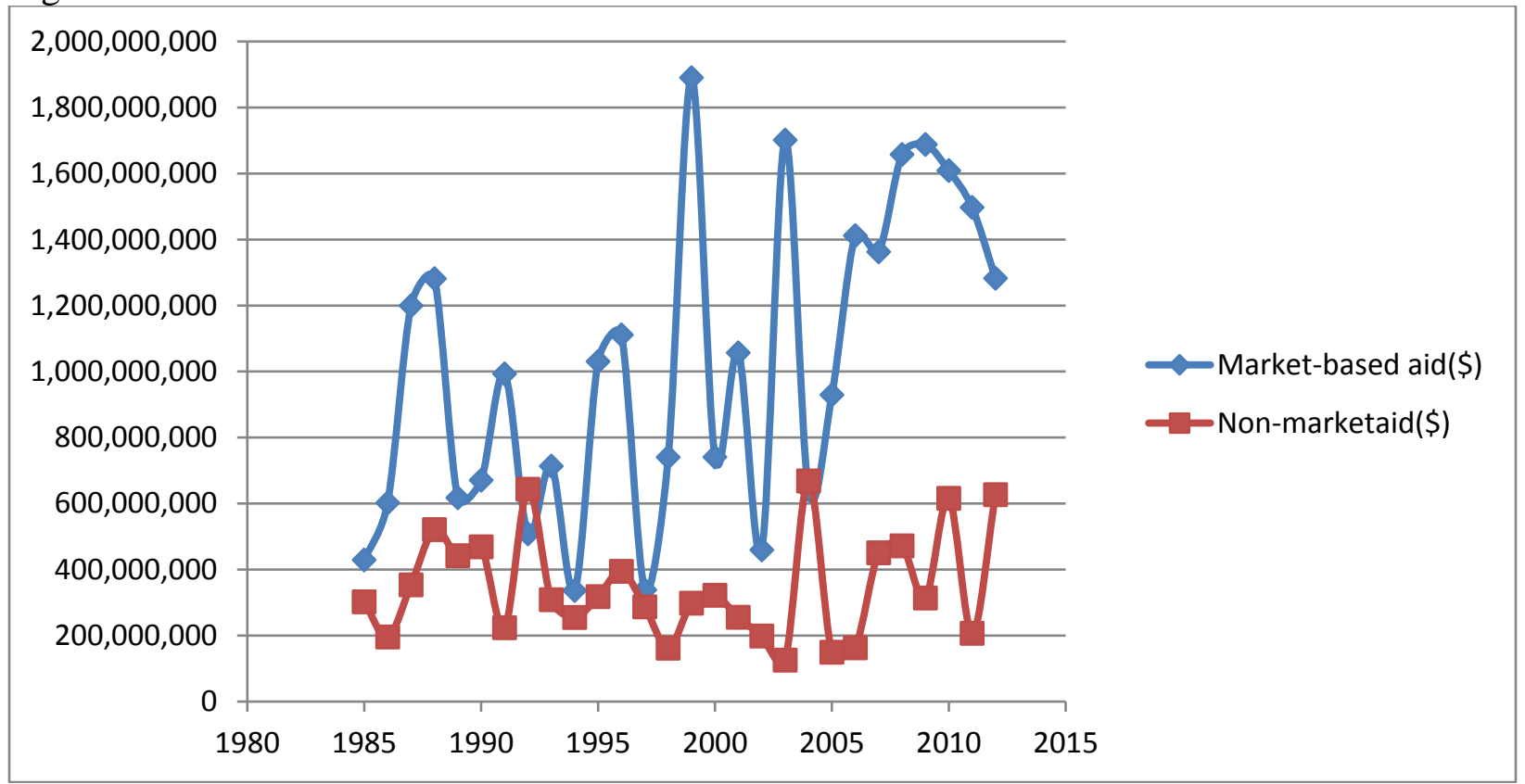

Source: Aiddata.org

Between 1985 and 2012, aid agencies allotted a significant amount of market-aid toward promoting economic freedom. This included aid toward education, healthcare, government and civil service, security, transport and communication infrastructures, energy generations, etc. Though inconsistent, as evident, market-aid contributions have generally been greater relative to non-market aid over the years. This is especially in light with the push for liberalizing policies starting in the 90s. However, this move has also contributed to the growing levels of the informal sector, which has resulted in the government having to depend on aid to execute its day-to-day functions since a lack of infrastructure to capture domestic taxes continue to persist. 
When trying to assess the effects of market-based aid on economic freedom, it is important to also consider the depth of the informal economy that has historically dominated the Ghanaian economy. While this phenomenon existed in Ghana's traditional construct, it has been furthered and reinforced by both capitalism and structural adjustment policies. In essence, the nation building process became so heavily influenced by ideas of modernization and economic unification, which has contributed to many elites and political leaders ignoring the local cultures that defined Ghana's economy in pre- and prost-independence. Thus, it is the understanding that local elites abandoned the traditional economic structures that involved their own conceptualization of the free-market system and the use of chiefs to facilitate trade with the state because they were made to believe that such institutions were inferior and therefore it was important that they adapt new measures. This included collaborating with aid institutions to help mitigate the informal economy by implementing appropriate regulatory frameworks that aligns with capitalist ideals so that the state could extract taxes from citizens and enterprises to fund its development agendas. However, a failure to do so has had some ramifications on the sustainability of the government and economy, according to one country expert. Specifically, he argued that economic freedom has been the bedrock of the Ghanaian culture whereby people have been working for themselves. Liberalization policies furthered the economic freedoms of Ghanaians; however, it has also decreased the already small number of citizens working within the formal sector, especially for the government. Thus, the government has been forced to rely on a small tax base because the state's tax administration continues to be inefficient in terms of casting a wider net to capture more taxes. Central to this problem is that the government uses a V.A.T system which generally employs a 17.5 flat rate but is sometimes reduced in some strategic sectors. Three of the country experts indicated that due to this high rate, many 
Ghanaians consciously evade paying taxes, because many do not consider the social returns to be greater than the amount of taxes they are asked to pay considering their low incomes. Therefore, two country experts suggested that lowering taxes may better allow the government to expand their tax net because it may entice more citizens to buy-in.

Two country experts added to this discussion by articulating that Ghana is steeped in a culture of freedom which extends beyond the political sphere to the economic arena and therefore, while aid toward liberalization policies has contributed to the economic freedoms of Ghanaians, it has also had some negative effects, namely because it has been disastrous for the country in terms of the destruction of the local industries. This is important to discuss because local industries are supposed to help drive to economy at the macro-level by bringing in foreign exchange; however, when the state and private sector abandoned some industries, such as textiles, sugar, and agriculture, it meant locals had to depend more on imports, which could be more expensive when the local currency is often unstable. This, in turn, limits their ability to freely engage in the marketplace; meaning, when the local currency fluctuates the protections the state provides become obsolete considering it could have a domino effect in that it could ease those in the formal sector into the informal section, and those in the informal sector to unemployment. Moreover, according to three country experts, market integration has been promoted as an essential need to fuel the Ghanaian economy, because that model comes with certain initiate rights that governs how individuals participates in the market through economic transactions and securing property rights.

Over the years, the state has instituted several measures to help mitigate the informal sector while also promoting and guaranteeing the rights of individuals and entrepreneurs. Those 
includes, but certainly not limited to, the 1992 Constitutional amendment - Article 24. This amendment is geared toward guaranteeing every citizen with certain economic rights to participate in the market. Specifically, Article 24 provides (i) every citizen the right to work under adequate, safe and healthy conditions in return for fair wages without any form of discrimination; (ii) guarantees individuals with sufficient rest, leisure and reasonable working hours, and holidays with compensation; and (iii) rights to establish and/or join trade unions that may promote and protect their individual economic interests. However, compliance has been and continues to be issue since the government does not have the capacity to enforce its policies.

Additionally, there are other laws that strictly forbid the performance of some activities and engagements of some groups of people within the market. One of those policies is the Children's Act of 1998, which prohibits exploitative labor such as child domestic labor. The conceptualization of exploitative labor is outlined under Section 87 of the Act and is supported by Article 28 of the 1992 Constitution wherein it stipulates that minimum age for legal employment in Ghana is 15 years. However, some exceptions can be made for children as young as 13 years of age, but it must only involve light work. Moreover, there is the 2003 Labor Act, which guarantees the rights and duties of employees and employers. Specifically, this Act outlines the employment protections, conditions of employment, termination of employee contracts, etc. Furthermore, it outlines the equal pay for equal work to mitigate gender disparities, sets out minimum way provision, maximum work hours as well as workers compensations and benefits, etc. Central to this Labor Act is the provision granting every citizen the Constitutional right to form and/or join trade unions to promote and protect their economic interests. Thus, collective bargaining is embedded in the Labor Act. 


\section{Tradition, social capital and economic freedom:}

While the aforementioned measures have been better enforced within the formal sector, individuals operating within the informal sectors are also protected, unless citizens are ignorant of the laws and are unable to obtain sufficient legal support in seeking justice. However, what is prevalent is that while social capital between citizens and the state have been deteriorating, it has traditionally been strong between citizens, especially those belonging to the same ethnic, religious, regional and communal groups, etc., according to four country experts. One stated that "trust is a big problem amongst many Ghanaians. Except for close family members, especially of the different ethnic groups are not at the level one will expect." Furthermore, though many are motivated to become entrepreneurs and start enterprises, when the enterprise grows they are expected to employ others to assist with the daily operations but this dynamic has changed over the years due to trust levels eroding. Trust used to be a value that was central to the culture; however, this is no longer the case, resulting in individuals electing to resist the temptation of going from micro- and small-level entrepreneurship to medium and large-scale investments. Generally, entrepreneurs of micro- and small-level enterprises still seem to prefer being 'one man operations' where they have full control over the day-to-day operations of their enterprises rather than relinquish control, which is necessary as the enterprise grows. However, that is not to say that there are no risk-taking entrepreneurs but rather they are not enough who are willing to put aside their fear that others may not be willing to help them advance their business.

In contrast, in instances where trust levels are high it serves as a currency and it is generally relied upon to regulate and enforce social contracts or agreements. In essence, because economic transactions in the informal sector are generally not put together under the guise of 
written contracts, trust or social capital becomes important in policing contracts and brining about some levels of justice since failure to comply with social rules is likely to strip individuals of their social capital and "branded as social outcasts", according to one country expert. Considering the growing informal sector, many seem to value their social capital and therefore, work consistently to further enhance it by placing much emphasis on social relationships, networks, values, families, kin relations, ethnic relations, religious ties, communities, regions, and access to resources, etc., as a means secure market transactions while also reducing transaction costs based on the strength of one's social capital. This goes to say that that access to the market hinges upon 'who you know.' The implication is that while some may get greater access to the market based on the social groups they are a part of others are also likely to be limited as a result of not being a part of sufficient or certain social groups. Thus, those that benefit are generally the individuals that spend a lot of resources building and maintaining strong social capital which in turn affects their market access and market potential therefore, to a certain extent it is these networks or groups that helps to maintain certain social protections of individuals in the economy to freely participate. Similarly, social capital is also important for driving entrepreneurship because the aforementioned factors, such as trust, networks, values and social groups, etc., helps entrepreneurs to gather working capital to start SMEs. In turn, those factors have traditionally triggered reciprocity, solidarity and trust and enhanced social networks to help Ghanaians mobilize capital.

However, while some of the cultural traditions have somewhat promoted the furthering of economic freedom, others have placed some emphasis on obedience and community rather than individualism. Some aspects of Ghana's culture frowns on individualism, which essentially lowers the potential control and autonomy of individuals and therefore, this also affects their 
choices to take risks and pursue entrepreneurial endeavors. This is because to a certain extent individualism is viewed in a context of it being damaging for social groups as a whole. The same logic applies to obedience in that high levels of obedience is likely to negatively affect economic growth and development by contributing to less economic transactions relative to states that value autonomy and individualism. This is important because concepts such as trust, selfdetermination, autonomy, etc., lends much needed support to economic freedom and subsequent economic growth, while endorsing obedience and frowning on individualism are more likely to stifle the prospects of economic growth (Tabellini 2009; Harper 2003).

Similarly, much emphasis is also placed on respect, which also helps to secure economic freedom. Specifically, a greater level of respect generally relates to a greater tolerance for others. Therefore, the expectation is that greater tolerance comes with a greater likelihood of showcasing an accepting attitude toward others, especially in times of trading with others that may be deemed as 'outsiders.” This in turn fuels economic freedom to participate in the market and subsequent economic growth and development. Therefore, at its core respect is a value that many Ghanaians embrace. This, in contrast, implies that economic interactions and exchanges can be negatively affected by a lack of respect for others. This does exist in Ghana as there is generally lower social capital between ethnic groups, which influences the level of respect they utilize in economic interactions and therefore also limiting their economic opportunities they may have access to. This is because social capital in Ghana generally influences the level of respect your garner in your community and thus the extent of one's economic interaction is generally limited to those that are related (Platteau 2000; Coyne and Williamon, 2009). 
That said, the cultural attributes of Ghana plays an important role in influencing economic freedom and subsequent economic growth. That is because culture has provided both a binding and flexible constraint on economic transactions. Generally, trust plays a pivotal role in this process because it influences economic outcomes by affecting transaction costs. In other words, in circumstances where individuals are more trustworthy, transaction costs as well as monitoring costs are much lower and therefore, property rights are better secured. Thus, greater levels of trust is expected to trigger greater levels of economic freedoms and subsequent economic growth and development. In contrast, lower levels of trust and respect coincides with smaller trading networks between individuals, resulting in higher transactions costs. As a result, one's market transaction potential becomes smaller relative to what it would have been had their levels of trust and respect levels been higher (Boettke, 2009; Williamson and Kerekes, 2008; Fukuyama, 1996; Knack and Keefer, 1997; La Porta et al, 1997; Woolcock, 1998).

\section{5: Examining the role of culture, market-based aid and private sector investment.}

Figure 7.4: Market- and non-market aid for private sector development between 1985 and 2012.

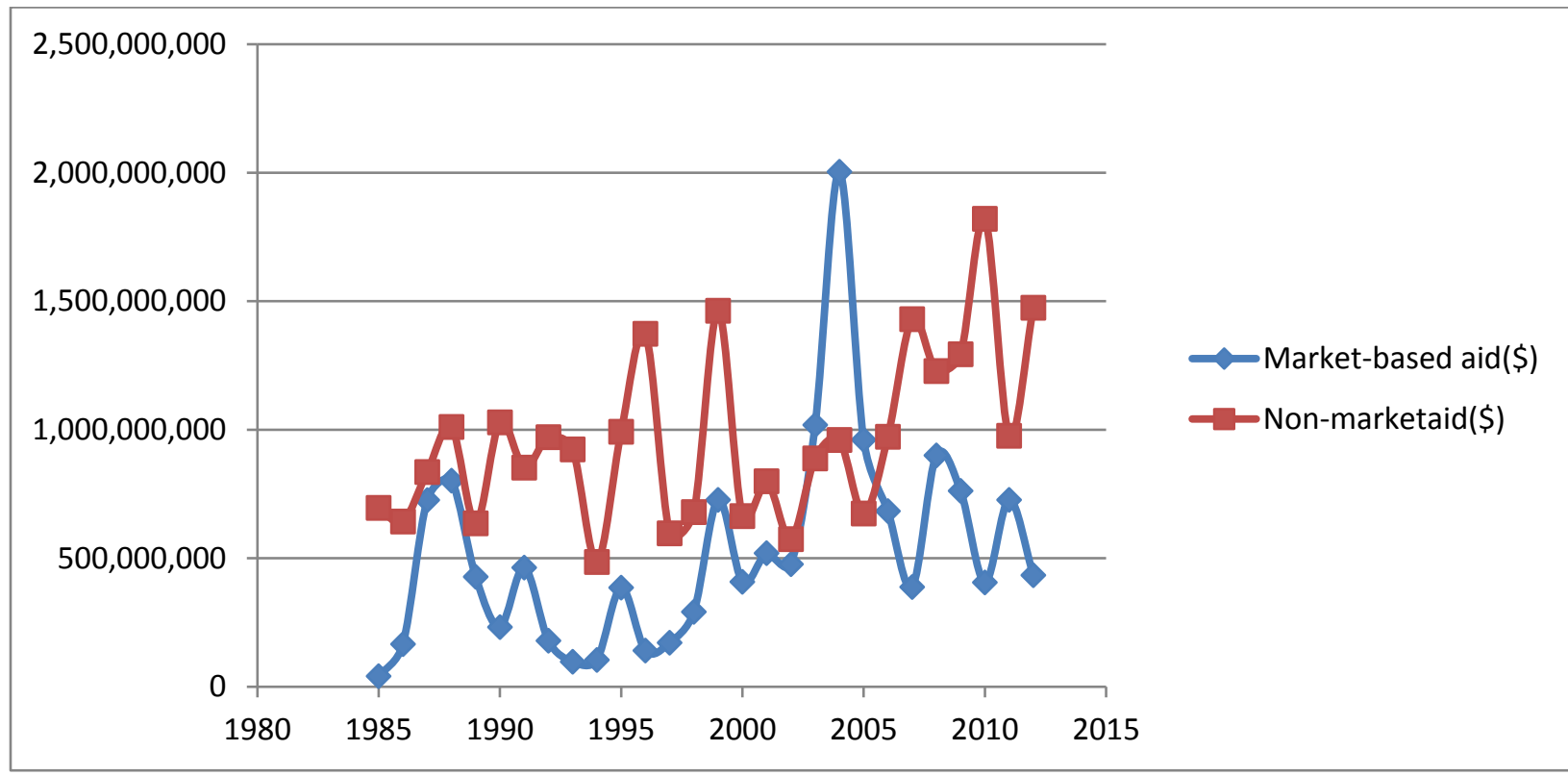

Source: Aiddata.org 
Ghana has been the recipient of massive market-aid toward its private sector development. This is specifically aid for banking and financial services, government services, budget support, and debt relief. For instance, in 1985 Ghana received approximately \$42 million in aid and by 2012, this increased to approximately $\$ 400$ million. In contrast, non-market aid increased from approximately $\$ 700$ million to 1.5 billion in the same timeframe, respectively. Though the disparity in the distribution of these aid types, the private sector continues to thrive, especially with micro-financing, however this is within the informal sector.

Colonialism helped to solidify a small entrepreneurial class, which continues to play a pertinent role in the private sector. Specifically, due to the political and economic framework that was established under the colonial system, a small group was provided with Western education to help the state govern the population. This has in turn played a role in transferring a small class of entrepreneurs as acquired knowledge and resources were distributed to help maintain communal standing. That said, market-based aid has especially been helpful to this group because they are more aware of the availability of this resource, has more access as a result of their communal standing, and are willing to take the risks as they are generally more ambitious in terms of pursue entrepreneurial endeavors that are beyond the micro-and small levels, according to one country expert.

However, the government has been putting measures in place to help encourage all citizens to be more opportunistic by pursuing entrepreneurism, which has sound footing in its culture dating back to pre-colonialism and was later fueled by colonialism. Many producers in the productive sectors as well as arts and crafts played prominent roles in the free-market system 
wherein they local chiefs helped to organize the markets and facilitate fair exchange of goods and services between community members. However, colonialism fueled the process as there was more of a need to produce on a massive and consistent scale. The state developed a twostage system wherein they provided the chiefs with the necessary resources they needed to help fund the productive sectors for mass production, the producers then turned their produce over the local chiefs who in turn handled all transactions with the state. The chiefs, for their role, were provided with a stipend to maintain social order and govern production that aligned with the colonial agenda. That said, at the dawn of colonialism, many of those individuals used some of the skills and knowledge learned to begin SMEs. However, many were limited as a result of lack of funding, connection to funding agencies, social capital (Arthur, 2006; Asem et al, 2013).

However, when JJ Rawling was elected to office there were some efforts to encourage more entrepreneurism by breaking away from the more socialist ideal of embracing the state as a big family. Instead, more emphasis has been placed on encouraging individualism wherein individuals are essentially expected to take more control of their destinies. In order to assist this process, the government has put in place several initiatives and projects in order to promote the growth of the private sector. One of the primary measures that it installed was securing more funding to help relieve the private sector of funding issues and therefore helping to drive both startups and expansions. One of the major contributors of this process has been the National Board for Small-Scale Industries (NBSSI), which is a non-profit public sector organization that is housed under the Ministry of Trade, Industry and Presidential Initiatives that began in 1985. At its core it helps to spur micro and small enterprises, which has historically been the backbone of the economy and its economic development. Thus, in an effort to ensure economic growth, the Ghanaian government established the NBSSI Act in 1981. A pivotal part of the initiative is to 
mobilize funding. For instance, in 2001 over 600 entrepreneurs that operated micro and small scale enterprises were provided small loans assistance under the financial arrangement with NBSSI. In 2002, an additional 104 entrepreneurs were provided small concessional loans. Moreover, they help to provide capacity building programs and activities to enhance the success of these enterprises and to help increase repayment efforts. In regard to the productive sector, capacity building efforts include the distribution of higher yielding seeds, planting equipment, fertilizers, and other necessary agrochemicals that producers need, improving water management and harvesting techniques, etc. Thus far, the program has supposedly helped to establish close to 800 new enterprises - mainly in areas of agricultural production, textile, shoe making, bakeries, and arts and crafts, which are all areas that established a niche within the Ghanaian market over the years (NBSSI, 2003; Arthur, 2006; Steel and Andah, 2003; Dzisi and Obeng, 2013).

Moreover, in collaboration with the U.S the Ghanaian state government was able to secure \$2 million per year for five years from the African Development Fund to help support SMEs between 2004 and 2008. Additionally, the Italian government provided a \$10 million loan in 2004 to also help fuel the entrepreneurial spirits of Ghana. However, there were some stipulations to this aid in that it was only supposed to be used toward entrepreneurs in the manufacturing and agricultural sectors as well as purchasing and importing equipment. These initiatives also helped to foster yearly "Growing the Young Entrepreneur" competition which awards three business plans with startup capital and training. These progresses have contributed to a growing private sector. However, this potential depth has been somewhat strained by the lack of information on external markets and inadequate physical infrastructures that continues to hamper the growth of the private sector. Part of the problem has been the poor energy infrastructure, especially in the rural areas, that has led to power outages from their two main 
energy suppliers -Volta River Authority (VRA) and the Electricity Company of Ghana (ECG). This is has placed an unnecessary and costly burden on the private sector, more so the manufacturing subsector since it affects productivity; disconnects those in the rural areas from the urban areas; and contributes to minimizing potential inputs of citizens to the economy (Arthur, 2006).

Furthermore, although the government has made efforts to reduce corporate taxes, they have in turn tried to compensate by increasing tax burdens in the form of higher levies, tariffs, import duties, and local and state taxes. This has served to impede economic activities within the business sector since potential entrepreneurs has less capital to utilize. Moreover, historically the state has made it a habit of importing cheap foreign imports while utility tariffs are high, which has made the cost of production and conducting business very high. Plus, there are regulatory frameworks that has also contributed to the failure to expand because the bureaucratic process for both registering and starting up SMEs carries high costs due to delays in obtaining licenses as well as debt burden that comes with credit acquisition. For instance, domestic banks help rates of about 38 percent to private enterprises around 2002 while inflation rates hovered around 14.8 percent. Those factors have all contributed to undermining the private sector depth (ISSER, 2002; NBSSI, 2003).

Even more disturbing is that although Western banks and credits unions have increased their presence since the end of colonialism, especially in the urban areas thus giving reasons for optimism, a large faction of entrepreneurs (and the population as a whole) still lack access or accounts as there has been an issue of trust when it comes to borrowing or saving money in formal banking systems. This stems from the fact that people are still skeptical about using 
formal banking due to a lack of lack of trust, according to two country experts. This lack of trust came as a result of the government historically using formal banks as their personal banks without exercising urgency to make amends. Furthermore, those banking institutions have also shown some reluctance to meet the needs of the entrepreneurs because considering the high interest rates the risks are high. This is also substantiated by the fact that many small- and medium-scale entrepreneurs have often failed to capture sufficient funds that is necessary to open and maintain formal bank accounts, which also made it more difficult considering that substantial collateral has historically been demanded by those formal banks as security in order to secure capital. This certainly acts as a deterrent for both banks and entrepreneurs. Therefore, many entrepreneurs have been tasked with relying more on indigenous financial arrangements such as social capital or networks to help gain access to much needed financing to startup or expand on their enterprises. However, this is something that has been refuted by one country expert who argued that as more formal banks came to Ghana it created more competition, which has helped to improve trust levels and enabled people to contribute to the private sector and economic through micro-financing (Chambers-Wright, 1997; Asem et al, 2013).

Also, while micro- and small loan schemes exists, especially at the communal level, that could be used to provide financial support to help the deepening of the private sector, especially small-scale manufacturing and production they also may not come with micro- or small-scale interest rates. For instance, the standard interest rates applied to micro- and small loans could be 20 percent or higher. Moreover, socialism has had a negative effect on the growth of the venture capital market in Ghana. Currently, there is only a small number of capital firms present in Ghana due to the stringent criteria in place making it difficult for private businesses to strive and maximize their potential, especially those in the formal sector and when it comes to small-scale 
entrepreneurs accessing capital. Furthermore, venture capitalism emphasizes not only good management but also factors such as growth potential of the market, the level of competition that the venture may face, the market served, technology and technology, resource availability, and potential profit margins, etc., before determining whether or not a business would be fruitful. However, that is still very much a Western concept that is only slowly being endorsed by local entrepreneurs in Ghana.

\section{6: Culture, market-based aid and domestic savings.}

Figure 7.5: Market- and non- market aid contribution that affects domestic savings.

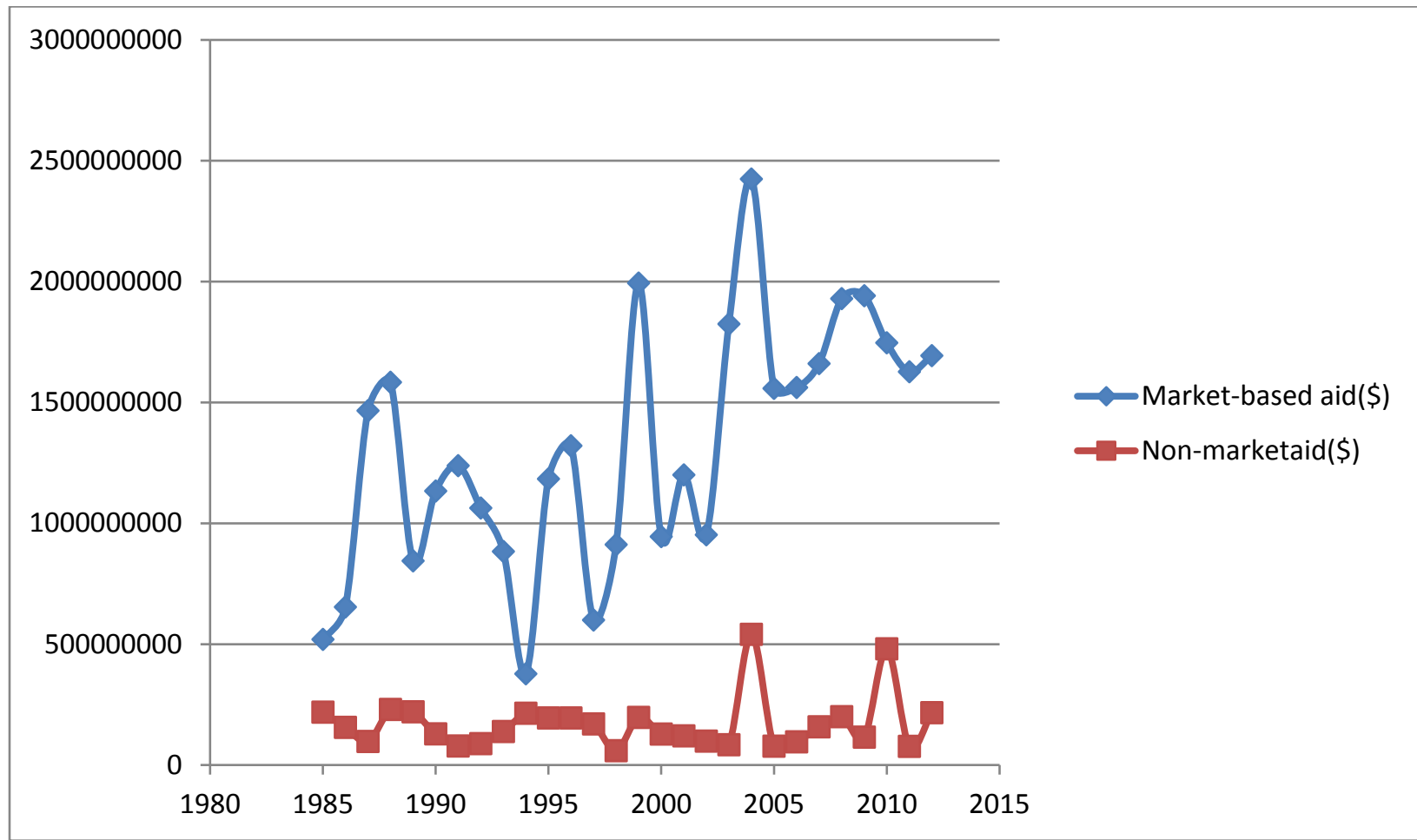

Source: Aiddata.org

Above is an illustration of the amount of aid market-based aid that contributes to domestic savings relative to non-market aid. For instance, aid that goes toward consumption such as humanitarian aid and reconstruction has been relatively low to market-based compared to aid 
contributing to the agricultural production, business sector, financial services sector, security, education, healthcare, etc. For instance, the lowest market-aid contribution was approximately \$400 million in 1994, while the highest was in 2004 at approximately \$2.4 billion. In contrast, non-market aid was in 2011 at approximately $\$ 77$ million, while the highest was approximately \$540 million in 2004.

That said, and not surprising, responses from the country experts were mixed in regards to the relationship between market-based aid, culture and domestic savings. However, they agree that the concept of savings is not foreign to Ghana. In fact, there is a long tradition dating back to the pre-colonial period of individual and group saving practices as a means to initiate SMEs and enhancing their social standing. ${ }^{75}$ Plus, the emergence of formal saving institutions during the post-colonial era along with traditional savings (Susu ${ }^{76}$ - a microfinance scheme) has greatly helped to embed the savings culture in Ghana at the communal level; however, this emphasis on savings has failed to translate to the national level. According to one country expert, "Unfortunately, these cultural elements have not been successfully translated onto the national level. The idea of saving/balanced budget or surplus is not common at the national level. State officials tend to misuse national resources and are not efficient in saving or managing state resources well.” This has in turn helped Ghana's economy to thrive because of some of the economic policies undertaken by the state after independence to liberalize the market and

\footnotetext{
${ }^{75}$ Prior to formal banking, there were several savings practices such as digging holes to store both cash and jewelries; placing cash under beds; and lending cash to family and friends that was later retrieved. Then there was the "Susu" schemes, which was followed by formal savings institutions.

${ }^{76}$ Senegal's Tontine system shares some similarities in terms of the process and purpose. However, the primary difference is that the Susu system is non-rotational scheme whereby savers periodically deposits a set amount of cash to a designated collector at a predetermined time and waits for it accumulate to a set amount. Generally, savers have to pay a fee to Susu collectors, while Tontines may generate a small interest because the money is often used to as loans to non-contributors.
} 
encourage entrepreneurism ${ }^{77}$ (Asiama and Osei, 2007; Alabi et al, 2007; Aryeetey and Udry, 1995).

Market-based aid has helped not only with developing and implementing macroeconomic policies but also formal banking institutions that have made efforts to encourage saving practices through capital formation by providing credit while also providing security of said credit. ${ }^{78}$ This has allowed for entrepreneurs to contribute to the economy. As recently indicated, one of the cultural values of Ghana is the amount of emphasis that they place on wealth accumulation that stems from a culture of "deferred gratification", according to one country expert. This practice is deeply rooted in Ghana's cultural traditions and became even more embedded as a result of colonialism since it helps many to work hard to develop themselves and save for the future in the forms of education, building projects, etc. Elite education that local elites were exposed to and which coincided with wealth formation became a measure of social excellence. Thus, more and more Ghanaians were driven to acquire education and wealth since they were made to believe that those two elements did not co-exist independently. This allowed them not only to trigger their entrepreneurial and innovative spirits but also their drive to invest to further expand their private capital. One country expert conceptualized this idea as "announced competition” because it has become common whereby

\footnotetext{
77 This included making provisions to subsidize credit; the development of the National Investment Bank in 1963, which is geared toward fueling industrial, commercial, productive and other enterprises. Moreover, there was the creation of the Agricultural Development Bank in 1965 to aid the productive sector; the development of the Rural and Community Banks; liberalization of economic policies starting in the early 1980s; and the 1991 provision to establish savings and credit unions.

78 There has been some mistrust of the formal banking institutions in the past, especially immediately after independence because the government used them as their private banks. While they often pressured these institutions to give them exceptionally concessionary loans they often failed to repay, leaving savings and banks short of capital. However, Western pressure has forced them to adjust their borrowing practices, which has changed the attitudes of locals.
} 
Ghanaians like to showcase their levels of achievement. This also provides the incentive for many to save money at the individual levels in demonstrating their wealth accumulation. This is paramount especially considering the family/communal system that Ghanaians live in which demands that they save and contribute to supporting family and communal members, especially in times of births, deaths or other social celebrations, which pressures individuals into saving habits; otherwise, they live in fear of being an outcast due to failure to contribute to family and communal issues (Arhin, 1983; Wilks, 1975).

Similarly, education and private wealth accumulation are generally perceived as social norms and were accorded community and state recognitions, titles, privileges and social respect. Therefore, in many regards one's economic rank carries social weight that many are willing to aggressively pursue through entrepreneurism. The ability of individuals to advance their private wealth and status required more community involvement. Specifically, it is a social norm for wealthy individuals to use their wealth toward advancing the community as a whole rather than simply serve self-aggrandizement purposes. This practice has historically served as a mutual benefit. In essence, while many may use their wealth to provide services to the community it helped them to solidify social capital while also generating fiscal capital in the process as well. This seems to dominate contemporary behavior in Ghana, according to three country experts.

The growing depth of formal banking institutions which has made capital more accessible has also contributed immensely to private wealth creation. However, though the state economy has shown signs of developing, one of the key issues that has limited its potential is the government's inability to implement an infrastructure to better mobilize funds at the local level, which could then be re-invested. This is important in the case of Ghana if they aim to enhance 
the size of its domestic savings and subsequent economy through investing in manufacturing, infrastructural development, etc. However, the private sector has made attempts to network with the informal saving sector by engaging with Susu collector so that they could deposit their purses with them at competitive interest rates. For instance, Barclays Bank Ghana started an initiative a few years ago aimed at reaching out to the informal saving sector, which they accounts for an estimated 110 million euros per years in Ghana Ghana. This initiative has been reasonably successful considering that it has gotten more Ghanaian involved in formal banking (Kunzemann, 2007).

Currently, one of the primary ways in which the government has been able to mobilize capital is through taxation. It uses a Value Added Tax (VAT) system that could be as high as 17.5 percent, which is supposed to be used for further investments in further development. However, the formal sector is still small considering that it contributes to approximately 15 percent of the economy. Therefore, a lot of money is being re-directed through the failure of the government to capture both savings and taxes as a result of the historically large informal market and savings sectors. However, in 2004 the state government did try to address this issue by creating the National Revenue Authority, which brought together three former independent agencies - the Customs Excise Preventive Service, Internal Revenue Service and VAT service. This has somewhat helped the financial institutions to more efficiently mobilize funds, especially from the formal sector while they are trying to efficiently and effectively tap into the informal sector by working with entrepreneurs in the informal sector to convert them to the formal sector (Osei-Boateng and Ampratwun, 2011; Ghana Banking Survey, 2011; Owusu-Danka and Aghoado, 2015). 


\section{Informal savings:}

Informal credit access - there has been informal banking institutions in Ghana known as the "Susu” banking, which is a process of putting petty cash away for various purposes, such as to fund social events, insurance in time of emergencies, or to initiate micro- and small enterprises. This practice is generally conducted by individuals who put aside cash or participate in small social groups. A trusted Susu collector is assigned the task of collecting and keeping the purse. Though it is a practice that is generally done by women, it is culturally encouraged from a very young age starting at childhood wherein individuals are encouraged to contribute to local Susu boxes to help support Christmas and birthday events, etc. This becomes a habit based on self-discipline as well as commitment in order to put away cash on a daily, weekly, bi-weekly or monthly basis for the unforeseen or planned. Moreover, to a certain extent it requires some level of prudence in that those that are not high income earners are tasked with making the necessary sacrifices in order to meet their savings goals. This is important, because relative to the Senegalese culture that endorses the notion of consumption, the Ghanaian culture promote the need to save and be forwardthinking with one's earnings and savings. Thus, according to two country experts, many use their earning and savings toward entrepreneurs such as arts and crafts, cocoa farming, and services and trade, etc.

However, as previously mentioned, though savings has been deeply rooted at the individual levels, it has not translated at the national levels, because the political culture is different at the national level relative to the ordinary Ghanaians, according to one country expert. Corruption continues to be rampant, which has contributed to the national expenditure careening out of control and the bureaucracy becoming more bloated whereby the government developed 
new agencies to audit or keep each other in check; however, they often find themselves having overlapping jurisdictions and functions thus leading to unnecessary overspending, wasteful spending, and oftentimes willful extravagance with public funds and financial ambiguities. Another country expert suggests this has led to further distrust between the state and citizens, resulting in a large number of Ghanaians still choosing to keep their money out of the formal banking system, "It is still common where people keep their monies under their pillows rather than keeping their monies in the bank hence the low effect on national savings.” This is partly because many Ghanaians, especially those in the rural areas, continue to be "suspicious that their money will be embezzled when kept in the bank. The trend is changing though.” This is because the landscape is changing, namely because people are becoming more informed and therefore they are starting to gain more confidence in the banking system, especially those in the urban areas. Moreover, fair interest rates have incentivized savings habits, according to three country experts.

\section{7: Other factors shaping reform efforts and development in Ghana.}

\section{Corruption:}

Both incidental and systematic corruption continues to be a major issue in Ghana, and an argument could be made that this has contributed to the state's failure to reform and meet development objectives. The World Economic Forum ranks Ghana $98^{\text {th }}$ out of 144 states on its global percentile measure that accounts for irregular payments of bribes and issuance of public contracts. Historically, there has been a patron-client relationship between public officials (and tribal leaders) and their constituents wherein they indulge in what is considered corrupt behavior to establish, maintain and enhance their social and/or political powers. Specifically, politics and 
ethnicity are closely intertwined in Ghana; meaning, politicians generally rely heavily on those within their own ethnic groups and districts to elect and keep them in office. Oftentimes, this means that political officials has strong bonds with their constituents and therefore, it is not uncommon for constituents to queue outside the homes of their political representatives to discuss some of the pertinent issues they are experiencing, solicit advise, get updates on existing or anticipated issues, or solicit some form of aide or resource. This could be money or jobs. Thus, assistance that is supposed to be distributed to all gets localized to constituents ${ }^{79}$. The existence of this culture of dependence seems to foster what could be perceived as laziness considering that in exchange for votes, public officials are expected to perform tasks that would be considered unethical, such as funding funerals, local festivals and church fundraising, allocating jobs and contracts to constituents, etc. However, what is often considered corrupt behavior elsewhere might be considered a 'moral' or social obligation of these public officials in Ghana - and the same applies for those with resources (World Economic Forum; Lindberg, 2003).

According to Hasting (2005), corruption is not facilitated by selfishness or private gains in Ghana but rather by social gains - namely power, privilege and responsibility. As a result, while the notion of indulging in corrupt activities are discouraged, the aforementioned sociocultural attributes teaches many Ghanaians to embrace what is considered corrupt behavior. This type of attitude exists not only at the local but also state levels whereby the state government indulges in corrupt activities in its bid to satisfy the social, cultural and material needs of its people even if it means redirecting funds that were allotted to serve a different purpose. Thus, due to the growing expectations of the public, it is not uncommon for public officials to reach

\footnotetext{
${ }^{79}$ Lindberg (2003) argued that in many cases, jobs that are supposed to be open to all become 'job for the boys.'
} 
into the state's coffers in order to try and meet the needs and expectations of constituents (Aboagye, 2005; Hasting, 2005)

\section{Debt issues}

Ghana continues to face serious debt issues despite numerous debt reliefs by the G8 countries through the Heavily Indebted Poor Countries (HIPC) initiative. According to the World Bank, Ghana owed approximately 600 million in 1970. In 2016, debt rose to approximately 21.4 billion. This could be traced back to the SAP efforts after independence; rise in oil prices and interest rates; debts incurred by energy state-owned enterprises, rising costs of electricity and the need to meet capacity and demands, debt servicing fees which are often too high to honor due to short maturities, and loose fiscal policies. However, this has compounded and made matters worse for Ghana in the long-term considering that rising debt is unsustainable and could contribute to a potential debt crisis, which may render the state unworthy of further credit. This would mean possibly seeking assistance from the private sector, which often impose higher interest rates with shorter maturities (Frimpong and Oteng-Abayie, 2006; Anning et al, 2016; World Bank).

The debt burden of Ghana constrains its ability to execute its development agenda, because the reality is that the lack of funds limits it in terms of implementing appropriate macroeconomic policies. Poor fiscal policies and spending practices are expected to continue adding to Ghana's debt burden. Recently, the government attempted to sell approximately 10 billion of local currency debt - which is mainly arrears owed by state electricity and petroleum utilities; however, investors were not willing to take on the risk and therefore only were only willing to take on approximately a quarter of the debt with a short maturity. 


\section{Gender inclusiveness:}

There is relative inclusiveness in Ghana for both genders, and the government continues to employ policies that push this notion through land and property rights; access to credit, finance, and collateral, and inheritance; rights to education, and equality before the law, etc. Thus, Ghanaian men and women have equal legal rights when it comes to procuring land and other properties. Furthermore, there is some gender equality in the labor market considering women are permitted to work many of the same jobs as men; however, traditionally some jobs have been culturally tied to men, while others are tied to women. This is seen in the informal sectors which fosters entrepreneurial activities that are open to both men and women.

In order to comprehend how and why entrepreneurism has been so prominent in the Ghanaian society, one must understand the customary laws, which essentially dictates the rights of inheritance along patrilineal and matrilineal lines; meaning, individuals can born into a matrilineal or patrilineal society thus making their lineage through their mother or father, respectively. However, if the chief land and property owner dies, then only someone within the appropriate gender has a chance to succeed depending on the type of society they were born into. In contrast, their chances are zero if they born into one type of society that misaligns with their gender. That said, considering it is customary for women to enter into early marriage in order to reproduce heirs, women are often tasked with bypassing tertiary education in pursuit of jobs that would help them supplement family incomes, which is often required to provide much needed resources to help the sustenance of immediate family and relatives, such as childcare, offsetting living expenses, and achieving economic independence, etc. This has traditionally led to women engaging in trade within the informal sector, namely because many jobs are low skilled and thus 
require little or no education to be productive earners (Rogerson, 1996; Dzisi, 2008; Agboli, 2007).

However, while men generally play a lesser role in the actual marketplace relative to women, it does not necessary mean that they do not play an important or equal role. Specifically, from a traditional standpoint men are often tasked with playing a more pivotal role at the primary and secondary phases of many business ventures. For instance, men tend to indulge in the labor intensive phases, such as farming, fishing, processing and packing, and carrying produce to market, while women tend play a more dominant role in the actual marketplace.

Though the state continues to invest in measures to further gender inclusiveness to foster entrepreneurism and investments with the establishment of Private Sector Advisory Group, The Ghana Promotion Centre, The Business Assistance Fund, the Rural Finance Project, and Investor's Advisory Council, etc., the reality is that a majority of entrepreneurs exists within the informal sector and therefore, it is difficult for the state to capture taxes. This, in turn, affects the ability of the state to invest in policy development and enforcement.

\section{Economic diversity:}

Ghana is quite economically diverse, hinging mainly on agriculture (mainly cocoa), fruits, fishing, mining (manganese, gold, diamonds), and with recent production of oil. However, historically, the economy has depended on agriculture and mining which exists within the informal sector but could be sold to the state through marketing boards. However, producers are also seeking other external markets to sell their products if the state does not pay competitive prices. This going to bordering states that may provide higher prices. Moreover, access to 
microfinance has contributed to economic diversity since it fosters micro and small enterprises in agriculture, fishing, trade, service, etc. However, considering enterprises exist outside the scope of government regulation, those that borrow money to start a business is essentially only tasked with repaying the loans with previously agreed upon interest. As a result, this freezes the government out of much needed revenues, which results in them having to borrow more funds to employ their policy agenda (Dzisi and Obeng, 2013; Egyr, 2010).

Informal sector:

According to the Ghana Statistical Service, approximately $85 \%$ of all employment exists within the informal sector (approx. 90\% women, 80\% men) wherein their market activities are not controlled, regulated or standardized by the local or state government. Thus, only the approximately $15 \%$ in the formal sector legally contributes to driving economic transformation. This great divide between the formal and informal sectors could be traced back to the free market practice in pre-colonialism and continued in post-colonialism wherein the government tried to foster industrialization through socialist models that required massive injections of funds to develop and control large state-owned enterprises that put the state in position to be the majority employer. This same could be argued with the advance of SAPs in Ghana to foster liberalization of the economy, because it facilitated capitalism and was reinforced by structural policies. Neither of those policies worked since the economy fell short of expectations. This led to the state laying off a large amount of its personnel due to slow growth and growing state budget. Thus, individuals had to create their own opportunities due to them not being able to depend on the state to provide sufficient jobs and resources to meet their needs (Haug, 2014; Osei-Boateng and Ampratwun, 2011). 
Currently, there are three main areas of informal markets in the rural areas. This includes agriculture, fishing, and agro-based processing.

(i) Agriculture - this generally pertains to small, family owned farming, which a large number of individuals do. Many of these individuals are generally considered illiterate or semi-illiterate and therefore, a lack of formal education or training limits their ability to seek employment in other fields. Furthermore, there is a legacy value in farming because many farmers came from a line of farmers. Plus this is a low technology practice and there is a lot of accessible land that allows farmers and potential farmers to indulge.

(ii) Fishing and fish processing - along the coastal lines, it is not uncommon for individuals to indulge in fishing and fish processing. The knowledge and experience acquired often transcends generations or through practice from a young age. They then add value by processing fish by salting and/or smoking the fish before taking them to market, which is a task generally undertaken by the women.

(iii) Agro-based processing - many farmers generally involve processing local produce, such as cassava to gari and flour; palm kernel, peanut, and copra (coconut) oils, etc. Generally, this segment of economic activities is dominated by women.

There is also a thriving informal sector within urban settings, namely in the services; construction; and manufacturing sectors.

(i) Services - this includes food traders, wholesalers and retailers, caterers, etc. This sector is generally dominated by women who are low-income earners. Furthermore, there are individuals in the healthcare and sanitation sectors, namely individuals selling medicinal and 
herbal remedies; chemical sellers; garbage collectors, etc. Additionally, there are domestic workers; appliance repairer (radios, refrigerators, cars, etc.).

(ii) Construction - this includes carpenters, masons, plumbers, etc., that are generally young men with the necessary skills to practice through short-term apprenticeships.

(iii) Manufacturing - this includes food processing, wood processing, fashion and garments, etc.

The Ghanaian people continue to find ways to exist within the informal sector, which has traditionally been the case. However, they do so with some risks considering there is no job security, social security, and often minimum wage, etc. Traditionally, it is women that have dominated the market sector or engage in actual trade while men dominate in the more labor intensive parts of the process. However, it is evident that there is some collaboration between men and women, which has historically helped men to advance their skillset to use their strength to boost production, while women have advance their abilities in becoming better traders. However, the reality is that instead of reducing as the modern economy grows, the informal sector actually continues to grow, which has contributed to the state's ability to design and implement its reform agenda (Hormeku, 1998; Osei-Boateng and Amptratum, 2011; Ghana Banking survey, 2011).

Though the government has made some efforts to mitigate the growing informal sector problems to help generate revenues to help foster its policy agenda, it has not been very successful. A majority of the informal sector are self-employed and therefore, they control their own incomes. This autonomy is embraced by many, and even in light of a recent Labor Law (Act 651, 2003), employers do not seem to be complying with it. Furthermore, even though there is a 
legal infrastructure in place, the employment characteristics of the informal workers and the various agreements between employers and employees make enforcement somewhat problematic.

That said, the rest of this case analysis will focus on discussing the various findings that was gathered from five country experts as well as country reports and empirical journals as a means to help explain the relationship between market-based aid and economic reforms while accounting for how Ghana's steeped cultural traditions may have affected this relationship. The expectation is to highlight some of the key cultural and traditional attributes and their effects on aid effectiveness. 


\section{Chapter 8: Conclusion}

The sub-Saharan region continues to receive more aid relative to other regions, yet it remains without doubt the poorest - with many of the poorest states in the world accounted for. Donors and policymakers have employed various policy measures over the years to try and change the growth and development trajectory of the region, such as the "Big Push", import substitution industrialization, SAPs, aid for trade, etc. While some of those efforts have had some meaningful success, it was not enough to lift Africa out of its current state of dependence, which has left many Africans disillusioned about their futures. That said, a central part of my research was to re-examine the aid-reform nexus and propose a simple but logical way in which subSahara could achieve some sustainable economic growth and development. Specifically, I argue that donors need to re-examine their policies regarding the aid types they allot to sub-Saharan states considering not all aid types have the same or similar effects on reform and subsequent economic growth and development. Particularly, more efforts must be made to allot more market-aid relative to non-market aid. This is because non-market aid feeds consumption and is more likely to extend the current cycle of poverty, while market-aid provides an avenue to foster pragmatic economic reforms which are necessary to support long-term economic growth and development. The long-term expectation is that implementing policies that accounts for the local conditions of individual states would put these states in positions to take leadership roles in their own growth and development agendas.

That said, in order to gain a better understanding of my theory, I conducted both quantitative and qualitative analyses. In the quantitative analysis, the findings were inconsistent with my predications and the literature. This may have been the result of the data used; the states 
examined, the statistical technique used, or a combination of those factors. However, failure to acquire findings that are supported by the literature still lends to our understanding of how aid works or does not work. This is more important when asserting that statistical models cannot be fully relied on to explain how aid works in individual states. That is why I examined two states in West Africa - Ghana and Senegal, because case analyses helps to reveal certain nuances that cannot be captured by statistical models. Both states share some similarities and dissimilarities, which makes them interesting to compare. Upon gaining independence, they experienced different levels of growth and development, namely because of the huge disparities in market-aid aid allotted in post-independence era; varying policies they have implemented which has had different levels of success; cultural and social systems that governs decision-making and how policies are implemented; and how resources are distributed. I argued that cultural attributes play a pivotal role in facilitating the success of reform efforts thus I made an effort to place sufficient emphasis on how key traditional and cultural elements may have affected the relationship between market-aid and economic reforms, which includes government capacity building, economic freedom, private sector development, and domestic savings. This is supplemented by the literature as well as country experts from different disciplines.

\section{1: Summarizing cases findings.}

\section{Senegal:}

Senegal has been touted as the most stable state within the sub-Saharan region. However, political and economic stability have not translated to sufficient economic reforms and subsequent economic growth and development. Many Senegalese live by a different code in that they do not place too much emphasis on wealth accumulation. Instead, they seem to place more 
value on building social capital or social standing within their communities. From a young age Senegalese are taught to share, and this sharing culture appears to affect their ability to save. While many indulge in micro-level savings, namely Tontine schemes, there are social pressures to invest savings to benefit others - mainly community and/or family needs, such as community events, births, funerals, etc. This culturally rooted perspective on wealth accumulation is also evident at the national level. However, country experts had mixed perspectives in terms of whether or not market-aid is likely to positively affect domestic savings while accounting for the cultural practices of Senegal. Specifically, while there were some suggestions that market-aid fostered a positive relationship, others suggested otherwise.

Though left with a strong state capacity after independence, especially in urban and key rural areas, policy success continues to be influenced by the ability of public officials to collaborate with Marabouts who citizens generally favor when they need advice - whether it is political, economic, or religious. Colonialism helped to enforce this two tier system between state and society wherein Marabouts, the religious leaders at the communal levels, were essentially legitimized by the French administration in order to more effectively and efficiently administer its policies at the local level. However, in the post-independence era, this system have created some frictions since the Marabouts have gained considerable influence and have deeply embedded themselves in the political arena. As a result, this relationship has affected policies toward the private sector since the state is generally tasked with providing financing to promote SMEs at the local levels. Funds are generally distributed to Marabouts who, in turn, distribute said funds to their disciples. However, in cases where these religious leaders deem the policy not to be in the best interests of their communities, they are likely to reject both the policy and funds given to implement the policy, which is likely to leave public officials in a dilemma until a 
compromise could be made. The ability of public officials to convince religious leaders to employ state policies is paramount. Over the years, heads of states that have embraced this traditional institution have had more success in their reform efforts relatives to those that threatened to separate politics from religion. Generally, public officials that do not gain the support of Marabouts are less likely to gain access to office.

Failure to secure compliance with Marabouts generally has a negative effect on the private sector, especially in the rural areas. The state generally distributes resources to the Marabouts who then distributes them to their followers. And as previously indicated, in times when there are disagreements with policies choice, it often has a negative effect on the ability of individuals to contribute to the economy since the funds that come with the policy is rejected.

Lastly, findings regarding the effects market-aid has on economic freedom were mixed; however, there were some agreements that economic freedom have been a part of the Senegalese culture. There is a large informal sector and traditionally, Senegalese have heavily relied on social capital to enforce contracts between market participants. This allowed individuals with great social capital to have greater market maneuverability, while the opposite is true for those that have limited or not social capital.

Ghana:

Ghana remains one of the largest recipients of foreign aid in the post-independence era; yet it remains dependent on aid to execute its functions. While the state has the capacity to design and implement domestic policies, traditions steeped in economic freedom combined with liberal policy directives have led to an expansion of the informal sector and a failure of the state to effectively enforce its tax system to capture a larger tax base which, in turn, inhibits its ability 
to design and implement reform efforts without further leaning on aid contributions. Similarly, with a large informal sector the private sector continues to grow; however, it also remains generally unregulated by the government even though there have been many efforts to regulate it, but those efforts have generally eased into the background due to failure to comply.

Another component that needs to be addressed is the growing presence of Chinese aid relative to Western aid in Ghana. Though China have been present in Africa since the 1950s or so, they have only announced themselves as legitimate rivals to the West in the past two decades or so. According to AidData.org, China has surpassed U.S aid in Africa and is on course to rival the West, in general. This shift in the aid landscape is also reflected in Ghana wherein there has been some sentiments that the Chinese are better partners, namely because they operate with less red tapes and do not get involved in domestic politics. Whether or not this approach is destined to provide Ghana (and the rest of Africa) with sufficient avenue to build capacity so that it could further its policy framework to promote economic freedom, private sector investments, and domestic savings is still debatable; however, it is a matter that we must continue to monitor as China continues to raise its influence within Ghana and the region.

Lastly, although many Ghanaians save, often using informal means, the saving culture is different at the national level wherein public officials often overindulge in corrupt behaviors, which mitigate its saving potential. This overindulgence breaks away from the culture embraced by individuals who generally invest in "susu" schemes if they have plans to start a small enterprise or to save as insurance. In order for Ghana to save, the government needs to embrace more a saving mentality. The reality is not that they cannot save. Rather, those in power choose not to save. 
That said, like the findings in the statistical analysis there were some inconsistencies in the qualitative analysis section. However, the qualitative analyses did provide much needed insights into some of the nuances of each state, which could contribute to the understanding why aid may not be working and how it could possibly be more effective. Considering what was learned from the literature and, more importantly, the country experts, it is important that more emphasis be placed on the critical development approach, because considering what we know it is apparent that neoliberal, one-size-fits-all approaches that are promoted or imposed by the west has not worked. Emerging economies are all different and therefore has unique factors that must be accounted for in development policy design if aid is to be maximized.

\subsection{Critical development approach: aid and development in sub-Sahara Africa}

Amidst the expanding development literature, a shift is evident in regards to the rhetoric used to articulate the interaction between aid effectiveness and development across the subSahara region. Specifically, a large volume of the literature continue to fail in adequately addressing the foreign aid (in) effectiveness-development nexus. This is due in part because it place too much emphasis on macro-level indicators, which have generally been critiqued for failing to capture valid understandings of the realities and conditions of African states and therefore, in turn, it fails to contribute to the formulation of pragmatic development policies. This issue is especially the case considering Africa is rich in diversity in terms of its myriad of cultures, traditions, ethnicities, religious beliefs and practices, and other social constructs. Therefore, trying to employ western ideas and/or 'one-size-fits-all' models contribute to the underdevelopment of the region rather than support development, because they fail to account for the local realities and conditions of individual states, which are pivotal for addressing basic 
needs, such as the interconnected freedoms identified by Sen (1999): economic, political, and social freedoms as well as transparency and protective security. Failure to address the aforementioned elements is likely to support underdevelopment (Escobar, 1995; Sen, 1999; Rodney, 1973).

That said, when trying to understand the relationship between foreign aid and development across the sub-Saharan region, it is important that it is examined through the African context. Particularly, each state is different - and even within each state there are apparent differences that has to be accounted for when trying to understand aid effectiveness and development. Therefore, without placing sufficient emphasis on understanding the local cultures, traditions and conditions of individual states or soliciting vital input from local individuals and communities to help address their own problems, the likelihood of aid being effective will remain low. Therefore, more systematic efforts need to be made to understand and cater development policies to accommodate the internal dynamics of aid recipients if it is to contribute to meaningful development. Generally, individuals and groups have different fundamental beliefs, practices and traditions, which are factors that help to shape their perceptions and understanding of what development means and should look like. Therefore, the expectation is that if the aforementioned factors are not accounted for, then it is impossible to have a more holistic comprehension of the dynamics between foreign aid, culture, and socio-economic and political development across the region.

\section{Driving forces of aid failure in sub-Sahara:}

There continues to be some contention regarding what has been at the core of explaining the failure of aid to be effective across the sub-Saharan region. In other words, is the failure of 
aid to transform sub-Saharan states the result of internal factors, such as failure to reform, corruption, lack of leadership, etc.? Or, could it be attributed to external issues, such as an unfair global economic system that marginalizes many African economies? Or is it both? According to Akonor (2008), foreign aid to the region has been tantamount to a "band-aid" and thus far has lacked the potential to foster long-term solutions since it is not intended to structurally adjust the struggling African economies to ease them out of their dependent situations. However, he asserted that meaningful development may be achieved if donors consider investing in projects such as infrastructures, telecommunication, and energy sectors, etc. Others have emphasized that the global economic system has played a pivotal role in facilitating Africa's dependency. Frank (1966) argued that in order to understand underdevelopment across the region one must have some understanding of the global economic system, which has contributed to Africa's current fate wherein capitalism has helped to further marginalize the region. This notion is supported by Bauer (2000) who argued that foreign aid facilitates dependency because it promotes the notion that mitigating poverty hinges upon states being able to attract more foreign aid rather than on the efforts and motivation of citizens and the development of appropriate and functional institutions (Frank, 1966; Amin, 1972; Bauer, 2000; Akonor, 2008).

Additionally, the often perceived lack of effective governance and bureaucracies has been argued to be a key contributor of Africa's development condition. However, considering the various phases of development that Africa has navigated through, the aforementioned notion seems somewhat contradictory considering the emphasis that has been placed on employing neoliberal principles to mitigate the role of the state in its domestic economy. Although some critics suggest foreign aid has contributed to the weakening of state bureaucracies and the ability to govern, the capability of state bureaucracies are essentially unaffected by foreign aid, 
according to Goldsmith (2003). Similarly, the literature also suggests that Africa's failure to develop may rest on the notion that state institutions generally do not have the capacity to adhere to its development goals and objectives. Moreover, the supposed failure to establish capable institutions have contributed to many leaders taking advantage of these states by converting them into "vampire" or "pirate" states whereby leaders use the state for selfish reasons or to accumulate massive wealth at the expensive of citizens. Therefore, efforts need to be made to remove these leaders from office if they are to design and implement sustainable development plans (Chakravarti, 2005; Goldsmith, 2003; Ayittey, 2002b).

The importance of culture in development policy design:

According to Rostow (1960), the development of Africa hinges on its ability to rid itself of its "traditional societies" and conform to Eurocentric cultural values, beliefs, and ideologies. Others have generally failed to place sufficient emphasis on the importance of culture when designing policies to foster Africa's development strategies. This is primarily because 'culture' as a concept is considered to be too vague and dynamic to address within development plans and strategies. Therefore, this makes it challenging to formulate policies when certain factors are too vague and are continually changing. Though the aforementioned has some merit, it is still important that policymakers and donors are able to account for the local knowledge, cultures, traditions and conditions of the recipients as those factors could contribute to development of recipients rather than impede it. For example, Ghana and South Korea had similar economic growth trajectories during the 1960s; however, presently, while South Korea has made tremendous strides in terms of securing economic growth and industrialization, Ghana continues to solicit aid for its sustenance. Huntington (2000) attributes this difference to the role of culture. 
Specifically, he argued that "South Korea valued thrift, investment, hard work, education,

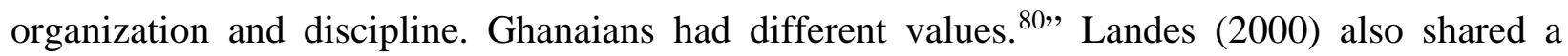
similar view by suggesting, "if we learn anything from the history of economic development, it is that culture makes almost all the difference.” Therefore, while foreign aid could support development, it could also hurt the process if cultural attributes are not incorporated, because the reality is that in order to address a state's problems ideas and solutions from within must be considered. According to Sen (2004), since "culture engulfs our lives, our desires, our frustrations, our ambitions and the freedoms that we seek," pursuing for instance a "high GNP per head but little music, arts, literature, etc., would not amount to a major developmental success." Thus, the assertion is that culture is important because it helps to shape our behaviors, values, and ambitions, etc. (Landes, 2000; Huntington, 2000; Rostow, 1960).

Granted, culture does not fully explain the failure of aid to effectively promote development. However, it is essential that donors incorporate the cultures of recipients when designing policies if they truly hope to maximize aid allotments, because "integrating value and attitude change into development policies, planning and programming is...a promising way to assure...the world does not relive the poverty and injustice (Harrison, 2000). This notion is supported by Hyden (2006) who asserted that donors should not undermine the value of culture because it forms the foundation from which both formal and informal institutions emanate. This is especially essential in Africa considering the level of diversity, which has contributed to its rich socio-cultural roots in its political arena. Therefore, it is crucial that donors are willing to

\footnotetext{
${ }^{80}$ Interestingly, Huntington does not explain what those values are that he may be referring to. However, what seems somewhat apparent is that he is suggesting that Ghana must shape its culture and character in order to attempt to catch South Korea. Moreover, he is grading both states according to western scales and values. Therefore, Ghanaians - and even south Koreans could interpret this differently from he does.
} 
collaborate to design and implement appropriate development paths for recipients to adhere to. This begins with donors making conscious efforts to comprehend the local realities of individual states. Therefore, investing more money is not the sole mechanism through which states could pursue its development objectives. Measures need to be put in place to understand and incorporate the myriad of cultural attributes into decision-making if the sustainable development is to occur (Harrison, 2000; Hyden, 2006).

The above sentiment is reinforced by Escobar (1995) and Reusse (2002), who argued that when foreign paradigms are imposed upon recipients without any considerations for the domestic socio-cultural dynamics, it is a recipe for failure. Therefore, they argue that if donors expect aid to work it is essential that they gain an understanding of the internal cultural dynamics before designing and "applying an interventionist paradigm because development efforts...must be situated within the cultural contexts” (Reusse, 2002). Equally important is the need to also include the people that the aid is targeting so that they could participate in the decision-making process. In other words, the opinions and suggestions of recipients and the local people should be captured and incorporated into the policy designs. This is expected to help mitigate the constraints of both physical and institutional distance that generally exists between donors, recipients, and society that are affected and the decision-making processes which, in turn, fosters greater buy-in and accountability.

Moving from statist toward a bottom-up approach:

Modernization theory gained a lot of traction in development planning during the 1960s as many African states were earning their rights to self-govern. Modernization theorists argued that in order for African states to modernize like their western counterparts, it was important that 
they abandoned their traditional constructs and employ similar social and institutional systems that were found in the west. However, despite the great disparities in terms of cultural and traditional systems between African states and their western counterparts, modernization theory became a powerful development strategy, especially for those seeking to gain economic development. Central to this strategy was the need to emphasize building industries and promoting trade in order to foster economic growth. However, in order for this strategy to succeed, states were required to invest heavily in large-scale projects, including infrastructures, energy, and communication systems, etc. Generally, these projects were supported and coordinated by the state, World Bank, IMF, etc., as a means to facilitate development (Lewis, 1955; Rostow, 1960).

Though modernization theory gained a lot of leverage in the development literature, in retrospect, it is understood to have contributed to the destruction to many institutions and cultures of recipient states. Though international aid agencies and foreign states employed central planning to help better the lives of Africans, the reality is that such objective has still not been realized. Instead, what continues to be evident is a growing number of poor and vulnerable Africans due to the failure of the statist, trickle-down approaches that were initially viewed as the best way forward for Africa and Africans. Even in cases when donors elected to transfer technology to recipients with the expectation that it would help drive the development process, it generally failed work. Therefore, while this transfer of technology often helped to solidify the economic standing of donors within the global economic system, the economic wedge between the rich and poor within recipient states appear to be widening (Brohman, 1996; Chambers, 1974; and Gerrit, 1997; Stiglitz, 2002). 
The failure of modernization theory contributed to the emergence of dependency theory. This theory attempted to explain the causes of poor economic performance and growing poverty rates across emerging economies, especially in Africa. However, like modernization theory, it became apparent that dependency theory placed too much emphasis on large-scale economic factors while ignoring key factors, such as the role of social, cultural, and political context of recipients in decision-making processes (Willis, 2005).

Those shortcomings resulted in scholars looking for alternative approaches to help foster aid effectiveness and development across the Africa (and the developing world, in general). Central to a new alternative was the need to account for internal differences across recipients. This includes variation in cultures, traditions, ethnic composition, and religion, etc. Therefore, it is important that when designing appropriate development policies the policymakers must consider the dynamic social, cultural, and political contexts of recipients. Thus, in order to best break the cycle of underdevelopment, states must develop and/or adopt individualized alternatives that incorporate their own conditions and realities (Rahim, 1994; Hague, 1999).

Considering the aforementioned theories failed to emphasize a key element of development efforts across Africa - the people/local participation, aid agencies have since made, and should continue to make, efforts to support more people-centric approaches in order to facilitate sustainable development. This much needed shift promotes the need for individuals and community-based involvement in decision-making. Specifically, this approach focuses more on gathering grassroots information and data wherein individuals not only voice their specific needs and expectations but also contribute to the decision-making processes regarding appropriate action plans and implementation and resist the imposition of development measures that were 
formulated by external parties without contributions from local actions. Therefore, the local people become vital agencies through which decisions are made. Therefore, in formulating meaningful development policies it is important that the state and donors acknowledge and respect the local people and communities in that they are given the opportunity to decide both the values and meanings of development rather than allow the state and donors to dominate the development process in spite of them lacking sufficient knowledge and information of the people's need and desires. Therefore, according to this argument, in order for aid to become most effective, the people that aid allotments are targeting must be encouraged to become more involved in the decision-making process, because they could provide pivotal local knowledge and policy support, while also becoming empowered (Ragim, 1994; Brohman, 1996; Waddington and Mohan, 2004; Egger, 1995; Henkel and Stirrat, 2001; Keough, 1998).

Thus, as previously mentioned, in response to, and rejection of, the top-down or statist approach to development, donors are beginning to endorse bottom-up approaches as the most pragmatic way forward for Africa's development. This is because this approach allows for more plurality for achieving set development goals and objectives, while allowing citizens to participate in the decision-making process of policies that will affect them. Considering the state is viewed more of an impediment to participation, the bottom-up approach promotes the notion that civil society could better organize and the local levels to formulate more creative and appropriate solutions to address their own problems - and usually this is done in concert with those that are expected to be affected by the policies. Generally, the state apparatus and large aid institutions are inflexible, overly bureaucratic, and unaccountable. Civil society, in contrast, is regarded as more accountable and aware of their own realities and conditions, because individuals and local communities are better positioned to understand their own needs and to 
consider the roles of local institutional structures and traditions, which are likely to be more efficient than what they are often credited for by the state and also donors that are foreign or uninformed about the local cultures and conditions. This results in them (donors) imposing foreign development concepts on recipients even though logic would indicate that foreign development models that has no consideration for local conditions have thus far failed recipients. This is because donors have failed to arm themselves with sufficient knowledge and respect for local cultures, traditions, and conditions of recipients. The only way forward is to support approaches and strategies that emphasizes bottom-up processes, which endorses social inclusiveness. Therefore, people-centric models could help to break the cycle of poverty across the sub-Sahara region because participation in the decision-making processes fosters much needed capacity building and empowerment since this helps to generate information and data on the specific needs and expectations of citizens while also helping to secure much needed support in implementation process. This, in turn, contributes to aid becoming more effective (Mohan and Stokke, 2000; Hyden, 1997; Martinussen, 1997; Easterly, 2006).

Empowerment is critical to this process, because the expectation is that local individuals and communities could be called to not only define but also set their own development goals and objectives; assess the implications of policies that are brought before them, and be held responsible for decisions they made in pursuit of their agreed-upon development agendas. Therefore, through empowering individuals, the expectation is that they would more effectively communicate their issues, ask the right questions, and contribute to pragmatic solutions. This would involve locals coming together to share and develop ideas and consensus as a means to gain more control over their own realities by organizing, initiating appropriate development plans, taking action when necessary and being able to lead and/or contribute to the 
implementation processes of their development plans (Waddington and Mohan, 2004; Brohman, 1996).

Including women in development planning:

The roles of women are generally ignored and/or overlooked when formulating development agendas. This has essentially led to their interests and voices being neglected in a majority of the statist approaches, despite the fact that they play a crucial role in the productive sectors in emerging economies, especially across Africa. Therefore, in order to seriously design appropriate development plans, it is imperative that aid agencies and donor states make more of a serious attempt to recognize, integrate and improve women’s involvement in their initiatives as a means to further facilitate pragmatic and sustainable development strategies (Cornwall, 2003; Brohman, 1996; Koczberski, 1998).

Central to this process would be start supporting initiatives that promote efforts to integrate women into development planning within their communities and at the national levels too, because having decision-making authority at the national level affects how planning are conducted at the local levels. This would play a pivotal role in recognizing that woman could be key decision-makers within society and could contribute immensely to their futures by being productive citizens rather than remaining marginalized in development planning. One of the key issues facing Africa and Africans is poverty, however, women and children seems to be more vulnerable. Therefore, it is imperative that women are called upon so they could emphasize strategic gender needs, expectations and how they could possibly address their issues through social change. 
One initiative that could give voice to women is through proactive community organizations, which could help them to establish and maintain much needed solidarity and outcomes. Moreover, this avenue could possibly help provide the means through which women could advocate for their own needs. However, the reality is that there are risks, especially if these organizations are led and/or influenced by men and therefore they may use their positions to divert women from achieving their key objectives. Therefore, it is crucial that women with common ideals and goals that are willing to voice their opinions through their opinions are able to openly do so through community activism so that they could participate in the decisionmaking and planning process of development efforts.

\section{Encouraging more civic engagement:}

Central to development and employing sound development strategies is the need to encourage more civic engagement - or in other words, active citizenship. This is pivotal because it promotes the idea of freedom of expression and the right to contribute to decision-making and policies that affects one's self. Generally, this involved individuals willingly partaking in the political, communal and social arenas in hopes of shaping their environments. The expectation is that through civic engagement, individuals will be able to enhance their social standing or capital which, in turn, will increase the level of control they have in the distribution of socio-economic resources and therefore, contribute to the transformation of how development plans are formulated and implemented by fostering stronger and more collaborative relationships with agencies, NGOs, and communities through dialogue and participation at the state and society levels. Civic engagement becomes even more pertinent for minorities and marginalized groups who are generally ignored at the state level - or are pushed to the social peripheries. Through 
civic engagement, the expectation is that development agencies and civil societies would be better positioned to use alternative approaches which would improve the outcomes of development strategies through active participation. However, central to achieving that feat would be to encourage state governments to respect the rights of their citizens to participate in civil society by voicing their opinions and contributing to decision-making (Cornwall, 2003; Gaventa, 2004; Hickey and Mohan, 2004).

Incorporate local values and knowledge:

Local values and knowledge has not always been considered as an important factor in the development literature. However, in recent years this has changed. Many scholars assert that individuals who have lived or spent their entire lives within a community setting or has direct stake in the outcome(s) of any development agenda are expected to have very insightful and knowledgeable contributions that they could share with donors to enhance the effectiveness of aid contributions. However, the reality is that modernization approaches have largely been dismissive of traditional knowledge by articulating that traditional knowledge is part of the problem and not the solution, namely because many of the traditional understandings, especially across Africa, are considered too primitive, misguided and unsubstantiated. The reality is that planners from external agencies that are tasked with designing and implementing development policies for Africa oftentimes perceive the realities and conditions of African states differently. This, of course, contributes to development efforts failing to yield expected outcomes. This has contributed to the notion that the level of effectiveness that any development intervention achieve will partly rest on the efforts that donors take to understand and integrate the local knowledge, customs and practices of Africa. This includes being respectful of the various local 
concepts, beliefs, values, goals, and processes that may have been proved effective in the past. Central to taking this route is that it helps to foster respect and trust between the planners and locals as well as build much needed support or buy-in (Brohman, 1996; Mathur, 1995; Keough, 1998; Stiglitz, 2002).

Failure to promote inclusiveness and dialogue with the local people and communities is likely to foster unnecessary suspicions that decisions made on the behalf of the local people and communities may have, in actuality, been made on behalf of special interests. Therefore, engaging in dialogue could encourage the transfer of knowledge and information; promote the sharing of ideas and critical thinking on key issues, and help to establish appropriate development goals and objectives while accounting for the internal dynamics of the recipients (Stiglitz, 2002; Freire, 1972).

That said, the aforementioned could have played a crucial role in furthering the legitimacy of the study. Gaining access to local individuals and communities that may have played a role in formulating their own development agenda could have helped to substantiate the need for more emphasis on employing critical development alternatives. If there were sufficient resources available, it would have been logical to at least consider moving beyond the opinions of country experts and go the source - local individuals and communities - to more closely examine whether market-based approach is working or not. If so, then could be done to further development on the ground across Africa. Would this involve emphasizing market-based approaches? Or should there be more emphasis on social development wherein there is a conscious investment in people? Either way, what many would agree on is that more efforts need to be made to remove or mitigate barriers that prohibit individuals and communities from 
pursuing betterment. This may start with catering to their educational, healthcare and security needs, which may contribute to their long-term economic prosperity. This is because an educated community is more likely to contribute innovatively to fixing their local problems; if they are healthy they are likely to be more productive, and if they are provided with a safe environment they could help secure development initiatives.

\subsection{Future directions:}

There are two areas that are being considered for expanding this research. First, considering that I am examining only two case studies, an argument could be made that findings are difficult to generalize. Therefore, I believe that expanding the number of cases may allow me to gain a better understanding of the relationships I am studying - and make findings more generalizable. Specifically, increasing cases would require including more sub-Saharan states to determine if differences in culture, geography, colonial legacies, political structures, and aid allocations, etc., have affected the relationship between market-aid and economic reforms. Moreover, I would also like to determine if there are differences across other developing regions, especially Latin America.

Secondly, qualitative analyses are important in documenting some of the nuance elements that are difficult, if not impossible, to capture in quantitative methods; however, I believe including a more rigorous quantitative methods section would add more legitimacy to my study, in general. Specifically, conducting some regressions using a different technique to determine if findings either confirms or disconfirms qualitative findings would add some rigor. 
Appendix A:

Purpose statement:

A country's unique culture, traditional beliefs, norms and practices as well as its political and economic policies and framework, etc., contributes to its long-term growth and development. That said, central to this study is trying to further my understanding of how Ghana's/Senegal's cultural and historical attributes may have affected the relationship between market based-aid and its ability to reform economically. Specifically, I would like to determine whether or not higher market-based aid appropriations may have had a positive effect on reform efforts across Ghana/Senegal and the role cultural attributes may have played in this process.

\section{$\underline{\text { Research questions: }}$}

QI: How has Ghana’s/Senegal's unique history and traditions together with market-based aid affected its domestic saving practices? In other words, considering Ghana's/Senegal's history and cultural traditions, do you believe aid allocations have affected state saving practices?

Q2: Economic freedom - defined as the ability of individuals to engage in free enterprises (free markets or trade) and the government securing one’s property rights, etc. - plays a crucial role in advancing reforms. Has Ghana's/Senegal's history and traditions been conductive for individualism in terms of fostering autonomy, risk-taking, and entrepreneurship? Furthermore, how has market-based aid allocations contributed to this process?

Q3: Aid is often viewed as a vehicle for building strong government capacity considering it may provide much needed technical assistance and transfer of knowledge through collaborations and training, which may help governments to design pragmatic policy solutions that account for local realities (rather than implement polices modeled after western ideals). That said, has market-based aid together with Ghana's/Senegal's history and traditions helped to enhance its capacity to govern?

Q4: Reform is pivotal for private sector development and investments. That said, accounting for Ghana's/Senegal's traditions and history, has market based aid appropriations affected the size of the private sector or investments?

4b: Has market-based aid together with Ghana's/Senegal's traditions and history helped to facilitate investment and innovation in the private sector?

* Market based aid is conceptualized as capital flows from donors (both bilateral and multilateral) to recipients that goes toward building government capacity, which helps them to develop and implement appropriate policy frameworks (including trade policies and regulations); drive economic freedom; develop private sector, and help enhance domestic savings. 
Specifically, this may include aid specifically for technical training/education, trade policy development, communications infrastructure, business and banking sector development, financial services development, security, etc. 


\section{Bibliography:}

Abuzeid, F (2009) Foreign aid and the big push theory: Lessons from sub-Saharan Africa. Stanford Journal of International Relations.

Acemoglu, D., et al (2001) The Colonial Origins of Comparative Development: An Empirical Investigation. American Economic Review.

Acemoglu, D., et al (2003) Institutional causes, macroeconomic symptoms: Volatility, crises and growth. Journal of Monetary Economics.

Adkins et al (2002) Institutions, freedom, and technical efficiency. Sothern Economic Journal.

Adkins, Lee C., et al (1998) The determinants of international variation in technical efficiency: Estimates from a stochastic frontier production. Presented at the 1998 Southern Economic Association Meetings, Baltimore.

African Progress Report 2010 - Africa Progress Panel

Agboghoroma et al (2009) Aid for trade: Making trade effective for development - case studies from Kenya, Tanzania, and Uganda. PricewaterhouseCoopers and Hamburg Institute of International Economics.

Aisen, A and Veiga, F (2010). How does political instability affect economic growth? IMF Working Paper

Ajayi, L and Michael Oke (2012) Effect of external debt on economic growth and development of Nigeria. International Journal of Business and Social Science.

Akono, K (2008). Foreign Aid to Africa: A Hollow Hope? International Law and Politics

Akoto, W. (2013) Debt relief under the HIPC initiative: Why some countries complete the Programmes fasters than others. Working Papers.

Akramov, K (2012) Foreign aid allocation, governance and economic growth, University of Pennsylvania Press, Philadelphia.

Alabi, J., et al (2007) Effects of "Susu” - A Traditional Microfinance. Working Paper.

Alesina, A. and Weder, B. (2002) Do Corrupt Government Receive Less Foreign Aid?” The American Economic Review.

Alesina, A., and Dollar, D. (1998) Who Gives Foreign Aid To Whom and Why?. NBER Working Paper.

Alesina, A.,et al (1996) Political instability and economic growth. Journal of Economic Growth. 
Alsan, M., et al (2006) The Effect of Population Health on Foreign Direct Investment Inflow to Low- and Middle-Income Countries. World Development

Amin, A (2013) Africa's Development: Institutions, economic reforms and growth. International Journal of Economics and Financial Issues.

Amin, S (1972). Underdevelopment and Dependence in Black Africa: Origins and Contemporary Forms. The Journal of Modern African Studies.

Amissah, A (1973) Recent Developments in Ghana, Uppsala: The Scandinavian Institute of Africa Studies.

Anaman, K. (2006) What factors have influenced economic growth in Ghana? A publication of the Institute of Economic Affairs.

Appiah, K et al (2000) 'Poverty in a Changing Environment', in E. Aryeetey, J. Harrigan and M. Nissanke (eds.) Economic Reforms in Ghana.

Arieff, A (2013) Senegal: Background and U.S. Relations. Congressional Research Service.

Arslanalp, S and Peter Blair Henry (2003) Is debt relief efficient? Working Paper.

Aryeetey, E and Christopher Udry (2010) Creating Property Rights: Land Banks in Ghana, Proceedings, American Economic Review

Aryeetey, E., and F. Tarp (2000) Structural Adjustment and After: Which Way Forward. In E. Aryeetey, J. Harrigan and M. Nissanke (eds), Economic Reforms in Ghana: The Miracle and the Mirage.London: James Curry.

Asem, F., et al (2013) Private Sector Development and Governance in Ghana. IGC Working Paper. London: International Growth Centre.

Asem, F., et al (2013) Private Sector Development and Governance in Ghana. IGC Working Paper. London: International Growth Centre.

Asiama, P. and Osei, V. (2007). Microfinance in Ghana: An overview. Research Department.

Asiedu, E. (2003) Debt relief and institutional reform: a focus on Heavily Indebted Poor Countries. The Quarterly Review of Economics and Finance.

Asiedu, E., \& Villamil, A. P. (2000). Discount factors and thresholds. Working Paper.

Austin, G. (2008) Resources, Techniques, and Strategies South of the Sahara: Revising the Factor Endowments Perspective on African Economic Development, 1500-2000. Economic History Review. 
Ayittey, G (1994) Aid for Black Elephants: How Foreign Assistance Has Failed Africa, in Perpetuating Poverty: The World Bank, the IMF, and the Developing World, ed. Doug Bandow and Ian Vasquez. Washington: Cato Institute.

Ayittey, G (2002) The myth about foreign aid. Working paper.

Ayittey, G (2002b). Why Africa Is Poor in Julian Morris, ed., Sustainable Development: Promoting Progress or Perpetuating Poverty. Profile Books, London

Ayittey, G (2012) Promoting economic freedom in Africa. The Journal of Economic Enterprise

Ayittey, G. (1992) Africa Betrayed. New York: St. Martin’s Press.

Baker, C., B et al (1986) African Industrialization, Gower Publishing Company Limited, Aldershot.

Bandow, D. (1995) A new aid policy for a new world. Cato Institute Policy Analysis

Bandyoppadhyay, S and Katarina Vermann (2013) donors motives for foreign aid. Federal Reserves Bank of St. Louis.

Banerjee, S. and Dennis Rondinelli (2003) Does foreign aid promote privatization? Empirical evidence from developing countries. World Development.

Barker, J (1977) Stability and Stagnation: The State in Senegal. Canadian Journal of African Studies

Barker, J (2012) A rentier class: economic aspects of colonial legacy in Senegal. E-International Relations students.

Bar-on, A (1997) Assessing sub-Saharan Africa's structural adjustment programmes: the need for more qualitative measures. Journal of Social Development in Africa.

Barro, R (1996) Getting it Right: Markets and Choices in a Free Society, Cambridge, Mass: MIT

Barro, R. (1991) Economic Growth in a Cross Section of Countries, Quarterly Journal of Economics.

Barro, R. (1997) The Determinants of Economic Growth: A Cross-Country Empirical Study. MIT Press, Cambridge

Basnet, H (2013) Foreign aid, domestic savings, and economic growth in south Asia. International Business sand Economic Research Journal.

Basnett, Y., et al (2012) Increasing the effectiveness of Aid for Trade: The circumstances under which it works best'. Working Paper 353. London: ODI. 
Bates, R (1981) Markets and States in Tropical Africa. Berkeley: University of California Press

Bauer, P (2000). From Subsistence to Exchange and Other Essays. Princeton University Press. Princeton, N.J

Bearce, D. at al (2012). 'Has Aid for Trade increased recipient exports? The impact of US AfT allocations 1999-2008’. Revised version of June 2010 Report prepared for USAID.

Bearce, D.H., Tirone, D.C., (2010) Foreign aid effectiveness and the strategic goals of donor governments. J. Polit.

Beck, L (2008) Brokering Democracy in Africa: The Rise of Clientalist in Senegal. Palgrave MacMillan.

Beck, N et al (1998) Taking Time Seriously: Time-Series-Cross-Section Analysis with a Bi-nary Dependent Variable. American Journal of Political Science.

Beck, R. (1999) Senegal's enlarged presidential majority: Deepening democracy or detour. In R.

Joseph, ed.(1999), State, conflict, and democracy in Africa. London: Lynne Rienner Publishers.

Behrman, L (1977) Muslim Politics and Development in Senegal. The Journal of Modern African Studies.

Bello, A. (2000) External Debt, Investment and Economic Growth in Nigeria. Working Paper.

Ben, L. (2010) The Legacy of the Jubilee Debt Relief Movement: Agreements, Lessons, and Remaining Challenges; center for global development essay

Bennett, V.P (1975) Malcontent in Uniform - The 1972 Coup D'etat. Working Paper.

Berg, E (1981) Accelerated Development in Sub-Saharan Africa: An agenda.

Berggren, N (2003) The benefits of economic freedom. Independent Review.

Bhattarai, B. P. (2009). Foreign Aid and Growth in Nepal: An Empirical Analysis. The Journal of Developing Areas

Birdsall, N., and Francis Fukuyama (2011) The Washington Consensus. Foreign Affairs.

Blomstrom, M et al (1996) is fixed investments the key to growth? The Quarterly Journal of Economics.

Boettke, P. (2009) Review of Eric L. Jones Cultures Merging: A Historical and Economic Critique of Culture. Economic Development and Cultural Change. 
Boettke, P. and Leeson (2004) Liberalism, Socialism, and Robust Political Economy.

Boockmann, B., Dreher, A., (2003) The contribution of the IMF and the World Bank to economic freedom. Eur. J. Polit. Econ.

Boone, Catherine (1990) The Making of a Rentier Class: Wealth Accumulation and Political Control in Senegal.” The Journal of Development Studies.

Boone, P (1996) Politics and the effectiveness of foreign aid. European Economic Review

Boone, P. (1994) The Impact of Foreign Aid on Savings and Growth. Centre for Economic Performance Working Paper

Boye, F (1993) Economic mechanisms in historical perspective. Senegal: Essays in statecraft. Ed. Momar Coubma Diop. Codesria Book Series. Oxford.

Brautigan, D and Stephan Knack (2004) Foreign aid, Institutions, and governance in sub-Saharan Africa. Economic Development and Cultural Change.

Brautigan, D. (2000) Aid Dependence and Governance. Stockholm: Almqvist \& Wiksell International.

Brohman, J (1996) Popular Movement: Rethinking the Theory and Practice of Development. Oxford: Blackwell Publishers Ltd.

Brown, E (2001) Tinkering with the System: Adjusting Adjustment. In Structural Adjustment: Theory, Practice and Impacts. Giles Mohan, Ed Brown, Bob Milward, and Alfred B. ZackWilliams, eds. Pp 119-139. New York: Routledge

Brunelli, B (2007) Structural Programs and the delivery of Health Care in the Third World. Pell Scholars.

Buame, S (1996) Entrepreneurship: A Contextual Perspective. Dkcuurses and Prark of Ennepreneurid licrivities Within the Institutional Contes of Ghana, Lund: Lund University Press.

Buccola, S and James McCandlish (1999) Rent seeking and rent dissipation in state enterprises. Applied Economic Perspectives and Policy.

Bulte, E. et al (2005) Resource Intensity, Institutions, and Development. World Development

Burke, P. J. and Ahmadi-Esfahani, F. Z. (2006). Aid and Growth: A Study of South East Asia. Working Paper.

Burnside, C. and David Dollar (2000, 2004) Aid, Policies and Growth. The American Economic Review. 
Cadot, O et al (2013) Success and failure of African exporters. Journal of Development Economics.

Calderisi, R. (2006) The trouble with Africa: Why foreign aid isn't working. New York: Palgrave McMillan

Calì, M. and te Velde, D.W. (2011) Does Aid-for-Trade Really Improve Trade Performance? World Development.

Carlsson, F. and Susanna Lundstrom (2002) Economic freedom and growth: decomposing the effects. Working Paper.

Carmody, P (2011) The new scramble for Africa. Polity Press.

Carroll, C.et al (2000) Saving and growth with habit formation. The American Economic Review.

Casey, K. (2011) Senegal 2012 Presidential elections: Potential for unrest. Human Terrain System, G2 Analysis and Production, United States Army Africa.

Cax, I. (2005), Does Debt Relief Enhance Growth in Third World Countries? Working Paper.

Chakravarti, A (2005). Aid Institutions and Development: New Approaches to Growth, Governance, and Poverty. Edward Elgar Publishing Ltd., Cheltenham, Northampton.

Chambers, R. (1974) Managing Rural Development: Ideas and experience from East Africa. Uppsala: Scandinavian Institute of African Studies.

Chamlee-Wright, E. (1997) The Cultural Foundations of Economic Development: Urban Female Entrepreneurship in Ghana. New York: Routledge

Chaney, T (2008) Distorted Gravity: The Intensive and Extensive Margins of International Trade. American Economic Review.

Chazan, N (1983) An Anatomy of Ghanaian Politics: Managing Political Recession, 1969-1982, Boulder: Westview

Chenery, H.B. and Strout, A. (1966) Foreign Assistance and Economic Development. American Economic Review.

Claessens, S. (1990). The Debt Laffer Curve: Some Estimates. World Development

Claessens, S. (1997) Corporate Governance and Equity Prices: Evidence from the Czech and Slovak Republics. Journal of Finance 
Clemens et al (2004) Counting chickens when they hatch: Timing and the effects of aid on growth. Center for Global Development. Working Paper.

Clemens, M and Jeffrey Williamson (2002) Why did the tariff-growth correlation reverse after 1950? Working Paper.

Clemens, M., and Todd Moss (2005) What's wrong with the millennium development goals? Center for Global Development.

Cling, J. P. (2006). Commerce, croissance, pauvreté et inégalités dans les PED: Une revue de la littérature. Working Paper.

Cohen, D (2000) The HIPC Initiative: True and False Promises. Technical Paper.

Cohen, Daniel (1993). 'Low Investment and Large LDC Debt in the 1980s. American Economic Review

Collier, P and Anke Hoeffler (2004) Aid, policy and growth in post-conflict societies. European Economic Review.

Collier, P and David Dollar (2002) Aid Allocation and Poverty Reduction. Working Paper.

Collier, P and Willem Gunning (1999) The role of IMF's structural adjustment. Working Paper.

Collier, P. (1997)The failure of conditionality. In Perspectives on Aid and Development, edited by C. Gwin and J. Nelson. Washington, D.C.: Overseas Development Council.

Collier, P. and A. Hoeffler (1998) On Economic Causes of Civil War. Oxford Economic Papers.

Collier, P. and A. Hoeffler (2000) On the Incidence of Civil War in Africa Mimeo. World Bank

Collier, P. and J.W. Gunning (1999) 'Explaining African Economic Performance', Journal of Countries”, Journal of Development Economics

Commission for Africa. (2005) Our common interest: Report of the commission for Africa. London: Commission for Africa.

Cornwall, A (2003) Who's voice? Whose choice? Reflection on gender and participatory development. World Development.

Coyne, C. and C. Williamson. (2009) Trade Openness and Culture. Working Paper.

Crook, Richard (2005) The role of traditional institutions in political change and development. Policy Brief. 
Dalgaard, C and Henrik Hansen (2001) On aid, growth and good policies. Journal of Development Studies

Dambisa, M (2009) Dead Aid: Why aid is not working and how there is a better way for Africa. Farrar, Straus and Giroux

Davis, A. (1994) South African Managed Trade Policy: The wasting of a Mineral Endowment.(London: Praeger).

Dawson, J. (1998) Institutions, Investment, and Growth: New Cross-Country and Panel Dada Evidence." Economic Inquiry.

De Melo, J. and Laurent Wagner (2015) Aid for Trade as finance for the poor. Working Paper

DeHaan, J. (2006) Political institutions and economic growth reconsidered. European Journal Of Political Economics.

DeHaan, J. and Sturm, J. E. (2000) On the relationship between economic freedom and economic growth,” European Journal of Political Economy

DeHann, J., and J. Sturm (2001) How Robust is the Relationship Between Economic Freedom and Economic Growth?" Applied Economics

Dembele, D (2003) Debt and Destruction in Senegal: A study of twenty years of IMF and World Bank Policies." World Development Movement.

DeMello, L. (1997) Foreign direct investment in developing countries and growth: a selective survey. Journal of Development Studies.

DeMelo, J and Laurent Wagner (2015) aid for trade as finance for the poor. Working Paper.

DeMelo, J. and Grether, J. M. (2000) Commerce international, théories et applications. DeBoeck Université.

Devarajan, S., et al (2001) Aid and Reform in Africa. Washington, D.C.: The World Bank. Development

Diallo, L. and Lafreniere, G (2014) Leadership and governance in Sub-Saharan Africa: Contextual and historical perspective. In: E. Shizha and A.A Abdi.

Dijkstra, D and Niels Hermes (2001) The uncertainty of debt service payments and economic growth of HIPCs. United Nations University.

Diop, M. (1984) L'Etat, la confrerie mouride et les paysans senegalais. Labour, Capital and Society. 
Diop, M. and Mamadou Diouf (1990) Le Senegal sous Abdou Diouf. Paris: Karthala.

Diouf, M (1992) State Formation and Legitimation Crisis in Senegal. Review of African Political Economy, No. 54, Surviving Democracy?

Diouf, M (1998) Political liberalization or democratic transition: African perspectives.

Dollar, D and William Easterly (1999) Aid, investments, and policies. Working Paper.

Dollar, D. and Jakob Svensson (2000) What explains the success or failure of structural adjustments programmes? The Economic Journal.

Dollar, D., and Aart Kraay (2003) Institutions, Trade and Growth. Journal of Monetary Economics.

Dowling, J and Ulrich Hiemenz (1983) Aid, savings, and growth in the Asian region. The Developing Economies.

Dreher, A. (2005) IMF and Economic Growth: The Effects of Programs, Loans, and Compliance with Conditionality, Proceedings of the German Development Economics Conference

Dreher, A., and Gehring K( 2012) Does Aid Buy (Economic) Freedom? Economic Freedom of the World: 2012 Annual Report. Fraser Institute.

Durevall, D. and Mabugu, R. (2000) Maize Markets in Zimbabwe. Stockholm, Swedish International Development Cooperation Agency (SIDA).

Dzisi, S. (2008) Women entrepreneurs in small and medium enterprises in Ghana. Working Paper.

Dzisi1,S., and Francis Obeng (2013) Microfinance and the Socio-economic Wellbeing of Women Entrepreneurs in Ghana. International Journal of Business and Social Research.

Easterly, W (1999) How did Highly Indebted Poor Countries become highly indebted? Reviewing two decades of debt relief. World Development

Easterly, W (2002) What did structural adjustment adjust? The association of policies and growth with repeated IMF and World Bank adjustment loans. Center for Global Development

Easterly, W (2003). Can Foreign Aid Buy Growth? The Journal of Economic Perspectives.

Easterly, W (2006) White man's Burden: Why the West's efforts to aid the rest have done so much ill and so little good. New York: Penguin

Easterly, W. (2001) The Elusive Quest for Growth. Cambridge, MA: MIT Press. 
Easterly, W. (2006) Reliving the 1950s: The Big Push, poverty traps, and takeoffs in economic development, Journal of Economic Growth.

Easterly, W. and Ross Levine (1997) Africa's Growth Tragedy: Policies and Ethnic Divisions. Quarterly Journal of Economics

Easterly, W. and Tobias Pfutze (2008) Where does the money go? Best and worst practices in foreign aid. Brookings Global Economy and Development

Easterly,W (2009) How the Millennium Development Goals are unfair to Africa. World Development.

Edlyne, A. (2004) The Structural Adjustment (SAP) and Urban Poverty Among Wage Earners South-Eastern Nigeria. In Globalization and Social Policy in Africa. South Africa: UNISA Press.

Edwards, S. (1998) Openness, productivity, and growth: What do we really know? Economic Journal

Egger, P. (1995) Freedom of association, Rural Workers’ Organizations and participatory Development in H. Schneider and M. Libercier(eds), Participatory Development from Advocacy to Action. Paris: OECD.

Esau, G (2012) Privatizing development: the limit of market-based approaches to development. E-International Relations students.

Escobar, A (1995) Encouraging development: The making and unmasking of the Third World, Princeton, NJ. Princeton University Press.

Fall, I.M (2009) Evolution constitutionnelle du Seengal - De la Veille de l'independence aux elections de 2007.

Fatton Jr., R(1986) Clientelism and Patronage in Senegal.” African Studies Review.

Fellis, S (1996) Africa Now: People, Policies and Institutions London, James Carrey.

Fikru .M, and B, Getachew (2008) Can Debt Relief lead to Development in Africa? Working Paper.

Fine, B et al (2001) Development Policy in the $21^{\text {st }}$ century: beyond the post-Washington consensus. Routledge studies in development economies.

Fontenay, C. (2004) The Dual Role of Market Power in the Big Push: From Evidence to Theory. Journal of Development Economics

Frank, AG (1966). The Development of Underdevelopment. Monthly Review 
Freire, P (1972) Pedagogy of the oppressed. London and New York: Penguin Book.

Friedman, Milton (1958). Foreign Economic Aid. Yale Review

Friedmann, J (1992) Empowerment: The Politics of Alternative Development. Cambridge, MA: Blackwell.

Fugazza, M (2004) export performance and its determinants-supply and demand export performance and its determinants: supply and demand constraints. U.N.

Fukuyama, F. (2001) Social Capital, Civil Society and Development. Third World Quarterly.

Gaventa, J (2004) Toward participatory governance: Assessing the transformative possibilities in S. Hickey and G. Mohan (eds), Participation from tyranny to transformation? Exploring new approaches to participation in development. London and New York: Zed Books Ltd.

Geertz, C (1962) The Rotating Credit Association: A 'Middle Rung' in Development. Economic and Development and Cultural Change.

Geo-Jaja, A. and Garth Mangum (2001) Structural Adjustment as an Inadvertent Enemy of Human Development in Africa. Journal of Black Studies

Gerring, J (2004) what is a case study and what is it good for? Cambridge University Press.

Gerrit, H (1997) Participatory action research and peoples’ participation.

Gertz, G. (2009) Kenya's Trade Liberalization of the 1980s and 1990s: Policies, Impacts, and Implications. Carnegie Endowment for International Peace

Ghana Banking Survey (2011)

Ghana Banking Survey (2011). Retrieved on April 30 from www.pwc/en_gh/gh/pdf/ghana banking-survey-2011.pdf

Glennie, J. (2008) The trouble with aid: Why less mean more for Africa. Zed Books.

Gloyd, S. ( 2004) Sapping the POOR: The impact of structural adjustment programs. In Meredith Forth, eds., sickness and Wealth: The corporate assault on global health

Godfrey, N (2008) Why is competition important for growth and poverty reduction? OECD.

Goldsmith, AA (2003). Foreign Aid and State Administrative Capability in Africa. In Nicolas van de W, Nicole B and Vijaya R eds., Beyond Structural Adjustment: The Institutional Context of African Development. Palgrave Macmillan, New York. 
Golub, S. and A. Mbaye (2002). 'Obstacles and Opportunities for Senegal's International Competitiveness: Case Studies of the Peanut Oil, Fishing and Textile Industries. Golub, S. and

Mbaye, Ahmadou Aly (2002). Obstacles and Opportunities for Senegal's International Competitiveness. World Bank; Africa Region Working Paper Series.

Gomanee, K., et al. (2002). Aid, Investment and Growth in Sub-Saharan Africa: Accounting for Transmission Mechanisms (Research Paper No. 02/05). Centre for Research in Economic Development and International Trade.

Greenaway, D., et al (2002), 'Trade Liberalization and Growth: New Methods, New Evidence', Journal of Development Economics

Grether, J. M. and J. de Melo (2000), Commerce International - théories et applications, De Boeck University

Grief, A. (1994) Cultural beliefs and the organization of society: A historical and theoretical reflection on collectivist and individualist societies. Journal of Political Economy

Gueye, Y (2008) Case study: Gender, human security and climate change in Senegal.” In WEDO Study: Gender, Climate Change and Human Security. New York: WEDO

Guillaumont, P and Chauvet, Lisa.(2001)Aid and Performance: A Reassessment. Journal of Development Studies

Guillaumont, P., and Guillaumont, S. (1988), Stratégies de développement compares. Working Paper.

Guyer, J. and LaRay Denzer (2009) The Craving for Intelligibility: Speech and Silence on the Economy under Structural Adjustment and Military Rule in Nigeria. In Economic Persuasions.

Gwartney, J et al (1996) Economic freedom of the world: 1975-1995. Vancouver: Frazier Institute.

Gwartney, J et al (2001) Economic freedom in the world. Working Paper.

Gwartney, J., et al (1999) Economic Freedom and the Environment for Economic Growth. Journal of institutional and Theoretical Economics

Hagen, R (2002) Marginalization in the Context of Globalization: Why Is Africa so Poor? Nordic Journal of Political Economy.

Hallaert, J. et al (2011). Estimating the Constraints to Trade of Developing Countries.

Hallaert, J.J (2012), Aid For Trade Is Reaching Its Limits, So What's Next? GEM Working Paper 
Hansen, E (1991) Ghana under Rawlings: Early Years. Oxford: Malthouse/African Association of Political Science

Hansen, H and F Tarp (2001) Aid and Regressions. Journal of Development Economics.

Hansen, H. and F. Tarp (2000) Aid Effectiveness Disputed. Journal of International Development.

Harrison, A. (1996) Openness and Growth: A Time-Series, Cross-Country Analysis for Developing. Working Paper.

Harrison, LE (2000). Why Culture Matters in Lawrence E. Harrison and Samuel P. Huntington eds., Culture Matters: How Values Shape Human Progress. Basic Books, New York.

Harvey, D (2005) A Brief History of Neoliberalism. Oxford: Oxford University Press.

Hausmann, R and Rodrik, Dani. (2006)Doomed to Choose: Industrial Policy as Predicament.

Hausmann, R., \& Fernandez-Arias, E. (2000). Foreign Direct Investment: Good Cholesterol? Inter-American Development Bank, Working Paper.

Hyden G (2006). African Politics in Comparative Perspective. Cambridge University Press, Cambridge. J. Econ. Growth.

Hyden, G. (1999) Governance and the reconstitution of political order. In: R. Joseph, ed., State, Conflict, and democracy in Africa. London: Lynne Rienner Publishers.

Heckelman, J. C., \& Knack, S. (2009). Aid, Economic Freedom, and Growth. Contemporary Economic Policy

Heidhues, F. and Gideon Obare (2011) Lessons from structural adjustment programmes and their effects in Africa. Quarterly Journal of International Agriculture

Helble, M et al (2012) Aid for trade facilitation. Rev. World Economics.

Henkel, H. and Stirrat, R (2001) Participation as spiritual duty: empowerment and secular subjection in B. Cooke and U. Kothari (eds), Participation: The New Tyranny. London and New York: Zed Ltd.

Hepp, R. (2005), Can Debt Relief Buy Growth?: University of California

Herbst, J (2000) State and power: Comparative lessons in authority and control. Princeton University press

Herbst, J. (1993). The Politics of Reform in Ghana, 1982-1991. Berkeley: University of California Press. 
Herzer, D. \& M. Grimm (2011) Does Foreign Aid Increase Private Investment?. Evidence from Panel Co-integration. Applied Economics

Hezel, F. (2009) The role of culture in economic development. Micronesian Seminar

Hill, W. (2011) International business: Competing in the global marketplace. 8th edition (New York: McGraw-Hill/Irwin).

Hirschman, A. (1958). The strategy of economic development. New Haven: Yale University Press.

Hoekman, B and Nicita, Alessandro (2008) Trade Policy, Trade Costs, and Developing Country Trade. Policy Research. Working Paper.

Hoekman, B. and Shepherd, B. (2013) Who profits from trade facilitation initiatives?. Working Paper.

Hoff, K (2000) Beyond Rosenstein-Rodan: The Modern Theory of Coordination Problems in Development. In Pleskovic, B. ed. Proceedings of the Annual World Bank Conference on Development Economics. Washington DC: World Bank.

Hoff, K and Stiglitz, Joseph. (2000)Modern Economic Theory and Development. In Meier, G. and Stiglitz, J. E. eds. Frontiers of Development Economics: The Future in Perspective. New York: Oxford University Press

Hoff, K. and J.E. Stiglitz, (2004) After the Big Bang? Obstacles to the Emergence of the Rule of Law in Post-Communist Societies”, American Economic Review

Huchet-Bourdon, M, et al (2009) Aid for Trade in Developing Countries: Complex Linkages for Real Effectiveness. African Development Review

Huhne, P et al (2013) Who benefits from aid for trade? Comparing the effects on recipient versus donor exports. Keil. Working Paper

Humphreys, M. (2005). Natural Resources, Conflict, and Conflict Resolution. Journal of Conflict Resolution

Huntington, S. (1996). The Clash of Civilizations and the Remaking of World Order, New York, Simon \& Schuster.

Huntington, SP (2000). Culture Counts. In Lawrence EH and Samuel. PH eds., Culture Matters: How Values Shape Human Progress. Basic Books, New York.

Huq, M. (1989) The Economy of Ghana: The First 25 Years since Independence. St. Martin’s Press. 
Hutchful, E (2002) Ghana's Adjustment Experience: The Paradox of Reform. Woeli Publishing Services: 2002 “Ghana.” The Library of Congress Country Studies Index

Hyden, G (2006). African Politics in Comparative Perspective. Cambridge University Press, Cambridge.

Hynes, W and Michael Plummer (2013) Regional aid for trade: An effective crisis response. International Trade Forum.

ICRG, 2005. Political Risk Indicators.

IMF (2007), International Financial Statistics, Washington D.C.: International Monetary Fund.

Inglehart, R and Wayne Baker (2000) Modernization, cultural change, and the persistence of traditional values. American Sociological Review.

International Monetary Fund (2012) Senegal: Third review under the policy support instrument and request for modification of assessment criteria - staff report; Informational annex; Press release; and Statement by the Executive Director for Senegal. IMF Country Report No. 12/227. International Monetary Fund (IMF) (2010) Senegal: Poverty reduction strategy paper annual progress report. IMF Country Report No. 10/368. Washington, DC: International Monetary

Isham, J et al. (2002) Social Capital and Economic Development: Well-Being in Developing Countries. Massachusetts: Edward Elgar Publishing

Islam, M (2005) Regime Changes, Economic Policies and the Effect of Aid on Growth.” Journal of Development Studies

ISSER, (2008). The State Of Ghanaian Economy. University of Ghana, Legon,Ghana

Jackson, R and Carl Rosberg (1982) Why Africa's weak states persist: The empirical and the juridical in statehood. Johns Hopkins University Press.

Jappelli, T and Parco Pagano (1994) Savings, growth, and liquidity constraints. The Quarterly Journal of Economics.

Jaylor, I and Paul Williams (2004) Africa in International Politics: External Involvement in the Continent. Round ledge.

Jedwab, R.(2011)Why is Africa So Urbanized? Evidence from Resource Exports in Ghana and Ivory Coast. Unpublished manuscript, Department of Economics, Paris School of Economics and London School of Economics

Jedwab, R., and R. D. Osei (2012). 'Structural Change in Ghana 1960-2010'.IIEP Working Paper. Washington, DC: Institute for International Economic Policy, George Washington University. 
Jensen, P and Martin Paldam (2003) Can the new aid-growth models be replicated. Working Paper.

Jhingan, M. (2005), the Economics of Development and Planning, thirty eight revised and enlarged edition. Johansson P. (2008), Debt Relief, Investment and Growth; JEL classification.

Johnson, M (2015) Donor Requirements and Pockets of Effectiveness in Senegal's Bureaucracy. Development Policy Review.

Jones, E (2006) Cultures Merging: a Historical and Economic Critique of Culture. Princeton University Press, Princeton

Jong-a-Pin, R. (2009). "On the measurement of political instability and its impact on economic growth. European Journal of Political Economy, Journal of Markets and Morality

Kapfer, S et al (2007) If you build it, will they come? Foreign aid's effects on foreign direct investment. Working Paper.

Karingi, S. N. and V. Leyaro (2009) Monitoring Aid for Trade in Africa: An Assessment of the Effectiveness of Aid for Trade. African Trade Policy Centre

Karras, G., (2001) Long-run Economic Growth in Europe: Is it Endogenous or Neoclassical? International Economic Journal

Kaufmann, D et al (2006) Governance Matters V: Aggregate and Individual Governance Indicators for 1996-2005. Policy Research Working Paper.

Keough, N(1998) Participatory development principles and practice: Reflections of a western development worker. Community Development Journal.

Kessler, Richerd J. (1980). Senegal in Transition. The World Today.

Kieh, G. (2008). Africa and the new globalization. Aldershot, England: Ashgate Pub. Co.

Kilby, C., and A. Dreher (2010) The impact of aid on growth revisited: Do donor motives matter?” Economics Letters

Killick, T. (1978) Development Economics in Action: A Study of Economic Policies in Ghana, New York: St. Martin’s Press.

Killick, T. (1991) The Developmental Effectiveness of Aid to Africa. Working Paper.

Killick, T. (2010). Development Economics in Action (Second ed.). London: Routledge.

Kim, J (2015) Aid and state transition in Ghana and south Korea. Third World Quarterly 
Kimeyi, M (2006) Economic reforms and pro-poor growth: lessons for Africa and other developing regions and economies in transition. Working Paper.

Kimura, H. and Y. Todo (2009) Is Foreign Aid a Vanguard of Foreign Direct Investment? Working Paper.

Kizza, L (2009). The relationship between aid and economic growth: What aid strategy should the government of Uganda promote? Working Paper.

Knack, S. and P. Keefer (2001) Aid-Dependency and the Quality of Governance: Cross Country Empirical Test. Southern Economic Journal.

Knack, S., \& Keefer. P. (1997). Does Social Capital have an Economic Impact? A CrossCountry Investigation. Quarterly Journal of Economics

Kneller, R et al (2008) Trade liberalization and economic growth. World Economy.

Knox, P et al (2003) The geography of the world economy. 4th edition (London: Arnold)

Koczberski, G (1998) Women in Development: A critical Analysis. Third Worldly Quarterly.

Kolver, L (2013) Shift from blame seeking will aid efforts to tackle SA’s AMD challenge. Mining Weekly.

Kraev, E. (2004) Structural Adjustment Policies in Ghana in the 1990s: An Empirical Analysis and Policy Recommendations. UNDP Discussion Paper.

Krueger, A (2008) Why Trade Liberalization is Good for Growth, in: Giorgio Secondi (ed.), The Development Economics Reader, New York: Routledge.

Krugman, P. (1988) Financing versus forgiving a debt overhang. NBER Working Paper 2486.

Krugman, P. (2012) End this Depression Now. W.W. Norton \& Company

Krugman, P., (1980) Scale Economies, Product Differentiation and the Pattern of Trade. American Economic Review.

Krugman, Paul. (1989) Market-Based Debt Reduction Schemes. In Analytical Issues in Debt. edited by Jacob Frenkel, Michael Dooley, and P. Wickham. Washington: International Monetary Fund.

Kuklick, H. (1979) The Imperia2 Bureaucrat, Stanford, CA: Hoover Institution Press

Kunzemann, T., (2007) Do you susu? Article on Microfinance. Allianz Knowledge Partner site. Allianz. 
La Porta, R., et al (1997), Trust in Large Organizations, American Economic Review

La Porta, R., et al (1999). The quality of government. Journal of Law, Economics and Organization.

Laird, S (2007) Cool aid or kool aid? Discussion paper series.

Lancaster, C. (2007). Foreign Aid: Diplomacy, Development, Domestic Politics. Chicago, IL: The University of Chicago Press.

Landes D (2000). Culture Makes Almost All the Difference. In Lawrence EH and Samuel P Huntington eds., Culture Matters: How Values Shape Human Progress. Basic Books, New York

Landes, D (1998) The Wealth and Poverty of Nations: Why Some Are So Rich and Others Are So Poor. New York: W.W. Norton \& Co.

Landes, D (2000). Culture Makes Almost All the Difference. In Lawrence EH and Samuel P. Huntington eds., Culture Matters: How Values Shape Human Progress. Basic Books, New York.

Lehmann, N. et al (2013), Does foreign aid promote recipient exports to donor countries? Review of World Economy

Leite, C., \& Weidmann, J. (1999). Does Mother Nature Corrupt? IMF Working Paper

Levine, R (1997) Financial Development and Economic Growth: Views and Agenda. Journal of Economic Literature

Lewis, W (1955) The theory of economic growth. Homewood: Irwin.

Linder, B (1961) An essay on trade and transformation. Working Paper.

Lipumban, H., Nguyuru. (2004),Debt Relief, Sustainable Development and achieving Millennium Development Goals in Sub Sahara Africa. Dare as Salaam.

Liu, J. and Guo, Z.F. (2002). Positive analysis of causal relationship between saving rate and economic growth in China's economy.

Logan, F.(2015) Did structural adjustment programmes assist African development. EInternational Relations Students.

Luckham, R (1975) Politicians and Soldiers in Ghana, 1966 - 1972, London: Frank Cass.

Makin, J.H. (2006) Does China save and invest too much? Cato Journal.

Manranz, D(2001) African Friends and Money Matters: Observations from Africa. 
Martinussen, J (1997) Society, state, and market: A guide to competing theories of development. The University of Chicago Press.

Mathur, H (1995) The role of social actions in promoting participatory development at local level: a view from India, in H. Schneider and M. Libercier (eds), Participatory Development from Advocatory to Action. Paris: OECD.

Matsumoto-Izadifar, Y (2008) Senegal: Making better use of agribusiness potential. Paris: OECD.

Mauro, P. (1995) Corruption and Growth. Quarterly Journal of Economics

Mavrotas, G (2002) Aid and growth in India: Some evidence from disaggregated aid data.

Mayer and Milberg (2013) Aid for Trade in a world of global value chains: chain power, the distribution of rents and implications for the form of aid. Working Paper.

McGillivray, M. and Oliver Morrissey (2000) Aid fungibility in Assessing Aid: red herring or true concern? Journal of International Development.

McKinnon, R. (1973) Money and Capital in Economic Development, Washington, DC: Brookings Institution

Medema, S., and Richard O. Zerbe(1999) The Coase Theorem. Encyclopedia of Law and Economics.

Megginson, W and Jeffrey Netter (2001) From state to Market: A survey of empirical Studies on privatization. Journal Of economic Literature.

Meier, G and Joseph Stiglitz (2001) Frontiers of Development Economics. Oxford University Press.

Melly, P (2012) Senegal's elections: Towards dictatorship or consolidating democracy? Africa programme paper AFP PP 2012/02. London: Chatham House.

Mendes, a et al (2014) Industrialization in sub-Saharan African and import substitution policy. Brazilian Journal of Political Economy.

Meredith, M (2011) The fate of Africa - A history of the continent since independence. New York: Public Affairs.

Meredith, M. (2005) The Fate of Africa: A history of fifty years of independence. Public Affairs

Meuser, M. (2001), Repräsentationen sozialer Strukturen im Wissen. Dokumentarische Methode und Habitusreproduktion. Working Paper. 
Meuser, M. and Nagel, U. (1991) Expert In interviews. Working Paper.

Milberg, W. and Deborah Winkler (2013) Outsourcing economics: Global Value Chains in Capitalist Development. New York: Cambridge.

Milner, H (2005) Globalization, development, and international institutions: Normative and positive perspectives. Perspectives on Politics.

Milner, H., and Tingley, D. (2013). Introduction to the Geopolitics of Foreign Aid. In Geopolitics of Foreign Aid, Geopolitics of Foreign Aid.

Milward, B (2000) What is Structural Adjustment? In Structural Adjustment: Theory, Practice and Impacts. Giles Mohan, Ed Brown, Bob Milward, and Alfred B. Zack-Williams, eds. P 24-37. New York: Routledge

Mohan et al (2000) Structural Adjustment: Theory, Practice and Impacts. Routledge

Mohan, G. and Hickey, S (2004) Relocating participation within a radical politics of development: A critical modernism and citizenship, in S. Hickey and G. Mohan (eds), Participation from Tyranny to Transformation? Exploring new approaches to participation in development. London and New York: Zed Book Ltd.

Mohan and Stokke (2000) Participatory development and empowerment: The dangers of localism. Third World Quarterly.

Montinola, G (2007) When does aid conditionality work? Working Paper.

Moore, M (1993) Declining to learn from the East? The World Bank on governance and development.

Morrissey, O. (2001) Pro-poor Conditionality for Aid and Debt Relief in East Africa. CREDIT Research Paper No. 01/15. Nottingham: The University of Nottingham

Moshi, H and Ali Kilindo (1999) The impact of government Policy on Macroeconomic variables: A case study of private investment in Tanzania. Working Paper.

Mosley, P., et al (1987) Aid, the public sector and the market in less developed countries. Economic Journal .

Moss T. (2006), Will Debt Relief Make a Difference? Impact and Expectations of the Multilateral Debt Relief Initiative; Centre for Global development. Working Paper

Moyo, D. (2009). Dead aid: Why aid is not working and how there is a better way for Africa. New York: Farrar, Straus and Giroux. 
Munemo, J. (2011). Foreign aid and export diversification in developing countries. Working Paper.

Munemo, J. et al (2007) Foreign aid and export performance: A panel data analysis of developing countries. In S. Lahiri(ed). Theory and Practice

Murphy, K. et al (1989), “Industrialization and the Big Push”, Journal of Political Economy

Ninsin, K. (1998) Ghana: Transition to Democracy, Legon, Ghana: Freedom Publications.

Noorbakhsh, F. \& Noorbakhsh, S. (2006). The Effects of Compliance with Structural Adjustment Programmes on Human Development in Sub-Saharan Africa. Department of Economics, University of Glasgow, Glasgow.

North, D. (1981) Structure and Change in Economic History. Norton, New York

Nowak, M. et al. (1996) Ghana, 1983-1991 In Hadjimichael, M. T. and others Adjustment for Growth: The African Experience, IMF Occasional Working Paper

Nowak-Lehmann D., et al (2009). Aid and trade. Working Paper.

Nowak-Lehmann, F., et al (2013), "Does foreign aid promote recipient export to donor countries? Working Paper.

Nugent, P (1995), Big-men, Small Boys and Politics in Ghana: Accra: Asempa Publishers

Nurkse, R. (1953) Problems of Capital Formation in Underdeveloped Countries. New York: Oxford University Press.

Nyerere, J. (1968), Ujamaa: The basis of African socialism, London: Oxford University Press.

Nyoro, J., et al (1999) Evolution of Kenya's maize marketing systems in the post-liberalization era. Paper presented at the Fourth Agricultural Transformation Workshop.

Nzau, M (1998) Africa's Industrialization Debate: A Critical Analysis. The Journal of Language, Technology and Entrepreneurship in Africa.

O’Brien, D. (1971) The Mourides of Senegal: The political and Economic Organization of an Islamic Brotherhood. Oxford: Clarendon Press.

O’Brien, Rita Cruise (1974) Some Problems in the Consolidation of National Independence in Africa: The Case of the French Expatriates in Senegal. African Affairs.

Ocquaye, M. (1980) Politics in Ghana, 1972-79, Accra: Tornado Publications 
OECD (2006) Aid for Trade. Making It Effective, Paris: Organization for Economic Cooperation and Development.

OECD and WTO (2011). Aid for trade: Showing results. Policy Brief.

OECD/WTO (World Trade Organization) (2011) Aid-for-Trade at a Glance 2011: Showing Results. Geneva: WTO, Paris: OECD.

Ogujiuba, K., et al (2011). Import substitution industrialization as learning process: Sub Saharan African Experience as Distortion of the "Good Business Model. Business and Management Review

Onis, Z and F Senses (2007) Global dynamics, domestic coalitions, and a reactive state: major policy shifts in post-war Turkish economic development. Working Paper.

Oppong, N (2013) The Good and the Bad of Structural Adjustment Programme in Africa: Evidence from Ghanaian Gold Mining Industry. International Journal of Business and Social Sciences.

Osei, A (1999) Ghana: Recurrence and Change in a Post-Independence African State. Peter Lang Publishing

Osei, D. (2000) Political Liberalization and the Implementation of the Value Added Tax in Ghana. Journal of Modern African Studies

Osei, R (2001) The HIPC initiative and poverty reduction in Ghana: An assessment. Working Paper.

Osei, R. et al (2005) The Fiscal Effects of Aid in Ghana. Journal of International Development

Osei, R. (2013) The political economic dimensions of macroeconomic management of aid in Ghana. Wider Working Paper.

Osei, R. D. (2012) Aid, Growth and Private Capital Flows to Ghana. Working Paper.

Osei, Robert et al (2013) The political economy dimensions of macroeconomic management of aid in Ghana. Working Paper.

Osei-Boateng, C. and Ampratwum E. (2011). “The informal sector in Ghana.” Ghana: Friedrich

Oshikoyo, T (1994) Macroeconomic determinants of domestic private investment in Africa. Journal of economic Development and Cultural Change.

Osogo, J.(1970) Kenya’s World of Commerce and Industry.

Ovaska, T( 2003)The Failure of Development Aid. Cato Journal. 
Owen, M (2006) Debt and development: Exploring the microfinance debate in Senegal. Scholarly Commons.

Owens, T. and John Hoddinott (1999) Investing in development or investing in relief: Quantifying the poverty tradeoffs using Zimbabwe household panel data, Working Paper.

Owusu, A. (1987). Agricultural development policy in Ghana. Food Policy

Owusu, F. (2003): Pragmatism and the Gradual Shift from Dependency to Neoliberalism. Working Paper.

Owusu, M (1975) 'Economic Nationalism, Pan-Africanism and the Military: Ghana’s National Redemption Council', Africa Today

Paldam, M. (1998) Does Economic Growth Lead to Political Stability? The Political Dimension of Economic Growth.

Papanek, G (1973) Aid, Foreign Private Investment, Savings, and Growth in Less Developed Countries. Journal of Political Economy.

Patillo, C, et al (2004) What are the Channels through which External Debt Affects Growth Relief Done for Low Income Countries? IMF Working Paper.

Pattillo, C et al (2002) External Debt and Growth. IMF Working Papers

Perreault, T (2003) Social Capital, Development, and Indigenous Politics in Ecuadorian Amazonia." Geographical Review

Perry, D. (2006) Microcredit and women moneylenders: The shifting terrain of credit in rural Senegal. Human Organization. Washington.

Pettersson, J. and L. Johansson (2013) Aid, Aid for Trade, and bilateral trade: An empirical study. Journal of International Trade \& Economic Development

Pitlik, H. (2002) The Path of Liberalization and Economic Growth. Working Paper.

Platteau, J. (2000), Institutions, Social Norms, and Economic Development. Harwood: Academic Publishers \& Routledge.

Poole, R. (1996) Privatization for Economic Development. The Privatization Process. Ed. Terry L. Anderson and Peter J. Hill. United States of America: Rowman \& Littlefield Publishers, Inc.

Portugal-Perez, A and John Wilson (2008) Why trade facilitation matters to Africa. World Trade Review.

Powell, R. (2003), Debt Relief, Additionally, and Aid Allocation in Low-Income Countries, An IMF Working Paper 
Poyi, B.B. (2006). The Effect of Recent Changes in the Financial Sector Development in Nigeria. Paper presented at 15th AFRACA General Assembly, Nov. 27-Dec. 2, Burkina Faso.

Prebisch, R. (1950) The Economic Development of Latin America and Its Principal Problems. New York: United Nations.

Prowse, S (2005). Aid for Trade: Increasing Support for Trade Adjustment and Integration.

Przeworksi, A and James Vreeland (2000) The effect of IMF programs on economic growth. Journal of Development Economics.

Radelet, S (2004) Aid Effectiveness and the Millennium Development Goals, Center for Global Development Working Paper

Radelet, S (2006) A primer for foreign aid. Center for Global Development

Rahim, S (1994) Participatory development communication as a dialogical process, in S.A White, K.S. Nair and J. Ascroft (eds), Participatory Communication Working for change and development. New Delhi, Thousand Oaks and London: Sage Publications.

Rajan, R \& Subramanian, Arvind(2005) Aid and Growth: What Does the Cross-Country Evidence Really Show? IMF Working Paper

Rajan, R. and Arvind Subramanian (2008) Aid and Growth: What Does the Cross-Country Evidence Really Show? The Review of Economics and Statistics

Ranis, G (1996) One fast-disturbing policy-based loans. Background paper.

Rapley, J. (1996) Understanding development in the third world. Boulder CO: Lynne Rienner Publishers

Refer to K- Ahin (1983) Rank and Class among the Asante and Fante in the Nineteenth Century.

Remmer, K (2004) Does Foreign Aid Promote the Expansion of Government? American Journal of Political Science.

Reusse, E (2002). The Ills of Aid: An Analysis of Third World Development Policies. University of Chicago Press, Chicago, London.

Richardson, J. (1990) The political economy of strategic trade policy. International Organization Rimmer, D (1992) Staying Poor: Ghana’s Political Economy (1950-1990). Pergamon Press

Rizvi, S (2013)Structural adjustment: economic panacea or development ailment? Working Paper. 
Robert, J (2010) U.N. Millennium Development Goals: Foreign Aid v. Economic Freedom. Heritage Foundation.

Robinson, D (2000) Paths of Accommodation: Muslim Societies and French Colonial Authorities in Senegal and Mauritania, 1880-1920. Oxford: James Currey.

Robinson, J. (1952) The generalization of the general theory. In: The Rate of Interest and Other Robinson, James D. 1989. "Concluding Impressions" in Third World Debt: The Next Phase Edward R. Fried and Philip H. Trezise editors, Brookings Dialogues on Public Policy. The Brookings Institution, Washington, D.C. page 101-103

Robinson, J. et al (2006) Political Foundations of the Resource Curse. Journal of Development Economics

Rodney, W (1973). How Europe Underdeveloped Africa. Bogle-L'Ouverture Publications, London and Tanzanian Publishing House

Rodrik D (2001). The Global Governance of Trade as if Development Really Mattered. UNDP, Geneva.

Rodrik, D (2000) Institutions for high-quality growth: What they are and how to acquire them. NBER Working Paper

Rodrik, D and Arvind Subramanian (2008) Why did financial globalization disappoint? IMF.

Rodrik, D and Francisco Rodriguez (2000)Trade Policy and Economic Growth: A Skeptic's Guide to the Cross-National Evidence," in NBER Macroeconomics Annual. Ben S. Bernanke and Kenneth Rogoff, eds. Cambridge, Mass.: MIT Press, chapter 5.

Rodrik, D. (1996). Understanding economic policy reform.” Journal of Economic Literature.

Rono, J. (2002) The impact of the structural adjustment programmes on Kenyan society. Journal of Social Development in Africa.

Rosengren, J and John Jordan (2000). Building an infrastructure for financial stability: an overview.

Rosenstein-Rodan, P (1943) Problems of Industrialization of Eastern and South-Eastern Europe. The Economic Journal

Ross, Eric S. (2008) Culture and Customs of Senegal. Greenwood Press: Westport, CT, Kindle Edition.

Ross, M (2001) Extractive Sectors and the Poor: An Oxfam America Report. Boston: Oxfam America 
Rostow WW (1960). The Stages of Economic Growth: A Non-Communist Manifesto, Cambridge Press, Cambridge.

Rostow, W. (1960) The Stages of Economic Growth, Cambridge University Press, Cambridge, UK.

Rotberg, R. Failed state, collapse stats, weak states: causes and indicators

Rothbard, M (1962) Man, Economy and State: A Treatise on Economics. Princeton,D. Van Nostrand.

Rothchild, D (1991) Ghana: The Political Economy of Recovery. Lynne Rienner Publishers

Sachs, J. (1984) Theoretical issues in international borrowing. Princeton Studies in International Finance.

Sachs, J. (2003) Institutions matter, but not for everything. Finance and Development.

Sachs, J. (2005) The end of poverty: Economic possibilities of our time. The Penguin Press, New York

Sachs, J. and Andrew Warner (1995). Economic reform and the process of global integration. Brookings Papers on Economic Activity

Sachs, J.D. (2002) Resolving the Debt Crisis of Low Income Countries. Brooking Papers on Economic Activity.

Sachs, Jeffrey D. (1989) The Debt Overhang of Developing Countries', in Guillermo A. Calvo, Ronald Findlay, Pentti Kouri, and Jorge Braga de Macedo (eds), Debt,Stabilization and Development: Essays in Memory of Carlos Díaz-Alejandro. Oxford and Cambridge, MA: Blackwell, 80-102.

Sala-i-Martin, X., \& Subramanian, A. (2003). Addressing the Natural Resource Curse: An Illustration from Nigeria. NBER Working Paper

Sandbrook, R (1991) The state and economic stagnation in tropical Africa.

Sarkar, P. (2005) Rising Manufacture Exports and Terms of Trade: The Case Study of Korea. Progress in Development Studies

Sarkar, P., and Singer, Hans. (1991) Manufactured Exports of Developing Countries and Their Terms of Trade Since 1965. World Development

Schumpeter, J. (1911) The Theory of Economic Development. Cambridge, MA: Harvard University Press 
Seawright, J and John Gerring (2008) Case selection techniques in case study research. Political Research Quarterly.

Seck, A (2005) Senegal emergence d'une democratie modern - 1945-2005 - Un itineraire politique (1960-2008). Paris: Editions Karthala.

Sen, A (2004). How Does Culture Matter. In Vijayendra R and Michael W eds., Culture and Public Action. Stanford University Press, Stanford, California (1999). Development As Freedom. Anchor Books, New York.

Sen, A. (1999). Development as freedom. New York: Random House.

Shaw, E. (1973) Financial Deepening in Economic Development. New York: Oxford University Press

Shillington, K.(1992) Ghana and the Rawlings Factor, London: Macmillan.

Shimeles et al (2009) Computations of development financing gap: Some conceptual and empirical issues. development Research.

Shleifer, A. (2009) Peter Bauer and the failure of foreign aid. Cato Journal

Singer, H. (1950) The Distribution of Gains between Investing and Borrowing Countries. American Economic Review

Skocpol, T and Margaret Somers (1980) the uses of comparative history in macrosocial inquiry. Comparative Studies in Society and History.

Sobel, R., \& Leeson, P. T. (2007). The use of knowledge in disaster relief management. The Independent Review.

Solow, R (1957) A Contribution to the Theory of Economic Growth. Quarterly Journal of Economics

Sorens, J. (2009) Development and the political economy of foreign aid. The Journal of Private Enterprise.

Steel, W (2003) rural and microfinance in rural Ghana. Africa region Working Paper.

Steel, W. and Andah, D. O. (2003).Rural and Micro Finance Regulation in Ghana: Implications for Development and Performance of the Industry: Africa Region. Working Paper Series

Stein, H. (1994): Theories of institutions and economic reform in Africa. In: World Development Stephen Gudeman, eds. Pp 97-117. New York: Berghahan Books.

Stern, N. (1991). The determinants of growth. Economic Journal. 
Steven, R (2003) Challenging Foreign Aid: A Policymaker's Guide to the Millennium Challenge Account (Washington: Center for Global Development).

Stiglitiz, J (2004) Capital-market liberalization. Globalization and the IMF. Comparative Political

Studies

Stiglitz, J (2002) Globalization and its discontents. New York: W.W. Norton

Stiglitz, J (2002) Participation and development: Perspectives from the Comprehensive Development Paradigm. Review of Development Economics.

Stiglitz, J (2004) The post Washington consensus. The initiative for public dialogue.

Stiglitz, J. (1998) More Instruments and Broader Goals: Moving Toward the Post-Washington Consensus. WIDER Annual Lecture, Helsinki, Finland

Stiglitz, J. (1999)The World Bank at the Millennium. The Economic Journal

Stiglitz, J. and Andrew Charlton (2006) aid for trade. Working Paper.

Stiglitz, J.(2002) Globalization and Its Discontents. New York: Norton

Stiglitz, Joseph (2002) Overseas Aid is Money Well Spent. Financial Times

Stone, R (2004) The Political Economy of IMF lending in Africa. American Political Science Review.

Storm, S. (2010). Import substitution industrialization. In Kenneth A. Reinert and Ramkishen S. Rajan(Eds.), The Princeton encyclopedia of the world economy.

Subramanian, A et al. (2000) Trade and Trade Policy in Eastern and Southern Africa. IMF

Summer, L. (2000). International Financial Crises: Causes, Prevention and Cures. American Economic Review.

Suwa_Eisenmann, A. and T. Verdier (2007) Aid and Trade. Oxford Review of Economics

Svensson, J (2003) Why conditional aid doesn’t work and what can be done about it? Journal of Development Economics

Svensson, J. (1999). Aid, growth and democracy. Economics and Politics

Svensson, J. (2000). When is foreign aid policy credible? Aid dependence and conditionality. Journal of Development Economics 
Sy, S. (2009) Les regimes politiques Senegalais de l'independence l'alternance politique (1960). Paris: Editions Karthala.

Tamang, R. (2009) Geopolitics and Shifts in Development Aid Policies: The Effects on Poverty in Nepal. Journal of sustainable development.

Tar, U (2008) The Politics of Neoliberal Democracy in Africa: State and Civil Society in Nigeria. London: I.B. Tauris Company.

Tavares, J (2003) Does foreign aid corrupt? Economics Letters.

Taylor, I. (2004). Blind spots in analyzing Africa’s place in world politics. Global Governance.

Teal, F. (2001). Education, Income, Poverty and Inequality in Ghana in the 1990s, Centre of the Study of African Economies. Department of Economics

Teal, F.(2002)Export Growth and Trade Policy in Ghana in the Twentieth Century. The World Economy

Thiele, R et al (2009) Sectoral Aid Priorities: Are Donors Really Doing their Best to Achieve the Millennium Development Goals? Working Paper.

Thirtle, c et al (2003) The impact of research-led agricultural productivity on poverty reduction, Asia and Latin America.

Thomson, A. (2010) An Introduction to African Politics, $3^{\text {rd }}$ Edition. New York: Taylor \& Francis.

Thorbecke, E (2000) The evolution of the development doctrine and the role of foreign aid, 1950-2000. Foreign aid development.

Thorbecke, E., \& Jung, H. (1996). A multiplier decomposition method to analyze poverty alleviation. Journal of Development Economics, 48(2), 279-300

Tisdell, C. and Mohammad Alauddin (2002) Market-Oriented reforms in Bangladesh and their impact on poverty? Working Paper

Todaro, M., and Stephen Smith (2009) Economic development. Addison-Wesley, Harlow

Tosh, J. (1980) The Cash Crop Revolution in Tropical Africa: An Agricultural Reappraisal. African Affairs

Toye, J. (1993) Dilemmas of Development: Reflections on The Counter-Revolution in Development Economics, Oxford: Blackwell Pub. 
Tsikata, Y. M. (2001). 'Ghana'. In S. Devaraian, D. Dollar and T. Holmgren (eds), Aid and Reform in Africa: Lessons from Ten Case Studies. Washington, DC: World Bank Report.

Tullock, G.(2005)Bureaucracy. Vol. 6 of The Selected Works of Gordon Tullock. Edited by Charles Rowley. Indianapolis: Liberty Fund.

United National Development Programme (UNDP) (2011) Human development report 2011. Explanatory note on 2011 HDR composite indices, Senegal.

United Nations (2000) Millennium Declaration

Vasquez, I (1998) Official assistance, economic freedom, and policy change: Is foreign aid like champagne? Cato Journal

Vasquez, I (2009) Foreign aid and economic development. Cato Handbook for Policymakers, $7^{\text {th }}$ edition

Vijil, M et al (2011) aid for trade: a survey. Working Paper

Vijil, M. and L. Wagner (2010) Does Aid for Trade enhance export performance? Investigating on the infrastructure channel. Working Paper

Villalon, L. (2011) Senegal: Assessing risks to stability. Center For Strategic and International Studies.

Wacziarg, R and Karen Welch (2008) Trade Liberalization and growth: New Evidence. The World Bank Economic Review.

Waddington, M and Mohan, G. (2004), 'Failing Forward: going beyond imposed forms of participation’, in Hickey, S. and Mohan, G. (eds) Participation: From tyranny to transformation? Zed Books, London.

Wade, A (1967)La doctrine Economique du Mouridisme. Faculté de droit et science économique annales africaines, Dakar.

Wagner, J (2014) Optimizing Foreign Aid to Developing Countries: A Study of Aid, Economic Freedom, and Growth. Working Paper.

Watkins, T (2004) Political and Economic History of Ghana. San José State University Economics Department

Weber, M. (1930) The Protestant Ethic and the Spirit of Capitalism. London, Allen \& Unwin.

Wedel, J (1999) U.S. Assistance for Market Reforms Foreign Aid Failures in Russia and the Former Soviet Bloc. The Independent Review 
Weede, E., and S. Kampf (2002). The Impact of Intelligence and Institutional Improvements on Economic Growth. Working Paper.

Weissman, R (2000) Structural Adjustment Program (SAP) alert on IMF and World Bank lending to Tanzania. Globalization Challenge Initiative.

Werlin, H. (1991) Ghana and South Korea: Lessons from World Bank Case Studies. Public Administration and Development.

Werlin, H.(1994) Ghana and South Korea: Explaining Development Disparities - An Essay in Honor of Carl Rosberg.” Journal of Asian and African Studies.

Wilks, I (1975), Asante in the Nineteenth Century: The Structure and Evolution of a Political Order, Cambridge: Cambridge University Press.

Williamson, C (2009) Exploring the Failure of Foreign Aid: The Role of Incentives and Information.

Williamson, J. (2004) The strange history of the Washington Consensus. Journal of Post Keynesian Economics.

Willis, K. (2005) Theories and Practices of Development. New York, Routledge.

Winters, A., et al (2004) trade Liberalization and Poverty: The Evidence So Far. Journal of Economic Literature.

Woolcock, M. (1998) Social Capital and Economic Development: Toward a Theoretical Synthesis and Policy Framework. Theory and Society.

World Bank (1981) Toward Accelerated Development in Sub-Sahara Africa: An Agenda for Action. Washington, D.C

World Bank (1994) Adjustment in Africa: Reforms, Results and the Road Ahead. New York: Oxford University Press; World Bank. 2000. Can Africa Claim the Twenty-First Century?

World Bank (1994) World Bank Development Report.

World Bank (1998). Assessing Aid: What Works, What Doesn't, and Why (Oxford: Oxford University Press).

World Bank (2002) A Case for Aid: Building a Consensus for Development Assistance.

World Bank (2002). Globalization, Growth and Poverty: Building an Inclusive World Economy.

World Bank (2007) International Development Association and International Finance Corporation country assistance strategy for the Republic of Senegal for the period FY07- FY10. 
Report No. 36608-SN. Poverty Reduction and Economic Management 4, Country Department AFCF1, Africa Region.

World Bank (2010) A Review of IDA's Long Term Financial Capacity and Financial Instruments (IDA16 Replenishment Report). Washington, DC: The World Bank.

World Bank (2012) World Bank Development Report

World Bank (2014) Steering Senegal Towards Greater Transparency in Governance and Public Finance Management

World Bank (2002) World Development Indicators 2002 database. Washington, DC.

World Bank (1994) Adjustment in Africa: Reforms, Results, and the Road Ahead. World Bank Policy Research Report. Oxford University Press.

Wright, J and Matthew Winters (2010) The politics of effective aid. The Annual Review of Political Science

Yanbing, Z \& Huang Ying (2007) Foreign Aid: The Ideological Differences between China and the West. CIR. 